\title{
LOCATING IMAGINATION IN POPULAR CULTURE
} PLACE, TOURISM AND BELONGING

\section{Edited by}

Nicky van Es, Stijn Reijnders,

Leonieke Bolderman, and Abby Waysdorf

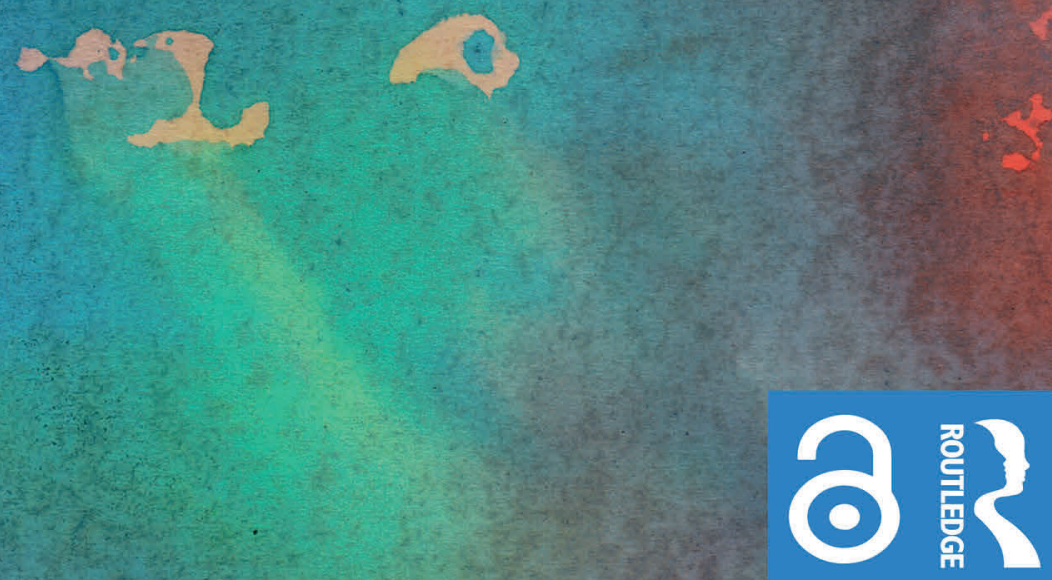




\section{Locating Imagination in Popular Culture}

Locating Imagination in Popular Culture offers a multidisciplinary account of the ways in which popular culture, tourism, and notions of place intertwine in an environment characterized by ongoing processes of globalization, digitization, and the increasingly ubiquitous nature of multimedia.

Centred around the concept of imagination, the authors demonstrate how popular culture and media are becoming increasingly important in the ways in which places and localities are imagined and how they also subsequently stimulate a desire to visit the actual places in which people's favourite stories are set. With examples drawn from around the globe, the book offers a unique study of the role of narratives conveyed through media in stimulating and reflecting desire in tourism.

This book will have appeal in a wide variety of academic disciplines, ranging from media and cultural studies to fan and tourism studies, cultural geography, literary studies, and cultural sociology.

Nicky van Es, MSc, is currently a lecturer at Erasmus University Rotterdam. Next to teaching within the International Bachelor of Arts \& Culture Studies, he co-founded the MA programme Place, Culture \& Tourism (2018). In addition, he is working towards finalizing his dissertation (exp. 2020) on literary tourism as part of the Locating Imagination project, funded by the Dutch Science Foundation. Among his published research articles are "Chasing Sleuths" (Annals of Tourism Research, 2016) and "Capital Crime Cities" (European Journal of Cultural Studies, 2016) and several book chapters, and he is the main editor of the upcoming edited volume Locating Imagination in Popular Culture (Routledge, 2020).

Stijn Reijnders, PhD, is Full Professor of Cultural Heritage, in Particular in Relation to Tourism and Popular Culture at Erasmus University Rotterdam. His research focuses on the intersection of media, culture, and tourism. Currently he leads two large international research projects: Worlds of Imagination, funded by the European Research Council, and Locating Imagination, funded by the Dutch Science Foundation. He has published many research papers and has co-edited The Ashgate Research Companion to Fan Cultures (2014), Film Tourism in Asia: Evolution, Transformation and Trajectory (2017), and Locating Imagination: Place, Tourism and Belonging in Popular Culture (2020).

Leonieke Bolderman, PhD, is Assistant Professor, Cultural Geography and Tourism Geography and Planning at the University of Groningen, the Netherlands. Her research concerns the role and meaning of music heritage and tourism in urban and regional development, on which she has published in various journals and edited volumes.

Abby Waysdorf, $\mathrm{PhD}$, is currently a postdoctoral researcher with the CADEAH project, researching how individuals and groups reappropriate and recirculate audiovisual heritage materials. She did a research master at Utrecht University in media and performance studies, with a specialty in sport media and fandom, and her $\mathrm{PhD}$ at Erasmus University Rotterdam, where her dissertation, "Placing Fandom," focused on film tourism and fan use of place. Her general research interests are audience practices and uses of media, fandom, the television industry, and how all of these things intersect. 


\section{Routledge Research in Cultural and Media Studies}

Inhuman Materiality in Gothic Media

Aspasia Stephanou

Millennials and Media Ecology

Culture, Pedagogy and Politics

Edited by Anthony Cristiano and Abmet Atay

Media Cultures in Latin America

Key Concepts and New Debates

Edited by Anna Cristina Pertierra and Juan Francisco Salazar

Cultures of participation

Arts, digital media and cultural institutions

Edited by Birgit Eriksson, Carsten Stage and Bjarki Valtysson

Adapting Endings from Book to Screen

Last Pages, Last Shots

Edited by Armelle Parey and Shannon Wells-Lassagne

Migration, Identity, and Belonging

Defining Borders and Boundaries of the Homeland

Edited by Margaret Franz and Kumarini Silva

Exploring Seriality on Screen

Audiovisual Narratives in Film and Television

Edited by Ariane Hudelet and Anne Crémieux

Locating Imagination in Popular Culture

Place, Tourism and Belonging

Edited by Nicky van Es, Stijn Reijnders, Leonieke Bolderman, and Abby Waysdorf

For more information about this series, please visit: www.routledge.com/ Routledge-Research-in-Cultural-and-Media-Studies/book-series/SE0304 


\section{Locating Imagination in Popular Culture \\ Place, Tourism and Belonging}

\section{Edited by \\ Nicky van Es, Stijn Reijnders, \\ Leonieke Bolderman, and \\ Abby Waysdorf}


First published 2021

by Routledge

2 Park Square, Milton Park, Abingdon, Oxon OX14 4RN

and by Routledge

52 Vanderbilt Avenue, New York, NY 10017

Routledge is an imprint of the Taylor \& Francis Group, an informa business

(C) 2021 selection and editorial matter, Nicky van Es, Stijn Reijnders, Leonieke Bolderman, and Abby Waysdorf; individual chapters, the contributors

The right of Nicky van Es, Stijn Reijnders, Leonieke Bolderman, and Abby Waysdorf to be identified as the authors of the editorial material, and of the authors for their individual chapters, has been asserted in accordance with sections 77 and 78 of the Copyright, Designs and Patents Act 1988.

The Open Access version of this book, available at www.taylorfrancis.com, has been made available under a Creative Commons Attribution-Non Commercial-No Derivatives 4.0 license.

This book is published open access through an Open Access Fund grant by the Netherlands Organisation of Scientific Research (NWO), grant number [36.201.008].

Trademark notice: Product or corporate names may be trademarks or registered trademarks, and are used only for identification and explanation without intent to infringe.

British Library Cataloguing-in-Publication Data A catalogue record for this book is available from the British Library

Library of Congress Cataloging-in-Publication Data

A catalog record for this book has been requested

ISBN: 978-0-367-49262-5 (hbk)

ISBN: 978-1-003-04535-9 (ebk)

Typeset in Sabon

by Apex CoVantage, LLC 


\section{Contents}

List of figures viii

List of contributors $\quad \mathrm{x}$

Introduction: locating imagination in popular culture:

place, tourism, and belonging 1

STIJN REIJNDERS, ABBY WAYSDORF, LEONIEKE BOLDERMAN

AND NICKY VAN ES

\section{PART I}

Theorizing the imagination

1 Imaginative heritage: towards a holistic perspective on media, tourism, and governance

STIJN REIJNDERS

2 The open-ended ruin: imaginative authenticity as a driver of alternative tourism

ANDRÉ JANSSON

3 No place like Birmingham? The politics of immobility, invisibility, and resentment

DAVID MORLEY

4 I just can't get you out of my head: how music triggers the imagination

5 Space, lived culture, and affectivities in stirring imagination 
6 Screening the west coast: developing New Nordic Noir tourism in Denmark and using the actual places as full-scale visual mood boards for the scriptwriting process ANNE MARIT WAADE

7 Flying down to a cosmopolitan-tropical paradise BIANCA FREIRE-MEDEIROS

8 Following Oshin and Amachan: film tourism and nation branding in the analogue and digital ages

ELISABETH SCHERER AND TIMO THELEN

9 Touring the videogame city BOBBY SCHWEIZER

10 Locating the literary imagination: broadening the scope of literary tourism NICKY VAN ES

\section{Part III}

Being there

11 Toy tourism: from Travel Bugs to characters with wanderlust

KATRIINA HELJAKKA AND PIRITA IHAMÄKI

12 On (be)longing: the Der Bergdoktor phenomenon at the European cultural periphery

ANDREJA TRDINA AND MAJA TURNŠEK

13 Live event-spaces: place and space in the mediatized experience of events

ESTHER HAMMELBURG

14 Fans and fams: experience and belonging aboard a cruise ship music festival 


\section{Part IV}

Returning home: memory and belonging

15 Strange spaces of mediated memory: the complicating influence of Roots on heritage tourism in The Gambia, West Africa

JASON GREK-MARTIN

16 How stories relate to places? Orhan Pamuk's Museum of Innocence as literary tourism

MARIE-LAURE RYAN

17 Placing fandom: reflections on film tourism

ABBY WAYSDORF

18 The National Theatre, London, as a theatrical/ architectural object of fan imagination

MATT HILLS

Index 


\section{Figures}

1.1 The co-production of media tourism. 24

2.1 A typology of ruins. $\quad 38$

2.2 Approaches to authenticity in tourism experiences. 42

6.1 Filmby Aarhus' New Nordic Noir. 99

6.2 Ringkøbing-Skjern municipality on the west coast of Denmark. $\quad 104$

6.3 Houvig bunker from the Second World War. 109

6.4 Stakeholders from Ringkøbing-Skjern municipality visiting Ystad Studios Visitor Center, April 2018.

8.1 Kokeshi (wooden doll). 141

8.2 Unidon. 143

9.1 San Francisco depicted in Killing Cloud (1991) for the Commodore Amiga. 152

9.2 Player-created tourism videos on YouTube. 161

11.1 Kewty-pie's customized Blythe dolls are all set for travel
with their owner.

11.2 Damara DeWildt, a Sylvanian Families “cheetah”, has visited Helsinki, Finland. 189

11.3 A Travel Bug called Dr. Geocacher. 193

11.4 Heidi's Barbie doll has travelled to Rome to see
the Colosseum.

11.5 A typology of toy tourism: From paedic to ludic 197 play practices. 197 13.1 Quotes and photo by Simone, taken at Oerol
Festival (2017).

13.2 Overview datasets. 219

13.3 Visual presencing at Oerol17. 225

15.1 Kunta Kinteh Island and vicinity. 253

15.2 Ruined fortifications on Kunta Kinteh Island. 256

15.3 The Museum of the Slave Trade, Juffure. 260

16.1 Real and imaginary geographies as targets of
narrative tourism. 
Figures ix

16.2 The Museum of Innocence in Istanbul (the dark, narrow building on the left).

16.3 General view of the Museum of Innocence.

16.4 One of the displays of the Museum of Innocence.

275

16.5 The spiral, symbol of the unity of (narrative) time, on the ground floor, that people see from the third floor at the end of their visit. 


\section{Contributors}

Leonieke Bolderman, PhD, is Assistant Professor, Cultural Geography and Tourism Geography and Planning at the University of Groningen, the Netherlands. Her research concerns the role and meaning of music heritage and tourism in urban and regional development, on which she has published in various journals and edited volumes.

David Cashman, $\mathrm{PhD}$, is an associate professor and researcher at Central Queensland University in northern Australia. He publishes within the intersection of place and music. He is also a pianist and popular music educator with an interest in performance practice of popular music.

David Crouch, $\mathrm{PhD}$, is Emeritus Professor, Cultural Geography, at the University of Derby, UK. His most recent books are Flirting with Space: Journeys and Creativity, Ashgate 2010/Routledge 2016, and The Question of Space: Interrogating the Spatial Turn between Disciplines, edited with Marijn Nieuwenhuis, Rowman and Littlefield (2017). Previous books include The Media and the Tourist Imagination (2005), Visual Culture and Tourism (2003), and Leisure/Tourism Geographies: Practices and Knowledges (Routledge, 1999), all edited volumes. He has published in numerous academic journals across geography, including themes of visual and cultural studies, on landscape, identity, and belonging. David is an exhibiting painter whose work is frequently related to the kind of ideas, feelings, and encounters expressed in this chapter.

Bianca Freire-Medeiros, $\mathrm{PhD}$, is Sociology Professor at University of São Paulo (USP) and coordinator of the UrbanData - Brazil: databank on urban Brazil. She is one of the main references for those interested in the so-called poverty tourism field in Brazil and abroad. Her book Touring Poverty (Routledge, 2013; 2015), as well as the documentary film based on her research project, A Place to Take Away (2012), have been highly praised both in and outside academia. Her work has been published in several languages, and she was a visiting researcher at Princeton University, El Colegio de Mexico, and Lancaster University and a Tinker visiting professor at the University of Texas at Austin. 
Jason Grek-Martin, $\mathrm{PhD}$, is a cultural and historical geographer devoted to critically analyzing the rich and multifaceted concept of place, particularly the dynamic and power-laden processes by which places are constructed, contested, and imbued with complex meanings by individuals and communities. His current research explores place-making primarily in the context of travel and tourism to heritage sites with a dark past, drawing on robust interdisciplinary scholarship developing at the intersection of dark tourism, media tourism, heritage studies, and geographies of memory. His Gambian Roots research is one facet of this ongoing project, which also includes emerging work on the diverse ways in which the familiar narrative of the RMS Titanic has been emplaced and reshaped within the various commemorative sites on both sides of the Atlantic Ocean that can claim a direct historical connection to this infamous disaster - including several sites in my own city of Halifax, Nova Scotia, Canada.

Esther Hammelburg, MA, is a PhD candidate at the Amsterdam School for Cultural Analysis, University of Amsterdam, and lecturer at the Faculty of Digital Media and Creative Industries, Amsterdam University of Applied Sciences. Her chapter is based on research for her dissertation focused on liveness within the mediatized experience of cultural events. Supervisors on this PhD project are Dr. José van Dijck, Dr. Thomas Poell, and Dr. Jeroen de Kloet. Esther's research and teaching areas include liveness, media and citizenship, media representations, media literacy, visual culture, media, and art philosophy.

Katriina Heljakka, PhD, holds a post-doctoral position at University of Turku (digital culture studies) and continues her research on toys; toy fandom; and the visual, material, digital, and social cultures of play. Her current research interests include the emerging toyification of contemporary culture, toy fandom, and the hybrid and social dimensions of ludic practices.

Matt Hills, PhD, is Professor of Media and Film at the University of Huddersfield. He has published widely on media fandom and cult TV, with a particular focus on Doctor Who. Matt's work on fandom began with the book Fan Cultures in 2002 and includes material in The Pleasures of Horror (2005), Triumph of a Time Lord (2010), and Doctor Who: The Unfolding Event (2015). He is currently working on a follow-up to Fan Cultures for Routledge, Fan Studies, which will include material on David Hare and theatre fandom.

Pirita Ihamäki, PhD, received her MA in digital culture in 2006, MSc in marketing in 2011, and $\mathrm{PhD}$ in digital culture in 2015 from the University of Turku at Pori Unit. She is currently working as Project Manager involved in game-related projects at Prizztech Ltd. She has also worked as a researcher at different universities. Her current research interests 
are game design, gamification, gamified tourist services, service design, toyification, the Internet of Toys, and toy tourism.

André Jansson, PhD, is a professor of media and communication studies and Director of the Geomedia Research Group in the Department of Geography, Media and Communication, Karlstad University, Sweden. His most recent publications include Mediatization and Mobile Lives (Routledge, 2018) and Cosmopolitanism and the Media (with M. Christensen, Palgrave Macmillan, 2015).

David Morley, PhD, is Professor in the Department of Media and Communications, Goldsmiths. His publications include The Nationwide Audience (BFI, 1980); Family TV (Comedia, 1986); Television, Audiences and Cultural Studies (Routledge, 1992); Stuart Hall: Critical Dialogues in Cultural Studies (edited with Kuan-Hsing Chen, Routledge, 1996); Home Territories (Routledge, 2001); British Cultural Studies (edited with Kevin Robins, OUP, 2003); Media, Modernity and Technology (Routledge, 2006); and most recently Communications and Mobility: The Migrant, the Mobile Phone and the Container Box (Wiley Blackwell, 2017).

Stijn Reijnders, PhD, is Full Professor of Cultural Heritage, in Particular in Relation to Tourism and Popular Culture at Erasmus University Rotterdam. His research focuses on the intersection of media, culture, and tourism. Currently he leads two large international research projects: Worlds of Imagination, funded by the European Research Council, and Locating Imagination funded by the Dutch Science Foundation. He has published many research papers and has co-edited The Ashgate Research Companion to Fan Cultures (2014), Film Tourism in Asia: Evolution, Transformation and Trajectory (2017) and Locating Imagination: Place, Tourism and Belonging in Popular Culture (exp. 2020).

Marie-Laure Ryan, PhD, is an independent scholar based in Colorado, working in the areas of narrative theory, media theory, and representations of space. She is the author of Possible Worlds, Artificial Intelligence and Narrative Theory (1991); Narrative as Virtual Reality: Immersion and Interactivity in Literature and Electronic Media (2001/2015); and Avatars of Story (2006) and the co-author of Narrating Space/Spatializing Narrative (2016), as well as the editor of several books. She has been Scholar in Residence at the University of Colorado, Boulder, and Johannes Gutenberg Fellow at the University of Mainz, Germany, and she is the recipient of the 2017 lifetime achievement award from the International Society for the Study of Narrative.

Elisabeth Scherer, $\mathrm{PhD}$, is a lecturer and research associate at the Department of Modern Japanese Studies, Düsseldorf University. Scherer has studied Japanese studies and rhetoric at the University of Tübingen and Dōshisha University (Kyoto). She obtained her PhD in Japanese studies 
from the University of Tübingen in 2010 with a thesis on female ghosts in Japanese cinema. Scherer's areas of research interest include Japanese popular culture, rituals and religion in contemporary Japan, gender studies, and the reception of Japanese art and popular culture in the West.

Bobby Schweizer, $\mathrm{PhD}$, is an assistant professor journalism and creative industries at Texas Tech University. His research considers how built environments such as cities and theme parks are mediated through video games and how games influence our conception of real space. Bobby is the co-author of Newsgames: Journalism at Play (MIT Press, 2010) and co-editor of Meet Me at the Fair: A World's Fair Reader (ETC Press, 2014).

Timo Thelen, PhD, is an associate professor at the Faculty of Letters, University of Kanazawa, Japan. Thelen has studied Japanese studies at Düsseldorf University, Keio University (Tokyo), and Kanazawa University (Ishikawa). His PhD thesis focused on rural revitalization measures in the Noto Peninsula, Ishikawa Prefecture. Thelen's areas of research interest include rural culture and society, Japanese popular culture, tourism, and mobility.

Andreja Trdina, $\mathrm{PhD}$, is an assistant professor at the Faculty of Tourism, University of Maribor, and a researcher at the Institute for Developmental and Strategic Analyses (IRSA), Ljubljana. She has a PhD in media studies and in her research focuses on popular culture and media and sociology of taste, class, and distinction with a special regard for contemporary material/consumer culture. She is currently dealing mainly with research on mediatization of tourism, travel as social and cultural practice, and politics of mobility. She has participated in various research projects and recently published an article, "Nation, Gender, Class: Celebrity Culture and the Performance of Identity in the Balkans" (with B. Luthar, Slavic Review, 2015).

Maja Turnšek, $\mathrm{PhD}$, is an assistant professor at the Faculty of Tourism, University of Maribor. She graduated and finished her PhD studies in media and communication at the Faculty of Social Sciences, University of Ljubljana. Her research interests cover the interconnections between media and travel studies. She has participated in several national and international research projects. Currently she is involved in the project Mediatisation of Public Life, coordinated by Prof. Slavko Splichal, Faculty of Social Sciences, University of Ljubljana, and financed by the Slovenian Research Agency.

Nicky van Es, MSc, is currently a lecturer at Erasmus University Rotterdam. Next to teaching within the International Bachelor of Arts \& Culture Studies, he co-founded the MA programme Place, Culture \& Tourism (2018). In addition, he is working towards finalizing his dissertation (exp. 2020) on literary tourism as part of the Locating Imagination project, funded 
by the Dutch Science Foundation. Among his published research articles are "Chasing Sleuths" (Annals of Tourism Research, 2016) and "Capital Crime Cities" (European Journal of Cultural Studies, 2016), and several book chapters, and he is the main editor of the upcoming edited volume Locating Imagination in Popular Culture (Routledge, exp. 2020).

Anne Marit Waade, $\mathrm{PhD}$, is an associate professor in media studies, Aarhus University, Denmark. Her research interests include mediated places, creative industry and promotional culture, landscapes in Nordic Noir, place branding, travel series, and travel journalism. She has published a range of articles and books, such as Locating Nordic Noir (2017), Wallanderland (2013), and "When Public Service Drama Travels" (2016). More recently, she holds the grant for the large-scale research project What Makes Danish TV Drama Travel? (DFF, 2014-18), and she is part of Rethink Coastal Tourism (2016-2019, Danish Innovation Fund) and Television in Small Nations (AHRC, 2015-2016).

Abby Waysdorf, PhD, is currently a postdoctoral researcher with the CADEAH project, researching how individuals and groups reappropriate and recirculate audiovisual heritage materials. She did a research master at Utrecht University in media and performance studies, with a specialty in sport media and fandom, and her $\mathrm{PhD}$ at Erasmus University, Rotterdam, where her dissertation, "Placing Fandom," focused on film tourism and fan use of place. Her general research interests are audience practices and uses of media, fandom, the television industry, and how all of these things intersect. 


\title{
Introduction
}

\section{Locating imagination in popular culture: place, tourism, and belonging ${ }^{1}$}

\author{
Stijn Reijnders, Abby Waysdorf, \\ Leonieke Bolderman, and Nicky van Es
}

The Baltimore State Hospital for the Criminally Insane is a fictional psychiatric institution. It is where Dr. Hannibal Lecter, the main character in a series of suspense novels by Thomas Harris, has been incarcerated for a very long time. Dr. Lecter is highly intelligent, erudite, and intellectual, but at the same time devoid of empathy and afflicted with a macabre abnormality in that, in terms of his preferred diet, he is partial to human flesh. Hence, he has acquired the nickname Hannibal the Cannibal. Hannibal Lecter is without doubt one of the most notorious serial killers in Western popular culture. For years, he has been locked up in the deepest, darkest cellar in this establishment, where he receives visits only from mice, rats, and a stoic guard who comes to bring him food. His cell, at the end of the corridor, is small, four by four meters, with three stone walls, no window, and a wall of bars on the fourth side. How does Hannibal cope with this situation? How does he manage to counteract total madness and deal with the isolation? $\mathrm{He}$ uses a well-known cognitive technique: he closes his eyes for a few hours a day and enters the palace of his imagination. This palace is imaginary but constructed in great detail. It is strikingly large, made up of countless rooms, corridors, and halls, with windows opening up views onto all the places that are important to Hannibal. The walls are adorned with frescos depicting his own memories, fantasies, and dreams for the future - all these scenes have their own place in the palace of his imagination and are retrievable down to the smallest detail.

The palace of Hannibal Lecter's imagination is a compelling literary idea. Using this device, the author, Thomas Harris, manages to give the character of Hannibal more depth and connect the dark cell in the basement of an institution to all kinds of other locations that are important for the story. Yet this device is not just a matter of fiction, as the "mind palace" is not only found in literature. In fact, a similar situation occurred in reality a few years ago. The Dutch tourist Sjaak Rijke, a 51-year-old train driver from the small city of Woerden, was held hostage by Muslim extremists in Mali for three and a half years before being fortuitously freed by French soldiers in April 2015. In one of the first interviews after his release, Rijke explained how he had managed to maintain his sanity and peace of mind during his 


\section{Reijnders, Waysdorf, Bolderman and van Es}

time as a hostage in the desert: by rebuilding his actual house every day in his imagination, stone by stone and room by room.

Both examples are extreme: one is a fictional serial killer in a dark cell, while the other is a real-life Dutch citizen who was held hostage for years in the desert. Yet both examples illustrate the same phenomenon: the power of the imagination. Human beings are able to create a model of the world in their thoughts, a representation that can have a close resemblance to reality. But imaginary worlds can also alter reality by simplifying it, embellishing it, or even making it frightening. The imagination is a universal given: everyone has the capacity to transport themselves elsewhere with their own thoughts, to places that are related to the past, the present, or the future. The imagination therefore not only recreates images based on prior sensory experiences; it does more. In fact, we are surrounded by an enormous, chaotic abundance of sensations, and it takes the imagination to channel all those sensations, via our five senses, into the idea of a coherent and univocal reality.

Though the imagination is a universal given and fundamental to how human beings experience life (and conceptualize the afterlife, for that matter), little is known about what the imagination exactly is and how it operates in society and everyday life. Within the world of modern science, the concept of the imagination (defined here as the mental visualization of things that are not present) has long been viewed with suspicion (McGinn, 2004). Recent years have seen an increased interest in topics related to the imagination, but these attempts have mainly focused on the role of imaginaries - loosely defined as representations of the social. As Lean et al. state in their introduction to Travel and Imagination (2014), there is still a need for "perspectives that stretch beyond imaginaries to a more holistic view on the imagination". In other words, we need to transcend the level of representations and explore how the imagination operates (or perhaps sometimes fails to operate) in the lives of individuals and small groups in a diverse set of practices.

This challenge is picked up by the current edited volume. More particularly, we aim to investigate the multifaceted relations between imagination, place, and popular culture in the context of contemporary society. As we will argue in this Introduction and the following chapters, questions related to the presence and effects of the imagination have become even more pressing in today's mediatized society. In a world that is increasingly populated with stories from the media, reality is - now more than ever - governed by media technology and images. This not only works towards informing and shaping a perception of the world but simultaneously opens up way(s) of being in that world in which the boundaries between the imagination and the real are critically at stake. This development is visible in, for example, the growth and popularity of phenomena that are analysed in this volume, such as film and TV tourism (Chapters 6, 8, and 17) festival experiences (Chapters 13 and 14), and a different form and shape of heritage locations and experiences (Chapters 2, 3, 15, and 18). Diverse as these examples are, we argue they have one fruitful analytical lens in common: the imagination. 
In this changing mediatized landscape, what are the potential innovations of a theorization of imagination, as envisioned in this volume? Most importantly, the concept of the imagination can serve as a - thus far - missing link between media studies, cultural geography, cultural studies, and tourism studies. After all, it is the imagination that connects the consumption of mediated landscapes and the act of visiting actual places in physical reality. Imagination is the device to both process media content; to integrate those media narratives into existing geographies; and to move individuals around the world in search of validation, authenticity, belonging, or whatever it is that may drive them. This circular process can be playful or serious, and it might reflect desires or fears, but in all cases, it will be based on individual emotions and memories as well as culturally and historically grounded notions about one's own subject position in the world. If imagination is indeed such an important tool for understanding notions of selfhood and belonging in today's globalized media society, its further conceptualization is expected to prove a very rich enterprise for all disciplines involved.

Furthermore, for media and cultural studies, the concept of imagination might prove to be a prime opportunity to strengthen a non-mediacentric approach to media culture (Morley, 2009). Advocates of this approach urge a shift in focus from the rapidly changing media forms and outputs towards how people actually use media within the context of everyday life, including the investigation of more permanent characteristics underlying mediarelated practices (Couldry, 2012). In this respect, imagination as a universal given, yet culturally shaped capacity, may provide an innovative starting point for such practice-oriented perspectives. Instead of starting from the media and their possible effects on society, the concept of the imagination starts by asking: How do people experience living in a mediatized culture, and how do they conceptualize and visualize their own lives within that larger society? This approach differs fundamentally from more traditional related concepts within media studies, such as "reception", "encoding/ decoding", "appropriation", and "active audiences", because ultimately, these latter concepts one by one still start from the idea that the media are (at) the centre of our society: the media are actively being received, encoded, decoded, appropriated or loved. This "fetishization" of the media has played an important and logical role in showing why media mattered during the early development of media studies. The issue of mediacentrism, however, has increasingly been raised with the maturation of the discipline and is being explicitly questioned in the current era (cf. Couldry, 2006). A focus on the imagination shifts the perspective by taking the human mind as its starting point and thus allowing for a more nuanced and holistic perspective on the role and importance of the media in everyday life.

Last but not least, for cultural geography, a theory of the imagination has the potential to strengthen the theoretical base of core notions such as "topophilia" and "sense of place" that explore ways people feel at home in the world. The term "topophilia" refers to the emotional attachment to 


\section{Reijnders, Waysdorf, Bolderman and van Es}

place that is central to human experience (Tuan, 1974). Yi-Fu Tuan's work on topophilia has been celebrated by many, but as of yet, little has been done to further develop this idea or theorize how humans relate to and develop a love for specific places and how this phenomenon might differ from culture to culture as well as within cultures. In more recent work, the broader concept "sense of place" is used, encompassing three related dimensions of place experience (Lewicka, 2011): a cognitive dimension (often consisting of cultural meanings attached to place that are shared among groups - the concept of "place identity"), emotional meanings (often relating to personal experiences - conceptualized as "place attachment"), and finally particular behaviour, which can strengthen the sense of place (Scannell \& Gifford, 2010). The question is how these dimensions relate and become intertwined in lived human experience. In our opinion, the imagination is a fruitful way to explore these processes. In short, the way people connect to places; come to love places; and make connections between cultural identities, places, and ways of belonging still leaves a lot of ground to be covered in terms of theorizing and research. The imagination, as mediator between cognitive, emotional, and practiced experiences of place, could be an important concept for future efforts in this direction.

The imagination is therefore a multifaceted concept that in this volume is used in diverse ways to analyse and explain contemporary phenomena and to expand on current theories and ideas that relate to social life and human belonging in the world. Before we can turn the page to these different parts of the book, we would like to further clarify our conceptual approach to the imagination, since, as we have stated, this is not done often enough. Following an overview of the development of thinking about the imagination, we will zoom in on the role and importance of imagination in today's mediatized world, thus paving the way for the chapters to come.

\section{Defining imagination}

Although the imagination seems to be a universal given, little is known about its exact role in and meaning for human consciousness. As mentioned previously, the concept of the imagination has long been viewed with suspicion. Classical philosophers gave primacy to the thinking mind: mankind had to rely on reason in order to achieve true insight. The imagination was seen as the antithesis to logic. In the eyes of many philosophers - with a few exceptions - it was a dangerous distraction or an illusion, which would only lead to delusion. Within Rationalism and Enlightenment thinking, the imagination was even interpreted as an obstacle to the progress of mankind. Romanticism admittedly offered an important alternative viewpoint, with thinkers such as Rousseau and artists like William Blake, who praised the imagination as the sixth sense forming the basis of the most beautiful things humanity had ever produced. But despite this evolution, the imagination as a concept has never really established a foothold within modern science - and 
certainly not when it comes to the role and meaning of the imagination in everyday life (Streminger, 1980).

One of the most important exceptions is the work of the 18th-century philosophers David Hume and Immanuel Kant. In 1740, the 29-year-old Hume wrote that "It has been observ'd, in treating of the passions, that men are mightily govern'd by the imagination" (Hume, 1740/2000: 123). According to Hume, the imagination is an essential part of cognitive ability, responsible for the creation of ideas (which he called "mental images"). According to Hume, these images were always reproductive, because they were derived from sensory perceptions. Over time, these ideas could grow into a broader framework, in which old experiences were ranked and new experiences were interpreted. Thus, individuals became aware of the world surrounding them without having to experience every aspect of that world constantly; the imagination created "the absent present".

Almost half a century later, Immanuel Kant continued to build on Hume's line of thought by stating that in addition to reproductive power - the power to process sensory experiences into more abstract ideas - there also has to be a productive capacity. According to Kant (1781/2015), people are surrounded by a torrent of sensory stimuli. It requires imagination to categorize and interpret that chaos on the basis of so-called "schemata" (thinking patterns). Without such a predetermined categorization, the whole idea of an unambiguous and coherent experience of reality is simply impossible. Therefore, in Kant's approach, the imagination did not follow the sensory experience (Hume's "copy principle") but preceded it.

Although Hume and especially Kant have become regarded as leading philosophers over time, their ideas about the imagination have remained largely unexplored. In fact, it is only in recent decades - against the background of postmodernism and discussions about contemporary visual culture - that the imagination has once again been adopted as a serious philosophical and scientific subject. One of the important sources in this respect is the book Imagination and the Imaginary by the British philosopher Kathleen Lennon (2015). What makes her book relevant is that she combines Kant's theory of the imagination with insights from phenomenology. The phenomenological method is ideally suited to bridge the gap between Kant's abstract, sometimes somewhat mechanical, logic and the practicalities of everyday life. In order to understand the workings of the imagination, Lennon asserts we must first of all accept that individuals do not operate in isolation and according to a fixed logic but that they live in and with the world. Individuals are an integral part of reality, while they also help shape that reality.

This phenomenological approach has three main consequences for thinking about the role of the imagination within the context of everyday life. First, it presupposes a certain form of "agency". The imagination is not fixed, ingrained in the "schemata" transferred to us via external sources; human beings themselves also influence the design and selection of "schemata". This implies that reality is represented and experienced in diverse, individual 
ways. Second, it means that imagining is an affective matter. Forming images of other places and localities in which we are not present at that moment is not a cold and technical operation but is strongly connected to the feelings - both positive and negative - that individuals can develop about specific places. In other words, feelings of belonging are integral to the imagination - as are feelings of fear or horror (cf. Tuan, 1974). Finally, Lennon (2015) assumes that the development of the imagination takes place within a social context. Individuals learn from the people around them to look at the world in a certain way and to interpret new experiences.

Building on the work of Hume, Kant, and Lennon, we would like to state that the imagination is a crucial part of human consciousness and is almost constantly present within the context of everyday life, albeit on a semi-conscious level as a "silent force". This power of the imagination is twofold. On the one hand, it makes it possible to turn the chaotic flow of sensory experiences into an unambiguous and coherent perception of the immediate surroundings. On the other hand, it is the imagination that lifts people above the temporal and spatial limitations of sensory perception and situates their own "existence" within a broader context: a larger world that extends beyond our horizon and that has its own past and future. It is a world to which people feel connected in some way, but also one that can inspire fear (cf. Klinkman, 2002: 7). To put it differently, through the imagination, human consciousness is extended in time and place.

There is, however, an intrinsic paradox to the imagination. On the one hand, the imagination sets us free. It offers individuals a way of imagining other worlds, where they are not present. Almost everything can happen out there. The world of the imagination does not seem to obey the law of gravity or other rules of our known reality. On the other hand, the imagination is not fully detached from real life, either. As Immanuel Kant already pointed out in his Kritik der Reinen Vernunft in the late 18th century, human beings can only imagine things that are close to what they are familiar with. In other words: the imagination lets people float a little bit, meaning that it gives them the liberty to leave this world temporarily but only one minor step and never far away from the presence of their known reality.

Moreover, the imagination is coupled with an urge to locate. People want to relate their imaginations to what they consider reality. One clear example of this is the fact that almost all of the stories we enjoy are set in a known environment. Whether we are talking about beloved TV series, movies, novels, or oral stories, they all take place in environments and landscapes that seem more or less familiar to us. Even genres like science fiction and high fantasy are to a large degree place based. Think, for example, of the fantasy world of Harry Potter and how that is intimately connected to stereotypes of Britishness through its abundant use of the red phone booths, double-decker busses, school uniforms, and wizards. Or think of the Lord of the Rings film trilogy and how fans of these movies relate this diegetic world to the landscape of New Zealand. In these examples, the power of the imagination 
lies not in offering an escape but in its potential to refurbish and transform the known world, to change the ways we deal with ourselves and the people around us, the ways of being in this world.

In some cases, the will to locate the imagination takes on actual form and literally moves people around the globe. There is a centuries-old tradition of readers trying to locate and visit the locations associated with their beloved stories, a tradition that possibly started with the work of Petrarch in the 14th century and took high flight during the Age of Romanticism. Recent decades have seen a dramatic, worldwide increase of this type of tourism, further sparked by the rise of film, television, and, more recently, video games and social media. This type of "media tourism" (Reijnders, 2011) is saturated by imaginative practices. After all, the phenomenon of media tourism is not limited to the actual act of tourism but is embedded in a longer process of the imagination, which stretches out over time, a process that begins with the consumption of the media narrative and fantasizing about the "fictitious" locations concerned and ends with a look back on the experience (Connell, 2012: 1024; Lean et al., 2014; Urry \& Larsen, 2011). Novels, television series, and films create elaborate imaginary worlds. These worlds are reproduced in the imagination of the readers/viewers while they are reading, watching, and/ or listening. In many cases, the readers/viewers identify with one or more of the characters in the story and in their minds transport themselves into and through this imaginary world. When the media tourist finally makes his or her journey to "places of the imagination" (Reijnders, 2011), this trip more or less represents a realization of an earlier imaginary journey (cf. Adams, 2014; Ehn \& Löfgren, 2010: 142; Laing \& Crouch, 2009).

One could state that this tension between imagining and locating, as described previously, has always been present and is part and parcel of the ontology of the imagination. We would agree with that, but only to a certain degree. It seems like more is going on: the increasing tension between imagining and locating cannot be seen separately from major transformations in our society. The mediatization of our world has created a situation in which our imagination is booming. More and more stories are on offer, stories that bring us all over the world and beyond. At the same time, our society is going through processes of globalization, bringing the world closer to home. In this increasingly mobile world, people will search for new and inventive ways of creating a sense of home, a sense of belonging. As such, consuming and appropriating stories from popular culture has become an important way of doing so.

\section{Imagination, place, and popular culture}

In 1984, the American anthropologist John Caughey wrote an elaborate book about the role and meaning of the imagination in present-day society. In Imaginary Social Worlds, Caughey suggests that people live in two different worlds simultaneously. On the one hand, they live within a reality 


\section{Reijnders, Waysdorf, Bolderman and van Es}

perceptible to the senses, contained within time and physical space. By means of sight, smell, touch, taste, and hearing, they create an impression of their immediate surroundings. On the other hand, people move in an inner spiritual world built on memories, visions of the future, fantasies, daydreams, and stories which play out elsewhere - in a different time or place, a world that thrives by virtue of the imagination.

What Caughey goes on to assert is that this world of the imagination is not an individual matter but has largely a social character. Fantasies, daydreams, visions of the future, and memories are normally about our relationships (whether real or not) with other places and people. Our imaginative world is populated by people - either people we know from our immediate environment or celebrities whom we have become acquainted with via the media. Almost no dream, fantasy, or memory is protected from the appearance of our peers. At a more fundamental level, it may be argued that the whole fabric of our imagination is shaped by a sociocultural context. It is culture that provides the building blocks for the composition of the fantasies and dreams that populate our inner beings. Instinctive, organic emotions such as fear, love, hate, and lust will also excite the imagination, but then it is the schemata of our culture that determine how these emotions take shape and result in certain scenarios, roles, and locations.

As we have argued elsewhere (Reijnders, 2016), narratives play an essential role in this process. Stories are crucial to the way we interpret the world around us, and they provide meaning for us. Some cultural scholars even claim that we are not homo sapiens (the thinking man) but in fact homo narrans: creatures that like to tell and hear stories in order to provide meaning to the chaos that surrounds them (Berger, 1997: 174). Narratives give order to a complex and often chaotic reality: they form a causal connection between events, creating the appearance of stable identities, and - last but not least - they give shape and colour to our imagination (Gottschall, 2013).

Without doubt, popular culture plays a pivotal role in producing and circulating narratives in contemporary society. For example, it has been reported that the average person in the West spends more than three hours a day watching television. Television offers the viewer the promise of literally being able to see events far away, of being able to consume images and sounds from other places far from the location the viewer is in, places where the viewer cannot or need not physically be. News and current affairs programmes bring stories about the big bad world of terrorist attacks, wars, disasters, and elections (Bird, 1988). Genres such as action, romance, and reality TV take the viewer to luxuriously rich or notoriously poor neighbourhoods, far-away cities, and exotic places (cf. Orgad, 2012), without having to leave the safe confines of the home.

All these stories, circulating in the media and beyond, together create a rich associative imagination of the world. We can imagine what Indonesia is like or what it is like to live in an igloo or to visit the native people of the Amazon in a canoe. The vast Russian steppes, the summit of Kilimanjaro, 
the lakes and highlands of Scotland - these are all "tourism imaginaries" (Salazar \& Graburn, 2014) stored in our imagination. Sometimes these will be nothing more than stereotypes or loose associations and far removed from what the landscape looks like in reality. In other cases, the representations are richer and more detailed. But it is important to note that every person has to a greater or lesser extent such an imagination, which is based to a significant degree on associations derived from popular culture. For many people, television, film, and other forms of popular culture act as a depot for the imagination or, in the words of André Malraux, a "musée imaginaire" (Malraux, 1947, quoted in Lukinbeal \& Fletchall, 2014: 225). According to the American anthropologist Arjun Appadurai (1990), globalization has brought momentum to this development. In a world of intercontinental migration and free movement of people and goods, according to Appadurai, it is the well-known stories from movies and TV shows that still provide something to hang on to for world citizens far from whatever place they consider "home".

How to pinpoint this relation between imagination, place, and popular culture? Partly, that is what the rest of this edited volume is about - exploring this pressing question in a wide variety of contexts. But in order to take a first step, it is worthwhile to first zoom in on the definitions used in this discussion. If we define stories as a causal concatenation of meaningful events (Bal, 1994: 5, 43) and events in turn as "something that happens", then it follows that stories always literally take place somewhere. Stories do not occur in a vacuum but in particular areas, whether these are identifiable or not. The areas in which the story takes place are not randomly chosen but serve to support the narrative. They create an atmosphere in which certain fictitious actions may take place which are, to varying extents, considered credible by the audience. In other words, the narrative space plays a supporting role in almost all stories. This leads to a situation in which many sites are known for the stories that take place in them, which may be symbolically associated at a later stage with the plot and moral themes of the story concerned. There is also a certain reciprocity here: locations are chosen because they fit well with the story, but at the same time, these stories reaffirm and empower the associations that the location inspires, creating powerful "imaginative geographies" (Urry \& Larsen, 2011).

In many cases, the symbolic meaning of these imaginative geographies is not invented for the story but related to the morphological characteristics of the landscape in question (Stedman, 2003). Deserts, forests, seas, and urban landscapes too have a significant amount of symbolic potential because of their distinctive character (Riley \& Van Doren, 1992). In this regard, care must be taken to guard against essentialism (Ehn \& Löfgren, 2010: 159-160; cf. "environmental determinism" in Riley \& Van Doren, 1992: 20). For example, it is tempting to see "the island" as a place of isolation. However, this association is not universal and timeless but typical of the contemporary era in which traffic often takes place via motorways and 
railways and water usually forms a barrier. In earlier times - when traffic was still largely by water - islands were seen as important junctions in (inter-) national traffic routes (Kinane, 2017). Another example concerns the sea. In the tradition of Jung and Freud, the sea is often associated with the subconscious (cf. Nash, 1997: 64-66). However, the question is whether the sea carries a similar meaning for all people and cultures. Perhaps people who spend a large part of their lives at or near the sea, such as divers, fishermen, or seafarers, attribute a completely different meaning to the sea than these two psychoanalysts from Central Europe - far away from the coast. The symbolic meaning of landscapes is not static and intrinsic but tied to time, place, and social group, as Andrea Trdina and Maja Turnšek explore in detail in Chapter 12.

These associations between story and place can go in two directions. On the one hand, stories can contribute to a positive evaluation of certain sites where the relevant (urban) landscape is associated with positive values such as security, nostalgia, happiness, freedom, and safety. Thus, a form of topophilia (Tuan, 1974) may occur: the love of a place, which in this case arises from the love of a story that takes place there. Certain landscapes seem particularly well suited to stimulating the imagination in this way. In this regard, Ehn and Löfgren (2010) use the term "dreamscapes": these are specific landscapes, such as the desert, the hills, the woods, or the beach, which because of their distinct physical characteristics can easily serve as carriers of meaning (ibid: 157-160). Comparable is the term "symbolic environment" in the work of Donald Meinig (1979, cited in Riley \& Van Doren, 1992). An example of such a dreamscape would be the mountains of New Zealand that have set the scene for several mythical narratives, ranging from Samuel Butler's Utopian society of Erewhon, published in 1872, up to the more recent The Lord of the Rings trilogy (Buchmann, 2006; Jones \& Smith, 2005).

Equally, stories can lead to forms of topophobia: fear of a place. Popular culture has a colourful mix of narrative genres in which horrific, frightening, or dramatic events take place, ranging from classical genres like the ghost story or the murder song to more contemporary (media) genres such as the thriller or horror story. These stories are usually played out in recognizable, topographically identifiable locations but at the same time concern locations that can be traced back to certain archetypes that we, developing the themes of Ehn and Löfgren (2010), could label "fearscapes". Examples of these might include abandoned houses, remote hamlets, basements and forests, wild and deep seas, or dilapidated neighbourhoods. The imagination can recognize many of these dark points of reference where evil seems to have nested.

Related but not identical to the dichotomy between topophilia and topophobia is the contrast between the "Self" and the "Other". According to cultural sociology, these two categories are the basis of how individuals and groups define and categorize the social reality around them. People are constantly trying to highlight their own identity vis-à-vis an imaginary "Other" 
(Goffman, 1959). This cultural categorization has a spatial counterpart: certain locations are considered their own territory by individuals or groups (the home, the office, the place they were born, the homeland, the place where they live), while other locations are considered the territory of the "Other" (the city of a rival football team, a neighbouring country, another continent).

Territories of the "Self" usually have explicitly positive connotations: these are related to safety and security, to the Heimat and the roots of people's own identity. While territories of the "Self" are often appreciated, territories of the "Other" frequently coincide with forms of topophobia. However, there is, of course, no iron law in this regard. In practice, many different variations are conceivable, for example, when the "Other" is associated with positive values and the distant, unknown land has an exotic if not mysterious pulling power (e.g. Laing \& Crouch, 2009). In those cases, the "Other" is not home to the danger of attack but quite the opposite: it represents the promise of transformation or transgression - a desirable adaptation of what is considered the current "Self".

Essentially, what we are saying here is that the imagination is a universal phenomenon: every human being has the capacity to create mental constructions of places where one is not present at that moment in time. At the same time, the imagination is bound up and intertwined with concrete, sensory experiences of space and place. We have argued that it's precisely this double nature that makes the imagination a fundamental part of our consciousness - of how we experience dimensions of time and place. Furthermore, while acknowledging the continued importance of the imagination throughout time, we also underlined the topical character of our volume's topic: in today's mediatized society, imaginative practices are omnipresent. Popular media culture offers important building blocks for our imagination: stories inject the imagined landscape with meaningful, emotional associations, either positive or negative, and locate the "Self" and the "Other" symbolically in this imagined space. What we presuppose is that these associations are at the root of the phenomenon of tourism, in particular the niche of media tourism. Based on the processes of topophilia/topophobia presented in popular stories, and identification with these, people may take the decision to make a journey, visit the related locations, and thus come closer to their beloved story through materializing their imagination. It is now time to further scrutinize these claims and to investigate in detail how the connections between imagination, place, and popular culture are made in cultural practice.

\section{Structure of the volume}

In the following 18 chapters, we will investigate the connections between imagination, place, and popular culture in contemporary society from a wide variety of perspectives. To this end, the volume is structured in four parts - the first of which is conceptual, whereas the latter three are empirical in nature. 


\section{Reijnders, Waysdorf, Bolderman and van Es}

In the first part, Theorizing the Imagination, the concept of the imagination is critically reflected upon in a variety of contexts. The latter three, more empirically oriented, parts, are divided along the lines of the three stages of every journey: preparing to go (Mediating Place), being there (Being There), and eventually returning home (Returning Home: Memory and Belonging).

Starting out with Part I, Theorizing the Imagination, Stijn Reijnders opens the theoretical discussion by arguing for a holistic and process-based perspective on the development of media tourism. By conceptualizing "imaginative heritage", the chapter reflects on the active involvement of a multitude of actors - fans, tourists, creative and tourism industries, governments - in (co-)creating "places of imagination" through projection of, or appropriation by, popular fictional narratives on specific sites and throughout different times. André Jansson, in the second chapter, analyses the role of "imaginative authenticity" in contemporary (post-)tourist practices, utilizing an illustrative case study of urban explorers to expand upon the tensions between, at one end, pushing towards a more "authentic" imaginary of a place than professional media offers, and, at the other, social media's capacity to codify particular practices and concepts that might interrupt this.

In Chapter 3, David Morley presents a more critical take on the role of place-narratives in their ability to create a sense of place. Or rather, how the top-down enforcement of rapidly changing place-narratives can destabilize or even destroy a certain sense of place. Through scrutinizing Birmingham's recent history of rather failed place-making projects, the argument is being put forward that numerous attempts to re-brand and re-imagine the city have rendered its identity obsolete. As a result, Birmingham has become a quintessential non-place, lacking a coherent sense of place and increasingly problematizing the potential to belong and feel "at home". Leonieke Bolderman expands on the visual focus of many conceptualizations of the imagination in Chapter 4, based on a discussion of contemporary music tourism. Arguing that music puts into focus the affective and embodied dimensions of imagining, she makes a compelling argument for looking beyond vision in thinking about mediatized experiences of place and belonging.

David Crouch, in the final chapter of the first part, closes out the theoretical discussion by critically reviewing the role of the imagination in everyday life and how a variety of media interrelate in the process of shaping the imagination. Media, as argued, is not a prime determinant of shaping the imagination but rather one of many. As such, the imagination can at best be perceived of as a "hybrid site", one in which located memory and mediated influences and affectivities come together, intertwine, and commingle. Whether being at home or far away, it is this constellation of located and mediated impressions and experiences that provide the framework through which mankind makes sense of the world around them and their place in it.

In the wake of this theoretical discussion, a more empirical engagement with the imagination kicks off in Part II, Mediating Place. In the sixth chapter, Anne Marit Waade sets out to closely investigate the ways in which the 
Danish West Coast is utilized and represented in the production process of the New Nordic Noir series. Predominantly focusing on the role that locations play in the early stage of the production of a new series, Waade adopts a multiactor perspective in outlining the ways in which local governments, and both private and public institutions are internationally collaborating in the creation of an increasingly popular television drama series. The chapter shows how the creation of "places of imagination" and popular TV series are from the outset intimately connected to each other, building on and consolidating the imagination of Denmark - or Scandinavia as a whole - in line with its particular dark and raw representation in Nordic Noir.

Bianca Freire-Medeiros places the focus in Chapter 7 on Brazil. More specifically, she examines how the Hollywood musical Flying down to Rio (1933) significantly contributed to putting Rio de Janeiro on the map for the international public. In managing to shape the collective imagination of an international audience, a subsequent desire to visit Rio was sparked in many after the musical hit the stages. As a result, inbound tourism to Brazil's capital city witnessed an increase as people came from far and wide to fly down to Rio and see it with their own eyes. Timo Thelen and Elisabeth Scherer shift the focus to Japan, taking a close look at the historical development of Japanese morning drama series (asadora) in Chapter 8, shedding light on the historical development of representations of different regions of Japan and their connection to "Japaneseness" in this popular television genre. Engaging in a comparative analysis between two popular series Oshin (1983) and Amachan (2013), Thelen and Scheeren illustrate how the popular imagination and representation of locality in Japan in popular morning dramas has developed over time and stimulated a diverse range of tourism practices in the transition from the analogue into the digital age.

Speaking of digitality, Chapter 9 presents Bobby Schweizer's investigations of the videogame tourist, looking at how certain players seek to "possess" the cityscapes of digital worlds and share these virtual touristic experiences with others. Nicky van Es, in closing out the second part with the tenth chapter, brings forward the venerable tradition of literary tourism, expanding its scope to the digital age. Based on five years of empirical research, a critical reflection is offered on the distinctive role (nay: place) of literature in imagining, experiencing, and reflecting on place and locality in an environment increasingly characterized by digital and multimedia.

Though the previous chapters have also already touched upon the role and importance of the imagination when it comes to having an embodied experience of place, the chapters contained in the third part all present empirical research on instances of Being There. Katriina Heljakka and Pirita Ihamäki analyse in Chapter 11 how the idea of wanderlust not only includes human travellers but extends to human-created objects through an exploration of toy mobility. By teasing out the different online and offline practices of toy tourists, they explore how the imagination, its realization in travel practices, and its spreadability through social media are driven by elements 


\section{Reijnders, Waysdorf, Bolderman and van Es}

of play. Andrea Trdina and Maja Turnšek analyse in Chapter 12 how Slovenian fans of the German-Austrian TV series Der Bergdoktor appropriate the imaginary and real region of Tyrol through diverse narrative layers, with a special focus on the role of Slovenia's post-socialist reality in the practices of these media tourists. Esther Hammelburg and David Cashman explore the central notion of being there in relation to embodied and aural experiences of place. As we have defined the imagination in this introduction as a primarily visual capacity, Hammelburg expands upon this idea of imagining in Chapter 13 by focusing on the notion of "liveness" and the role of media in creating experience "bubbles" during festivals. Last, David Cashman focuses in Chapter 14 more explicitly on the role of music in media event "bubbles" during festivals through an analysis of cruise ship music festival tourism.

After experiencing "places of imagination", there inevitably comes a moment of returning home, filled with memories and a potential strong longing to go back. The final part of this volume, Returning Home: Memory and Belonging, reflects on ways in which memories and stories are connected to place(s), creating spaces of belonging. Jason Grek-Martin expands on the theme of ambiguous narrativity in Chapter 15, in which he juxtaposes the reflections of literary tourists and heritage tourists at slavery sites in the Gambia, showing a complicated relationship between place and, at times conflicting, mediated memories connected to it. Marie-Laure Ryan, in Chapter 16, elaborates on how spaces are converted to places via stories and narratives, imbuing it with meaning and significance. In doing so, Ryan analyses how literary narratives in particular are powerful in stimulating the imagination and subsequently providing a place-narrative. Through looking at Orhan Pamuk's novel Museum of Innocence (2008) and the corresponding real-world Museum of Innocence located in Istanbul, Ryan shows how the worlds of imagination and reality collide and are intertwined in situ through Pamuk's fictional narrative. Chapter 17 sees Abby Waysdorf reflecting on the role of fandom in film tourism, exploring the multiplicity of ways fandom, place, and notions of belonging influence each other in the contemporary media environment. Matt Hills provides the final chapter of the volume and investigates the convergence of theatre and architectural fandom in looking at how iconic buildings function as part of a "mnemonic imagination".

With these diverse chapters, this collection shows the variety of ways the imagination, place, and popular culture intersect, challenge, and nurture each other. In investigating media narratives and their related places, we show here the depth and range of these connections and how they can both imaginatively and figuratively move audiences. It is to these explorations that we now turn.

\section{Note}

1 The first section of this chapter is partly based on the (unpublished) inaugural lecture Lights in the Forest, written by the first author. For the second section, we have made use of text fragments from the paper "Stories that Move", written by 
the first author and published in the European Journal of Culture Studies in 2016. We are grateful to the editors of EJCS for their permission to re-use parts of this publication. This project has received funding from the Netherlands Organization for Scientific Research (NWO, grant number PR-11-77), as well as the European Research Council (ERC) under the European Union's Horizon 2020 research and innovation programme (grant number 681663).
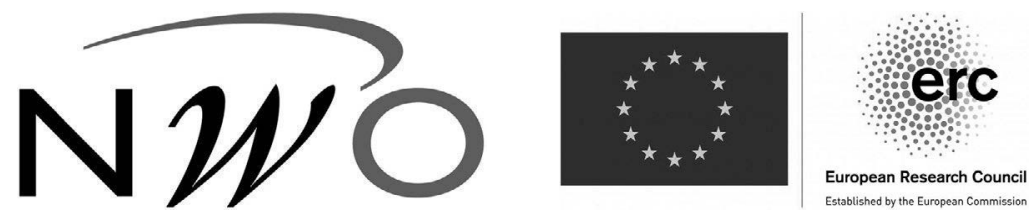

\section{Bibliography}

Adams, J.D. (2014). Embodied travel: In search of the Caribbean self in tropical places and spaces. In: G. Lean, R. Staiff \& E. Waterton (eds.), Travel and imagination, pp. 25-38. Farnham: Ashgate.

Appadurai, A. (1990). Disjuncture and difference in the global cultural economy. Public Culture 2(2): 1-24.

Bal, M. (1994). Narratology: Introduction to the theory of narrative. Toronto: University of Toronto Press.

Berger, A.A. (1997). Narratives in popular culture, media, and everyday life. London: Sage.

Bird, S.E. (1988). Myth, chronicle, and story: Exploring the narrative qualities of news. In: J. Carey (ed.), Media, myths and narratives: Television and the press, pp. 67-87. London: Sage.

Buchmann, A. (2006). From Erewhon to Edoras: Tourism and myths in New Zealand. Tourism Culture and Communication 6(3): 181-189.

Caughey, J.L. (1984). Imaginary social worlds: A cultural approach. Lincoln: University of Nebraska Press.

Connell, J. (2012). Film tourism: Evolution, progress and prospects. Tourism Management 33: 1007-1029.

Couldry, N. (2006). Culture and citizenship: The missing link? European Journal of Cultural Studies 9(3): 321-339.

Couldry, N. (2012). Media, society, world: Social theory and digital media practice. Cambridge: Polity Press.

Ehn, B. \& Löfgren, O. (2010). The secret world of doing nothing. Berkeley: University of California Press.

Goffman, E. (1959). The presentation of self in everyday life. Garden City: Doubleday.

Gottschall, J. (2013). The storytelling animal: How stories make us human. Boston: Mariner Books.

Hume, D. (1740/2000). A treatise of human nature: Being an attempt to introduce the experimental method of reasoning into moral subjects. Oxford: Oxford University Press.

Jones, D. \& Smith, K. (2005). Middle-Earth meets New Zealand: Authenticity and location in the making of the Lord of the Rings. Journal of Management Studies 42(5): 923-945. 


\section{Reijnders, Waysdorf, Bolderman and van Es}

Kant, I. (1781/2015). Kritik der reinen Vernunft. Cologne: Anaconda Verlag.

Kinane, I. (2017). Island worlds. In: M. Wolf (ed.), The Routledge companion to imaginary worlds, pp. 153-160. London: Routledge.

Klinkmann, S. (2002). Popular imagination: Essays on fantasy and cultural practice. Turku: Nordic Network of Folklore.

Laing, J. \& Crouch, G.I. (2009). Exploring the role of the media in shaping motivations behind frontier travel experiences. Tourism Analysis 14: 187-198.

Lean, G., Staiff, R. \& Waterton, E. (2014). Reimaging travel and imagination. In: G. Lean, R. Staiff \& E. Waterton (eds.), Travel and imagination, pp. 9-24. Farnham: Ashgate.

Lennon, K. (2015). Imagination and the imaginary. London: Routledge.

Lewicka, M. (2011). Place attachment: How far have we come in the last 40 years? Journal of Environmental Psychology 31: 207-230.

Lukinbeal, C. \& Fletchall, A. (2014). The hollowed or hallowed ground of Orange County, California. In: J. Lester \& C. Scarles (eds.), Mediating the tourist experience, pp. 223-236. Farnham: Ashgate.

Malraux, A. (1947). Le musée imaginaire. Genève: Skira.

McGinn, C. (2004). Mindsight: Image, dream, meaning. Cambridge and London: Harvard University Press.

Morley, D. (2009). For a materialist, non-media-centric media studies. Television \& New Media 10(1): 114-116.

Nash, R.J. (1997). Archetypical landscapes and the interpretation of meaning. Cambridge Archaeological Journal 7(1): 57-69.

Orgad, S. (2012). Media representation and the global imagination. Cambridge: Polity Press.

Reijnders, S. (2011). Places of the imagination: Media, tourism, culture. Farnham: Ashgate.

Reijnders, S. (2016). Stories that move: Fiction, imagination, tourism. European Journal of Cultural Studies 19(6): 672-689.

Riley, R. \& Van Doren, C.S. (1992). Movies as tourism promotion: A 'pull' factor in a 'push' location. Tourism Management 13(3): 267-274.

Salazar, N.B. \& Graburn, N.H.H. (2014). Toward an anthropology of tourism imaginaries. In: N.B. Salazar \& N.H.H. Graburn (eds.), Tourism imaginaries: Anthropological approaches, pp. 1-28. New York: Berghahn.

Scannell, L. \& Gifford, R. (2010). Defining place attachment: A tripartite organizing framework. Journal of Environmental Psychology 30: 1-10.

Stedman, R. (2003). Is it really just a social construction? The contribution of the physical environment to sense of place. Society and Natural Resources 16: 671-685.

Streminger, G. (1980). Hume's theory of imagination. Hume Studies 6(2): 91-118.

Tuan, Y. (1974). Topophilia: A study of environmental perception, attitudes, and values. Englewood Cliffs: Prentice-Hall.

Urry, J. \& Larsen, J. (2011). The tourist gaze 3.0. London: Sage. 


\section{Part I}

\section{Theorizing the imagination}


$\because$ Taylor \& Francis

Taylor \& Francis Group

http://taylorandfrancis.com 


\title{
1 Imaginative heritage \\ Towards a holistic perspective on media, tourism, and governance ${ }^{1}$
}

\author{
Stijn Reijnders
}

\section{Introduction}

In the south of Croatia, on the coast of the Adriatic Sea, lies the port of Dubrovnik. This ancient fortified city is widely known as the "Pearl of the Adriatic", a reputation which derives largely from its medieval city centre and the impressive city walls that rise high above the harbour. Dubrovnik has been attracting a steady stream of tourists for decades. However, the flow of tourists has recently increased dramatically. Since the city centre of Dubrovnik has been used as a recording location for the worldwide popular TV series Game of Thrones, the harbour town has become one of the major tourist hotspots in Europe. Groups of tourists are already assembling in the city at dawn.

At first, the local population was happy with the increased interest; tourism was an important tool for strengthening the local economy after the crisis of the Yugoslav civil war of the 1990s. But as the influx of Game of Thrones fans began to grow significantly, the mood changed. Residents complained not only about the massive number of tourists but also about the underlying idea that tourists were not so much there to visit Dubrovnik as to experience the fictional city of King's Landing: "The whole thing is chaos" locals commented, "It's like living in the middle of Disneyland" (Associated Press, 2018). In 2018, the mayor decided to combat over-tourism by setting a limit on the number of tourists, and crash barriers were installed at the gates to the city.

Dubrovnik is not an isolated case. More and more often, it happens that a certain city or region suddenly becomes the centre of attention because of its association with a well-known film, TV series, book, or video game. Popular culture, in other words, has a growing influence on the way people form an image of the world around them and on the affection that they may or may not develop for certain cities or countries (Reijnders, 2016). This phenomenon is not new: as early as the 19th century, literary pilgrims went to Scotland, England, and France in search of traces of novels beloved to them. It could even be argued that there is an age-old, mutual relationship between travelling and telling stories (Gottschall, 2013; Lean et al., 2014). Nevertheless, the increasing influence of popular media in our society has accelerated 
this development. It is no longer just traces but a network of popular associations that extends to every corner of a city or region (e.g. Roberts, 2012). Every year, new films, TV series, and books are released which show the city or region from a specific perspective. Some stories fall into oblivion; others are the source of inspiration for new expressions of popular culture. Thus a rich cultural "soil layer" is built up over the years (Roberts, 2012).

With the boom in media tourism in recent decades, academic attention for this topic has likewise grown. Starting with a few stand-alone, exploratory studies in the 1980s and 1990s (e.g. Cohen, 1986; Butler, 1990; Riley \& Van Doren, 1992; Riley et al., 1998) and followed by the work of tourism scholar Sue Beeton in the 2000s (e.g. Beeton, 2001, 2004, 2006), the research field of media tourism took off a decade ago (Roesch, 2009; Beeton, 2010; Reijnders, 2011a; Kim, 2012; Connell, 2012; O'Connor \& Kim, 2014). Recent years have seen a further flourishing of a multidisciplinary, global interest in the relationship between popular culture and tourism (Reijnders et al., 2015; Smith, 2015; Mansfield, 2015; Beeton, 2016; Cohen, 2017; Seaton et al., 2017; Kim \& Reijnders, 2018; Lundberg \& Ziakas, 2019; Tzanelli, 2019).

Notwithstanding these diverse contributions, most of the existing research remains limited to two major themes: the impact of media tourism on local communities and the way media tourism is experienced by tourists. This question was particularly important during the early phase of media tourism, when this phenomenon was still driven by the interest and fascination of individual travellers. However, over the years, media tourism has grown into an important niche within the tourism sector with a huge economic impact and has gradually been taken over by the media and tourism industries. At the same time, the media and tourism industries are increasingly converging (Tzanelli, 2004; Tzanelli, 2007; Gyimóthy et al., 2015). These power dynamics behind media tourism have remained off the radar for (too) long. Therefore, we need a broader, multiactor approach to media tourism that takes into account not only the fans and travellers but also the role of media producers, tourism professionals, locals, and other stakeholders involved in the development of media tourism.

Following this line of thought, this chapter argues for a holistic, processbased approach to the development of media tourism. To be able to investigate and map this dynamic, the term "imaginative heritage" is introduced in this chapter. In particular, I refer to the multitude of popular fictional narratives that have been projected upon or appropriated by specific sites throughout time and that together make up an important part of local place identity. As I will argue, imaginative heritage results from an active involvement of not only fans and tourists but also the media industries, the tourism industries, and the local governments.

What is the added value of the concept of imaginative heritage? First, and in line with the previous, it allows for an in-depth analysis of the power configurations behind media tourism, looking at the roles of the different actors that are involved in the development of this phenomenon. Second, 
this concept forms a welcome intervention in a research field that is strongly compartmentalized. Media tourism includes a wide range of media, including literature, film, novels, video games, and animation. In practice, these media also overlap. But research into this phenomenon still largely takes place along the lines of traditional disciplines: literary scholars investigate isolated examples of literary tourism, and media scholars keep an eye on tourism related to specific movies or TV series, while game researchers focus on the interfaces between tourism and video games. The concept of imaginative heritage invites scholars to transcend individual cases and to look beyond the boundaries of "their" medium.

Third, this concept aims to intervene in the domain of heritage studies by addressing the role that popular stories play in shaping heritage. We typically think of heritage as based in reality; it derives its power from being "authentic" (Otero-Pailos et al., 2010). As this chapter aims to show, the fictitious can actually contribute to heritage and in some cases might even be at the heart of a local place identity. Fiction doesn't flow freely above places but is engrained in the very "roots" of a place. By exploring the reciprocal nature of the relation between fiction, heritage, and place, this concept also questions the dominant dichotomy between tangible and intangible heritage, in line with the work of critical heritage scholars like Rodney Harrison (2011). Imaginative heritage is not about the tangible or the intangible but precisely about the cross-pollination of both dimensions.

Last but not least, and as will be argued in the following section, the concept of imaginative heritage can be used as an important instrument by local governments. On the one hand, it allows them to stimulate new media tourism initiatives that align with other types of local heritage. On the other hand, it will help them to unlock "forgotten" forms of imaginative heritage from the past. ${ }^{2}$

\section{Theorizing imaginative heritage}

The starting point for this chapter is the idea that media tourism emerges from a more general process of place identity formation. As is now generally accepted, places do not have one static identity. On the contrary, the identity of a place is constantly being (re-)negotiated, based on an intrinsic dynamic between the geographical characteristics, the living practices, and the symbolic representations of a certain location (Vanclay, 2008). In theorizing about place, cultural geographers have, for a long time, acknowledged the presence of the symbolic dimension, while never particularly emphasizing it (Lefebvre, 1991; Gieryn, 2000; Easthope, 2004; Vanclay, 2008). However, in order to acknowledge today's increasingly mediatized society, several authors have argued that the effect of popular culture on the formation of place identity needs to be put more to the fore (Morley, 2001; Edensor, 2002; Orgad, 2014; Gyimóthy et al., 2015: 21-22). In addition to popular culture, other "sign industries" (Tzanelli, 2004, 2007) should also be taken into 


\section{Stijn Reijnders}

account, such as the tourism industry. Tourism is one of the fastest-growing industries and is increasingly involved in the formation of place identity.

This chapter proposes to launch a new concept to further pinpoint and theorize this dynamic between popular culture, tourism, and place. With "imaginative heritage", I refer to the multitude of popular fictional narratives that have been projected upon or appropriated by specific sites throughout time and that together make up an important part of local place identity. In a sense, imaginative heritage is composed of the sum of literary heritage, cinematic heritage, television heritage, videogame heritage, folk tale heritage, and so on, while also acknowledging the many links between these domains. For example, as van Es and Reijnders (2018) showed in their study on detective tours, literary heritage and cinematic heritage are often combined in media tours, especially where cinematic adaptations of original novels are concerned. In these instances, the literary links are often considered "more authentic" and closer to the "core" of the city than their cinematic counterparts (van Es \& Reijnders, 2018: 511).

Imaginative heritage has become an increasingly relevant player in the competition for tourists, yet popular culture as a legitimate vehicle for articulating place identities often remains contested in the localities concerned, especially in those instances where representations from popular culture are seen as non-native and hostile. For example, while many international tourists are eager to visit locations related to the Netflix series Narcos (2015-2017), many Colombians decry the underlying negative associations between their country and drug traffic, which reinforce traditional stereotypes of Colombian history and identity. Another example would be the popularity of Dracula tourism in Romania, cherished for the tourist revenues but at the same time criticized by many Romanians for the portrayal of Romanian culture as backward, in particular concerning the association between Dracula the vampire and national hero Vlad Tepes (Reijnders, $2011 b)$. That said, there are also examples in which imaginative heritage is actually celebrated by the local community and seen as complementary to other, more factual heritage discourses, such as in the case of Twilight in Montepulciano (Larson et al., 2013), Game of Thrones in Northern Ireland (Mannheimer, forthcoming), and Millennium in Sweden (Lind \& Kristensson Uggla, 2019).

The concept of imaginative heritage is partly inspired by the notion of "cultural landscapes", as discussed by Beeton and Seaton (2018), Salazar and Graburn's use of "tourism imaginaries", (2014) and the concept of "imaginative geographies", as developed by Said (1978; cf. Roberts, 2012 on "cinematic geographies"), but differs from these in two ways. First, it focuses more explicitly on the role of fictional narratives in the formation of place identity. ${ }^{3}$ Imaginative heritage refers to the reciprocal nature of the relation between fiction and place. Media tourism often involves everyday places such as an alley or a square, which would not normally be worth visiting. But precisely because of the association with a beloved story, these places 
suddenly acquire a special quality: they form a gateway to that other, imaginary world (Reijnders, 2011a). Everyday places gain something "special" from being associated with powerful stories, while these stories themselves derive their power partly from their near-real character. As such, it escapes the classical, Cartesian binary between tangible and intangible heritage (cf. Harrison, 2011). Imaginative heritage is not so much about the material or the spiritual world but about the many instances when those two worlds meet and mutually reinforce each other.

Second, it shifts the emphasis from actual landscapes and their representations to the heritage practices performed by the stakeholders involved. Here I interpret "heritage" in line with the critical heritage studies approach as advocated by scholars like Harrison (2011) and West (2010). Imaginative heritage should not be seen as a static and undisputed collection of artefacts (e.g. the canonical novels and movies set in a specific city) but as a dynamic, social process of heritage-in-the-making, involving several actors and authoritative discourses, as well as conflicting notions of identity and heritage. Heritage needs to be "performed" - for example, by doing a walking tour - in order to exert its power. The challenge is to capture the dynamics of this dispute between the different actors involved, investigating how sites related to popular culture become designated (or not) as a valuable part of local, national, or transnational identity.

In this process, three key steps are identified (see Figure 1.1). First, the media industry and its fans are involved in the production and consumption of popular movies, novels, films, and video games. As I will argue, popular narratives are always set in specific places, either real or not. Thus, the media industries are engaged in imagining place. Fans and other audiences expand these imaginary worlds through world-building practices and co-determine which of these productions become truly popular. Second, the tourism industry is eager to appropriate these imaginations and "drag" (Torchin, 2002) them to recognizable, geographical locations within their vicinity, making them part of the imaginative heritage of a place. Tourists are evidently part of these practices, but they are, just like fans, not easily manageable; tourist flows are notoriously unpredictable. Finally, local governments try to develop policies that help to stimulate the media and tourism industries and their joint ventures, thus hoping to contribute to a community which is economically viable and comfortable to live in. Some of these governments will also have to deal with grass-roots place-making practices that actually protest against media tourist initiatives, for example, because the local community is dissatisfied with the way it is represented by the media and "consumed" by tourists. Ultimately, these place-making practices will prompt and streamline new initiatives for imagining and touristifying place - an unending process that adds layer upon layer of imaginative heritage to a place. These three steps of imagining, touristifying, and making place - each with their own dynamic - will be further elaborated upon in the following subsections. 


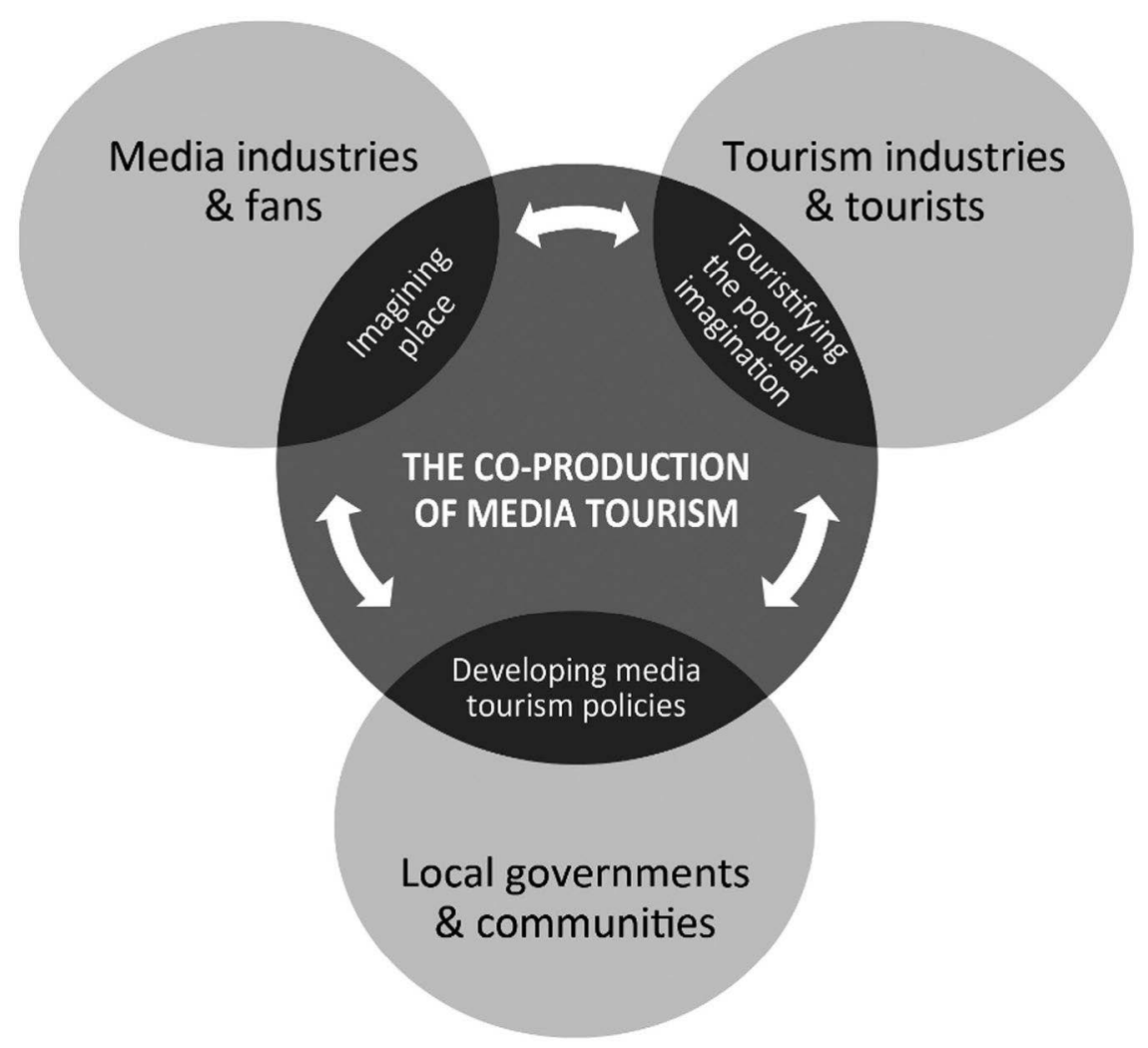

Figure 1.1 The co-production of media tourism.

\section{Imagining place}

In pre-modern societies, it was mainly oral narratives that painted a picture of the outside world. Myths, legends, gossip, and songs described distant wars, violent crimes in nearby towns, or magic and supernatural events in places outside the safe borders of the village community. In modern societies, a major player has been added: media. In particular, film and later television are considered the storytellers of the 20th and 21st centuries, joined more recently by the genre of video games. Recent years have also seen an increasing collaboration and convergence between these different media platforms (Jenkins, 2006), creating powerful transmedia franchises build around successful "brands" such as Harry Potter, whose world is rolled out in novels, movies, cartoons, theme parks, etcetera (Boni, 2017). These popular representations together offer the promise of literally being able to see events far away (cf. Orgad, 2014). As argued in the Introduction, all these stories, circulating in the media and beyond, together create a rich associative imagination of the world (Lukinbeal 
\& Fletchall, 2014). Of course this imagination is not equally spread across the globe; the popular imagination has its own centres and peripheries. Likewise, not every individual and every country is equally involved in these world-building practices (Boni, 2017). But overall, one can identify an intimate relation between popular culture, imagination, and place on a global scale.

How do these associations between story and place come about? As I've argued elsewhere (Reijnders et al., 2015), stories do not occur in a vacuum but always literally take place somewhere. Narratives, defined here as a string of events (Bal, 1994), need a space in which to unfold. In some cases, these narrative spaces might be little more than a backdrop to the story. In other cases, the narrative space takes a leading role in the narrative development, steering the story in certain directions and - as was the case in many Romantic novels from the 19th century - symbolizing the emotional states of the central characters. When popular narratives occupy recognizable, "real" locations, they even have the potential to "inject" landscapes with certain symbolic meanings that go beyond the narrative realm. In this way, the media industries, mostly unintentionally, pave the way for the construction of imaginative heritage - waiting to be appropriated and "anchored" in space by their audiences. Fans have a pivotal role in this process: their consumption practices not only co-determine which media products become truly popular, but many fans are also involved in world-building practices. For example, the fantasy world of Game of Thrones has been expanded way beyond the original TV series in the many online fan productions, such as narrative maps, drawings, and fan fiction, together creating a rich "hyperdiegetic world" (Hills, 2002) of the Seven Kingdoms.

Little is known about how this process of imagining place takes place in practice. What locations are selected as backdrops for popular media products? Who are the gatekeepers in this process (O'Connell, 2014), and how do they choose locations, based on what criteria? What is the role of the tourism industry in this process? How do fan practices affect the imagination of place? At the same time, it is relevant to investigate how places might actually take an active role in the creative process of media production. More than just being backdrops, places have the power to inspire the creative professionals of media industries from an early phase onwards in the production process and steer the narratives based on the geographical, cultural, or social conditions of a place. Moreover, little is known about how these production practices might differ between media such as film, television, video games, or literature.

\section{“Touristifying” the popular imagination}

From the moment a film, TV series, book, or game breaks through and enjoys popularity among the public, the likelihood increases that the locations from these stories will become tourist attractions. The tourism industry is aware of the influence of popular culture on travel and consumer behaviour and 


\section{Stijn Reijnders}

has therefore developed various strategies to influence this process (Busby \& Klug, 2001; Connell, 2012; Gyimóthy et al., 2015; Lundberg et al., 2018). However, research into these strategies is still scarce and fragmentary (Lundberg et al., 2018). I would like to propose to investigate these strategies in relation to each other under the umbrella term of "touristification". I follow Freytag and Bauder (2018) in interpreting the term "touristification" in a broad sense as "the process of a tourism and tourist-based transformation" of specific locations, involving a wide spectrum of stakeholders and actors, ranging from national tourism boards and travel organizations to individual guides. In the case of media tourism, I distinguish three steps of "touristification": appropriating, marking, and commodifying.

The notion of "appropriation" refers to the phenomenon in which people interpret cultural products in a way that is in line with their world view and interests (De Certeau, 1980). In the case of media tourism, it involves mostly a spatial appropriation, in which a fictional environment is linked to an existing geographical location by individuals or companies that benefit from this association. Such appropriations are increasingly being made, but in essence, they remain an artificial construct. Fiction, by definition, takes place in an imaginary world. Even if the media product contains literal references to geographical realities, it is by no means true that both worlds are actually the same. The artificial nature of this act is confirmed by the fact that there are several known cases in which locations compete with each other for the "authenticity claim".

The appropriation of fictional worlds into more general "tourism imaginaries" (Salazar \& Graburn, 2014) is followed by the marking of specific locations in the (urban) landscape as being "special" because of their link to fictional worlds. Buildings, squares, rooms, or doors that have figured in popular stories are highlighted by guides and guidebooks as concrete proof of the supposed link between both worlds, thus celebrating the imaginative heritage of a place. In some cases, placards or information boards are posted that report on the scenes recorded at these locations. Part of the "marking" also takes place online, when fans on Instagram or other social networks testify as to their presence at a movie or TV location. But in all cases, the same claim arises: here a place of the imagination is marked in everyday life, and therefore this place is worth a visit.

The process of "touristification" is completed by linking the experience of being there with the consumption of concrete products. Buying such a product is not only a financial transaction but also a symbolic act in which one crosses the border between the "ordinary" and the "imaginary" world. Almost all parts of the tourism sector have become involved in this process. For example, tour operators offer film and television tours and - more recently apps that provide users with information and accompanying images from films, series, and games on location. Event managers are involved in organizing temporary exhibitions of popular film props. The publishing industry produces maps and travel books on media tourism, while several hotel chains 
are advertising "special" rooms where certain characters or actors slept. These are all examples in which imaginative heritage is being commodified: turned into an economic good.

Some might protest this commodification claim by stating that there are also a lot of non-commercial initiatives, such as fans organizing an individual "media pilgrimage" to filming locations or authors' homes. Indeed, fans are often the first explorers of new places of the imagination, paving the way for other travellers. However, as soon as these fans share their experiences with other fans and stimulate the awareness of a certain site, they will, at least to a certain degree, contribute to the overall process of touristification. It's also important to acknowledge that tourists are not always that easily manageable. Whether a (media) tourist site will become a popular attraction, and for whom, depends to a large degree on the individual choices made by fans and other tourists.

I expect that the more intensively the media and tourism industries work together, the more intertwined the processes of mediatization and "touristification" will become. However, empirical research is required to critically investigate these claims. Media theme parks like The Wizarding World of Harry Potter in Orlando, Bollywood Parks in Dubai, and Star Wars: Galaxy's Edge in Anaheim would offer a great point of departure for these research lines.

\section{Developing media tourism policies}

In addition to the media and tourism industries, a third major party is involved in the development of media tourism, namely national and local governments. They are responsible for the development of policy in both sectors and therefore have a significant influence. The starting point is the idea that in the long term, governments will not benefit from the unilateral encouragement of more and more tourists. I assert that the cultural policy of governments should not limit itself to "branding" a certain country or city but that it should think about what a community needs from a more holistic perspective and how tourism can play a role in that. Tourism must serve a community in a sustainable way, without disturbing the local balance between "people, profit and planet" (Waligo et al., 2013; Twining-Ward \& Butler, 2002). In that sense, tourism is not an end in itself but a means. Greg Richards (2017a, 2017b) points out the importance of place-making as an alternative to place marketing. Lundberg et al. (2018) and Mason and Rohe (2019) also point to the possible contribution of media tourism to forms of place-making.

A disadvantage of the concept of place-making is that it has not yet fully crystallized and is interpreted differently within different disciplines. According to a recent review article, at least two different approaches can be identified (Lew, 2017). On the one hand, from an urban planning perspective, place-making is discussed as a top-down policy instrument, aimed 
at organizing and regulating public space. On the other hand, the concept of place-making within cultural geography is interpreted in a completely different way, as a bottom-up process assuming that individuals and social groups are naturally inclined to shape their environment in line with their own values, needs, and world vision (Lew, 2017).

What I propose in this chapter is that governments play a dual role in this field of tension. They will have certain ideas about how the city or the country should be organized and what role (media) tourism can play in this, but at the same time, these governments and local councils are dealing with locals who may not agree with the choices made and protest against the way in which their habitat is taken and used by the media and tourism industries. In the past, various cases have arisen in which local residents and environmental action groups have protested against the admission of media productions into their community and the resulting tourism flows (e.g. Kousis, 2000; Novy \& Colomb, 2016; Hughes, 2018; Barton, 2019).

In practice, this will most probably come down to finding a balance between, on the one hand, the development of an active media tourism policy in which new media productions are welcomed and facilitated as much as possible and, on the other hand, listening to the needs and experiences of the local population. Media tourism can be used to contribute to a culturally proud and economically viable community, but the imaginative heritage of popular culture can also conflict with other notions of heritage, such as local histories or religious heritage. Consideration could also be given to making cooperation between the media production team and the local population a requirement. Past experience has shown that deploying locals as extras or advisers can have a positive effect on both the production team and the local population (Mayer, 2016).

An interesting suggestion has been made by Lundberg et al. (2018), who argue that local authorities should try to align new media productions with local heritage, because this would add to the "authenticity" of the place. Although notions of authenticity are highly debatable in this context, and there has in fact been no proper investigation into these dynamics, it would be a valid idea to do further research into the relationship between popular fiction and local history. In my view, the concept of imaginative heritage, which is being launched in the current chapter, offers a valuable tool to pick up that particular gauntlet - this based on the premise that popular fiction offers more than only a boost to existing heritage; it has the potential to become heritage itself.

In this setting, it is crucial to pay attention to the societal context in which media tourism is created. A clear blueprint for the development of media tourism does not exist, as each national or urban community has its own challenges and local issues. It is precisely for this reason that it is essential to conduct empirical, comparative research into current policies with regard to media tourism in different contexts. 


\section{In conclusion}

At the end of the afternoon, when the cruise ships have departed, peace returns to the centre of Dubrovnik. The city walls are deserted, except for a few last visitors, and Venus, the evening star, appears high above the sea, followed by several stars that light up one by one in the evening sky. The stars above the Adriatic Sea have something magical: they show the immense size of the universe, the gaping vortex above us. Perhaps it was precisely the fear of this vortex that once moved man to develop a system of constellations, through which the overwhelming chaos of the starry sky could be partially contained and framed in earthly metaphors such as Scorpio, Sagittarius, and Cygnus.

For a long time, research into media tourism has also been driven by a fascination for individual cases: one square, street, or house that has suddenly acquired something "magical" through its association with a well-known story from popular culture. These places functioned as magical, star-dusted portals that offered access to another, fictional reality. Research into such individual cases has yielded a great deal, but I think it is time to enrich the field with more case-transcending research, looking at the way in which these cases relate to each other, both in space and in time, and together form networks scattered around the world. Only in this way can we acquire a better understanding of the phenomenon of media tourism. Such a holistic approach not only provides insight into recurring patterns in a multitude of individual cases but also reveals the relationships and hierarchies between these cases. In this context, explicit attention must also be paid to the diachronic dimension: how popular stories have contributed to the development of a place identity over time. Old histories are forgotten but also make way for new stories in the "soil layer" of our culture. Moreover, instead of focusing only on the experiences of individual fans, it is time to acknowledge the complex power configurations that are at play behind media tourism, exploring why certain narratives are told, while others are not.

It is like looking through a magic filter: suddenly we see the Earth with all the routes that fictional characters have ever travelled in a myriad of stories, from the first Egyptian stories to the latest video games. The world is littered with a layered network full of such stories and characters, visible to anyone who wants to see it. One of the ways to explore these networks and their underlying mechanisms is through the concept of imaginative heritage introduced in this chapter.

\section{Notes}

1 This project has received funding from the Netherlands Organization for Scientific Research NWO and from the European Research Council (ERC) under the European Union's Horizon 2020 research and innovation programme (grant agreement No. 681663). I am grateful to Balazs Boross, Emiel Martens, Victoria 
Balan, Emily Mannheimer, Amanda Brandellero, Henry Chow, Matt Hills, and Jason Grek-Martin for their feedback on an earlier draft of this chapter.
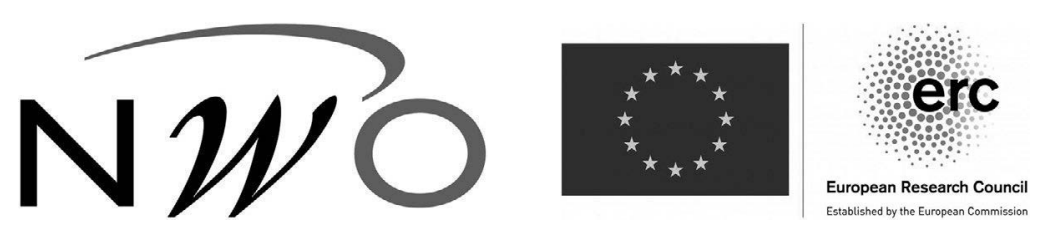

2 It would be challenging to visualize these networks of imaginative heritage (per city or region) on a digital map. Such a map should then have a layered character, in the tradition of "deep maps", in which each medium or franchise is assigned its own layer (Bodenhamer et al., 2015; Fitzjohn, 2009). A dynamic display with a historical lapse of time is also possible.

3 One could argue that place identities are always narratively constructed and as such, the difference between fictional and factual narratives is artificial. However, such a line of argument ignores the fact that this divide between fiction and fact is experienced as very real by most media tourists. The marking and temporary crossing of the symbolic divide between a world of fiction (rooted in imaginative practices) and the "real" world (rooted in sensory experiences) is key to understanding the joy of participating in such a media ritual (Reijnders, 2011a).

\section{Bibliography}

Associated Press. (2018). Mass tourism threatens Croatia's 'Game of Thrones' town. Retrieved from www.voanews.com/a/mass-tourism-threatens-croatia-s-game-ofthrones-town/4581869.html (15-03-2020).

Bal, M. (1994). Narratology: Introduction to the theory of narrative, 2 nd ed. Toronto: University of Toronto Press.

Barton, R. (2019). The force meets the Kittiwake: Shooting Star Wars on Skellig Michael. In: C. Lundberg \& V. Ziakas (eds.), The Routledge handbook of popular culture and tourism, pp. 300-310. London: Routledge.

Beeton, S. (2001). Lights, camera, re-action: How does film-induced tourism affect a country town? In: M.F. Rogers \& Y.M.J. Collins (eds.), The future of Australia's country towns, pp. 172-183. Bendigo: La Trobe University.

Beeton, S. (2004). Rural tourism in Australia: Has the gaze altered? Tracking rural images through film and tourism promotion. International Journal of Travel Research 6(S): 125-135.

Beeton, S. (2006). Understanding film-induced tourism. Tourism Analysis 11(3): 181-188.

Beeton, S. (2010). The advance of film tourism. Tourism and Hospitality Planning \& Development 7(1): 1-6.

Beeton, S. (2016). Film-induced tourism. Bristol: Channel View Publications.

Beeton, S. \& Seaton, P. (2018). Creating places and transferring culture: American theme parks in Japan. In: S. Kim \& S. Reijnders (eds.), Film tourism in Asia, pp. 251-267. Singapore: Springer.

Bodenhamer, D.J., Corrigan, J. \& Harris, T.M. (2015). Deep maps and spatial narratives. Bloomington: Indiana University Press. 
Boni, M. (ed.). (2017). Worldbuilding: Transmedia, fans, industries. Amsterdam: Amsterdam University Press.

Busby, G. \& Klug, J. (2001). Movie-induced tourism: The challenge of measurement and other issues. Journal of Vacation Marketing 7(4): 316-332.

Butler, R.W. (1990). The influence of the media in shaping international tourist patterns. Tourism Recreation Research 15(2): 46-53.

Cohen, J. (1986). Promotion of overseas tourism through media fiction. In: Tourism services marketing: Advances in theory and practice: Special conference series, vol. 2, pp. 229-237. Coral Gables: University of Miami.

Cohen, S. (2017). Decline, renewal and the city in popular music culture: Beyond the Beatles. London: Routledge.

Connell, J. (2012). Film tourism: Evolution, progress and prospects. Tourism Management 33(5): 1007-1029.

De Certeau, M. (1980). L'invention du quotidien: Arts de faire. Folio: Gallimard.

Easthope, H. (2004). A place called home. Housing, Theory and Society 21(3): 128-138.

Edensor, T. (2002). National identity, popular culture and everyday life. London: Bloomsbury.

Fitzjohn, M. (2009). The use of GIS in landscape heritage and attitudes to place: Digital deep maps. In: M.L.S. Sørensen \& J. Carman (eds.), Heritage studies: Methods and approaches, pp. 237-252. London: Routledge.

Freytag, T. \& Bauder, M. (2018). Bottom-up touristification and urban transformations in Paris. Tourism Geographies 20(3): 443-460.

Gieryn, T.F. (2000). A space for place in sociology. Annual Review of Sociology 26(1): 463-496.

Gottschall, J. (2013). The storytelling animal: How stories make us human. Boston: Mariner Books.

Gyimóthy, S., Lundberg, C., Lindström, K., Lexhagen, M. \& Larson, M. (2015). Popculture tourism: A research manifesto. In: D. Chambers \& T. Rakic (eds.), Tourism research frontiers: Beyond the boundaries of knowledge, pp. 13-26. Bingley: Emerald Group Publishing.

Harrison, R. (2011). Heritage: Critical approaches. London: Routledge.

Hills, M. (2002). Fan cultures. London: Routledge.

Hughes, N. (2018). 'Tourists go home': Anti-tourism industry protest in Barcelona. Social Movement Studies 17(4): 471-477.

Jenkins, H. (2006). Convergence culture: Where old and new media collide. New York: New York University Press.

Kim, S. (2012). Audience involvement and film tourism experiences: Emotional places, emotional experiences. Tourism Management 33(2): 387-396.

Kim, S. \& Reijnders, S. (2018). Film tourism in Asia. Berlin: Springer.

Kousis, M. (2000). Tourism and the environment: A social movements perspective. Annals of Tourism Research 27(2): 468-489.

Larson, M., Lundberg, C. \& Lexhagen, M. (2013). Thirsting for vampire tourism: Developing pop culture destinations. Journal of Destination Marketing \& Management 2(2): 74-84.

Lean, G., Staiff, R. \& Waterton, E. (2014). Reimagining travel and imagination. In: G. Leab, R. Staiff \& E. Waterton (eds.), Travel and imagination, pp. 9-24. Farnham: Ashgate.

Lefebvre, H. (1991). Critique of everyday life: Foundations for a sociology of the everyday, 2nd ed. Brooklyn: Verso.

Lew, A.A. (2017). Tourism planning and place making: Place-making or placemaking? Tourism Geographies 19(3): 448-466. 


\section{Stijn Reijnders}

Lind, J. \& Kristensson Uggla, B. (2019). The narrative capital of the place: How the Millennium narratives generate place-related values and attract tourists to Sweden. In: C. Lundberg \& V. Ziakas (eds.), The Routledge handbook of popular culture and tourism, pp. 311-324. London: Routledge.

Lukinbeal, C. \& Fletchall, A. (2014). The hollowed or hallowed ground of Orange County, California. In: J.A. Lester \& C. Scarles (eds.), Mediating the tourist experience: Brochures to virtual encounters, pp. 223-236. Farnham: Ashgate.

Lundberg, C. \& Ziakas, V. (eds.). (2019). The Routledge handbook of popular culture and tourism. London: Routledge.

Lundberg, C., Ziakas, V. \& Morgan, N. (2018). Conceptualising on-screen tourism destination development. Tourist Studies 18(1): 83-104.

Mannheimer, E. (unpublished). Game of Thrones tourism and the imaginative heritage of the 'new Northern Ireland'. (work in progress).

Mansfield, C. (2015). Researching literary tourism. Bideford: Shadows.

Mason, P. \& Rohe, G.L. (2019). Playing at home: Popular culture tourism and placemaking in Japan. In: C. Lundberg \& V. Ziakas (eds.), The Routledge handbook of popular culture and tourism, pp. 353-364. London: Routledge.

Mayer, V. (2016). The production of extras in a precarious creative economy. In: M. Curtin \& K. Sanson (eds.), Precarious creativity: Global media, local labor, pp. 63-87. Berkeley: University of California Press.

Morley, D. (2001). Belongings: Place, space and identity in a mediated world. European Journal of Cultural Studies 4(4): 425-448.

Novy, J. \& Colomb, C. (2016). Urban tourism and its discontents: An introduction. In: C. Colomb \& J. Novy (eds.), Protest and resistance in the tourist city, pp. 1-30. London: Routledge.

O'Connell, D. (2014). The Irish film board: Gatekeeper or facilitator? The experience of the Irish screenwriter. In: C. Batty (ed.), Screenwriters and screenwriting: Putting practice into context, pp. 113-129. London: Palgrave Macmillan.

O'Connor, N. \& Kim, S. (2014). Pictures and prose: Exploring the impact of literary and film tourism. Journal of Tourism and Cultural Change 12(1): 1-17.

Orgad, S. (2014). Media representation and the global imagination. Hoboken: Wiley \& Sons.

Otero-Pailos, J., Gaiger, J. \& West, S. (2010). Heritage values. In: S. West (ed.), Understanding heritage in practice, pp. 47-87. Manchester: Manchester United Press.

Reijnders, S. (2011a). Places of the imagination: Media, tourism, culture. Farnham: Ashgate.

Reijnders, S. (2011b). Stalking the count: Dracula, fandom and tourism. Annals of Tourism Research 38(1): 231-248.

Reijnders, S. (2016). Stories that move: Fiction, imagination, tourism. European Journal of Cultural Studies 19(6): 672-689.

Reijnders, S., Bolderman, L., van Es, N. \& Waysdorf, A. (2015). Locating imagination: An interdisciplinary perspective on literary, film, and music tourism. Tourism Analysis 20(3): 333-339.

Richards, G. (2017a). From place branding to placemaking: The role of events. International Journal of Event and Festival Management 8(1): 8-23.

Richards, G. (2017b). Making places through creative tourism?. In: Keynote presentation at the conference 'Culture, sustainability and place: Innovative approaches for tourism development', vol. 13. Ponta Delgada, Azores, Portugal. 
Riley, R., Baker, D. \& Van Doren, C. (1998). Movie induced tourism. Annals of Tourism Research 25(4): 919-935.

Riley, R. \& Van Doren, C. (1992). Movies as tourism promotion: A 'pull' factor in a 'push' location. Tourism Management 13(3): 267-274.

Roberts, L. (2012). Film, mobility and urban space: A cinematic geography of Liverpool. Liverpool: Liverpool University Press.

Roesch, S. (2009). The experiences of film location tourists. Bristol: Channel View Publications.

Said, E. (1978). Orientalism. New York: Pantheon Books.

Salazar, N.B. \& Graburn, N.H.H. (2014). Toward an anthropology of tourism imaginaries. In: N.B. Salazar \& N.H.H. Graburn (eds.), Tourism imaginaries: Anthropological approaches, pp. 1-28. New York: Berghahn.

Seaton, P.A., Yamamura, T., Sugawa-Shimada, A. \& Jang, K. (2017). Contents tourism in Japan: Pilgrimages to "Sacred Sites" of popular culture. Amherst: Cambria Press.

Smith, M.K. (2015). Issues in cultural tourism studies. London: Routledge.

Torchin, L. (2002). Location, location, location: The destination of the Manhattan TV Tour. Tourist Studies 2(3): 247-266.

Twining-Ward, L. \& Butler, R. (2002). Implementing sustainable tourism development on a small island: Development and the use of sustainable tourism development indicators in Samoa. Journal of Sustainable Tourism 10(5): 363-387.

Tzanelli, R. (2004). Constructing the 'cinematic tourist': The 'sign industry' of the Lord of the Rings. Tourist Studies 4(1): 21-42.

Tzanelli, R. (2007). The cinematic tourist: Explorations in globalization, culture and resistance. London: Routledge.

Tzanelli, R. (2019). Cinematic tourist mobilities and the plight of development: On atmospheres, affects and environments. London: Routledge.

Vanclay, F. (2008). Place matters. In: F. Vanclay, M. Higgins \& A. Blackshaw (eds.), Making sense of place: Exploring concepts and expressions of place through different senses and lenses, pp. 3-11. Canberra: National Museum of Australia Press. van Es, N. \& Reijnders, S. (2018). Making sense of capital crime cities: Getting underneath the urban facade on crime-detective fiction tours. European Journal of Cultural Studies 21(4): 502-520.

Waligo, V.M., Clarke, J. \& Hawkins, R. (2013). Implementing sustainable tourism: A multistakeholder involvement management framework. Tourism Management 36: 342-353.

West, S. (ed.). (2010). Understanding heritage in practice. Manchester: Manchester University Press. 


\title{
2 The open-ended ruin Imaginative authenticity as a driver of alternative tourism
}

\author{
André Jansson
}

\section{Introduction}

Historical ruins belong to some of the most classical tourist sights, often depicted in postcards and guidebooks. People travel from afar to see worldfamous places like Pompeii, Knossos, and the pyramids of Egypt, whose historical authenticity is confirmed by heritage institutions. Since the industrial era, they have turned into objects of mass tourism. At the same time, there are people not at all interested in heritage sites, as well as people who want to escape the tourist bubble and find alternative places to explore. Typically, they feel that the intensely mediated and staged appearance of heritage sites takes away the magic of foreign places, making tourism experiences per se less authentic. Instead, they prefer more ethnographically oriented forms of travelling where they can meet ordinary people or discover historical places that are not (yet) on the radar of commercial tourism (e.g. Munt, 1994; Jansson, 2010). One such alternative form of tourism is ruin tourism. Another, more extreme form, whose supporters reject the very emblem of tourism, is urban exploration. What these types share is an interest in ruins that belong to the relatively recent history of industrial society and are not promoted as tourist destinations. In comparison, though, urban explorers are more concerned with abandoned places - especially buildings but also other human-made constructs - that have not yet been visited by others and are not open to visitors.

How are we to understand the attraction of abandoned buildings whose status as ruins has not yet been (and in most cases will never be) named by the heritage industry? Is it possible to distinguish any particular traits of these kinds of places that explain the thrill experienced by alternative tourists? Or do these ruins function just as means of distinction, giving certain groups a convenient way to escape the tourist crowd and classify themselves as more sophisticated travellers?

While people's habitus is certainly a key factor (as I will come back to in the concluding section), in this chapter, I will argue that the attraction of abandoned buildings also stems from their open-ended nature as ruins whose histories and futures are more or less unknown and not yet told. I argue that such open-ended ruins sustain a particular kind of authenticity; what I call imaginative authenticity. This type of authenticity can 
be experienced only inasmuch as the process of decay is considered open ended and non-staged and invites one to imaginative work. At the heart of imaginative authenticity is the freedom to fantasize and reconstruct fractured meanings and interrupted narratives of a particular location (cf. Introduction; Lennon, 2015). As such, imaginative authenticity does not fit easily with any of the approaches to authenticity that have figured previously in tourism research - notably, objective authenticity, constructive authenticity, and existential authenticity. Imaginative authenticity is at the same time object related (tied to the particular character of open-ended ruins) and activity related (residing in the explorative practices sustaining imagination). It cannot do without either of these components and thus begs us to develop a more relational approach to authenticity in tourism. By extension, this would open up new avenues for studying the role of imagination as a driver of tourism.

I base my arguments on a case study of urban explorers, whose main interest is to discover abandoned buildings, preferably without guidance, and explore and document them before they disappear or get re-appropriated and categorized as named ruins (e.g. Garret, 2014a, 2014b). The study was part of a larger project and comprises nine interviews conducted in 2016 with urban explorers in Sweden. ${ }^{1}$ These explorers were specialized in different types of buildings and places (e.g. industrial plants and private houses). While the sample is small, its demographic profile corresponds to what is known about the community globally, consisting mostly of men and individuals with relatively high levels of education (e.g. engineer, photographer, public administrator, and university student). This underscores the view of urban exploration as an adventurous yet intellectualized middle-class pastime (see Jansson, 2018a, 2018b). The specific setting of the interviews (Sweden) is not likely to have affected the argument I want to pursue here. The findings teach us something about the volatile status of ruins and abandoned places as sites of imagination in a mediatized culture where it gets more and more difficult to keep things hidden from public display.

The chapter is divided into four parts. First, I provide a typology of different ruins in order to define what is unique about abandoned buildings. Second, I overview different approaches to authenticity in tourism and suggest a tentative notion of imaginative authenticity. Third, I turn to the study of urban explorers in order to grasp what kinds of spatial experience and attraction open-ended ruins give rise to. Finally, I use the empirical observations to highlight the need for a social theorization of imaginative authenticity in tourism.

\section{A typology of ruins}

Some of my strongest childhood memories involve ruins. When I was six years old, my family and I went to Crete on vacation. While there, it was more or less mandatory to join the bus trip to Knossos to see the ruins of 
Europe's oldest city and its palace complex - the mythological home of King Minos. It is estimated that in the 18 th century BC, the population of Knossos was 100,000 people, but some hundred years later, it was abandoned. As a six-year-old, I was absorbed by the historical legends and the visualizations of what the palace had once looked like. As we followed the guided tour, I could almost sense the bustling street-life and the affluence of the Knossos aristocracy. After the visit to Knossos, I continued for a long time to read about ancient palaces and dreamed about becoming an archaeologist who could discover and explore previously unknown ruins.

From about the same age, I can also remember an entirely different type of ruins. In the 1960s and 1970s Sweden underwent a rather dramatic process of urban change. A cornerstone of the social-democratic welfare programme was the production of one million new homes between 1965 and 1975. The programme brought along large "sanitization projects" in which entire neighbourhoods, proclaimed to be too run-down to be preserved, were demolished and replaced by modern housing complexes. Still, in the late 1970s, these sanitization areas presented frightening sights. I grew up outside Gothenburg, and when visiting the city, we often passed through areas where aggressivelooking bulldozers were tearing down houses and buildings. Through the car window, I could sometimes see straight into the former apartments and get glimpses of wallpapers and other interior details before everything was reduced to piles of stone and dust. I remember these journeys through the ruinscapes of Gothenburg as very sad experiences. What had happened to the people who used to live in the houses? And what was to happen with all these empty places?

It is probably not a coincidence that these childhood memories are so strong. The ruin can be seen as one of the most powerful sites of imagination. As Walter Benjamin wrote about the decaying arcades of late 19thcentury Paris (see Benjamin, 1983), the ruin is a site of (lost) dreams, around which society can congregate and conceive of itself, its past, and its future. It constitutes a place where the narratives of social life have been broken. After people have left, only memories and a peculiar kind of materiality remain, a materiality marked by escalating porosity. Benjamin first wrote about porosity in his 1925 essay on Naples. He uses the term to describe a bewildering city of disorientation, imagination, and openended decay.

Side alleys give glimpses of dirty stairs leading down to taverns, where three or four men, at intervals, hidden behind barrels as if behind church pillars, sit drinking.

In such corners one can scarcely discern where building is still in progress and where dilapidation has already set in. For nothing is concluded. Porosity results not only from the indolence of the Southern artisan, but also, above all, from the passion for improvisation, which demands that 
space and opportunity be at any price preserved. Buildings are used as a popular stage.

(Benjamin, 1925/1978: 166-167)

Whereas Benjamin certainly did not present Naples per se as a ruin, the interesting thing is how he describes the lack of clear-cut demarcations between the old and the new, between dilapidation and reconstruction, between exterior and interior. The porosity of Naples makes the city reminiscent of a vast ruin, whose lure consists in the element of surprise and the possibility to discover what otherwise lies concealed (see Gilloch, 1996: 25-36). Naples is thus a space of ambiguity, where the visitor can easily get lost, and where maps are of little help. As Benjamin writes, the "banal tourist" may run into trouble, since "even Baedeker cannot propitiate him" (Benjamin, 1925/1978: 164). Any encounter with Naples is bound to be open ended. Similarly, the imaginative force of ruins can be traced to their porosity. Ruins can hardly be grasped in any purely intellectual sense. They urge us to speculate and fill in the blanks. They urge us to fantasize and dream, and to improvise, just like children do in their play.

If we go back to the opening examples, they represent two distinct types of ruins, as well as two different ways of relating to porosity and imagination. Knossos can be described as a named ruin. It is one of the most famous heritage sites of Western civilization and a place whose history is constantly explored and given more detail. It is also a ruin that constantly expands as scientists dig out more areas and make more documentation available to the public. While Knossos in the material sense constitutes and must remain a ruin, it is also much more than a ruin. It is a cultural icon and a machinery of historical knowledge and tourism phantasmagoria - a site of fixed, or controlled, porosity, or what Arboleda (2019) calls arrested decay. The demolished areas of 1970s Gothenburg, by contrast, represent what we may call transitory ruins. Their porosity remained only long enough to send nostalgic shock waves and sensations of bewilderedness through the occasional passer-by. Today we can only learn about these ruins and their short-lived existence through old photographs and history books. As with other regeneration sites, their temporariness was a calculated part of a sociopolitical project. They had no other future than to be replaced, as quickly as possible, by new material structures and new forms of social life.

But there is also a third category of ruins (see Figure 2.1), open-ended ruins, which falls in between the previously mentioned types. Such ruins come particularly close to Benjamin's description of Naples. They are neither explicitly named as ruins and thus not given the status of heritage nor destined to be replaced, regenerated, or otherwise eliminated as ruins. Instead, they are human-made structures that have been abandoned and whose future is uncertain. From a material perspective, their status as "ruins" may be questionable, since there is no exact threshold as to when a decaying structure turns into a ruin. From a social perspective, however, the process of 


\begin{tabular}{lccc}
\hline & State of materiality & $\begin{array}{c}\text { Dominant forms of } \\
\text { representation }\end{array}$ & $\begin{array}{c}\text { Dominant forms of } \\
\text { imagination }\end{array}$ \\
\hline $\begin{array}{l}\text { Named ruins (heritage } \\
\text { sites) }\end{array}$ & $\begin{array}{c}\text { Organized preservation; } \\
\text { enclosed porosity }\end{array}$ & $\begin{array}{c}\text { Touristic naming and } \\
\text { framing }\end{array}$ & $\begin{array}{c}\text { Staged historical } \\
\text { imagination }\end{array}$ \\
$\begin{array}{l}\text { Transitory ruins } \\
\text { (regeneration sites) }\end{array}$ & $\begin{array}{c}\text { Organized demolition or } \\
\text { regeneration; } \\
\text { solidification }\end{array}$ & Spatial planning & $\begin{array}{c}\text { Non-staged historical } \\
\text { imagination; scripted or } \\
\text { reimagined future }\end{array}$ \\
$\begin{array}{l}\text { Open-ended ruins } \\
\text { (abandoned buildings } \\
\text { and other sites) }\end{array}$ & $\begin{array}{c}\text { Open-ended decay; } \\
\text { extended porosity }\end{array}$ & $\begin{array}{c}\text { Incoherent forms of } \\
\text { (non-)mediation }\end{array}$ & \begin{tabular}{c} 
Open-ended imagination \\
\hline
\end{tabular} \\
\hline
\end{tabular}

Figure 2.1 A typology of ruins.

ruination - and thus the growth of porosity - begins as soon as a place is no longer in use or ascribed any particular purpose. Even the future of Knossos was entirely open from around the 12th century BC, when the population for unclear reasons abandoned the city, until the late 19th century, when it was rediscovered and excavations started.

The distinct quality of open-ended ruins is their extended porosity. Their pasts are not described in guidebooks. Their futures are not envisioned in planning documents. They are culturally, socially, and materially abandoned, suspended in time, which also means that they offer us a sense of freedom to explore, fantasize, and lose ourselves in alternative pasts and alternative futures (Edensor, 2005, 2007). This goes for places that have been abandoned by their inhabitants and/or users, as well as for constructions that were never completed and whose material remnants do not refer to any other social history than the plans and dreams affiliated with their origination. We can find these strangely tantalizing places especially in areas, and during periods, of socioeconomic stagnation. Arboleda (2019), for example, discusses the ambiguous cultural status of the many unfinished architectures found in the Sicilian post-2008 crisis landscape. In and through their incompleteness and porosity, they represent what society seemingly wants to forget and thus become part of our phenomenological construction of where "the margins" of society are geographically located and what they may look like (Shields, 1996).

At the same time, there is ruination taking place also at the centre. Even expansive cities harbour places of decay and degeneration, sometimes invisible to the public eye, sometimes spectacular reminders of a bygone industrial era. In relation to the urban credo of expansion and connectivity, such abandoned places stand out as anomalies whose very existence as openended ruins is bound to become relatively short lived. Sometimes they are 
turned into aestheticized tourist attractions, that is, named ruins. Sometimes they become part of urban regeneration and/or gentrification projects, incorporated into broader processes of heritage production, whereby dilapidated environments are moulded into something new by means of aestheticization and display (Kirshenblatt-Gimblett,1998). This has happened in many former harbour areas in cities around the world, modelled after London Docklands, where industrial land was turned into exclusive waterfront locations. It has also happened in post-industrial cities like Detroit (see Millington, 2013; Slager, 2013; Tegtmeyer, 2016; Fraser, 2018), the former world metropolis of automotive industries, where trendy travel agencies like Urban Adventures (2020) nowadays offer guided tours telling the story of the city's "rise, fall and renewal". During two-hour excursions, tourists are shown "which buildings have been restored and which await renewal" and invited to "marvel at all of Detroit's vacant buildings and what the future might hold for them".

Open-ended ruins are thus difficult to find - which partly explains why they are so attractive to alternative tourists wanting to go "off-the-beatentrack" to see places that are neither marketed nor clearly marked out as heritage or tourist sites. Similar impulses of non-touristic attraction can be seen, for instance, among people engaged in novel forms of neighbourhood tourism enabled by the sharing economy, especially mobile apps helping people to find private accommodation (Paulauskaite et al., 2017). Still, searching for open-ended ruins is very different from visiting previously unknown people's local neighbourhoods. The difference lies precisely in the imaginative affordances of open-ended ruins: the prospects of imaginative authenticity. This type of authenticity is best experienced at sites whose meanings and stories must be actively recreated by visitors through imagination - before, during, and after the exploration per se. Before showing how imaginative authenticity works as a driver of urban exploration (and possibly other forms of alternative tourism), I will define how it is theoretically related to pre-established notions of authenticity in tourism.

\section{Forms of authenticity in tourism}

Authenticity is one of the most-debated terms in tourism studies. It entered the stage with MacCannell's (1973) article on "staged authenticity", where he presented the desire for authenticity as one of the key drivers of modern mass tourism, whose commercial logic, in turn, contributed to the erosion of precisely the authentic qualities of tourist sites. Since then, the role of authenticity, especially as a form of attraction, has been analyzed in relation to a broad range of tourism fields, including heritage tourism (e.g. Halewood \& Hannam, 2001; Chhabra et al., 2003; Zhu, 2012), backpacking (Shaffer, 2004), volunteer tourism (Kontogeorgopoulos, 2017), film and media tourism (Månsson, 2010), and ancestral tourism (Bryce et al., 2017), just to mention a few examples. There are also different ways of interpreting the meaning of authenticity. In 1988, 
Cohen presented a critique of MacCannell's approach, stating that the concept of authenticity was not sufficiently problematized in MacCannell's work but relied on a rather intuitive understanding of authenticity as a genuine state of things to which the modern, alienated individual-as-tourist wanted to escape during leisure time. MacCannell's notion of authenticity, according to Cohen, also took for granted the superiority of the analyst (as opposed to the ordinary tourist) to objectively discern and judge what was the "real thing" and what was just staged versions of the original objects or practices.

Cohen's contribution is a good example of the gradual turn from realist to constructivist understandings of object authenticity, or from objective authenticity to constructive authenticity. As he puts it, "'authenticity' is a socially constructed object and its social (as against philosophical) connotation is, therefore, not given, but 'negotiable"' (Cohen, 1988: 274). Even commodified objects may gradually achieve a socially constructed, and more or less agreed upon, aura of authenticity. A generic destination such as the "beach resort" may seem authentic because it fits the imageries consumed by mass tourists, and the souvenirs and goods sold at heritage sites or museums may be part of the ongoing authentication of the site (e.g., Bruner, 1994; Halewood \& Hannam, 2001). However, the constructivist view has been criticized because it leads to an understanding of objectrelated authenticity that would ultimately include anything, depending on what people in different times and contexts perceive as authentic. Reisinger and Steiner (2006) go as far as to argue that the whole idea of object authenticity (whether realist or constructivist) is pointless altogether and that the term should not be used in tourism research because it obscures more than it explains.

An alternative view of authenticity is presented by Wang (1999), who argues that a large share of tourism is motivated not because of a desire to encounter authentic places, people, and things but because people want to reach a more authentic sense of self through activities that are freely chosen and resonate with their deeper understandings of who they are. Tourism, according to this understanding, is a liminal time-space that invites such activities of self-exploration and self-expression. The form of authenticity at stake is not object related but activity related. Wang (1999: 352) calls this existential authenticity, which "can have nothing to do with the authenticity of toured objects"; that is, people may choose to travel to a particular destination not because of the destination as such but because of the type of activities and experience they search for. These experiences, in turn, may be self oriented (see Hughes, 1995), as in the case of finding a place for peace and quiet or bodily challenges, or oriented towards social togetherness, or communitas, that actualizes the individual's sense of belonging. As Steiner and Reisinger (2006: 313) argue in their overview of existential authenticity in tourism research, there is also a need to engage with more overlooked dimensions of existential authenticity, such as anxiety, fear, and courage. 
There is not enough space in this chapter to delve deeper into the theoretical attributes of these views or to conduct a fuller overview of relevant research. I want to bring three points into the remaining discussion. First, in spite of the large and continuously growing body of research on authenticity and tourism, the three previously mentioned views are still the ones that dominate and define the main ontological and epistemological lines of division. Second, even though tourism researchers (and others) may debate what authenticity actually means, it is evident from empirical research that different tourists are drawn to different types of authenticity and that different types of journeys may be motivated by different desires. For instance, as Kontogeorgopoulos (2017) argues, even though the idea of objective authenticity may seem outdated or, rather, out of fashion among researchers today, tourists are often keen to see original heritage objects rather than replicas, meeting local people spontaneously rather than through organized tours, and so forth. Third, we should assume that a single journey may include experiences that actualize different types of authenticity. We should thus avoid establishing simple analogies between tourism genres and authenticity types.

These points alone should caution us from drawing too rigid lines between different types of authenticity or claiming one approach as superior to another. I find it particularly problematic to maintain the distinction between object-related and activity-related forms of authenticity. I do see that there are many cases when tourists are concerned only with seeing the "real thing" - and that is about all there is to a journey (whether the "real thing" is objectively "real" or perceived as such from a symbolic point of view). Tourism is replete with such practices, typically associated with the organized sightseeing tour, which in many cases constitutes merely a boxticking exercise. Similarly, there are many forms of tourism whose attraction resides in the truthfulness or deeper meaning of the practice itself, regardless of where it takes place. It is particularly obvious in cases where the very act of transportation, the moving through space, is key, as in train hiking or long-distance biking. But then there are other, more complex instances, when the truthfulness of the location matters just as much as the activities performed - and when the tourist's sense of authenticity emerges through the coming together of the two. Based on my study of urban explorers, I propose imaginative authenticity as one such relational form of authenticity. There might be others, which I will return to in the concluding section. Imaginative authenticity captures the motivational force behind certain forms of alternative tourism, for example, the exploration of open-ended ruins. Such explorations are driven by a desire to encounter previously unknown, yet strangely familiar places of non-orchestrated and non-mediated decay and to engage in the improvised reconstruction of spatial narratives through imagination. As suggested by Figure 2.2 - which is an elaborated version of a similar typology presented by Wang (1999: 352) - imaginative authenticity is neither an inherent quality of the site as such (since it ultimately 


\begin{tabular}{|c|c|c|}
\hline $\begin{array}{l}\text { Object-related forms of } \\
\text { authenticity in tourism }\end{array}$ & $\begin{array}{l}\text { Activity-related forms of } \\
\text { authenticity in tourism }\end{array}$ & $\begin{array}{l}\text { Relational (object- and activity- } \\
\text { related) forms of authenticity in } \\
\text { tourism }\end{array}$ \\
\hline $\begin{array}{l}\text { Objective authenticity refers to the } \\
\text { cognition among tourists that they } \\
\text { experience the authenticity of } \\
\text { originals. } \\
\text { Constructive authenticity refers to } \\
\text { the authenticity projected onto } \\
\text { toured objects by tourists or } \\
\text { tourism producers in terms of their } \\
\text { imagery, expectations, } \\
\text { preferences, beliefs, powers, etc., } \\
\text { and thus refers to a continuously } \\
\text { negotiated experience of symbolic } \\
\text { authenticity in objects. }\end{array}$ & $\begin{array}{l}\text { Existential authenticity refers to a } \\
\text { potential existential state of being } \\
\text { that is activated by tourist } \\
\text { activities, especially through the } \\
\text { liminal qualities of these activities. }\end{array}$ & $\begin{array}{l}\text { Imaginative authenticity refers to } \\
\text { the felt freedom among tourists to } \\
\text { recreate through imagination the } \\
\text { meanings and narratives of a } \\
\text { location whose transformation is } \\
\text { open-ended and non-staged (i.e., } \\
\text { non-orchestrated and non- } \\
\text { mediated), e.g., the open-ended } \\
\text { ruin. }\end{array}$ \\
\hline
\end{tabular}

Figure 2.2 Approaches to authenticity in tourism experiences.

Source: This typology is an adapted and extended version of the model presented by Wang (1999: 352).

depends on the relation between site and visitor and is only realized through imagination) nor a strictly activity-based experience (since it requires very specific spatial conditions). Rather, imaginative authenticity entails both a state of the object (open-ended porosity) and a state of activity (imaginative work). In order to make this theoretical argument more tangible, I will now provide an inside view of how this type of spatial attraction is played out among urban explorers, a particular group of alternative tourists whose travels are largely guided by the desire to encounter places that have been abandoned and left untouched for longer periods.

\section{Searching for imaginative authenticity: the appropriation of open-ended ruins among urban explorers}

Urban exploration is a relatively new phenomenon, even though its roots can be traced back to early modern tours of urban sewers, catacombs, and other hidden spaces. The very term was allegedly coined in 1996 by the Canadian urban exploration pioneer Jeff Chapman, also known by his alias Ninjalicious. In his book Access All Areas: A User's Guide to the Art of Urban Exploration, Chapman defines urban exploration as "an interior tourism that allows the curious minded to discover a world of behind the scenes sights" (Ninjalicious, 2005: 3). The parallel to tourism is not coincidental. According to Wikipedia (retrieved in April 2019), urban exploration is "the exploration of man-made structures, usually abandoned ruins or not usually seen components of the man-made environment. Photography and historical interest/documentation are heavily featured in the hobby and, although it 
may sometimes involve trespassing onto private property, this is not always the case". Urban explorers are thus mobile people, predominantly white men (see Mott \& Roberts, 2014), willing to travel long distances in their free time to discover, enter, and experience new sites, appropriating them as adventurous time-spaces and visual sights. In addition to abandoned buildings (e.g. industries, hospitals, and residential buildings), urban explorers seek out places that are hidden or difficult to access (e.g. urban rooftops, subterranean spaces, and military complexes). They document and share their experiences with other explorers, showing the rest of the community that they have visited a certain site.

While urban exploration entails a form of spatial consumption and circuits of representation that in key respects resemble tourism (cf. Jansson, 2007), it is also distinguished by its antagonistic relation to tourism; it is actively and explicitly defined in opposition to (mass) tourist practices. As Robinson (2015: 149) argues, urban exploration can be viewed as "a form of touristic activity, and, paradoxically, anti-tourist resisting all the formal tourism practices of signage, information, instruction and control". This was also a recurring theme in the interviews we conducted with urban explorers in Sweden, who were eager to underline that what they are up to is not ruin tourism.

It feels like it's really lost focus lately, what people have called urban exploration.... I wouldn't call it urban exploration to like join a guided tour at some old fortress with the family, that doesn't feel very much like urban exploration. That would be more like ruin tourism.... And if one would never consider to climb into a place then I think one is a ruin tourist and not an urban explorer.

(Sven, mid 50s)

From an analytical perspective, then, it seems relevant to categorize urban exploration as a form of alternative tourism, based on the fact that its basic shape corresponds to tourism (travelling to see, experience, and represent other places during leisure time), while its modus operandi is defined in opposition to mainstream tourism. Most notably, the sites and sights of urban exploration are located beyond the radar of commercial tourism, and the journeys are not commercially scripted or organized. Yet it is obvious that the level of "alternativeness" varies between different groups of urban explorers - ranging from those who do clearly illegal things (and thus do not fit common definitions of tourism) to those whose practices overlap with ruin and heritage tourism. This intermediary position makes urban exploration an interesting case to study if we want to grasp cultural tendencies on the fringes of tourism.

The defining feature of urban exploration is the desire to explore, document, and, ultimately, reimagine abandoned buildings that are neither marked out nor staged (or in any other way rearranged after they were 
abandoned). It is the first-hand encounter with uncontrolled decay, that is, the previously described lure of open-ended ruins, that matters - and gives rise to imaginative authenticity. Sven compares the experience of visiting a place that has been abandoned for 35 years to a "parachute jump" - an adventurous (and thus also well-prepared) vertical jump into the time-spaces of bygone eras, whose decaying and ghostly appearances may elicit physically thrilling and uncanny sensations in their visitors.

The non-staged and open-ended porosity of abandoned buildings is important to imaginative authenticity in two interconnected ways. First, there is a moment of exhilaration attached to the fact that one does not know what to expect once crossing the threshold of a new site. It may be vandalized or in dangerously bad condition. It may be occupied by other individuals, such as graffiti painters or homeless people.

You never know what you'll find, it can be a little dangerous, but hopefully it's safe. Perhaps you're not allowed to be there, that's quite exciting too.

(Olle, mid 20s)

This takes us back to Benjamin's (1925/1978) characterization of old Naples as a porous space: a space of blurred boundaries, disorientation, and surprise. Similarly, the desire for open-ended ruins is a desire for sites marked by extended porosity. The specific quality of open-ended ruins is that they are in an authentic state of flux (whether from an objective or constructive point of view) and become meaningful to visitors only through imaginative work.

Second, the porosity of open-ended ruins implicates that there is an invitation to imagine, that is, to construct one's own meaning of the place. This does not mean, however, that the ideal urban exploration site is an empty site. Rather, it is obvious that excitement is reinforced if there are certain material clues that may trigger imagination and establish meaningful links between the site and the interpretative universe of the explorer. These clues, according to the interviewees, should ideally take the shape of traces involuntarily left by the people who once occupied the site, thus signifying an interrupted narrative.

I like places where you get a feeling of how it was when it was alive. That there are things left from people who have lived there, and not just an empty barrack. . . . You start looking at your local environment in new ways. You search for it. You see a garden where nobody has mown the lawn for a long time and you get curious. . . . You're always on hunt.

(Milton, mid 30s)

As Milton describes, urban exploration gradually turns into a particular way of seeing and sensing the built environment. It can even be understood as a 
particular mode of consciousness marked by heightened sensitivity to porosity and ruination. In this sense, the experience that urban explorers search for is akin to Wang's (1999) notion of activity-related existential authenticity. Notably, the very act of imagination comes close to Wang's description of how tourism may evoke liminal and existentially charging experiences.

Still, the crucial point here is that imaginative authenticity cannot be reduced to either an activity-related or an object-related quality. It relies on both - which also makes it very fragile. In the interviews, the fragility of imaginative authenticity was articulated in two main ways. First, the liminal sensation of urban exploration was easily replaced by frustration and disappointment, a sense of decapsulation (Jansson, 2007), if a site was found to be damaged or rearranged by previous visitors.

One should take great care to leave the place exactly like it was. That is the worst thing I know, when people have been there and painted graffiti all over the walls. If I were to choose everything should remain as it is for another 1,000 years.

(Niklas, mid 30s)

I know that some people also rearrange the sites. When they enter a house they may put away certain things and instead place out table and chairs, making it look like things were just left behind. But we never do that. Perhaps some people think it looks better that way in pictures.

(Greta, mid 40s)

Greta's comment also highlights the fundamental tension between imaginative authenticity and mediation, residing in the fact that the desire to take good and "likable" photos may have a direct impact on the porosity of the site per se. In effect, the invitation to imagine is disrupted. Once an abandoned place is rearranged in order to be communicated, it starts performing like a named site and ultimately turns urban exploration into a pseudoevent, to paraphrase Boorstin (1961/1992).

This leads us to the second threat to imaginative authenticity. The general circulation of popular images of abandoned places (especially beyond urban exploration communities) may distort the possibilities to freely construct one's own meaning in relation to the site (Klausen, 2017). In one of the interviews, Milton described the growing dilemma of social media and online image-sharing sites whose popularity, in his view, distorted the prospects of appropriating place in an open-ended manner:

Last Monday there was a new place in Belgium, really an awesome place. But then [because of social media] I know that there were more than 50 people there already on Tuesday and then the charm totally disappears. It becomes almost like a tourist destination. ... If there have been 50 people there already it becomes difficult to do one's own thing. 
One gets influenced by the other pictures and may take the very same picture in the same way, and then it's not very exciting anymore.

(Milton, mid 30s)

This example shows how mediations of abandoned places contribute to the naming and staging of open-ended ruins, whose meanings are then gradually fixed. Industrial ruins, for example, may be recoded as "genuine" and "cool" and turned into sites of creative energy in urban areas where the dreams and desires of artists, tourists, entrepreneurs, politicians, and real estate developers come together to form new patterns of imagination (e.g. Jansson, 2005; Tegtmeyer, 2016; Fraser, 2018). However, the unruliness of ruins gets sacrificed when they are turned into heritage sites, tourist destinations, and/or aesthetic schemes of communication (Edensor, 2005). The imaginative force of porosity is lost and the open-ended ruin turned into a transitory or named ruin that no longer generates attraction among such alternative travellers as urban explorers.

MacCannell (1976) explicated these mechanisms in the 1970s in his writings on how the tourism industry works with "sight-sacralization", meaning that genuine places are named, framed, and mechanically reproduced as tourist sights in order to attract a bigger market (cf. Benjamin, 1935/1973). In times of hyper-connectivity and hyper-circulation, when spatial representations can be spread widely by anyone carrying a smartphone, there are reasons to revisit and rethink this dilemma. As told by the interviews with urban explorers in Sweden, mediation in general, and the expanding logic of spreadable social media in particular (e.g. Jenkins et al., 2013; van Dijck, 2013), contribute to turning abandoned places into sacralized tourist destinations, thus making it increasingly difficult to approach these sites without aestheticized expectations of what to see and how to see these sites. The prospects for imaginative authenticity, as well as the distinctive boundaries of this type of alternative tourism, are thus threatened (Jansson, 2018a, 2018b).

\section{Conclusion: toward a social theory of imaginative authenticity in tourism}

The interviews with urban explorers verify the relevance of different forms of authenticity while also showing that it may be difficult to keep these forms apart. First, the search for open-ended ruins that nobody has touched since they were abandoned corresponds to the realist understanding of authenticity as an inherent asset of the object itself. As discussed, as soon as a site of exploration is rearranged or, even worse, staged, it loses its lure. Urban explorers themselves thus perceive of their practices in a manner resembling MacCannell's $(1973,1976)$ approach to objective authenticity. At the same time, second, the very idea of what constitutes a proper site for urban exploration has been continuously (re)constructed through various forms 
of cultural mediation (cf. Cohen, 1988), especially since this type of alternative tourism is reliant on photographic practices and expressivity. Not all urban explorers are hardcore devotees who can only think of visiting places that have never been depicted and nobody has visited before; there are also explorers interested in certain types of derelict places whose attraction has gained aesthetic appeal through the circulation of images. In this sense, based on how urban explorers judge the authenticity of places and objects (also reflected in their attitudes to aestheticization and media circulation), it is even possible to identify different fractions of the community (Jansson, 2018b; Jansson \& Klausen, 2018). Finally, existential authenticity is also important to urban explorers. The process of finding and entering abandoned places and feeling the exhilaration of time travel constitutes a particular mode of consciousness (cf. Wang, 1999). Encountering the residues of unknown people of bygone eras provides new perspectives on one's existence in the larger scheme of things.

The study of urban explorers thus confirms that authenticity is a valuable concept for understanding the motives behind tourism. It also suggests that we can more fully understand the complexity of particular types of tourism if we combine different views of authenticity. Still, as I have shown in this chapter, none of the dominant perspectives fully captures the experiential core of such an alternative form of tourism as urban exploration. Even when combined, they leave us with a picture that points to what differentiates rather than what unites this particular field. Imaginative authenticity, then, is a way of grasping the shared raison d'être behind urban exploration - and possibly other forms of alternative or specialized tourism. Notably, imaginative authenticity problematizes the dichotomizing view of authentic tourism experiences as related either to clearly defined places or to activities that have nothing or little to do with place and location. Imaginative authenticity rather captures the experience of being immersed into non-scripted imaginative travel linked to a particular location, in this case the open-ended ruin. While this is not the place to assess the relevance of imaginative authenticity in other types of tourism, there seem to be interesting parallels to, for example, pilgrimage tourism. Among visitors to places like Santiago de Compostela, the deeper experience of authenticity emerges only through the combination of an authentic environment (let alone that the way of St. James is a case of refined heritagization rather than open-ended decay) and a certain ritualized way of appropriating and reimagining space through walking and contemplation (e.g. Nilsson \& Tesfahuney, 2016).

More research is needed to stake out the properties of imaginative authenticity and its applicability in different contexts. Based on that, it would also be possible to go further in the theorization of imaginative authenticity. One pathway that seems particularly promising, in my view, is Bourdieu's (1979/1984) social theory of habitus and the cultivation of taste. While in this chapter I have tried to carve out the unique imaginative qualities of the open-ended ruin, there is good reason to dig deeper into how sociocultural 
dispositions make some people more inclined than others to appreciate nonconventional tourist sights and engage in the type of spontaneous imaginative work described here. Imaginative authenticity may not by definition work as a distinctive code - but it certainly does so in those middle-classbiased settings of alternative tourism figuring in this study. Urban explorers describe their appreciation of abandoned buildings in ways that resonate with how Bourdieu (ibid: 273-283) portrays the "pure" gaze, that is, the distinctive and seemingly "natural" way of appropriating nature, landscapes, art, or other artefacts, which only those with certain resources (typically of an intellectual kind) can present - and only after having spent long time naturalizing the legitimate cultural schemes. As Austin (2007) demonstrates in an essay on 19th-century British tourism, the classifying role of the "pure" gaze - which I see as a close sibling to imaginative authenticity - has been integral to the definition of touristic behaviour for a very long time. According to influential writers of the time, tourism was never to live up to the "pure" pleasures of spontaneous visual and spatial consumption but rather relied on mimicry and standardized replications of the "picturesque". From such a neo-romantic standpoint, which can also be detected among urban explorers, tourism was (and still is) not only vulgar but also a source of embarrassment to those involved.

In sum, imaginative authenticity provides a way of gaining deeper insights into the role of imaginative work and imaginative pleasure as drivers of tourism. Furthermore, the outline presented here should serve as a steppingstone for the development of a relational approach to authenticity in tourism and thus (to paraphrase Bourdieu) to a social critique of the judgement of touristic taste.

\section{Note}

1 The interviews were carried out by $\mathrm{PhD}$ candidate Tindra Thor as part of the research project Cosmopolitanism from the Margins, funded by the Swedish Research Council and led by Professor Miyase Christensen, the Royal Institute of Technology, Stockholm. Parts of the current chapter have been published previously (Jansson, 2018c).

\section{Bibliography}

Arboleda, P. (2019). Reimagining unfinished architectures: Ruin perspectives between art and heritage. Cultural Geographies 26(2): 227-244.

Austin, L.M. (2007). Aesthetic embarrassment: The reversion to the picturesque in nineteenth-century English tourism. ELH 74(3): 629-653.

Benjamin, W. (1925/1978). Naples. In: P. Demetz (ed.), Walter Benjamin: Reflections: Essays, aphorisms, autobiographical writings. New York: Schocken Books.

Benjamin, W. (1935/1973). The work of art in the age of mechanical reproduction. In: H. Arendt (ed.), Walter Benjamin: Illuminations: Essays and reflections. London: Fontana. 
Benjamin, W. (1983). Charles Baudelaire: A lyric poet in the era of high capitalism. London: Verso.

Boorstin, D. (1961/1992). The image: A guide to pseudo-events in America. New York: Vintage Books.

Bourdieu, P. (1979/1984). Distinction: A social critique of the judgement of taste. London: Routledge.

Bruner, E.M. (1994). Abraham Lincoln as authentic reproduction: A critique of postmodernism. American Anthropologist 96(2): 397-415.

Bryce, D., Murdy, S. \& Alexander, M. (2017). Diaspora, authenticity and the imagined past. Annals of Tourism Research 66: 49-60.

Chhabra, D., Healy, R. \& Sills, E. (2003). Staged authenticity and heritage tourism. Annals of Tourism Research 30(3): 702-719.

Cohen, E. (1988). Authenticity and commoditization in tourism. Annals of Tourism Research 15(3): 371-386.

Edensor, T. (2005). The ghosts of industrial ruins: Ordering and disordering memory in excessive space. Environment and Planning D: Society and Space 23: 829-849.

Edensor, T. (2007). Sensing the ruin. Senses \& Society 2(2): 217-232.

Fraser, E. (2018). Unbecoming place: Urban imaginaries in transition in Detroit. Cultural Geographies 25(3): 441-458.

Garrett, B.L. (2014a). Undertaking recreational trespass: Urban exploration and infiltration. Transactions of the Institute of British Geographers 39(1): 1-13.

Garrett, B.L. (2014b). Explore everything: Place-hacking the city. London: Verso.

Gilloch, G. (1996). Myth and metropolis: Walter Benjamin and the city. Cambridge: Polity Press.

Halewood, C. \& Hannam, K. (2001). Viking heritage tourism: Authenticity and commodification. Annals of Tourism Research 28(3): 565-580.

Hughes, G. (1995). Authenticity in tourism. Annals of Tourism Research 22(4): 781-803.

Jansson, A. (2005). Re-encoding the spectacle: Urban fatefulness and mediated stigmatization in 'the city of tomorrow'. Urban Studies 41(10): 1671-1691.

Jansson, A. (2007). A sense of tourism: New media and the dialectic of encapsulation/decapsulation. Tourist Studies 7(1): 5-24.

Jansson, A. (2010). The city in-between: Communication geographies, tourism and the urban unconscious. In: B.T. Knudsen \& A.M. Waade (eds.), Re-investing authenticity: Tourism, place and emotions. Bristol: Channel View Publications.

Jansson, A. (2018a). Mediatization and mobile lives: A critical approach. London: Routledge.

Jansson, A. (2018b). Rethinking post-tourism in the age of social media. Annals of Tourism Research 69: 101-110.

Jansson, A. (2018c). 'This is not ruin tourism': Social media and the quest for authenticity in urban exploration. In: S. Lyons (ed.), Ruin porn: Essays on the obsession with decay. New York: Palgrave Macmillan.

Jansson, A. \& Klausen, M. (2018). The spreadable city: Urban exploration and connective media. In: K. Archer \& K. Bezdecny (eds.), Handbook of emerging 21st century cities. London: Edward Elgar.

Jenkins, H., Ford, S. \& Green, J. (2013). Spreadable media: Creating value and meaning in a networked culture. New York: New York University Press.

Kirshenblatt-Gimblett, B. (1998). Destination culture: Tourism, museums, and heritage. Berkeley: University of California Press. 
Klausen, M. (2017). The urban exploration imaginary: Mediatization, commodification, and affect. Space and Culture 20(4): 372-384.

Kontogeorgopoulos, N. (2017). Forays into the backstage: Volunteer tourism and the pursuit of object authenticity. Journal of Tourism and Cultural Change 15(5): $455-475$.

Lennon, K. (2015). Imagination and the imaginary. London: Routledge.

MacCannell, D. (1973). Staged authenticity: Arrangements of social space in tourist settings. American Journal of Sociology 79(3): 589-603.

MacCannell, D. (1976). The tourist: A new theory of the leisure class. London: Macmillan London Limited.

Månsson, M. (2010). Negotiating authenticity at Rosslyn Chapel. In: B.T. Knudsen \& A.M. Waade (eds.), Re-investing authenticity: Tourism, place and emotions. Bristol: Channel View Publications.

Millington, N. (2013). Post-industrial imaginaries: Nature, representation, and ruin in Detroit, Michigan. International Journal of Urban and Regional Research 37: 279-296.

Mott, C. \& Roberts, S.M. (2014). Not everyone has (the) balls: Urban exploration and the persistence of masculinist geography. Antipode 46(1): 229-245.

Munt, I. (1994). The 'other' postmodern tourism: Culture, travel and the new middle classes. Theory, Culture \& Society 11(3): 101-123.

Nilsson, M. \& Tesfahuney, M. (2016). Performing the 'post-secular' in Santiago de Compostela. Annals of Tourism Research 57: 18-30.

Ninjalicious. (2005). Access all areas: A user's guide to the art of urban exploration. Toronto: Infilpress.

Paulauskaite, D., Powell, R., Coca-Stefaniak, J.A. \& Morrison, A.M. (2017). Living like a local: Authentic tourism experiences and the sharing economy. International Journal of Tourism Research 19(6): 619-628.

Reisinger, Y. \& Steiner, C.J. (2006). Reconceptualizing object authenticity. Annals of Tourism Research 33(1): 65-86.

Robinson, P. (2015). Conceptualizing urban exploration as beyond tourism and as anti-tourism. Advances in Hospitality and Tourism Research 3(2): 141-164.

Shaffer, T.S. (2004). Performing backpacking: Constructing 'authenticity' every step of the way. Text and Performance Quarterly 24(2): 139-160.

Shields, R. (1996). Places on the margin: Alternative geographies of modernity. London: Routledge.

Slager, E.J. (2013). Touring Detroit: Ruins, representation and redevelopment. MA thesis. Eugene: University of Oregon.

Steiner, C.J. \& Reisinger, Y. (2006). Understanding existential authenticity. Annals of Tourism Research 33(2): 299-318.

Tegtmeyer, L. (2016). Tourism aesthetics in ruinscapes: Bargaining cultural and monetary values of Detroit's negative image. Tourist Studies 16(4): 462-477.

Urban Adventures. (2020). Detroit's rise, fall \& renewal: Tour snapshot \& highlights. Retrieved from www.urbanadventures.com/Detroit-s-Rise-Fall-Renewal (15-03-2020).

Van Dijck, J. (2013). The culture of connectivity: A critical history of social media. Oxford: Oxford University Press.

Wang, N. (1999). Rethinking authenticity in tourism experience. Annals of Tourism Research 26(2): 349-370.

Zhu, Y. (2012). Performing heritage: Rethinking authenticity in tourism. Annals of Tourism Research 39(3): 1495-1513. 


\title{
3 No place like Birmingham? The politics of immobility, invisibility, and resentment
}

\author{
David Morley
}

\section{Introduction: autobiography in/of the city}

My title takes its cue from an old song by Randy Newman which eulogizes the American city of Birmingham, disavowing its image as an unsophisticated, provincial kind of place. The song comes from his 1974 album Good Old Boys featuring the populist discourses (and prejudices) of a series of unsavoury characters from the American South. One of the other songs on the album, "Rednecks", reports that when a Birmingham politician (Lester Maddox) went on television in metropolitan New York, the people there treated him as a fool - to which the song's narrator objects that, despite Maddox's evident foolishness, the people of Birmingham nonetheless feel considerable loyalty to him, as their "fool". The narrator insists that despite Maddox's lack of metropolitan "cool”, the residents of New York are conceited to think that they are "better" than him (Hart, 2014). My own concern is not with that American city but with its namesake in the United Kingdom, the Birmingham in the English Midlands. However, I do want to invoke some of the things that the two cities have in common, and the populist politics at stake in all this are rather murky, as metropolitan sophisticates do tend to look down on both cities, disdainfully - especially with respect to their "funny" provincial accents.

My other starting point is how we should understand questions of place in the contemporary era, when we are so often told that geography is "dead", having become a victim of the time-space compression of experience produced by various new communications technologies. In this situation, we are said to live, virtually, in a mediated world of the "generalised elsewhere" (Meyrowitz, 1986). The anthropologist Marc Auge argues that in this condition of what he calls hyper-modernity, we increasingly live in a world of "non-place" - where all the shopping centres, road systems, and airports are increasingly the same everywhere (Auge, 1995). Thus, architecturally, wherever we go, it seems that there is no distinctive place "there" when we finally arrive. In this respect, Birmingham has become, in the popular imagination of the United Kingdom, the emblematic case of just such a "non-place" (to speak oxymoronically - in so far as any non-place can have something distinctive about it). 


\section{David Morley}

As Charlotte Brunsdon (2008) explains in her introduction to the work of the Midlands Television Research Group, the whole area has a dismal set of connotations in the United Kingdom. Having been heavily bombed during the Second World War, it was subsequently rebuilt in concrete, in a particularly brutal architectural style of modernism which imitated North American "motor cities". Its principal visual emblem has long been "Spaghetti Junction", the nightmarish motorway intersection featured in Atom Egoyan's (1999) film Felicia's Journey.

I should probably confess, at this stage, that there is an autobiographical dimension to all this, as I grew up in Birmingham. As a result, I was witness to the first phase of Birmingham's post-war town planning with its new brutalist architecture in the early 60s. I well remember my own grandfather refusing to go into the city centre any more once the pedestrians had been consigned to a series of badly lit underpasses in order to make way for the more "efficient" circulation of the cars through the city. I then spent my teenage years desperate to escape from what I experienced as Birmingham's provincialism, desperate to get to London, where I believed the future to be located. Physical escape being impossible at that stage, the next best thing was visiting the newly installed icons of 60 s modernism in the city centre. Despite my grandfather's abhorrence of the city's redesign, the 1960s Bull Ring shopping plaza became the Mecca of my own teenage years, as I and my friends faithfully made our pilgrimage there by bus every Saturday afternoon from the outer suburbs where we lived to gawp at the latest fashionable commodities in the shops. Of course, modernity is always relative, and over the following half-century, the Bull Ring plaza then gradually lost its shiny patina and was itself knocked down to make way for the more ambitiously titled Grand Central shopping centre.

Having spent my early teenage years desperate to escape the city, it was only with reluctance that I returned for my post-graduate education, in what later became known internationally as the Birmingham School of cultural studies. One could, in fact, reasonably regard the garnering of the Centre for Contemporary Cultural Studies' (CCCS) international reputation as itself an academic (if inadvertent) form of the "place-making" strategies which have played a large part in Birmingham's recent reinvention of itself. Indeed, it was only its strong international reputation that enabled Stuart Hall to save CCCS when it was originally threatened with closure by Birmingham University management in the early 1970 s as a thorn in their side. These days, although CCCS was finally closed down by the university almost 20 years ago, it has become part of the city's "heritage" strategy, with a commemorative blue plaque marking the otherwise undistinguished tower block in which the Centre was once housed. But my own relation to the city is even more complicated: in the 1980s, working at that time in the Comedia consultancy, I returned there as part of the team responsible for the strategy which transformed Broad Street (in the west of the city) into the heart of the new cultural tourism and entertainment district. Thus, in producing the subsequent 
analysis, I write as one who has been, at different times, a victim, a bystander, a critic, and a participant in the city's reinvention of itself.

\section{Geographies of circulation: material and virtual tourisms}

I take as my starting point a newspaper report form early 2017 about an increase in tourism in the city, headlined "Birmingham shrugs off grimy image, as city enjoys ... boom", announcing that Birmingham hotels reported 2016 as their most successful year ever, as it had featured a doubling in the proportion of visitors from overseas (Wood, 2017). The immediate academic context for my reflections on this news item concerns debates about media, ritual, and forms of pilgrimage - and in particular tourism to mediated sites. Here I reference Lauren Berlant's comments on how the construction of a community can often best be seen as an effect of both the virtual circulation of key symbolic imageries from centre to periphery, in combination with the physical circulation of the population around the sites whence these images originate. Thus, we have to deal with the two simultaneous modes of circulation "one in which ... the symbolic goods circulate among the viewers, and another in which the viewers circulate among the symbolic sites of the built environment" (Berlant, 1991; Lash \& Friedmann, 1992: 20). That, then, is to suggest that we need to approach media tourism as a particular subcategory of mobility, largely engaged in only by the relatively affluent citizens of the richer parts of the world but one which may nonetheless offer useful insights into a set of broader questions concerning the changing patterns of other modes of mobility, both virtual and actual.

The larger theoretical framework of my argument concerns some recent "materialist" interventions in new mobilities theory designed to redefine our idea of communications so as to include physical mobility and transport infrastructures within it rather than thinking of communications as only a matter of rhetoric and signs. Here I return to the classical 19thcentury definition of communications as involving the mobility of bodies and things, as well as information and images (cf. Morley, 2017; Parks \& Starosielski, 2015; Packer \& Crofts Wiley, 2012; see also Mobilities journal 2006-present).

In this context, we also have to address the shifting balance between virtual and material geographies, as well as the role of transport networks in changing the significance of distance between places. Thus, to take one example, we might usefully consider the ambivalent role of TGV rail systems in redrawing the map of Europe. On the one hand, the TGV system intensifies "connectivity" between the affluent cities of Northern Europe which are served by this network while, at the same time, often making transport to and from their intermediate localities more difficult than before. In this connection, we might also consider how enhanced rail connections with Northern Europe have had the effect of seeming to pulling the whole continent further away, as seen from the perspective of the coast of North 


\section{David Morley}

Africa. Correspondingly, to address my own principal area of geographical interest, the fact that the UK government has now chosen to make a massive investment in extending Britain's high-speed rail system ("HiSpeed2") so as to include Birmingham has itself played an important rhetorical part in transforming the city's confidence in its own future.

We could also usefully turn to the work of scholars such as Ginette Verstraete (2010) to help us understand the virtual and material dimensions of the strategies in play in the constitution of Europe's borders. These boundaries are not only enshrined in laws but also, as Tim Cresswell shows, in the architecture of places such as Amsterdam's Schiphol airport (Cresswell, 2012). At a cultural level, the reconstitution of Europe also involves the role of media strategies like "Euro-Images" and other forms of transnational co-ordination of media production and distribution. However, to return to the question of personal mobility, there are also questions of demography and population management at stake here - for instance, in educational strategies such as the "Erasmus" schemes. As Umberto Eco predicted, right at their inception, those schemes have effectively subsidized the creation of a whole new section of the European marriage market. The result has been a significant increase in the number of children born to parents of different European nationalities who met while one of them was studying abroad on Erasmus funding and who have now produced a new generation of transnational Europeans (Green, 2014).

\section{Technologies, demographies, and geographies: people and parcels}

Having evoked the EU's mobilization of the audiovisual industries for cultural purposes, let me now turn to questions of media consumption and how audience practices can articulate with particular demographic patterns of either sedentarist or mobile lifestyles. In this connection, Arjun Appadurai claims that, nowadays, we live in a world where "transnational media messages often meet audiences who are themselves in motion", and his emphasis on the role of the media in "writing the scripts of the migrant imagination" certainly opens up a productive perspective on the changing nature of contemporary media consumption (Appadurai, 1996: 4; Mai, 2001; Sabry, 2005). Equally, Kevin Robins and Asu Aksoy emphasize the complexity of transnational communications and transport patterns in the lives of the Turkish migrants in Europe that they have studied (Robins \& Aksoy, 2016). However, we are not by any means all equally mobile, and conversely, one must also pay attention to situations where media systems are buttressed by - and themselves support - relatively sedentarist lifestyles. In all of this, I also want to insist on the need to avoid "new media" fantasies of disembodiment and de-territorialization.

We do need to be sceptical of models which say that everybody is becoming a nomad: some categories of people may have increasing access to both 
virtual and actual forms of mobility, but others are now consigned even more to the localities in which they were born. Here it is also useful to recall Harm de Blij's insistence that the majority of the world's population (living as they do in the mega-slums of the poorest cities of the Third World) have neither the money nor the political entitlements for legitimate travel (de Blij, 2009). They can only access illegal forms of mobility, many of which are so potentially expensive as to leave the would-be migrant's family in debt to the people-smugglers for a generation. The issues here concern the extent of the control people have over their mobility - and the politics of how much waiting a person has to do - which is a key index of their position in the hierarchies of power and "connexity".

It is also instructive to consider not only the relative ease of transport as between different categories of persons but also as between things and people; for nowadays it is things that travel most easily. Today we see an overall tendency towards increased mobility for things alongside an ever greater scrutiny and supervision of personal mobility - except for those with the appropriate visa and a good credit rating (cf. Bauman, 1998). If, in the late 19th century, John Ruskin bemoaned the fact that the new modes of rail transport transformed the passenger into the equivalent of a (passive) parcel, conversely, the Moroccan writer Tahar Ben Jelloun recounts the story of a contemporary North African migrant wishing he were a parcel, as that would make his desire to access European territory so much smoother (Ruskin quoted in Schivelbusch, 1977: 38; Ben Jelloun, 2009).

Having put this theoretical framework in play as a way of understanding the changing geographies of our era, in both its virtual and material dimensions, let us now turn our attention to Birmingham itself as a place.

\section{From industrial workshop of the world to rust belt ... and after}

The media reports of a boom in tourism in Birmingham mentioned earlier claimed that the city was now shaking off its image of industrial decline and motorway strangulation to become a budding centre for financial services, new technology, and architectural showpieces, with a range of glitzy bars, Michelin-starred restaurants, and smart shops. To this extent, various local government spokesmen have claimed that the city is becoming one of the great cultural powerhouses of Europe. A few years previously, the local authority's "Birmingham Forward" campaign had reported (amidst much public hilarity and scepticism) that new "quality of life" surveys placed Birmingham ahead of Barcelona, Milan, and Rome.

This tourist boom has been widely regarded as newsworthy in the United Kingdom, not least because it has been widely perceived as counterintuitive ("Why on earth would you want to go to Birmingham?" most metropolitan types would ask, in a tone of scornful incredulity). This is, in part, because historically, while the city once played a crucial role in 


\section{David Morley}

Britain's industrial revolution, it has long had a very negative image. By the mid 20th century, it had come to be connotatively associated with a particularly brutalist architecture, enshrined in concrete ring roads and the dismal pedestrian subways which so disturbed my grandfather's sense of access to the city. It has also long been connotatively associated with a brash, commercial provincialism and an "uncultured" (if not downright stupid) population. All this is symbolized by the fact that, in a country in which class and status are deeply encoded in patterns of speech, "Brummies" speak in a nasally inflected accent with a despondent downward intonation at the end of each sentence, which is deemed extremely unattractive to the metropolitan ear (just as noted earlier, in relation to Randy Newman's observations on how New Yorkers react snobbishly to the "funny" speech of those from the American South). As David Parker and Paul Long noted some years ago, "by the 1980's, Birmingham had a uniquely abjured place within Britain's national imaginary ... associated with failing automated and engineering factories (and) shoddy, inhuman landscapes of discredited post-war development" (Parker \& Long, 2005: 159). However, this is best seen as merely one phase in Birmingham's longer history, and this negative imagery has quite a long history, into which we need to delve a little.

When Queen Victoria passed through Birmingham in 1832, she wrote in her diary of a town where you see "the fire glimmer ... (from) the engines.... The men, women and children, country and houses are all black. ... It is very desolate everywhere ... smoking and burning coal heaps are intermingled with wretched huts and carts and little ragged children" (Sandbrook, 2015: 12). Similarly, Charles Dickens' character Little Nell finds herself wondering through Birmingham in 1841, where "as far as the eye could see .... tall chimneys ... poured out (a) plague of smoke which obscured the light and made foul the melancholy air.... Strange engines spun and writhed like tortured creatures ... clanking their iron chains .... making the ground tremble" (in Dickens' The Old Curiosity Shop [1841], quoted in Sandbrook, 2015: 13). A decade later, in Hard Times, Dickens offers a description of the place he calls "Coketown" for which it has been suggested that Birmingham offered the model:

It was a town of red brick, or of brick that would have been red if the smoke and ashes had allowed it; but as matters stood, it was a town of unnatural red and black like the painted face of a savage. It was a town of machinery and tall chimneys, out of which interminable serpents of smoke trailed themselves for ever and ever, and never got uncoiled. It had a black canal in it, and a river that ran purple with ill-smelling dye, and vast piles of building full of windows where there was a rattling and a trembling all day long, and where the piston of the steam-engine worked monotonously up and down, like the head of an elephant in a state of melancholy madness.

(Dickens, 1854; Lodge, 1975) 
In the mid-19th century, Birmingham was widely known as the industrial "workshop of the world" and the surrounding "Black Country" (black by day with the smoke of the iron foundry chimneys and red by night with the flames of their furnaces) was the most heavily industrialized few square miles on the planet. Even now remnants of these trades remain, and some of them are well captured in Brian Griffin's evocative photographs of what he calls the "Black Kingdom" (Griffin, 2013). Perhaps most famous of all were the chain-makers who banged out the cables and anchors for the ships of the British empire. Indeed, it was in the Black Country foundries that the anchor for the ill-fated ship the Titanic was made, from what was then known world-wide as Netherton Crown Special Best Iron, and a replica of this anchor still stands in Netherton Town Square today (Cartwright, 2016).

Visiting the area in 1861, one commentator was struck not simply by the infernal spectacle of the roaring furnaces of the ironworks, but even more by the sound of it all: especially the industrial batteries, where the large hammers "moved by machinery smiting at the rate of 500 strokes a minute ... with a tremendous din" (Royal Society Librarian Walter White, quoted in Sandbrook, 2015: 12). Many years later, of course, this industry of "heavy metal" became the literal source of a genre of music which emerged from the Black Country to become world famous, as personified by bands such as Black Sabbath and Judas Priest - whose lyrics are saturated with references to the industrial past of the battering ram, the hammering anvil, and the furnace. As Sandbrook notes, the link is rather more than metaphorical Black Sabbath's guitarist, Tony Iommi, only developed his distinctive guitar playing style because he had lost the ends of his two middle fingers in an industrial accident on the steel press in the foundry where he worked as a teenager (Sandbrook, 2015: 14).

If looking for a contemporary analogy, one might say that in the mid-19th century, Birmingham represented the same kind of seemingly irresistible (indeed, awesome) symbol of industrial dynamism which Western visitors may find so troubling today when visiting some of the fast-booming new cities of East Asia. However, the city's key role in the first phase of heavy manufacturing industries turned very much to its disadvantage in the later 20th century. Then Birmingham's established industries (especially in the motor trade) suffered badly from competition from imported cars and other manufactured goods coming from the increasingly automated factories of Europe and the Far East. Thus, Birmingham, just like places such as Detroit in the United States, became part of an economically depressed rust belt, with very high levels of long-term unemployment. The city still struggles to escape those negative legacies, and my argument will attempt to explore some of the contradictions involved in this process.

\section{From "non-place” to the politics of heritage tourism}

As noted earlier, the city suffered a brutal phase of early modernization in the late 1950s and early 60s, when its chief architect, Henry Manzoni, 
supervised the knocking down of many of its slums and built a circuit of highways through the middle of the city, designed to make it a paradise for the motorcar. This particularly brutalist form of concreted-over modernization led it to function, as I noted earlier, as the epitome of a non-place in the popular imagination, and the desolation of the period is well characterized in Catherine O'Flynn's novel What Was Lost (O'Flynn, 2007) and Honor Gavin's Midland: A Novel in Time (Gavin, 2014).

The recent tourist boom which I noted in my introduction has been attributed to a number of factors - virtual, material, and political - which are together held to have greatly enhanced the image of the city. These factors include the success of the City Council's recent strategy of reorienting the city's economy around leisure services, up-market hotels, and restaurants. Further high-profile architectural initiatives have included the building of flagship department stores and of a spectacular new city centre library designed by the prestigious architect Zara Hadid, along with the current Paradise Circus redevelopment. All of these have undoubtedly helped attract tourism, trade, and employment to the city, even if its residents sometimes weary of trudging through the various building sites which always seem to dominate the city centre. This new "acculturation" of the city has also helped make the city more attractive to some young professional couples who, priced out of the London property market (now so inflated by the deeper pockets of the international super-rich), are now relocating to large houses in Birmingham's leafier suburbs.

Nowadays, the remnants of Birmingham's industrial past are repackaged as a form of industrial heritage for tourist purposes - in the refurbished buildings of the old Jewellery Quarter, in the mock-Victorian Coffin Factory, and the re-enactment of the "old trades" in the Black Country Living Museum. In the same spirit, Birmingham's extensive but long dilapidated network of canals - which were a key resource in establishing the city as a hub of economic activity in the early period of industrialization - has been cleaned to allow tourists to better admire the sights of what has been re-described in some of the city's marketing literature as the "Venice of the North". A further dimension of this PR strategy has involved the attempt to revive the positive legacy of the 18th-century inventors among the city's "Lunar Men" Society (who are now often described as part of a "Midlands Enlightenment" [cf. Uglow, 2003]). These elements of the city's cultural history sit alongside memories of Birmingham's days of Victorian greatness and of earlier political/intellectual traditions in the city - such as that of Neville Chamberlain and his civic liberalism. However, "heritage", while usually presented as an uncontroversially good thing, always requires a specific definition - and that inevitably raises contentious questions as to exactly which and indeed whose - heritages are to be commemorated and celebrated (Hall, 1999).

In this respect, alongside all these top-down re-branding strategies, there have also been a whole series of initiatives aiming to reinvent the image of 
the city from the bottom up. Thus, the Tindall Street Press, a publishing project featuring local authors, has played a very important role in giving a public voice to perspectives and identities previously silenced or marginalized - but now re-articulated in the work of authors such as Catherine O'Flynn and Anthony Cartwright (O'Flynn, 2007; Cartwright, 2009, 2013). Similarly, recent years have also seen a whole series of cultural strategies such as the Birmingham Film and Television Festival (itself an outgrowth of the earlier Channel 4-funded Birmingham Film and Television Workshop) and the annual Flatpack festival, all serving both to increase the visibility of the city's audiovisual industries and to enhance the diversity of representation of the city's many different cultures and communities.

Perhaps most notably, this period has also featured a number of highly successful fine art-based projects, including John Myers' photos of the lower middle class of this part of "Middle England", Richard Billingham's photos of his own family in their semi-derelict Birmingham housing estate, and George Shaw's paintings of the streets of the depressed urban area where he grew up. The surprising thing here has been that the extremely low cultural status of the subject matter of this work - the lives of poor, often long-term unemployed Midlanders living in depressing domestic circumstances - did not, as would previously have been expected, preclude either Billingham or Shaw from being nominated for the British contemporary art world's most prestigious award, the Turner Prize (Shaw, 2001, 2003, 2012; Billingham, 2000, 2004; Myers, 2012).

\section{Questions of place and visibility: race, ethnicity, and belonging}

In relation to the politics of place and of visibility, the key questions concern the relationship between physical and mediated forms of "real estate" in relation to the politics of absence, presence, and identity. The issues here are who can occupy which kinds of physical locations and who is to be represented within which kinds of virtual or broadcast spaces. There are many versions of this problem - in which being disadvantaged is not only a matter of material poverty or social exclusion but also of exclusion from positive forms of representation. Perhaps the best known concerns the extent to which the poor Arab populations of France have not only been long confined physically to outlying banlieux but also excluded, on the whole, from representation in what Hargreaves calls the "genres of conviviality" in the French media sphere (Hargreaves, 2001). The corresponding exception has, of course, been their hyper-visibility in the genres concerned with social problems. The role of films such as La Haine (Vincendeau, 2009) in bringing the world of the banlieux to some wider representation has been crucial - but to this day, a group of young people from one of those areas travelling into central Paris can still expect to be made to feel thoroughly out of place by metropolitan policing practices designed to limit access for "undesirables" who might distress the tourists in the city. 
In relation to these issues, Parker and Long rightly note that, at a moment in which Birmingham is being rebranded and a new set of large-scale public narratives are being constructed, there is an urgent question concerning "What does an urban population faced with the imperatives of change choose to remember? Which social groups' contributions to the city are to be commemorated?" The temptation here is simply to escape into fond, sepiatoned memories of a highly selective past. In such a vision, the golden years of "Old Brumajem" are all too easy to reconstruct in a soft-focus rendition of an urban Arcadia (Parker \& Long, 2005: 160, 162-164). Here we also must confront difficult questions of racism, because that picture often then displays what Stuart Hall once described as "white amnesia" (Hall, 1978) insofar as the "we" who constitute the remembered community characteristically excludes the large proportions of the city's population who are the descendents of those who arrived as immigrants in the post-war period. It is not only the well-established cottage industry of nostalgic local histories with titles such as The Golden Years of Birmingham which construct a racialized vision of communal harmony implicitly set in an era before immigration. Despite the fact that more than $30 \%$ of the city's residents are from minority ethnic backgrounds, even recent publications such as Positively Birmingham (Berg, 2015) largely omit any black or Asian faces from their portraits of community, except as a kind of exotic window-dressing at carnival or festival occasions.

The area does have an unhappy history of anti-immigrant racism, dating back to the days of Enoch Powell in the 1960s, with his poisonous appeals to the prejudices of the "forgotten minority" of authentic (white) Brummies. The disavowals continue - 30 years after John Akomfrah and the Black Audio Collective made their path-breaking film Handsworth Songs about the 1981 riots in what was already a major area of black immigration, the Birmingham press was still featuring nostalgic accounts of "Paradise Lost", recounting the sad story of how multiethnic Handsworth "swallowed up" the bucolic rural hamlet of Birchfield (Parker \& Long, 2005: 165). However, the racialized dynamics of these political conflicts are not so easily wished away. The book that subsequently became the classic study of the rise of Thatcherite authoritarian populism in the United Kingdom, Policing the Crisis, produced at the Birmingham CCCS in the 1980s, had its origins in a small-scale study of police overreaction to a particular street robbery in the same Handsworth streets in which Akomfrah's film was later shot. The reporting of this local event gave rise to the deployment of the North American terminology of "mugging" to highlight a specific form of blackon-white street crime throughout the national British news media. All of this played a crucial role in the development of the law-and-order rhetoric which subsequently came to dominate British politics for the next 30 years (Hall et al., 1979).

The question of representation - and of which communities are rendered visible (to themselves or others) remains crucial here, and in the absence of 
effective public provision, the preservation of the visual history of the city's ethnic communities has fallen, by default, to private individuals. Thus, the photographer Vanley Burke effectively took on the role of being the private curator of the city's black culture until the belated recognition offered by the retrospective exhibition of his own private collection held in the city's Ikon Gallery in 2016 and even more recently (April 2018) of his photographs in Birmingham Art Gallery (Burke, 2012, 2015).

\section{Birmingham on TV: Peaky Blinders and the return of cosmopolitics}

In all of this, televisual representations of the city are clearly a crucial issue. However, despite the long-term presence of both BBC and commercial television production facilities in the region, the city has been more noticeable by its televisual absence than its presence. The best-known imagery of the city is still probably that provided by the self-deprecating humour of regional TV comedians such as Jasper Carrot, Lenny Henry, and Frank Skinner. Alongside this, we still find the rather negative stereotypes of "Brummies" provided by the long-running, down-market soap opera Crossroads (1964-1988) set in a Midlands motel and classically parodied by comedienne Victoria Wood's skit on the programme, featuring an uneducated working-class Birmingham cleaner known as Mrs Overall. As Brunsdon has argued, if Crossroads came to be a key symbol of the dismal nature of life in the Midlands, the program itself also long stood as a shorthand for bad television - thus producing a "Midlands of the Mind" which was thoroughly deficient in both substantive and formal qualities (Brunsdon, 2008)

Questions of race and ethnicity have been almost entirely absent from these modes of televisual representation. There have been but a few honourable exceptions, such as the innovative 1970s BBC TV drama Gangsters and the black-focussed soap opera Empire Rd (Newton, 2013) and, more recently, the popular BBC TV series Citizen Kahn set among the city's Muslim community in Sparkhill. However, we must also consider the contribution to the more positive image of the city made recently by the impact (both in Britain and abroad) of a rather different television show - Peaky Blinders. It was first produced by BBC2 in 2013 and has now run to six series, becoming a major international success. It is set among the early 20th-century criminal gangs of the city and might be loosely described as a sort of soap-opera style version of Martin Scorsese's film Gangs of New York. In particular, I want here to address the positive contribution the series might be seen to have made to discourses concerning race and ethnicity, even if it could be said to present the issues at stake in a rather exoticized manner.

In contrast to the nostalgic amnesia described earlier, which would present a vision of Birmingham as an essentially white city, the series reintroduces the question of race and ethnicity right from the start. Early on, we are introduced to the flamboyant figure of Jeremiah Jesus, complete with flowing 


\section{David Morley}

dreadlocks, as played by the well-known black Birmingham poet Benjamin Zephaniah. It is also made clear that the city once had a strong Italian subculture, manifested by the presence of the Mafia-style gangsters from whose vengeance the hero, Tommy Shelby (played by the Hollywood star Cillian Murphy), has to save his brother. The fact that Shelby has come back from the First World War with a drug addiction also necessitates representation of the city's Chinese quarter in portraying his use of its basement opium dens. Having this charismatic hero played by a famously Irish actor serves to provide further echoes of another of the city's long-submerged ethnic subcultures. Indeed, the contentious question of Irish ethnicity and politics is central to the narrative of the series, with the initial storyline depending on the theft of British Army guns (which it is feared, may have got into the hands of the IRA) being investigated by a belligerent Northern Irish policeman who brings a particularly brutal style of policing to the city. It may, in some ways, be the Irish question (and its policing) which is most consequential here - to this day, Birmingham's culture is still haunted by the unresolved nature of the IRA bombings of two city centre pubs in 1974. Overall, as Brunsdon notes, Peaky Blinders, with its heritage aesthetic, dynamic violence, and rock soundtrack, has been mobilized by the city to market itself as distinctive - simultaneously modern and historical (Brunsdon, forthcoming).

\section{After globalization? From Brum to Brexit ...}

As indicated earlier, since the 1960s, one of the main effects of globalization in Birmingham has been the destruction of manufacturing industry by cheap imports. The consequent high level of unemployment among the city's indigenous white working-class population certainly paved the way for Enoch Powell and other racist politicians to exploit the anxieties the local working classes have long felt about their declining position in the world. To return to the general questions about relative rates of mobility which I discussed earlier, these are people who are largely consigned to the immobility referenced in my title. Far from engaging in any sort of tourism (whether media-related or not), even the annual package holidays to Spanish coastal resorts which some of them had enjoyed in earlier, more affluent times, before the factories closed down, are now largely a thing of the past. These days, they are stuck in their fast-declining local communities with little prospect of any escape at all, whether on a temporary or permanent basis, and for them, locality is increasingly destiny.

In this context, I want to try to articulate these local issues about race, ethnicity, and identity in Birmingham to the more general question of the emerging backlash in Britain against Europe. This can perhaps be understood to represent a kind of political revenge on the part of a group of people who have come to regard themselves as a forgotten minority who feel left behind by globalization (Goodhart, 2017; Mishra, 2017; Seidler, 2017; Jefferson, 2017). In the particular case of Birmingham, they also feel neglected 
by the political strategies of those who, rather than attempting to reinvigorate the city's manufacturing traditions, seem to them to be attempting to turn it into a service industry-based shopping emporium and leisure centre designed for the affluent, mobile middle classes of the world.

We can perhaps best understand these forms of particularist and reactionary localism as an understandable set of reactions to the destabilizing forces of globalization. These demands for some sense of control over their own communities and the resurgent desires for some more rooted sense of place represent a felt need for a consolatory and reassuring counterweight which can provide people with some sense of security in what Baumann called this newly "liquid" world of flux, threat, and instability. All those forces impact most sharply those at the bottom of the social hierarchy, who are least able to defend themselves against these pressures (Bauman, 2000). There we find people who feel that their voices have long been unheard and their identities invisible or undervalued - and when the media have paid them attention, it has only been in the exploitative form of making what have been called "poverty porn" documentaries about them (as in the case of Channel 4's notorious series about welfare recipients in one poor area of Birmingham called Benefits Street which caused a great deal of bad feeling among the city's residents when shown on Channel Four in 2014).

These are exactly the people whose lives the Tindall Street Press authors, along with the previously mentioned photographers and artists like Myers, Billingham, and Shaw, have been trying to make visible. This likewise has been the project of social commentators such as Lynsey Hanley (2016), who writes movingly about the devastation of the previously "respectable" "social housing" in the working-class areas of the city where she grew up. She also addresses the key ideological struggle over "respectability" and the invidious Thatcherite return to questions of how to distinguish between the "deserving" and "undeserving" poor. In considering the politics of how these different groups are to be given more visibility - and access to the media on their own account - I would suggest that here we might usefully return to some of Raymond Williams' comments on the importance of democratic inclusivity in the matter of representation (Williams, 1989).

For many years, having felt alienated by all the mainstream political parties, most of these people haven't voted at all and thus have long been politically invisible. The moment when it became clear to me just how much political trouble was looming over the horizon was on the evening before the European Referendum in 2016. The local Midlands television station that evening was doing vox pop interviews in the streets of a very depressed part of the Black Country called Rowley Regis, where my family still lives. The poor women being interviewed announced that they were planning to vote Brexit because they felt they'd "had nothing" for years and so felt - in a spirit of more or less nihilist resentment - that things simply couldn't get any worse for them, so they might as well just make a "protest vote" - without knowing or even seeming to care where that might lead. This is the politics 
of the disenfranchised, which, rather than being guided by rational calculations of the relative advantage to be gained by supporting this or that political party, functions more in the spirit of 19th-century Russian nihilism in wanting to simply exact some form of painful revenge on whatever victims are available for the wrongs which have blighted the lives of those to whom no one has been listening (cf. Mishra, 2017).

It is for all these reasons that the West Midlands region had the largest percentage of voters in the country $(59 \%)$ in favour of leaving the EU. In that sense, Birmingham and its intensely regional culture not only stand at the heart of the Brexit problem but also perhaps function as a harbinger of the dilemmas currently being experienced in many other parts of Europe. However heartening Birmingham's recent tourist boom may have been, both for the local hoteliers and for the politicians who have invested in what is now a clearly successful place-making strategy for the city, these are not problems that can be solved by increasing rates of hotel occupancy.

Birmingham's hotel beds and restaurants may well now be better occupied by the mobile middle classes, whom the forces of globalization increasingly bring to the city, in large numbers, from Europe, America, and East Asia. But the problem which increasingly demands attention concerns those who are less mobile. Until now, they have largely been not only immobile but also invisible - but the Brexit protest vote serves to "call time" on that scenario. We now perhaps enter, as Mishra has it, an "age of anger", where in the "swamp of fear and insecurity" in which the inhabitants of the deindustrialized regions of Birmingham and the Black Country live, we see what Hannah Arendt once called a "tremendous increase in mutual hatred ... a somewhat universal irritability of everybody against everybody else". This is perhaps best understood as a kind of "negative solidarity", as she puts it, of the type of which Nietzsche spoke when describing "the tremulous realm of subterranean revenge, inexhaustible and insatiable" of the ressentiment of the dispossessed (Arendt \& Nietzsche, quoted in Mishra, 2017: $19,13,14,9)$. This, in the parlance which has come to function as a kind of political shorthand to describe this situation, is the problem of the "left behind". If Birmingham as a city perhaps now feels less "left behind" by the rest of the country than it used to be, nonetheless, there remain, within and around it, many people who feel that the world is leaving them behind. They have all the corresponding anxieties that come with the chilling recognition inscribed in the old Soviet phrase which militantly announced - if in a different context - that "not everyone will be taken into the future" (cf. Kabakov \& Kabakov, 2018). To return to the terminology of Randy Newman's "Rednecks" with which I began, their disruptive potential may consist precisely of the fact that, feeling they have nothing left to lose, they have no specific political objective other than to try to make sure that others will now experience various forms of "hurt" in precisely the ways that they themselves have long suffered. 


\section{Bibliography}

Appadurai, A. (1996). Modernity at large. Minneapolis: University of Minnesota Press.

Auge, M. (1995). Non-places. London: Verso.

Bauman, Z. (1998). Globalisation. Cambridge: Polity Press.

Bauman, Z. (2000). Liquid modernity. Cambridge: Polity Press.

Ben Jelloun, T. (2009). Leaving Tangier. London: Arcadia Books.

Berg, J. (2015). Positively Birmingham. Birmingham: Picture Library.

Berlant, L. (1991). Anatomy of a national fantasy. Chicago: Chicago University Press. Billingham, R. (2000). Ray's a laugh in Richard Billingham. Birmingham: Ikon Gallery.

Billingham, R. (2004). Black Country. Sandwell: The Public.

Brunsdon, C. (2008). In focus: The place of television studies: A view from the British Midlands: Introduction. Cinema Journal 47(3): 122-127.

Brunsdon, C. (forthcoming). Television and the city. In: Z. Krajina \& D. Stevenson (eds.), The Routledge urban media companion. London: Routledge.

Burke, V. (2012). By the rivers of Birmingham. Birmingham: Midlands Arts Centre.

Burke, V. (2015). At home with Vanley Burke. Birmingham: Ikon Gallery.

Cartwright, A. (2009). Heartland. Birmingham: Tindall St Press.

Cartwright, A. (2013). How I shot Margaret Thatcher. Birmingham: Tindall St Press.

Cartwright, A. (2016, July). Black Country. Granta.

Cresswell, T. (2012). The production of mobilities at Schiphol airport, Amsterdam. In: On the move, pp. 231-270. London: Routledge.

de Blij, H. (2009). The power of place. Oxford: Oxford University Press.

Dickens, C. (1854). Hard times. London: Bradbury \& Evans.

Egoyan, A. (1999). Felicia's Journey. [Film]. Artisan Entertainment.

Gavin, H. (2014). Midland: A novel in time. London: Penned in the Margins.

Goodhart, D. (2017). The road to somewhere: The populist revolt and the future of politics. London: Hurst.

Green, C. (2014, September 24). Forget dating sites: Erasmus is the place to find true love. The Independent.

Griffin, B. (2013). The Black Kingdom. Stockport: Dewi Lewis Publishing.

Hall, S. (1978). Racism and reaction in commission for racial equality. In: Five views of multi-racial Britain. London: CRE Publishers.

Hall, S. (1999). Un-settling 'the heritage', re-imagining the post-nation whose heritage? Third Text 13(49): 3-13.

Hall, S. et al. (1979). Policing the crisis: Mugging, the state and law and order. London: Hutchinson.

Hanley, L. (2016). Respectable: The experience of class. London: Allen Lane.

Hargreaves, A. (2001). Media effects and ethnic relations in Britain and France. In: R. King \& N. Wood (eds.), Media and migration. London: Routledge.

Hart, S. (2014). He may be a fool, but he's our fool. In: Let the devil speak. Highland Park: Black Angel Press.

Jefferson, T. (2017). Race, immigration and the present conjuncture. In: J. Henriques, D. Morley \& V. Goblot (eds.), Stuart Hall: Conversations, projects and legacies. London: Goldsmiths Press.

Kabakov, I. \& Kabakov, E. (2018). Not everyone will be taken into the future. London: Tate Modern Gallery. 


\section{David Morley}

Lash, S. \& Friedmann, J. (1992). Modernity and identity. Oxford: Blackwell.

Lodge, D. (1975). Changing places. London: Penguin.

Mai, N. (2001). Italy is beautiful: The role of Italian TV in Albanian migration. In: R.

King \& N. Wood (eds.), Media and migration. London: Routledge.

Meyrowitz, J. (1986). No sense of place. Oxford: Oxford University Press.

Mishra, P. (2017). The age of anger. London: Penguin.

Morley, D. (2017). Communications and mobility: The migrant, the mobile phone and the container box. Oxford: Wiley Blackwell.

Myers, J. (2012). Middle England. Birmingham: Ikon Gallery.

Newton, D. (2013). Paving the empire road: BBC television and Black Britons. Manchester: Manchester University Press.

O'Flynn, C. (2007). What was lost. Birmingham: Tindall Street Press.

Packer, J. \& Crofts Wiley, S. (eds.). (2012). Communication matters. London: Routledge.

Parker, D. \& Long, P. (2005). Reimagining Birmingham: Public history, selective memory and the narration of urban change. European Journal of Cultural Studies 6(2): 157-178.

Parks, L. \& Starosielski, N. (eds.). (2015). Signal traffic: Critical studies of media infrastructures. Urbana: University of Illinois Press.

Robins, K. \& Aksoy, A. (2016). Transnational migration and the challenge for Europe. London: Routledge.

Sabry, T. (2005). The day Moroccans gave up couscous for satellites: Global television, structures of feeling and mental migration. Transnational Broadcasting Studies 14: 197-221.

Sandbrook, D. (2015). The Great British dream factory. London: Penguin.

Schivelbusch, W. (1977). The railway journey. Berkeley: University of California Press.

Seidler, V. (2017). Making sense of Brexit. Bristol: Policy Press.

Shaw, G. (2001). The new life. London: Anthony Wilkinson Gallery.

Shaw, G. (2003). The sly and unseen day. Gateshead: Baltic Centre for Contemporary Art.

Shaw, G. (2012). I woz ere. Coventry: Herbert Art Gallery.

Uglow, J. (2003). The Lunar Men: The friends who made the future 1730-1810. London: Faber.

Verstraete, G. (2010). Tracking Europe. Raleigh: Duke University Press.

Vincendeau, G. (2009). La Haine. London: IB Tauris.

Williams, R. (1989). Resources of hope. London: Verso.

Wood, Z. (2017, February 1). Birmingham shrugs off grimy image. The Guardian. 


\title{
4 I just can't get you out of my head How music triggers the imagination
}

\author{
Leonieke Bolderman
}

\section{Introduction}

Sound is an indelible part of how we construct and perceive reality. According to cultural geographer Tuan, without sound, "space itself contracts, for our experience of space is greatly extended by the auditory sense which provides information of the world beyond the visual field" (Tuan, 1974: 9). Concrete, sensory experiences of space and place play a central role in processes of imagining. Defined in the introduction of this volume narrowly as "the mental visualization of things that are not present" (Introduction: 3) and more broadly as "the capacity to create mental constructions of places where one is not present at that moment" (Introduction: 17), the current conceptualization of the imagination puts emphasis on the visual. This is not surprising, since the prominence of the visual chimes with a long tradition of foregrounding visual culture in studies of human meaning making, also referred to as the "visual fallacy" prevalent in cultural and media studies (Couldry, 2015).

In line with a call to explore how visual and auditory cultures illuminate each other (cf. Bolderman \& Reijnders, 2019; Keightley \& Pickering, 2006), in this chapter, I explore the role of sound and, in its wake, music, in conceptualizing the content and importance of the imagination. Based on an analysis of 52 interviews carried out in the context of a research project on music tourism, music is shown to be a particularly efficient mediator of cognitive, affective, and embodied ways of imagining. In this way, music offers an especially fruitful way of analysing how the affective and embodied dimensions of imagining enrich the cognitive. Thus, I conclude that expanding our conceptualization of the imagination to include other senses and media is an effective way to take the goal of a non-mediacentric approach to media studies (Introduction: 4) a step further.

\section{Conceptualizing the imagination through music}

In line with how the imagination is defined in the introduction of this book, I conceive of the imagination as a universal phenomenon that allows every 
human being to create mental constructions of places where one is not present at that moment in time. Concrete, sensory experiences of space and place play a central role in processes of imagining, creating an intrinsic paradox: imagining concerns both the absent and the present; it connects perception with the imaginary. Moreover, the imaginary capacities of human beings provide the world with "an affective texture" (Lennon, 2015: 18), offering patterns, images, and forms to experience the world. As stated in the introduction of this book, this makes the imagination a fundamental part of our consciousness - a fundamental part of how we experience dimensions of time and place (Introduction: 9).

Music is an imaginative practice and as such provides ways to make sense of our experience of "being in the world". As has been voiced in the field of ethnomusicology, music works by providing metaphors for how the world is imagined, lived, and felt (Cohen, 2007; Feld \& Basso, 1996; Hudson, 2006; Kong, 1995). Demonstrating the power of the imagination through music, these metaphors become part of shared cultural narratives, thereby "stimulating a sense of identity, preserving and transmitting cultural memory, transporting listeners to imaginary places and providing a map of meaning" (cf. Cohen, 2007).

Andy Bennett provides an example of this process in a study on the Canterbury sound (Bennett, 2002). Bennett refers to shared imaginary worlds as "'musical mythscapes': spaces that are "mythologized as in some way informing the essential spirit of a body of live and recorded music". Places become connected to the music in the imagination of the fans as "standing for" something essential in the music, providing "a point of reference" for sociability that functions as a unifying element for the fan community and a catalyst for channelling meanings attached to the music (both personal and collective).

Bennett shows the role of the media in the power of such globally circulating imaginaries as stories about music and place circulate in the media and are appropriated by fans, allowing the mythological place as imaginary to thrive. For this chapter, it is interesting to think about how music as an intangible medium is part of this process. Moreover, the question arises how these globally circulating imaginaries and metaphors become invested with affective meaning. In this chapter, I argue that an answer to these questions can be found by looking more closely at the relation between music and imaginative practices.

In my own previous work on this topic (Bolderman, 2020; Bolderman \& Reijnders, 2019), I identify two ways in which music stimulates the imagination and invests imaginary worlds with affective meaning, connecting cognitive and affective dimensions of imagining. Building on work by music philosophers Nicholas Cook (1990) and Thomas Walton (1994), music first of all stimulates the imagination cognitively. Listeners create a full image of what it is they are listening to through filling out the gaps of meaning between sounds, images, and words - what Cook (1990) calls an "interpretive position". This cognitive dimension of the imagination involves music's 
paratexts (cf. Genette, 1997), which can be linguistic (lyrics, sleeve notes, etcetera) or visual (music videos, album covers, etcetera).

Besides this interpretative cognitive position, music also evokes a different kind of imagining: that of experience. Most of the time, the listener is not concerned with music's interpretative meaning but with its effect. Walton (1994) argues that what the listener imagines when listening to music is not a visual perspective but the experience of mental states like feelings and emotions. This means that, as opposed to, for example, painting or literature, the music itself is not the prop of imagining, but the experience when we listen to it is what sparks our imagination. In semiotic approaches to music, this has been observed as well: in Saussurian terms, music is not a system of signs but a system of signifiers without signifieds (Turino, 2008).

As I argue, imagining is both an interpretative and experiential practice: imagining through music combines what one "sees" based on music's paratexts and how one "feels" through listening to music (Bolderman \& Reijnders, 2019). Elaborating on this previous work, I argue in this chapter that music combines the interpretive and the experiential in a particularly embodied way, mediating between cognition and affect. Music therefore is a medium for bridging and mediating these interlinked dimensions of the imagination.

A key step in this argumentation is the idea that music works in this embodied way through the medium of sound. Sounds, being vibrating air, have a tangibility that can be experienced through other senses than vision sound and, in its wake, music, can be felt. As put forward by several scholars (Cohen, 2007; DeNora, 2000; Hesmondhalgh, 2013; Turino, 2008), it is through these sonic qualities that music offers an embodied experience. Rhythms and melodies envelop and penetrate the listener; the listener can literally feel the music, offering the listener the possibility for "entrainment": to align emotions and moods with the rhythm or "feel" of the music (DeNora, 2000). As Turino explains in relation to belonging, this way, music provides an experience of whatever meaning is attached instead of about that meaning: "language provides propositions about belonging, music is the feeling or direct experience of belonging" (Turino, 2008: 241). In relation to the imagination, this has two consequences.

First, it means music can transport people in time and space in real time, for example, during a concert. Through the tactile quality of music, coming to the listener as well as travelling into the listener (Cohen, 2007: 181; Waitt \& Duffy, 2009), music creates its own time, space, and motion as a temporal medium, which makes places more intensely lived and tangible (Cohen, 2007; Hesmondhalgh, 2013; Smith, 2000; Waitt \& Duffy, 2009). In the words of Stokes: "a musical event evokes and organizes collective memories and present experiences of place with an intensity, power and simplicity unmatched by any other social activity" (Stokes, 1997: 3). Especially music's rhythmic quality and temporal unfolding are seen to play a major role in inducing these states of flow and even trance (Csikszentmihalyi, 1990; DeNora, 2000; Turino, 2008). 
Second, music mediates between a personal, affective level of experience and a cultural, shared level of meaning and identity. Listening together to music in real time can create a collective social identification, frequently called a sense of "communitas" in reference to Turner's anthropological work on rituals (Hesmondhalgh, 2013). Waitt and Duffy describe how people who listen to music together are taken on an embodied "aural journey" of music together (Waitt \& Duffy, 2009), while Hesmondhalgh points out that people who experience the same thing at the same time report experiencing a sense of belonging to a community (Hesmondhalgh, 2013).

Therefore, music mediates between cognitive, culturally shared dimensions of experience, described, for example, in Bennett's musical mythscapes, with affective dimensions of experience. Music does so in a particularly embodied way. This leads me to argue in this chapter that the imagination should be defined as being cognitive, affective, and embodied, conceptualizing these dimensions as being strongly connected and interrelated, between which music mediates. In order to bring empirical flesh to this theoretical idea, I will discuss this conceptualization of the imagination through an explorative interview study on music tourism, in which the musical imagination of 52 interviewed tourists played a central role.

\section{Methodology}

The research for this chapter has been conducted in the context of the Locating Imagination. An Interdisciplinary Perspective on Film, Literary and Music Tourism research project, conducted between February 2013 and 2017 at Erasmus University Rotterdam, supported by the Netherlands Organization for Scientific Research (grant number PR-11-77). It builds upon the findings of three case studies that focused on the ways in which tourists construct narratives of music and place (Bolderman, 2020; Bolderman \& Reijnders, 2017, 2019; Reijnders et al., 2015).

Designed from a grounded theory perspective (Charmaz, 2006), the analysis in this chapter follows on from 52 semi-structured interviews with music tourists in Europe. Twenty-one of the interviews were conducted face to face, while the others were Skype interviews. Generally, the interviews lasted about an hour. The interviews focused on the role of music in everyday life and the preparation, on-site experiences, and returning home after music-related holidays the interviewees engaged in. In the selection of respondents, I sought a balance between tourists who self-identified as fans and those who voiced a more casual engagement with music; I included a diverse array of music genres; and I researched diverse kinds of music tourism, ranging from walking tours and museum visits to music workshops and concert travel.

The analysis started with open coding (Charmaz, 2006), meaning that I read and re-read the transcript at hand to get a good feel for it and then would proceed with attaching codes freely. After the initial open coding phase, a process of selective coding followed (Charmaz, 2006) through which 
connections between and within categories and subcategories were made. At this stage, some codes and subcategories were resolved, while others emerged more comprehensively across the transcripts. I then moved towards identifying preliminary theories, collapsing categories into overarching themes through an iterative process of moving back and forth between the data, the research question, and the literature. Throughout the analysis, citations and examples from the interviews will be used to exemplify the main findings; interviewees have been anonymized.

\section{How music stimulates the imagination in practice: cognition, affect, and embodiment}

When Tara hears the song "Bad" by U2, something happens. She starts nodding, tapping her foot to the beat, and soon she will start singing along to the lyrics of the song. As a lifelong U2 fan, her behaviour is not limited to listening to the song on the radio. Tara travels frequently to U2 concerts, and during the interview, she recounted that when she hears the song live, something special happens. In her own words: "when I hear that it just knocks me senseless, if you talk to me during that song, you won't even get a response. . . . I get transported to a different planet, I get transported to planet Bono" (Tara, 43, British). U2 music, and this song in particular, has a special power to transport Tara in her imagination, taking her somewhere else.

Tara is not alone in this. All respondents who were interviewed for this project talked about the ways the music they like to listen to stimulated their imagination. Sometimes this was a particular song or composition by a favourite band or composer, such as getting transported to "planet Wagner" through listening to the Ring cycle or getting lost on "planet ABBA" through listening to "Dancing Queen". Other cases involved making music, in which participants described getting into moments of flow, being transported to a different dimension; listening to music while on a morning commute creating a personalized music bubble; or imagining the pleasurable experiences ahead while putting together a playlist for going on holiday.

It was not the case that all interviewees were transported to imaginary worlds all the time, nor to such an extent as in the account of Tara. Quite the opposite: the interviewees talked about consciously creating and entering imaginary worlds by listening to or engaging with music but also about consciously engaging with their environment by not listening to music. In all cases, though, the interviewees considered music a valuable part of their lives, permeating and soundtracking their everyday lives and dreams, evoking complex images in which time and place, perception and imagination converged.

\section{The cognitive dimension: how imaginary worlds are built through music}

What was the role of cognition in creating and engaging with these complex imaginary worlds through music? First of all, the caveat must be made that 


\section{Leonieke Bolderman}

even though music can evoke complex and powerful, detailed imaginary worlds, music could also evoke a more blurry, loose idea of an imaginary place, a "sense of place" that was not always visual. As explained by Bowen (1997) in a study on the Jimmy Buffet song "Margaritaville", the song leads some fans to imagine a concrete place somewhere in Key West, Florida, while others consider Margaritaville a state of mind, an intangible imaginary place removed from everyday life. This duality also surfaced during the interviews for this study:

With some music you have a very strong visual image of a place, for example that album by Jewel we talked about. With Bachata and Salsa, it is more a feeling of a place, and less visual images.

(Naima, 34, owner of a start-up)

During the interviews, it became clear that visual images were not the most prominent way music stimulated the imagination. Mood was the single most important theme to emerge, evoking a sense of place. As Naima explained, it was about having a certain feeling towards a broader idea of place, for example, a city, region, or country.

What this quote also shows is that music listening, in whatever situation, was a rich source of worldbuilding. In other interviews, music making (either individually or in groups) and engaging in music-related practices, such as travelling to concerts, engaging in fan activities, or playlist making, all triggered processes in which the interviewees imagined places and situations beyond their perceived reality. Jaap described how listening to a Bruce Springsteen song summoned a particular image in his mind:

That song by Bruce Springsteen ... when I close my eyes, I am sitting at the cabin again, the ambiance, the fun ... it's night time, we're all there... it was Jolien's birthday, so it had to have been the 8th of August ... we're having cocktails, with little umbrellas in them, there was a camp fire, there was a pool you could jump into in the middle of night.

(Jaap, 35, call centre employee)

Jaap saw a very specific scene in front of him. He described the moment during a holiday with friends when they celebrated a birthday. Music in this memory functioned as a powerful hook, evoking a complex image in which time, place, and memory converged. In these visual imaginations, place was not the centre of attention - Jaap emphasized this as well - but place and music were part of an imagination that revolved around something else: social relations and memory. Adding to the point made by Reijnders (2016), location is an important part of memories of beloved stories, and, as I suggest based on these interviews, location also matters to memories of beloved music.

Going more in depth comparing beloved stories to music, the question arises how exactly music was connected to locations. This question is 
interesting since there is not always a written text or an image to music that shows a location - as emphasized in the theory section, both readers and music listeners fill up the blank spaces between the lines to complete the mental pictures in their minds. The visual, tangible worlds evoked by music in the interviews could be connected to reality in four ways, which I have described elsewhere in more detail (Bolderman \& Reijnders, 2019). Music mediates between real and imagined locations through its sounds - an interviewee, for example, connected specific drums in a song to his honeymoon location in Sri Lanka. Lyrics and images could evoke particular places, such as a song in Italian evoking images of Italy. The biography of the musician or band was a third powerful mediator of imagined worlds, and, finally, the places where music was produced, made, or consumed functioned as anchors to music-related imaginings - legendary venues or recording studios were mentioned frequently or memories of festival experiences. What I would like to stress here is that these four mediations are not unique to music, since the birthplace of the author of a novel can also stimulate imagining in the same way a famous cinema can be an inspiring, stimulating location for the imagination. However, since music is also sound, besides possibly text and image, it provides a refocusing on processes of imagining through other media.

The worlds evoked through and with music are not necessarily related to the factual features and content of the music, although in the case of lyrics, places sung about of course featured more prominently in the imaginations of the interviewees. When an interviewee, for example, listened to instrumental music which included a didgeridoo, obvious connections to Australia were made, confirming how cultural schemata permeate imaginary worlds (cf. Reijnders, 2016) also in the case of music. Even so, returning to the quote by Jaap, Bruce Springsteen did not sing specifically about France, the country Jaap was celebrating his holiday in at the time. It was the personal memory of Jaap that was connected to the music and was evoked by the song.

According to Malpas (1999), visual imaginations are influenced by the experiences we have: they draw on our sensory input. What surfaced from the interviews for this project was that the interviewees had three main sources of sensory input to create visual imaginations. The most important source for interviewees was their own personal sensory experience of place, accessed through memory. A second source was the pictures and imaginaries accessed through family or friends. Images shown by family or friends, for instance, holiday snapshots, often created "inherited memories" (Keightley $\&$ Pickering, 2012), connecting music to the place in the picture, even if the interviewee had never actually been there:

Unfortunately, I have never been to Kenya, but when I listen to this music, I experience Kenya. My parents have been there, and they have told me about it, and it's almost as if you connect that memory to the 
experience of the music. And thereby place yourself back in time as it were, as if you were there yourself.

(Paul, 50, marketing manager)

The intrinsic paradox of the imagination comes to the fore in this quote, as Paul experienced a place that he was not in at that moment, a place that he actually had never been to and experienced himself. This imagined experience shows a play with memory, with time and space, playing with the boundary between perception and reality. The experience described by Paul comes close to how Svetlana Boym defines reflective nostalgia: feeling nostalgic for a reality that was never lived but feels familiar regardless (Boym, 2001).

Nostalgia especially played an important role in the third source of visual imagery the interviewees drew on to fill in their imagined worlds: the media. The interviews showed that mediated images filled in the gaps when music had no specific visual based on personal or inherited experience. As Liselotte explained:

Music sometimes gives me a nostalgic feeling ... it is a longing for the past, without the past. . . . I mentioned that when talking about Paris: I only know Paris the way it is now. But the way you see it in old movies, the way it is romanticised, it imprints a certain image in your head, and when I'm there, I search for some sort of recognition in those old images.

(Liselotte, 26, student)

Liselotte referred in this quote to how she made her own imaginary based on mediated images, imprinting "a certain image in your head". This process seems to correspond to the concept of "musical mythscapes" as posited by Bennett (2002), in which mediated connections and images between music and place are taken up by audiences and appropriated into new and more elaborated personal imaginary worlds. In this case, Liselotte does not create an idea about an entire body of music or music genre, but it worked the other way around for her: she built a specific imaginary place-image based on mediated images, evoked by music. As Bennett (2002) points out, these mythical locations are not trivial but can become symbolic places, reference points for sociability and identity. What became clear from the interviews of this study is that it is in the symbolic meaning of imagined places that the connection with the affective dimension of imagining can be found.

\section{Affective dimension: how imaginary worlds become affective worlds}

Whether clearly visualized or more free floating, the importance of a sense of place through music - attaching mood and affect to these imaginary worlds - puts us on the path of exploring what I have called in the theory section the experiential aspect of imagining through music. In a study on 
holiday playlists, I have uncovered the process underlying this affective attachment to imaginary worlds (Bolderman \& Reijnders, 2019). Alicia described the process very clearly:

Where the band comes from gets linked to the feeling the music evokes, and then that place also evokes that feeling in me.

(Alicia, 26, secretary)

In this quote, Alicia describes how she transposed the feeling of listening to her idea of place, infusing her "musical mythscape" with personal feeling. This process of turning cognitive worlds into affective worlds happened throughout the interviews and has already surfaced in previous quotes. Liselotte, for example, felt nostalgic when listening to certain music and connected that feeling to Paris; other interviewees talked about "peaceful Scandinavia" or "depressed England" - as referred to in the theoretical section, music offers metaphors for experiencing the world, and throughout the interviews, the stories of the interviewees were built on a specific type of metaphor when discussing imaginary worlds - a hypallage (Bolderman \& Reijnders, 2019) - injecting personal feelings evoked by listening to an idea of place.

These affective dimensions of imaginary worlds were meaningful to the interviewees because the worlds evoked by music were often connected to meaningful moments in the interviewees' lives. Music itself is a powerful technology of identity, a tool to tell the story of self (DeNora, 2000), and this was present throughout the interviews (as also described specifically for music tourists in Bolderman \& Reijnders, 2017). Interviewees described music as the "wallpaper to their life" (Peter, 37, tour guide), as representing who they are ("music is who I am", Philip, 30, account manager), and certain songs and musicians helped them through transitional moments in life (cf. Van Dijck, 2006), such as dealing with parents divorcing, moving out, getting married, having children, dealing with death and bereavement, and so on and so forth.

The way music stimulated the imagination was most often by conjuring up memories of these formative moments, for example, when Philip recounted how he shared music while on his exchange year to Japan, a formative trip and, in hindsight, with its own soundtrack that immediately transports Paul back to a specific square in Japan whenever he puts the music on. Another example is Jaap's memory of France, sharing a holiday with friends, cementing the bonds tying the friend group together. These memories are moments in which place, music, and personal identity meet, imbuing both place and music with personal meaning, creating a music-related form of what Tuan calls "topophilia": the emotional attachment to place that is central to human experience (Tuan, 1974). Reijnders speaks in this respect of "soulscapes": "symbolic environments which individuals identify themselves with, and where, in a lost moment, the soul wanders around happily" (Reijnders, 
2016: 683). Moreover, what we see here is how the cognitive, narrative layer of imagining becomes entwined with and imbued with affect - they cannot be seen separately from each other.

\section{Embodied dimension: how musical imaginary worlds are lived}

During the interviews, the physicality of the connection between music and imagining surfaced as a central aspect of imagining without being explicitly asked for. The embodied dimensions of music and of imagining seem central to its experience. For many respondents, experiencing music physically stimulated the imagination. Tara described very poignantly how she was transported to "planet Bono" while listening to the song during a concert, and many respondents described how they would turn on specific music when they wanted to think about certain moments and memories. This could be specific moments to sit down and listen, but what returned quite often was, for example, how interviewees would put on their holiday playlist while cleaning the house, temporarily being transported to their holiday space of mind while undertaking a mundane, quite physical activity.

Conversely, imagining musical imaginary worlds stimulated the engagement with and the experience of listening to music. As the interviews were conducted in the context of a research project on music tourism, the majority of interviewees gave examples of how having visited a certain musicrelated location changed or deepened their listening experience of the music upon return. As described in the introduction of this volume, media tourism is a way to engage with the imagination physically. This certainly turned out to be the case for the interviews conducted during this project, even if a part of those interviews were not focussed specifically on the act of music tourism (Bolderman \& Reijnders, 2019).

The physical aspects of music were present in processes of imagining in different ways, elsewhere described as ranging from an experience of immersion to absorption (Bolderman \& Reijnders, 2017). Research on immersive imaginative experiences refers often to the notion of "being there" (Waysdorf, 2017), "co-presence" (Urry \& Larsen, 2011), or "liveness" (Auslander, 2008; Chapters 13 and 14 in this volume) to describe the value of this experience to audiences. Specifically in relation to music, various ways in which music can be present and forms a physical part of experience have been analysed, such as through experiences of absorption (DeNora, 2000; Hesmondhalgh, 2013; Malbon, 1999; Turino, 2008). In this case, two ways musical embodiment played a role surfaced: the already extensively discussed experiences of being absorbed by live music, forming an immersive experience in time, and second, being immersed in the sonic landscapes or soundscapes of a place, which offered an immersive experience in place. 
First, many respondents talked about the special experience of hearing and attending live music events, either on holiday or in everyday life. A specific part of the study focussed on music workshops, where making music in a group also caused these moments of absorption and brought interviewees an experience of "flow":

When you're playing music with a group of people ..., there is just such a mental buzz, in a room. It's probably nothing you can see, but you can feel it. ... . You express yourself, but it's more than just expressing yourself, it is following on from what other people are doing, so they're expressing themselves and then you fit in with that and . . . collectively, you're doing something .... and it's very in the moment.

(Madison, 56, IT consultant)

As Madison explains here, she experienced a mental buzz, which transported the players and created a sense of connection as well. In this way, making music together, experiencing sounds together, can be a way of connecting between personal imaginary worlds and shared experiences of those worlds, making the imagination social. In the words of Simon Frith: "Music constructs our sense of identity through the direct experiences it offers of the body, time and sociability, experiences which enable us to place ourselves in imaginative cultural narratives" (Frith, 1996: 124).

What is especially interesting in the way Madison described her experience is the final remark: "it's very in the moment". As Frith also alludes to, the process of imagining involves the experience of time - and, in moments of immersion and absorption, of the dissolving of a sense of time. In his work on dance music, Malbon (1999) refers to this as the "oceanic feeling" music offers, in which personal identity is temporarily suspended. In her work on Beatles tourism, Sara Cohen (2007) similarly describes how hearing music during Beatles week formed an immersive space for tourists by creating a sense of direct, unmediated, non-cognitive experience in which music seemed to create its own time, space, and motion through music's texture and tactile sound, its physical presence. We can conclude that immersive experiences such as Madison's made the imagined world not just a reflexive, cognitive endeavour but a felt, lived, and affective experience, effectively connecting these layers of the imagination.

The second way music's sonic dimension contributed to immersive imaginative experiences was through its presence in the local soundscape. David, for example, mentioned how he realized during a trip to the German city of Bayreuth that the libretto of Wagner operas was not an artificial art language but actual spoken language surrounding him during his visit, giving a new dimension to his listening experience. Other interviewees talked about how they often listen to local radio while on holiday, immersing themselves in local places through knowing local hits and music genres. Finally, many 
interviewees mentioned how they did not need actual music played to still hear music in their mind - a very visceral experience of musically imagining. As recounted by Ricardo (24, student):

When you walk through that landscape, you hear the sounds around you: the water in the creek, the buzzing of the bees, and actually the silence, and the wind, so that is part of what you perceive. If you plug in [your earphones] in that moment, that part of perceiving the environment is missing. Of course, the music replaces it, but you miss the complete picture of experiencing that moment. But: if you perceive and experience that moment with all your senses, and then add music from memory ... it's like adding a layer, it's like a sixth sense.

Ricardo explained how he likes to experience the local soundscape by listening to nature, and he then "adds" music from memory - by hearing it play in his head imaginatively. Other interviewees remarked on this power of music as well, adding an imaginative layer over reality. Some talked about consciously creating playlists and adding music to their world, either as a way to add a layer of meaning or by creating a personal musical bubble to retreat in. For others, the experience was not always voluntary: Philip, for example, talked about hearing a U2 song play in his mind when exiting the Dublin airport, as he saw the flats the song is about - an example of involuntary musical imagery, hearing music that is not there (Bolderman \& Reijnders, 2017). In this way, music can be seen as an imaginative tool for experiencing the world around you in different ways, aided by current mobile technology.

Meike (29, psychologist) summarized the two ways music stimulates the imagination quite poignantly:

It's the idea of the modern pilgrimage, because you have a purpose. Whether that is because you're a fan of the music, or you have an entire world in your mind ... you want to go there. Because it's a nice goal to have. When you do a roadtrip, it's more about combining the experience with the music, to complete that experience as it were.

Meike in this quote described how music helped her to fantasize about locations, turning these into detailed imaginary worlds ("or you have an entire world in your mind") that subsequently stimulated a need to explore these worlds physically ("you want to go there"). At the same time, music helped Meike to connect to the landscape while on the road, adding to her experience of reality ("to complete that experience as it were"), helping her to immerse into her environment, just like Ricardo described.

What we see in these quotes is how the imagination is both a way of evoking what is not there and conjuring up "entire worlds" - what we have called the narrow definition of imagining in the introduction of this edited volume - while imagining is also about filling in the blanks of experiencing 
the world around you, of completing an idea and experience of being in the world - the Kantian tradition of conceptualizing the imagination more broadly, as the capacity for giving meaning to the experience, the precondition of functioning as a perceptual being (cf. Lennon, 2015). What makes the difference seems to be the situation and the matching function of music, calling attention to music's specific characteristics as a medium. Music can be like a book or painting, something to be pondered over, forming the start of developing elaborate imaginary worlds. Music, experienced in its unfolding over time, can also be a tool to set the mood and atmosphere of a place, used more instrumentally to enchant the physical world with that which is not present.

\section{Conclusion}

In the wilderness of Alaska stands an abandoned bus. In the bus, a notebook contains messages of people who have visited the bus over time. One message reads: Setting forth in the universe/Out here realigned/A planet out of sight/Nature drunk and high/Oh I'm free/I'm free ... The bus is the Magical Mystery Bus that plays a central role in the novel and subsequent movie Into the Wild. The lines in the notebook are part of the lyrics to the song "Setting Out" by Eddie Vedder, who wrote and performed the famous and successful soundtrack to the movie. The Magical Mystery Bus is an example of the attraction of imaginary worlds, as well as an example of the interplay of different media in creating and stimulating worldbuilding.

The Magical Mystery Bus is also a great example of the possible implications of the attraction of imaginary worlds. The novel, film, and soundtrack have each been huge commercial successes, alluding to the economic gains of stimulating the imagination - economic potential the literary, movie, and music industries play into. The bus itself has stimulated quite some media tourism, despite its hard-to-reach location in the wilderness of Denali National Park. The popularity of the bus and the dangers of reaching it finally prompted the local authorities to remove the bus from the wilderness in spring 2020. As this example shows, while the tourism industry and city marketers increasingly play into the potential of mediated narratives of place, local communities hold more ambiguous attitudes toward the sometimessudden increase in tourism flows. Thus, imaginary worlds have the power to transform people, communities, and industries.

Despite these important and ambiguous implications and consequences, the research on imaginary worldbuilding and related experiences is at its start. This edited volume is a contribution to further the understanding of the processes involved, and I would like to repeat the call voiced in the introduction to this volume: the wide-ranging consequences of imaginary worldbuilding make it imperative that we understand the underlying mechanisms and processes that make these worlds so powerful. How is the imagination 
stimulated, and how do audiences build and experience these worlds? Only by starting with these basic questions on the micro level of individual audiences can we get ahead in analysing and understanding what happens on the meso and macro levels of industries and societies.

These questions are especially relevant in the age of media convergence (Jenkins, 2004). With the rise of transmedia worlds and franchises, the focus of media industries, audiences, and scholars is increasingly shifting to everexpanding narrative universes, encompassing vastly diverging places, activities, experiences, and media. In this particular context, it is even more important to shift the focus to go beyond an analysis of the visual: how do media collide, how do they reinforce each other, how do new transmedia worlds remediate older ways of narrating and showing worlds of the imagination?

In this chapter, I have attempted to make a start with this endeavour by looking into one specific medium beyond vision: sound, and its wake, music. Through an analysis of 52 interviews with music listeners, I have shown the role of cognition in building musical imaginary worlds, how these worlds become affective worlds through music, and, finally, the way this process is necessarily embodied. Through the qualitative nature of this research project, I have been able to discuss in detail what specific role music's characteristics play in these processes.

First of all, music is able to evoke powerful imaginary universes, temporarily transporting listeners and audience members to a different "planet". Music seems to mediate between experience and imagination in four ways: through sound, through text and image, through biography of the artists, and through place. Sometimes this results in very vividly visual and specific imaginations, but more often, the interviewees talked about music conjuring up atmospheric ideas of places, influenced by cultural schemata of tropical paradise or nostalgic inner city. In all cases, musical imaginary worlds were based on memories, consisting of personal experiences; inherited memories from family and friends; or mediated memories installed by films, documentaries, and other images and photographs. During the interviews, this link with memory suggested the presence of a reflective nostalgia (Boym, 2001), which makes sense when compared to a narrow definition of imagining: to conjure up in the imagination that which is not physically there. This confirms that music indeed is able to stimulate the imagination through the general process of imagining described elsewhere (Lennon, 2015; Reijnders, 2016; Introduction to this volume), and that there are medium-specific connections to be made with regard to music (cf. Bolderman \& Reijnders, 2019).

Second, the analysis has shown that music plays a particular role in adding affective texture to experiences, showing the experiential side of imagining at play. The interviews showed how the process works in practice: listeners connect the feeling of listening to their imaginary of place. This allowed them to set the mood or influence the atmosphere of places, and, more importantly, this process explains how cognitive imaginary worlds are transformed into affective worlds. Moreover, the interviews consistently 
showed why elaborate imaginary worlds are so meaningful to the interviewees: they are symbolic of identity, both personal and collective. This finding is quite innovative, as it shows how cognition and affect are entwined in the imagination and why imaginary worlds are so powerful. Music allows a clear angle to explore these processes, because it channels, quite clearly and viscerally, a "sense of place".

Third and final, I have shown that music stimulates imagining in a particularly visceral and embodied way. Music as a sonic medium plays an important role in immersive experiences, as music is experienced in its unfolding over time. This specific sense of immersion through music emerged in two ways during the interviews, immersing interviewees in both time and place. With relation to temporal immersion, music offered a sense of absorption during live events, attending concerts, for example, or making music together. This immersive experience could be so intense, it has been analysed quite extensively in other research as an experience of absorption or flow. Dissolving a sense of time and identity, this experience was abundantly present during the interviews.

In relation to place, music offered an experience of immersion through its presence in local soundscapes, for example, by being present as local radio, as spoken language, and as sound environment. Interviewees also talked about actively seeking out this kind of immersion by layering music over their experience of the world. This could be done by adding music from memory, as musical imagery - hearing music in your mind - or by adding music to travel through playlists, setting the mood and atmosphere of place. This way, music united the experience of "being in the world", connecting to a broader definition of the imagination as the capacity to experience the environment.

In this chapter, I have shown that music is a focused and clear example of how the imagination works in practice, in both narrow and broader conceptualizations, adding to the fundamental understanding of this phenomenon. I have also argued that it is of value to look beyond the visual, especially if imagining is to be conceptualized as a broader mental capacity for understanding, a prerequisite for thinking and sensing the world around - more senses than the visual should be present in the analysis, if we accept that the imagination is based on our multisensory experience of reality. Even so, I do not ignore the importance of images and visual media in current media culture Western culture, at least, is a culture of the image. Since the media are audiovisual media, this chapter has been about redressing an imbalance, putting the visual in its place. A lot of research still remains to be done in the area of imagining, research that highlights and explores the mutual work between audiences and media in enchanting the world with something beyond sight.

\section{Bibliography}

Auslander, P. (2008). Liveness: Performance in a mediatized culture, 2nd ed. London: Routledge. 


\section{Leonieke Bolderman}

Bennett, A. (2002). Music, media and urban mythscapes: A study of the 'Canterbury Sound'. Media, Culture and Society 24: 87-100.

Bolderman, S.L. (2020). Contemporary music tourism: A theory of musical topophilia. London: Routledge.

Bolderman, S.L. \& Reijnders, S.L. (2017). Have you found what you're looking for? Analysing tourist experiences of Wagner's Bayreuth, ABBA's Stockholm and U2's Dublin. Tourist Studies 17(2): 164-181.

Bolderman,S.L. \& Reijnders, S.L. (2019). Sharing songs on Hirakata Square: On playlists and place attachment in contemporary music listening. European Journal of Cultural Studies. Advance online publication. https://doi.org/10.1177/1367549419847110.

Bowen, D.S. (1997). Lookin' for Margaritaville: Place and imagination in Jimmy Buffett's songs. Journal of Cultural Geography 16(2): 99-108.

Boym, S. (2001). The future of nostalgia. New York: Basic Books.

Charmaz, K. (2006). Constructing grounded theory: A practical guide through qualitative analysis. London: Sage.

Cohen, S. (2007). Decline, renewal and the city in popular music culture: Beyond the Beatles. Farnham: Ashgate Publishing.

Cook, N. (1990). Music, imagination, and culture. Oxford: Oxford University Press.

Couldry, N. (2015). Listening beyond the echoes: Media, ethics and agency in an uncertain world. London: Routledge.

Csikszentmihalyi, M. (1990). Flow: The psychology of optimal experience. New York: Harper Collins.

DeNora, T. (2000). Music in everyday life. Cambridge: Cambridge University Press.

Feld, S. \& Basso, K. (1996). Senses of place. Santa Fe: School of American Research Press.

Frith, S. (1996). Performing rites: On the value of popular music. Cambridge: Harvard University Press.

Genette, G. (1997). Paratexts: Thresholds of interpretation. Cambridge: Cambridge University Press.

Hesmondhalgh, D. (2013). Why music matters. Oxford: Blackwell.

Hudson, R. (2006). Regions and place: Music, identity and place. Progress in Human Geography 30(5): 626-634.

Jenkins, H. (2004). The cultural logic of media convergence. International Journal of Cultural Studies 7(1): 33-43.

Keightley, E. \& Pickering, M. (2006). For the record: Popular music and photography as technologies of memory. European Journal of Cultural Studies 9(2): 149-165.

Keightley, E. \& Pickering, M. (2012). The mnemonic imagination: Remembering as creative practice. Basingstoke: Palgrave Macmillan.

Kong, L. (1995). Popular music in geographical analysis. Progress in Human Geography 19(2): 183-198.

Lennon, K. (2015). Imagination and the imaginary. London: Routledge.

Malbon, B. (1999). Clubbing: Dancing, ecstasy and vitality. London: Routledge.

Malpas, J. (1999). Place and experience: A philosophical topography. Cambridge: Cambridge University Press.

Plate, L. (2006). Walking in Virginia Woolf's footsteps: Performing cultural memory. European Journal of Cultural Studies 9(1): 101-120.

Reijnders, S.L. (2016). Stories that move: Fiction, imagination, tourism. European Journal of Cultural Studies 19(6): 672-689. 
Reijnders, S.L., Bolderman, S.L., van Es, N. \& Waysdorf, A. (2015). Locating imagination: An interdisciplinary perspective on literary, film, and music tourism. Tourism Analysis 20(3): 333-339.

Smith, S.J. (2000). Performing the sound world. Environment and Planning D: Society and Space 18(5): 615-637.

Stokes, M. (1997). Ethnicity, identity and music: The musical construction of place, 2nd ed. Oxford: Berg.

Tuan, Y. (1974). Topophilia: A study of environmental perception, attitudes, and values. New York: Columbia University Press.

Turino, T. (2008). Music as social life: The politics of participation. Chicago: Chicago University Press.

Urry, J. \& Larsen, J. (2011). The tourist gaze 3.0, 3rd ed. Los Angeles: Sage.

Van Dijck, J. (2006). Record and hold: Popular music between personal and collective memory. Critical Studies in Media Communication 23(5): 357-374.

Waitt, G. \& Duffy, M. (2009). Listening and tourism studies. Annals of Tourism Research 37(2): 457-477.

Walton, K. (1994). Listening with imagination: Is music representational? The Journal of Aesthetics and Art Criticism 52(1): 47-61.

Waysdorf, A. (2017). Placing fandom: Film tourism in contemporary society. $\mathrm{PhD}$ dissertation. Rotterdam: Erasmus University Rotterdam. 


\title{
5 Space, lived culture, and affectivities in stirring imagination
}

\author{
David Crouch
}

\section{Introduction}

These promptings of enquiry necessarily take me into recent insights surrounding the complexity and nuance that is human life and how that living emerges in swirls of practice, memory, space, and time, along with a scatter of so-called wider, but often more incidental, influences marked in things like advertising, graffiti, or street signs, vibrating notions of class, ethnicity, gender, and age. Thus, cultural studies theorist and empirical researcher John Fiske (1989/2010) adroitly pursued the ground-breaking insight that situated popular culture is being made through human lives, not through outwardly influencing product promotions but based on cultural appropriations of those popular products within the context of everyday life.

In a deeper, more politically intent way, the cultural critic Raymond Williams pursued this kind of opening-up insight in terms of relations between everyday lives and more structural powers in his work on the structure of feeling that expounds that "culture is ordinary" (Williams, 1965). Williams considered and insisted that ideas, feelings, and values are always in process. So often, semi-popular writing on film, music, and other media "induction" of culture seems to be oblivious to the depth and quality of this whole range of cultural understanding. Moreover, is it not also more likely that high-scale media may produce and influence, mainly when it meets already existing tendencies towards a way of feeling, a connection in one's memory, a current awareness at other moments, and components of living?

In this chapter, I examine more recent contributions to our making sense of how imagination emerges, how creativity emerges and relates to imagination, and how both phenomena fit within a nuanced complexity of living. Of course, it is also necessary to introduce into this mixture or swirl of real life the possible influences of highly invested and stylized media by way of television, film, everyday newspapers, and popular and archival classical music as well as popular photography and other new art forms, literature on paper, and online. Yet in this chapter, my goal remains to illuminate our increasingly obfuscated everyday living as human beings (rather than consumers or tourists, just living people) and how this everyday context produces myriad 
resonances that may affect what we do and how we feel, in terms articulated as affectivities, atmospheres, and worlding. In other words, where does the multiplicity of difference amongst media "fit" in the embroilment of our lives?

Creativity is performative; it happens in living; it appeals because it is vital, a dynamic through which people live, individually and collectively. Hallam and Ingold explained: "creativity is a process that living beings undergo as they make their ways through the world. . . This process is going on, all the time, in the circulation and fluxes of the materials that surround us and indeed of which we are made - of the earth we stand on, the water that allows it to bear fruit, the air that we breathe" (Hallam \& Ingold, 2007: 2).

In this discussion, I focus upon the multiplicity of things, events, memories, actions, and performativities in which individuals are engaged, through which their imagination may be stimulated or ablated, stirred, or flattened. Closely akin to the notion of imagination sits the idea of creativity, and it is through this couplet, imagination and creativity, that the discussion progresses, with close attention to that swirl in and through which imagination and creativity may occur, may happen. Imagination, like creativity, is not located merely in the sphere of "cultural industries" or "creative people". Indeed, much of the time, contexts exemplified in "the media" flicker and affect but do not determine.

In particular, these considerations engage the anthropological thinking of Stewart $(2007,2011)$ on the atmospheres of everyday and far away space; philosophical work by Massumi (2002) and Manning (2009) on how affectivities occur, including engagement in tourism; and more tourism-explicit theorists who have made a number of distinct contributions to understanding tourism as an essentially human and also intersubjective process (e.g. Crossley, 1996). The anthropologist Ingold has tracked the occurrence of creativity that brings us close to locating imagination. Others, mainly anthropologists, close to making sense of the imaginative character and beingtourist are Hazel Andrews (2011), de Botton (2002), Ed Bruner (2005), and Sally Ness (2016), whose work individually and collectively is engaged with the humanizing of what we make of doing tourism and its hybrid or pervasive sites and practices of the imagination. I bring together progress in human geography, especially cultural geography, that further enlarges the significance of human action.

Throughout the pages that follow lies an insistence to critique the familiar emphasis, exemplified in tourism, of business as the producers of imagination. In the book The Media and Tourist Imagination, we first sought to challenge this duality (Crouch et al., 2005). The word Tourist in the title sets the scene for this refusal to find the tourists mere bystanders waiting for a fix. Here, my discussion works with insights that have been developed since. The section that immediately follows goes directly to the matter of locating. 


\section{Locating our thinking too}

The idea of locating could be taken to invite an approach that fixes the moment of being, of existence, whether human or other-than-human, as something that occurs in time and space. Or indeed, to focus a moment, it seeks a demarcation of the spatial in relation to an occurrence and indeed vice versa. There is, however, a more flexible way in which being located may affect the imagination. Imagination is not fixed but occurs, rather like creativity.

Hallam and Ingold (2007) focus upon the notion of cultural improvisation, which makes creativity universally available. There is a sense here, too, that perhaps because of the omnipresence of formalized, industrialist, and commercialized culture, as in film and kinds of musical and artistic performance, the everyday occurrent creativity may be submerged, obscured, even obliterated moment to moment by highly invested, often pseudo-crafted, mediated pressures. They change our thinking of creativity. Moreover, their ideas contrast with the notion that what people do in life is organized through a fixed plane of routine procedures. We are all able to be creative much of the time. Two further characteristics of creativity, and I argue this stretches comfortably to imagination, arise. The habitual and routine require adjustment and response, as the world and the way we feel at one moment and another. Our response to materials; tools; music; or an old, familiar photograph can be felt to take on another significance altogether. Doing tourism is performative and playful. Its adult play can reveal imagination and creativity. Taken seriously, play creates the desire to explore, to try something out - indeed, to "go further" in becoming (Crouch, 2010a: 63-82).

A more energetic, lively reading of creativity emerges from discussions of Deleuze and Guattari (1988). They do this in a way that brings our thinking around imagination into direct contact with space, at the same time sustaining the experience of living that includes affections. Their notion of space accommodates both place and space as a continual variation and an imagined rock of intimately felt reliability. That discourse is significant in terms of locating, too. Whilst locating imagination is our task as observers and interpreters of its emergence, as this chapter unfolds, our human relations with space in all its forms and characteristics turn out to be important and energetic components.

\section{Spaces and/of imagination}

For Deleuze and Guattari (1988), space consists of and exists in vitality and energy. Space is not merely here or there, as points with distances between, nor is it fixed in and by overriding governments, territories, and other structures. Space is more than their materials and their physical and metaphorical assemblage. Space is more and more understood as contingently related in flows, energies, and the liveliness of things - always in construction rather than fixed and certain. A space here or there may be felt to be constant, 
consistent, and uninterrupted, but that feeling is subjective and contingent. Indeed, Deleuze and Guattari argue that subjectivity works within the intensive capacity to affect and to be affected. They use the term spacing to introduce a fresh way of conceptualizing these process-dynamics of the unstable way in which space and life relate and participate in a world of vitalism. Spacing occurs in the gaps of energies amongst and between things: in their comingling. Their interest thus emerges in the middle of things, in the inbetween (Crouch, 2010a: 11-18).

As human beings, we act in ways that seek to engage the vitality of space. We are constantly seeking to go further, containing a sense of potentiality, and yet at the same time, we seek to hold on, to treasure and to be contained, having the feeling of being alive. As space emerges in our experience, practices, feelings, spaces, and affects commingle. We may project semi-conscious shapes and colours onto space, demarcating it as a "location", but this is unavoidably of at least practical subjectivity. Thereby, it is partly ours but partly also shared. Space may be affected by what a friend may have said, a fleck of memory of somewhere else, an earlier moment in this space, a television programme or a story we came across at random, or a film or sound we happen to have heard, positively or negatively.

I have been profoundly affected by the writing of another anthropologist, Kathleen Stewart, with regard to affect and atmosphere. In one of her recent papers, she describes these "atmospheric attunements" as follows:

Attention to the charged atmospheres of everyday life.... How circulating forces are generated as atmospheres per se, how they spawn worlds, animate forms of attachment and detachment and become the live background of living and living through things. Writing through several small cases selected out of countless potentially describable moments and scenes in which of something happening becomes tactile. I try to open a proliferative list of questions about how forces come to reside in experiences, conditions, things, dreams, landscapes, imaginaries, and lived sensory moments. How do people dwelling in them become attuned to the sense of something coming into existence of something waning, sagging, dissipating, enduring, or resonating with what is lost or promising? I suggest that atmospheric attunement are palpable and sensory yet imaginary and uncontained, material yet abstract. They have rhythms, valencies, tempos, and varied and changing lifespans. They can pull the sense into alert or incite distraction or denial.

(Stewart, 2011: 445)

Typically, Stewart silently informs us of her "research method" that nets the myriad components of lives and doings in observations and open conversations as well as hearing the background and the off-stage.

Stewart appeals because her abstractions work in articulating, sometimes even poetically, an ability to engage and relate numerous elements occurring 
in existence. Similarly, her space is fleshy, felt, malleable, shifting. "Things flash up - little worlds, bad impulses, events alive with some kind of charge" (Stewart, 2007: 68). Memory, across diverse and multiple spacetimes, can be jogged into new affectivities in the performative character of our actions (Crouch, 2003). Space is relational, subjective but also personal. The significant late geographer Doreen Massey articulated space to be a relative product or interrelations, connected through identities and entities that provide it with directions, scale, meanings, borders, and difference (Massey, 2005). A "contemporaneous plurality ... predicated on the existence of plurality" (ibid: 9), contingent upon those temporary moving relations that shape it by means of literature, metaphors, mathematics, art, and poetry. Space is a "simultaneity of stories-so-far" (ibid). It is Massey's "plurality" that calls attention to the multiplicities of attitudes, feelings, rememberings, directions, and happenstances that swirl in the moments of touring, which we may abbreviate as flirting with space, the feel of the possibility of becoming combined with uncertainty, the implicit if possibly agonizing hope of playfulness, contingent enjoyment, frustration, anxiety, and hope. In spacing, our emotions become alive in the tactility of our thought; any day, we can discover our life and its spaces anew (Crouch, 2005: 23-35, 2010a: 1-10). Numerous outward contexts (i.e. mediated from beyond our own lives) exist and may affect, yet not as primary or privileged but commingling unevenly with our ever-fluid memory, imagination and desires. These are all contexts that roll from moment to moment, gather, and break.

\section{Feeling, space, and knowing}

The art-influenced philosopher Erin Manning (2009) takes this approach further. "(A) feels the world. Watch her reading a book; she touches it, puts her face into it, listens to the pages rustling, smells it, looks at it. Becoming-bodies feel - with the world. Don't mistake feeling for emotion. Emotion is the rendering of an affect, feeling is its force" (ibid: 219). What is outward, a film, a book, a song, is meshed in and amongst our lives and feelings. Respectively, they do not take position in line, nor do they work in succeeding layers of significance and signification. Movement is foregrounded in diverse multiple atmospheres, not scales or layering in the sense of consecutively settled strata but sliced, dripping, and chopped into each other, commingling perhaps. What we call "the media" finds itself somewhere amongst these energies and movements in our lives. Manning argues a further animation of space:

This feeling - with its proprioceptive, immediately linked to our sense of balance, to our ability to space space. We don't need to put our hands on the walls to feel them, or to touch the ground to know where it is. Touch crossed with vision and sound field the environment, opening it to the relational multiplicity of movement, sensation, and space-time commingling.

(2009: 49) 
Atmosphere momentarily coagulates as the settings and contents of living and is full of life, as is space though spacing. The geographer Ben Anderson, like Stewart, finds that what matters about atmosphere is the ways in which it is actually lived, engaged, and made some sense of. Atmospheres change, multiply, contradictorily, amoebically (Anderson, 2009); so do the components and relations of the affective. Crucially, we may not be aware of being affected. Massumi puts it like this: "Affect as a whole, then is the virtual co-presence of potentials . . . our living bearing numerous possibilities in however modest ways that can merge, co-relate, affect. These potentials, as unexpected and unimagined possibilities, occur not only in our own self but in our relations with others, including the other-than-human and materialities" (Massumi, 2002: 203). In a direct consideration of art, Turions (2013) puts it this way: "Affect proved to be an elusive concept. ... Rather the force of manipulation that an artwork carries ... a tactic we use to press on each other" (also see Crouch, 2014, 2015).

Cultural geographer Hayden Lorimer emphasizes, too, the influence and affects we can find in our relation to "other than human" life (Lorimer, 2006). The philosopher Jane Bennett (2010: 109) argues:

to acknowledge the non-human materialities as participants in a political ecology is not to claim that everything is always a participant, or that all participants are alike. Persons, worms, leaves, bacteria, metals and hurricanes have different types and degrees of power, just as different persons have different types and degrees of power ... but surely the scope of democratisation can be broadened to acknowledge more non-humans in more ways in which we have come to hear the political voices of other humans.

As we gather and listen to, hopefully with sensitivity and depth, the responses of our "participants", it becomes clear that imagination emerges in us; it floats amongst things; it can be borrowed. Amongst these flecks emerge words, multiply expressed, and feelings become currency. As human beings, we do not need to leave capacities of imagination or creativity to the media and others particularly skilled - or not - in order to understand the imagination of tourism or anything else.... To do so makes a political as well as intellectual error in rendering importance, and power, by assuming what is thought important actually is. Moreover, we need to fragment the power to imagine and recognize its immanent presence in the complex whole of participants, energies, and atmospheres called life.

\section{Towards tourism and its filmic affectivities}

It is commonly presumed that where people go, and what they do there, is in response to particular mediated forms of knowing - in film, music, or other dominant contemporary cultural forms. Their imagination is stirred 
by it; their journey is shaped by its content; their potential for certain kinds of activities at particular times ruled by fashion. . . . In this way of thinking, people are positioned as recipients of imagination rather than making imagination themselves and consciously deciding to accept, appropriate, or reject these projected imaginations.

It is presumed that their journey is primed by the possibilities of the media. There is a prevalent idea that, in our time, perhaps the most powerful of such "inducements" rests in, or is owned by, film, expressed in the extreme term of film-induced tourism (Beeton, 2005), music-induced tourism, and so on. Familiar presumptions in cross-disciplinary contributions to the role of tourism in contemporary culture habitually locate cultural affects outside the intimacy of individuals' lives. In such a scenario, tourist imagination is constituted from "the outside". It follows that being-tourist is a matter of separation from everyday life and its living. Tourism equals escape, a labelling that immediately prioritizes the businesses' image of wonder in what, even more strangely, is applied to anywhere one may visit or go, whether that be a church, temple, rocky beach, mountain, local lake, or sea. Each is habitually characterized as a tourism product, each habitually transformed into a "destination image". Even if the "destination" is powered by, for example, dance events, these destinations are still the product of human activity - and human imagination - but not of the tourism industry. So whose imagination is actually at work?

That the word "induced" seems to be applied to an act and affectivity of any media is bemusing, rendering a character of giving birth (cf. Beeton, 2005). At its core, the word "induced" implies to bring about, to persuade, to convince, even to cause. In this discussion, I seek to examine what happens surrounding the doing or practice of tourism, being tourist, and so on. I am particularly concerned with entering and evaluating the nuance and complexity, indeed of feeling, as well as knowing, in which the individual (a part-time tourist, of course) engages. Enhancing such insight promises a fuller understanding of what is at play.

Thinking like this shares character with John Urry's (2011) widespread idea of the tourist gaze, the infectious enthusiasm for a one-dimensional reading of what people do and how they "consume" place based on certain "injected" media images; in the extreme, perhaps, the notion of beaches, mountains, even mosques, churches, temples are being constituted by tourism institutions as tourism products, a rather far-fetched notion by any standard. One more notion in a linked panoply of errors amongst tourism studies that may deserve fuller understanding is the romancing of mobilities, as though the whole world was on a big trip (Urry, 2007; Cresswell, 2006). In his defence, Urry proclaimed that distinctiveness amongst social groups born of strategies of mobilities is as important in understanding and explaining society as ethnicity, gender, class, and age in terms of social structure and difference (Urry, 2007). So often each of these "understandings" plays to the notion that much is led by business alone. People are enumerated in 
huge surveys that identify "truth" by statistical presumption. The tourist gaze hardly squares with the nuance and complexity of flirting with space; Manning's enlightenment concerning feeling; and Stewart's atmospheres, affects, and attunements. The latest edition of The Tourist Gaze does take into consideration early critique on the notion of the tourist gaze but fails to progress to these enlightenments offered by Manning, Stewart, and others (Urry \& Larsen, 2011).

In this chapter, the ideas of space and spacing are examined to consider how this character of emergence of imagination may involve some commingling with space and spacing. The ways and extent to which imagination may be brought forward by impulses and assertions, encouragements or accidents, may involve other ways of imagining, an imagining that may arise from energies and affects closer to individuals' lives.

Moreover, the pursuit of the multiplicity of actors, not merely participants surrounding and producing imagination, requires some attention to both imagination and another energy of things in relation, creativity, and considerations of the origin, purpose, and affectivities of play. In handling spacing, placing and positioning the multiple flows of moments rather than in fixed points of imagination rather than locating being merely a linear recourse to popping each component into a sequential position, individuals engage these flows with uneven and sometimes commingling acts of spacing (Crouch, 2010a, 2017).

I worked on a project with a professional photographer and film maker in an exploration of the possibility of projecting a re-imagination of locations of tourism attraction. Richard Grassick was a founding member of the Newcastle-based Amber Films. Sharing attitudes towards the overburden of particular filmic and otherwise promotional efforts to bind a region of Britain into a particular narrative, we set out to make in the first place a documentary-style photographic narrative of everyday lives in homes, workplaces, local community venues, pubs, and so on, as "People of the Hills" (Grassick \& Crouch, 1999; Crouch \& Grassick, 2005). The dominant narrative of the locality is "The Land of the Prince Bishops", whose importance dates from the best part of a millennium ago and whose influence survives in land ownership, castles, and power in local cultural reference. The contemporary regional corporate presentations project and promote a dominant culture and context through which visitors will - so they hope - experience ideas and values and maybe discover imagination: a "tourist product", though produced over nearly a millennium.

Supported by local funding, the Hills project might be understood or "consumed" [sic] as another facet of things to get into a visitor itinerary. Or it may be found as an alternative set of voices in the land, inscribing the daily lives, feelings, and attitudes of individuals working and living in the locality and their enjoyments and pastimes, pressures and concerns. This was only a small project but one that might be inspiring for others interested in multiplying the facets of experience and knowing 


\section{David Crouch}

amongst visitors whilst at the same time lending empowerment to local people beyond the marginal income from tourist letting. Throughout the project that stretched over more than two years, photographs and voices of the photographed were taken to many different venues in villages surrounding the area and its people photographed, enabling feedback and mutual participation. Projects such as this make possible a stir of locals' and visitors' imaginations; prompts, alternative attitudes, or atmospheres of almost-familiar locations that challenge other, prevailing commercial producers of imagination. Thankfully, recent years have seen increasing examples of similar artistic interventions in encouraging these open, collective, and grass-roots types of imagining place (Crouch, 2010a: 103-117).

Compare how the anthropologist Ed Bruner (2005) recounts the way individuals tend to talk about "home" when they are, supposedly, "away". Another anthropologist, Hazel Andrews, identifies the doings of particular groups of English visitors on charter trips to Magaluf with an assertion, a realization of Englishness, in, for example, all-day English breakfasts and, alas, sexist and racist events, that they feel denied back home, thereby feeling they can "hold on" to their identity whilst "away" from "home" (Andrews, 2011). Ness downplays the familiar "casting" of Yosemite in the glow of nation as a component of "home". Instead she identifies how, in walking and climbing, visitors to Yosemite National Park feel what matters there through the bodily "performance", knowing the feel of the rocks and tracks in a multiple range of performativities combined in a doing informed by previously spending time in similar sites or previous visits to this same location (Ness, 2016). In this they, too, discover becoming, a "going further", going beyond, outside a mediated script. In each of these examples, the significance of "home" is in its near-inducement of individuals' choice of tourism location. The location of their imagination is in everyday activities, connections, practices. Embedded in this, perhaps, is the significance of holidays spent visiting friends and relatives, often unrealized as the most popular form of vacationing.

Engaging with Colapietro's observation on the multiplicity of affectivities, Ness (2016: 23) explains:

The shift from representation to mediation reinforces the dance-like character of the pragmatic sign, rhetorically conceived. . . . Asserting that the play of relationships-in-movement in which all kinds of signs participate agentively can matter - can "bear fruits", or make differences ... . even when play entails nothing that could be identified as representational. Signs ... do not have to "stand for" to make sense. They can move (in-)formally as well.

For Tim Winter, the experience of Angkor Watt is mixed with being together with friends and family members. "Being there" is constituted by 
the feeling of having other people around and by memories from elsewhere (Crouch, 2010b). He situated his approach as follows:

Constructing an account of the tourist encounter around a subject centred temporality reveals the dynamics which facilitate the formation of a series of collective identities. More specifically, it will be seen that in addition to being rendered meaningful through the presence of imagined pasts and futures, an encounter with Angkor actually serves to give meaning to an abstract Cambodian history.

As the philosopher Alain De Botton (2002) skilfully narrated, autobiographically, we take our lives with us when we go away: relationships, ideas, feelings of belonging and wanting to "get away". I recall a Guardian newspaper travel editor remarking to me informally at a conference in the United Kingdom a quarter-century ago that most people seem to want to know they will be largely secure when away from home: times of meals, even television schedules. The media, including film, unmistakably can contribute to the shaping of our anticipation of holidays. These join an enormous diversity of features, impulses, and affectivities that constitute our feel and grasp of what we may like to do, whom we may like to be with, and where we may do so.

However, along with the notion of tourism being, even in very specific cases, predominantly film-induced, the too-easy label of such a thing as a "tourism bubble" similarly can be disrupted. The experience and practice of a holiday does not dispense with everyday life for the holiday duration. It may be unthought for a while, just as many moments, feelings, and events can be in any day we live. It is vital for our enquiries to do as these investigations have done: to go beyond finding how and how much this or that mediation affected and effected decisions and liking for kinds of trips, that way dramatizing what it selects. The rich challenge is to go beyond these and do so more deeply, relating different impulses, unpicking the complexity and nuance in life. Hence a more involved "research method" is required, one that relates rather than isolates.

Living happens in fluid, uncertain, and changing moments and memories. This everyday character of living, with its various time trajectories, is contextual, too - it shapes our ongoing feelings about life. It is amongst the multiplicity of things, events, memories, actions, and performativities through which we discover in a habitual and unrehearsed way and through which we move from "being" to "becoming", in which individuals are engaged and amongst others share, that we might term the art of "flirting with space" (Crouch, 2010a).

\section{Concluding observations}

Our doings, relations, and identities constitute and give character to the dynamic web that is culture. Another commingling, another resistance or 


\section{David Crouch}

avoidance, another creativity occurs. Thus, the liveliness of space is dynamic: iterative, variously felt, existing. It is into this pulsating mixture, this milieu, this atmosphere, that outwardly produced events and their media implant. Numerous multiple contexts flicker and nudge, not as primary or privileged but as part of our living, commingling with our ever-fluid memory, imagination, and dreaming desires. We listen to friends and exchange our memories of stories, even from childhood, envision the future and evoke spaces we knew, know, and might like to know. These moments are all contexts that roll moment to moment and gather and break. In these processes and practices, we become. We become creative, we imagine; we may imagine with the connection or disconnection that a new impulse, a film, a sound may incite as a stone in the water, as it slips into our living.

If we seek to discover the impact of, for example, an imaginative film or musical score, we should do so by starting with the question whether each may have been felt to be influential on a decision we may make. Inevitably, that focuses on the film or musical score and privileges this object on which we have chosen to focus. By prioritizing and privileging that object, its popularity is enhanced. But in the end, it may have been only one affect amongst numerous others. It is important to acknowledge and to celebrate everyday imagination and its spurs to creativity; let's acknowledge the everyday imagination that makes those affects possible in the first place.

\section{Bibliography}

Anderson, B. (2009). Affective atmospheres. Emotion, Space and Society 2: 77-81.

Andrews, H. (2011). The British on holiday charter tourism, identity and consumption. Bristol: Channel View Press.

Beeton, S. (2005). Film-induced tourism. Bristol: Channel View Press.

Bennett, J. (2010). Vibrant matter. Princeton: Princeton University Press.

Birkeland, I. (2005). Making place, making self: Travel, subjectivity. Farnham: Ashgate.

Bruner, E. (2005). Culture on tour. Chicago: Chicago University Press.

Cresswell, T. (2006). On the move. London: Routledge.

Crossley, N. (1996). Intersubjectivities. London: Sage.

Crouch, D. (1999). Leisure/tourism geographies. Practices and knowledge. London: Routledge.

Crouch, D. (2003). Spacing, performing, and becoming. Tangles in the mundane. Environment and Planet A 35(11): 1945-1960.

Crouch, D. (2005). Flirting with space: Tourism geographies as sensuous/expressive practice. In: C. Cartier \& A. Lew (eds.), Seductions of place. London: Routledge.

Crouch, D. (2010a). Flirting with space: Journeys and creativity. London: Ashgate/ Routledge.

Crouch, D. (2010b). The perpetual performance of heritage. In: E. Waterton \& S. Watson (eds.), Culture, heritage and representation. Farnham: Ashgate.

Crouch, D. (2012). Meaning, encounter, performativity: Threads and moments of space times in doing tourism. In: L. Smith, E. Waterton \& S. Watson (eds.), The cultural moment in tourism. London: Routledge. 
Crouch, D. (2014). Review essay: Reading/feeling. Emotion, Space and Society 12: 118-119.

Crouch, D. (2015). Afterword. From affect to landscape and back. In: N. Campbell \& C. Berberich (eds.), Affective landscapes in literature, art and everyday life. Farnham: Ashgate.

Crouch, D. (2017). Space, living, atmosphere, affectivities. In: M. Nieuwenhuis \& D. Crouch (eds.), The question of space: Interrogating the spatial turn between disciplines. London: Rowman and Littlefield.

Crouch, D. \& Grassick, R. (2005). Amber films, documentary and encounters. In: D. Crouch, R. Jackson \& F. Thompson (eds.), The media and the tourist imagination. London: Routledge.

Crouch, D., Jackson, R. \& Thompson, A. (eds.). (2005). The media and the tourist imagination: Converging cultures. London: Routledge.

De Botton, A. (2002). The art of travel. London: Hamish Hamilton.

Deleuze, G. \& Guattari, F. (1988). A thousand plateaux. London: Athlone Press.

Fiske, J. (1989/2010). Understanding popular culture. London: Routledge.

Grassick, R. \& Crouch, D. (1999). People of the hills. Newcastle: Amber/Side Gallery.

Hallam, E. \& Ingold, T. (2007). Creativity and cultural improvisation: An introduction. In: E. Hallam \& T. Ingold (eds.), Creativity and cultural improvisation, pp. 1-24. Oxford: Berg.

Lorimer, J. (2006). Nonhuman charisma: Which species trigger our emotions and why? ECOS 27: 20-27.

Manning, E. (2009). Relationscapes. Movement, art, philosophy. Cambridge: The MIT Press.

Massey, D. (2005). For space. London: Sage.

Massumi, B. (2002). Navigating moments (in conversation with Mary Zournazi). In: M. Zourzani (ed.). Hope: New philosophies for change, pp. 210-243. Annadale: Pluto Press.

Ness, S. (2016). Choreographies of landscape. Signs of performance in Yosemite. Oxford: Berghahn.

Smith, L., Waterton, E. \& Watson, S. (2012). The cultural moment in tourism. London: Routledge.

Stewart, K. (2007). Ordinary affects. Durham: Duke University Press.

Stewart, K. (2011). Atmospheric attunements. Environment and Planning D: Society and Space 29(3): 445-453.

Turions, C. (2013). Untitled. In: T. Baudoin, F. Bergholtz, \& V. Ziheri (eds.). Reading/ feeling. Amsterdam: If I Can't Dance, I Don't Want to Be Part of Your Revolution.

Urry, J. (1990, and with Larsen 2011). The tourist gaze. London: Sage.

Urry, J. (2007). Mobilities. London: Sage.

Williams, R. (1965). The long revolution. Harmonsworth: Penguin.

Winter, T. (2007). Landscapes in the living memory. In: N. Moore \& Y. Wheelan (eds.), Heritage, memory and the politics of identity. New perspectives on the cultural landscape, pp. 133-147. Farnham: Ashgate. 
$\because$ Taylor \& Francis

Taylor \& Francis Group

http://taylorandfrancis.com 
Part II

Mediating place 
$\because$ Taylor \& Francis

Taylor \& Francis Group

http://taylorandfrancis.com 


\section{Screening the west coast}

\section{Developing New Nordic Noir tourism in Denmark and using the actual places as full-scale visual mood boards for the scriptwriting process}

\section{Anne Marit Waade}

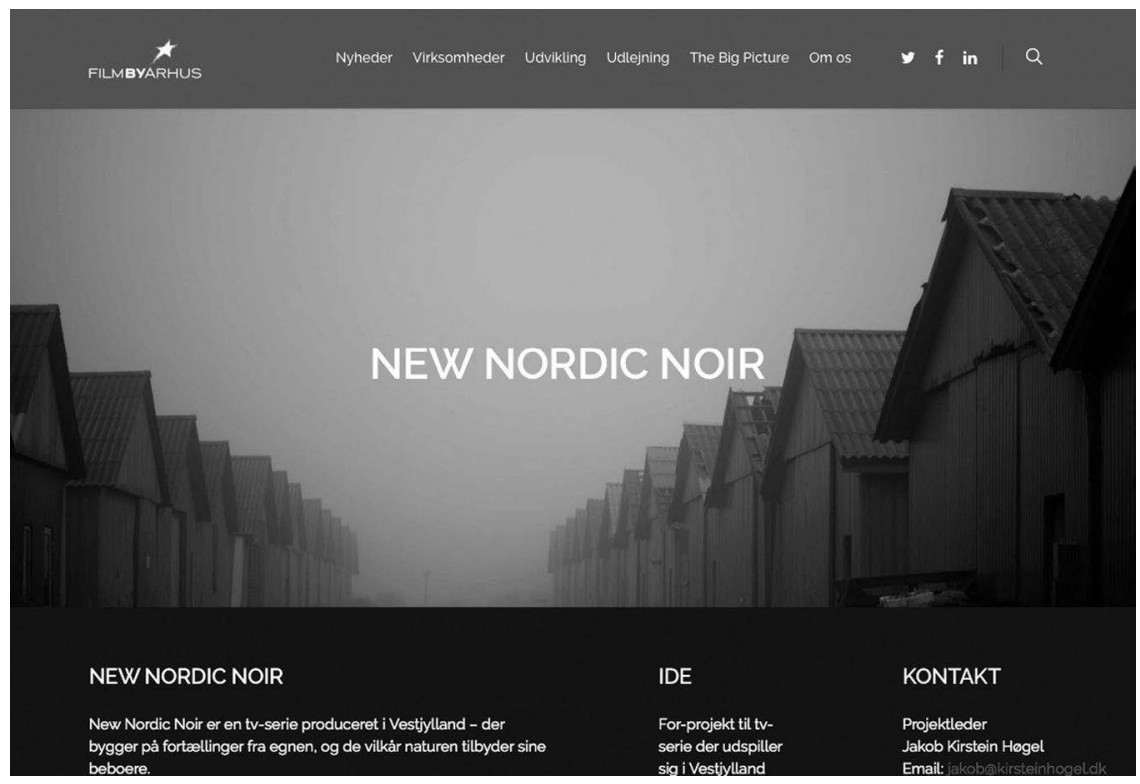

Figure 6.1 Filmby Aarhus' New Nordic Noir initiative encompasses ideas for several site-specific drama series, including an online, playable platform called The West Coast Universe, developed in close collaboration with Ringkøbing-Skjern municipality on the west coast of Denmark. The picture shows the German harbour in the popular tourist destination of Hvide Sande, one of the potential locations in the series and the online platform.

Source: Filmby Aarhus website. Reproduced with permission.

\section{Introduction}

Drawing on the international popularity of Nordic Noir crime series, New Nordic Noir is a project initiated by the regional media cluster Filmby 
Aarhus to develop a new kind of "site-specific" crime series to attract international viewers and tourists and to create new co-production business models within the screen industry. The New Nordic Noir project is based on specific location and local investments; the ideas for the series are based on the actual landscapes, stories, and heritage of the coastal municipality of Ringkøbing-Skjern (RKS) in Denmark; and the series will be shot on the west coast of Denmark. So far, the project encompasses ideas for three distinct drama productions, all of which are still under development, with the first one due to be aired in 2021.

In this chapter, I will give a brief introduction to Nordic Noir tourism based on crime fiction and crime drama series from the region, such as Wallander (Ystad), The Girl with the Dragon Tattoo (Stockholm), The Killing (Copenhagen), Dicte (Aarhus), The Bridge (Malmö and Copenhagen), and Trapped (Reykjavik). The significant use of Nordic locations, climate, light, and seasons in Nordic Noir crime series fascinates viewers around the world (Creeber, 2015; Roberts, 2016; Jensen, 2016; Hansen \& Waade, 2017). In continuation of this, I will present my empirical material based on the New Nordic Noir case study. I have followed the initial phase of the process, also called pre-preproduction (Wille, 2015), and the "screen idea development" phase (Redvall, 2013). My focus has been to study the role of locations in this early stage of the production process, as well as studying cross-sectoral collaboration. The modes of collaboration encompass collaboration between the culture, tourism, and strategic planning divisions of the municipality itself on the one hand and strategic partnerships with commercial players such as media producers and tourism agencies (as well as public partners such as museums and academic institutions) on the other. The study is part of the ongoing "Rethinking Tourism in a Coastal City" innovation project, which is funded by the Danish Innovation Fund.

This chapter contributes to the study of screen tourism in four distinct ways. First, it describes Nordic Noir tourism as a cultural phenomenon involving the significant use of locations, climate, and landscapes. Second, it illuminates an aspect of the production of "location imagination" which is often overlooked and hidden, since it takes place even before drama series are produced and broadcast. As such, the study draws attention to the imaginations, discourses, and expectations about landscapes that are already in play at the pre-production stage. For example, the way in which different imaginations of the coastline are embedded in cultural and historical contexts represents a hybrid landscape (Cosgrove, 1998; Urry \& Larsen, 2011). Third, the study focuses on screen tourism as a form of cross-sectoral collaboration and partnership. Until now, screen tourism has most often been studied from the tourism point of view, either in terms of destination marketing strategy (Beeton, 2005) or in terms of tourist experiences (Reijnders, 2011). This study thus broadens the scope and looks at the specific modes of dialogue and collaboration that take place across sectors and industries. Finally, the study 
reflects a new participatory and co-operative role of the researcher in screen tourism research and thus contributes to the location study approach in new and significant ways (Hallam \& Roberts, 2014; Hansen \& Waade, 2017).

\section{Nordic Noir tourism}

Scandinavian crime fiction has reached out to fans and readers around the world for decades, and authors such as Henning Mankell, Liza Marklund, Stieg Larsson, Jon Nesbø, and Jussi Adler Olsen have become extremely popular. Their books have been translated into many languages and exported to a number of continents and countries (Bergman, 2014; StougaardNielsen, 2017). Following this popularity, Nordic crime series have also been acknowledged internationally. The term "Nordic Noir" started popping up in news media and among fans back in 2010 just after the Danish public-service drama Forbrydelsen (The Killing, 2011-2014) hit the British television market (Agger, 2016; Redvall, 2013; Hansen \& Waade, 2017). Parallel to this story, fans, viewers, and readers of these popular crime stories started to travel to Scandinavia to take a closer look at the places where their favourite stories took place and where the series were shot. In fact, we have had screen (and literature) tourism within the Nordic region for a long time before Nordic Noir occurred, for example, tourism focusing on Astrid Lindgren (Pippi Longstocking, Sweden) as well as Thorbjørn Egner's (Kardemommeby, Norway) amusement parks and the Moomin museum in Finland related to Tove Jansson's works. However, until now, these attractions have primarily drawn domestic visitors and families from the other Nordic countries (Sjöholm, 2011).

In the early 2000s, the first German Wallander fans came to the local police station in Ystad and asked for inspector Kurt Wallander. The Swedish bestseller crime series is by Henning Mankell, and the media franchise consists of 12 novels and four TV series, of which there are one Swedish adaptation (SVT, 1994-2007) and one British adaptation (BBC, 2008-2016), starring Kenneth Branagh as the main character, and two spinoff series based on the characters from the novels, respectively, the Swedish series called Wallander (Yellow Bird, 2005-2013), starring Krister Henriksson as the main character, and the more recent Netflix series Young Wallander (2020-). The story about Wallander takes place in the small coastal city of Ystad, and the television series are shot in the city. When the German visitors asked for Wallander, the police officer was surprised that they could mix fiction with reality, but after a second, she decided to answer that Kurt unfortunately was not at work and suggested instead that they visited Mariagata, where Kurt Wallander lived (McClintock, 2010). In fact, this was the very beginning of Nordic Noir tourism, and it marked a new paradigm for the popular Scandinavian crime stories - they were no longer only books and television series that one could read and see but also destinations that people could visit. Parallel to this, we have also experienced a Nordic wave that included 


\section{2}

a global interest in food, design, and architecture from the region - as well as a more recent interest in Arctic destinations and winter tourism in the Nordic region. As Jon Sadler, the distributor of Nordic crime series on the British market, explains, it was not only the series and the stories themselves that fascinated the audiences but also an interest in the Nordic region itself: its culture, nature, and way of living:

They [the viewers] just became very interested in design as well as fashion and interior. People want to learn about tourism and culture, so why just tell them about upcoming DVD box sets? Maybe we should also be telling them about the different tours they can do, the places they can visit.

(cited in Hansen \& Waade, 2017: 2016)

The fans, readers, and viewers of Scandinavian crime fiction and crime series are relatively well educated and relatively well off. In terms of age, they are $40+$ (Jensen, 2016), and in a tourism context, this is a very strong segment with the resources needed to travel and an interest in doing so. In Ystad, the local tourism and culture division decided to take advantage of the new interest in the town and developed a wide-scale film tourism policy to attract tourists and engage local investors, institutions, and citizens. Wallander tourism has developed into a very successful and sustainable form of tourism (Waade, 2013), inspiring other destinations within the region as well as new collaborations across the creative, business, and tourism divisions of local municipalities. Here are some examples of this development: Millennium tourism in Stockholm (based on Stieg Larsson's Millennium Trilogy), Forbrydelsen tourism in Copenhagen (based on the television series The Killing), Bron tourism in Malmö (based on the television series The Bridge), Fjällbacka tourism on the west coast of Sweden (based on Camilla Läckberg's Fjällbacka Murders books), Dicte tourism in Aarhus (based on Elsebeth Egholm's books), and Trapped tourism in Reykjavik (based on the television series). The significant use of Nordic locations, climate, light, and seasons in these crime series has fascinated viewers around the world (Creeber, 2015; Roberts, 2016; Saunders, 2017; Jensen, 2016; Hansen \& Waade, 2017).

Even though there are many examples, the number of screen tourists visiting each place is quite small, and in general, Nordic Noir tourism cannot be regarded as a big industry. However, screen tourism is something that news media wants to cover. Furthermore, the fact that the viewers can visit locations from global media franchises such as The Hobbit (New Zealand), Harry Potter (London), and Sex and the City (New York) becomes part of the buzz and brings both extra funding and marketing to the production; screen tourism has increasingly become part of the business model for recent television drama series, both on local and transnational levels. For example, Game of Thrones has developed screen tourism as part of its business model 
by initiating partnerships with local film producers and tourism agencies in places such as Northern Ireland, Dubrovnik, Barcelona, and Iceland.

Screen tourism destinations offer visitors the chance to experience their favourite characters and stories first hand. They can see the places where the stories take place and the places where the series are shot. Screen tourists are keen to get close to the fictional world and to get behind the scenes and the production (Beeton, 2005; Månsson, 2015). Sometimes there are guided film tours and exhibitions showing the celebrities, locations, and set, with anecdotes being told by the crew. In other examples, there are online maps and mobile apps with a lot of routes and background information. For Nordic Noir series, it is particularly the Nordic landscapes, the cold (in some cases arctic) climate, the strong female characters, the gender equalities, and in general the Nordic welfare society and way of living that have fascinated the readers, viewers, and visitors. These elements have become selling points also when developing Nordic Noir tourism within the region (Roberts, 2016; Waade, 2018). This is the case for Trapped in Iceland, The Bridge tourism in Malmö, or the murder mystery tour in Fjällbacka in which you can "follow in the literary footsteps of Fjällbacka's queen of crime, Camilla Läckberg, and see the crime scenes she describes with your own eyes" (Fjällbacka Information, 2020; Hansen \& Waade, 2017).

\section{The New Nordic Noir case study}

New Nordic Noir is a project initiated in 2016 by the media cluster Filmby Aarhus with start-up funding from "Aarhus2017" (Aarhus was a European Capital of Culture in 2017). The idea was to develop a site-specific, transmedia crime drama series in collaboration with the coastal municipality of RKS. By calling the initiative New Nordic Noir, Filmby Aarhus sought to take advantage of the international popularity of Scandinavian crime series, as well as focusing on the Nordic rural landscapes, like many other recent crime series from the region (Roberts, 2016; Hansen \& Waade, 2017). Since the first initiative, ideas for more than one series have been developed, and at the moment, the project encompasses three different ideas that are still at a very early stage. At the same time, Filmby Aarhus and the RKS municipality are collaborating to develop an online playable platform called The West Coast Universe, using an open design process in which local institutions such as the historical museum and NaturKraft are engaged as well as the National Museum in Copenhagen, gaming and digital design companies, architects, and researchers. At this stage, they are still brainstorming about what the platform might look like and what kind of technology (open-source gaming software, augmented reality, etcetera) should be employed. The overall ambition has been that local places and history should play a significant role in the crime series as well as in an online platform with games and background information titled The West 


\section{Anne Marit Waade}

Coast Universe linked to the story in the television series. The series will also be shot within the municipality.

In addition to the New Nordic Noir project, the RKS municipality has also been involved in an innovation project called "Rethinking Tourism in a Coastal City" (2016-2019), funded by the Danish Innovation Fund. I became involved in the New Nordic Noir initiative as part of my engagement in the tourism innovation project. Despite the fact that RKS already has a strong tourist industry, the municipality had never been involved in screen productions or screen tourism before. Since my own field of expertise is television drama production and screen tourism, I was glad to help. My role as a researcher was thus not only to study the processes as they took place but also to contribute to the creative development process through participatory observations.

The New Nordic Noir initiative started with an on-site writing workshop in Hvide Sande (September 2016) aiming to train young European scriptwriters in developing strong ideas for crime series based in specific

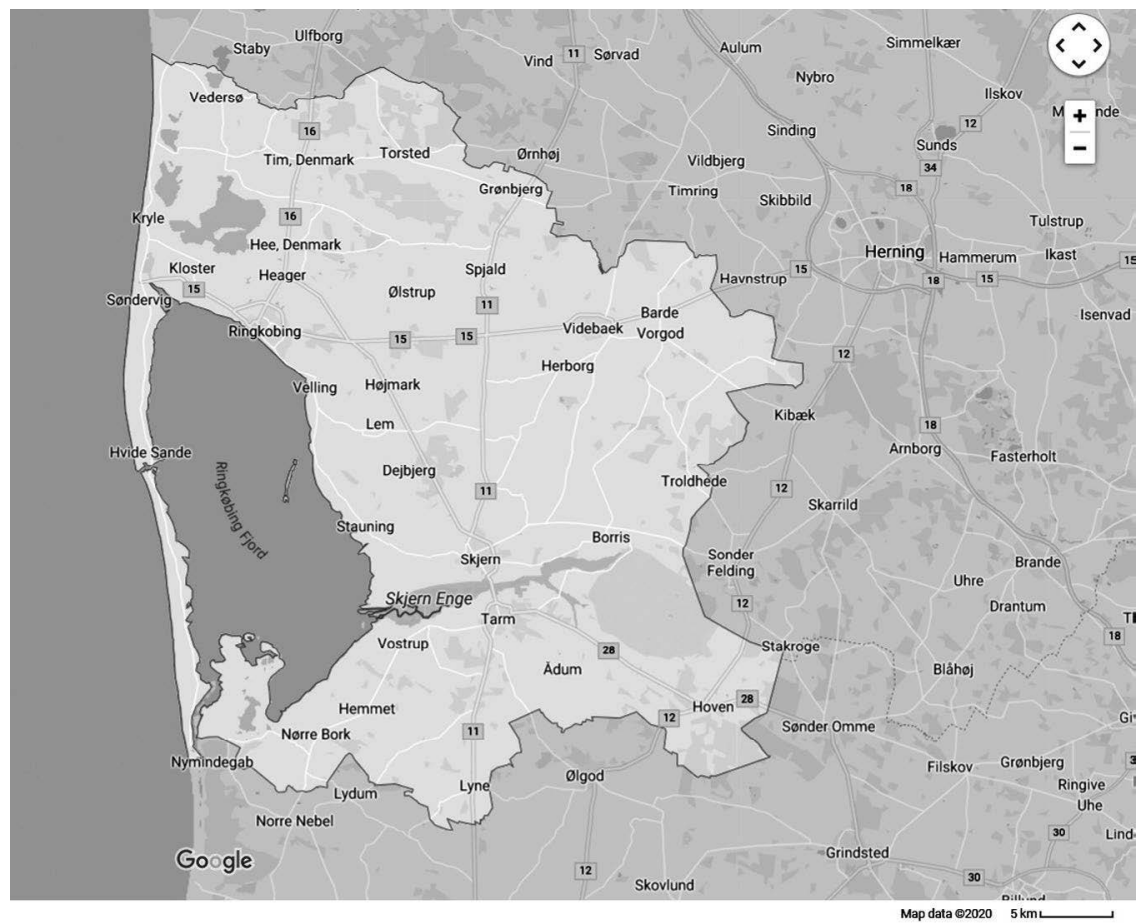

Figure 6.2 Ringkøbing-Skjern municipality on the west coast of Denmark. Hvide Sande is a small fishing harbour and popular tourist destination.

Source: Google (n.d.). 


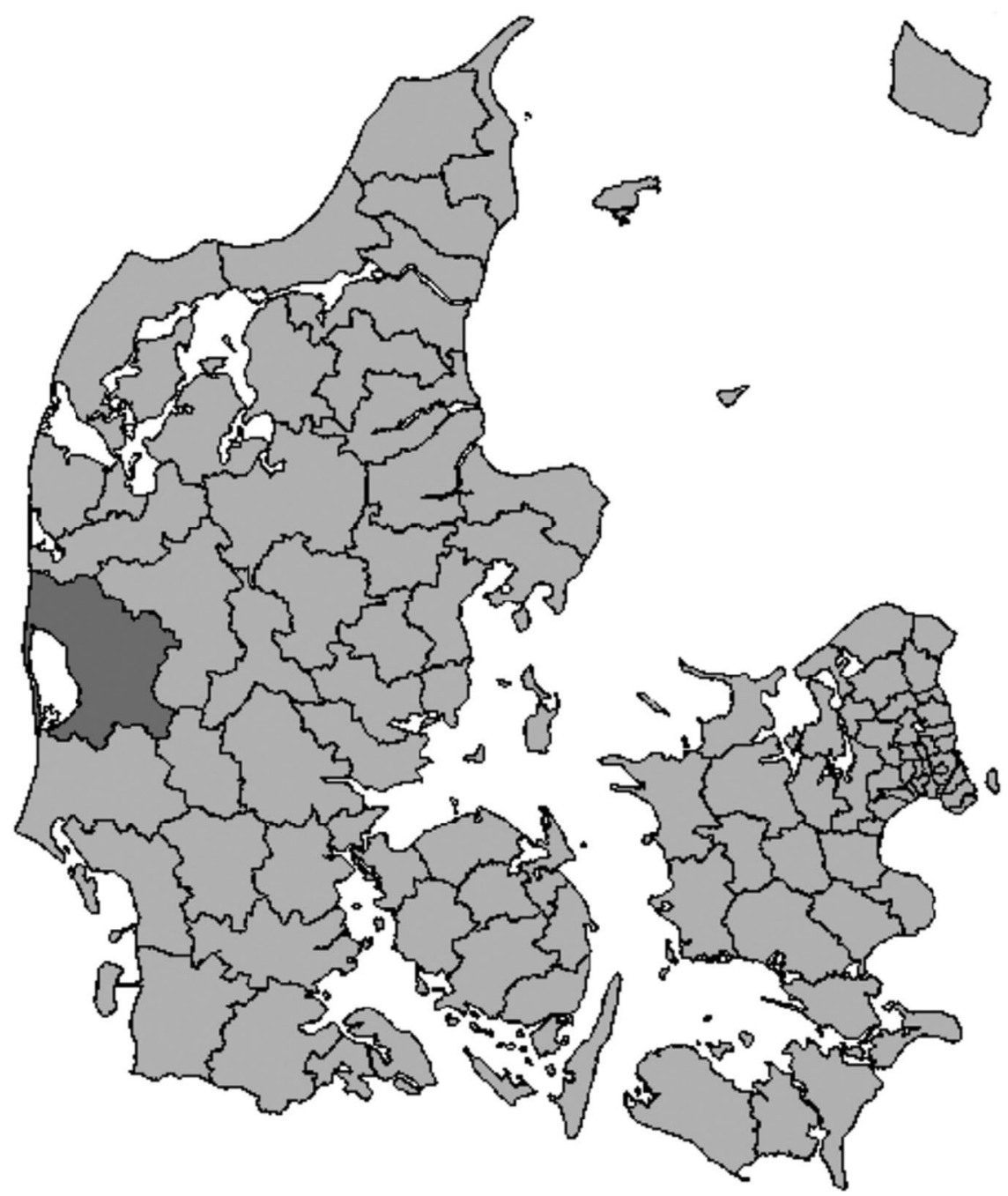

Figure 6.2 (Continued)

locations. In April 2017, Filmby Aarhus hosted a pitch seminar in Hamburg in which they paired Danish and German production companies and asked them to present ideas for a new drama series. At that point, the German film cluster Filmförderung Hamburg Schleswig-Holstein was already on board, and Filmby Aarhus was in contact with the Danish broadcaster TV2 and later the public-service broadcaster DR. In August 2017, the three writing teams attended a creative writing workshop in Hvide Sande together with 


\section{Anne Marit Waade}

the producers to develop their screen ideas further. One of the writing teams will finish their script by the end of 2018, and the plan is that the pilot for this series will be shot in the summer of 2019, with the series being shot in 2020 and premiere in 2021. At the same time, Filmby Aarhus and RKS municipality are co-hosting workshops for various stakeholders and creative partners to develop ideas and business models for the West Coast Universe.

\section{Methodological considerations: screen idea development and tourism intervention}

This chapter is based on three overall methodological approaches: the location study (Hansen \& Waade, 2017), the screen idea development study (Redvall, 2013), and place interventions as part of a creative innovation (Waade et al., 2018). In general, when dealing with the relationship between mediated and imagined geographical places, the semiosis of local colour, it is important to distinguish between: 1) the physical, geographical place; 2) the mediated place as it occurs in print, television, film or web; and 3) an individual's imagination of the place (Hansen \& Waade, 2017: 41; Falkheimer \& Jansson, 2006; Waade, 2013). The cultural meaning of a certain place or tourist destination is embedded in the interweaving meanings based on these three different aspects. With regard to New Nordic Noir, the physical, geographical place is a particular part of the west coast of Denmark, namely the harbour town of Hvide Sande and its surroundings. The mediated place in this context does not yet exist because the production is still in its initial phase. For example, genre-specific elements and conventions about locations in the crime genre will influence the production when it starts. The individual's imagination of the west coast of Denmark that I study in this context includes the people involved in developing the screen idea such as the scriptwriters, the producer, the film advisor, the head of culture, the head of tourism, the local stakeholders, and their strategic partners. With a view to gaining insight into their ideas and imaginations, I have met and talked to them, as well as taking part in workshops and events. The study thus includes observations and interviews.

The study of narrative places and shooting locations is a new interdisciplinary approach drawing on aesthetics, cultural analysis, media studies, and geography and is a way to empirically study how locations influence and are reflected in actual screen productions, both on and off screen. The off-screen conditions encompass how the local screen industry facilities and expertise, the geographical place, the local policies and funding opportunities, tourism, and more general cultural conditions may influence the way that locations are displayed on screen (Hansen \& Waade, 2017: 57). The on-screen location factors relate to the local colour in a specific drama series and cover elements such as how the shore, land, or islands are used as locations; how rural and/or urban elements are used; how climate, weather, and seasons are reflected in the story and the visual imagery; how mobility and 
infrastructure indicate a certain type of location; and how architecture, art, and design are reflected in the visual style and narrative concept. In general, this approach looks at the relationship between the on-screen local colour and the off-screen production conditions. The methods used to study the locations in a screen production represent a wide range of approaches such as textual analysis, genre analysis, document analysis, media system analysis, production observations, interviews with creative staff and local authorities, and geographical analysis. In relation to the New Nordic Noir case study, I have so far carried out participatory observations, media system analysis, document analysis, and geographical analysis. The series has not been produced yet, so it is not yet possible to see how the different cultural conditions and off-screen dimensions will influence it. However, I am able to study the location imaginations that are involved at this early stage and the role that the west coast of Denmark plays in this context.

Studying a drama production even before it has started is something Jakob Wille (2015) describes as a "pre-preproduction study". While preproduction is about finalizing the manuscript, the budget, casting, and setting up the production team, and the production phase is about shooting, prepreproduction concerns the process involved when the very first ideas for a series come to life. Studying this conceptual and creative part of a drama series is what Eva Redvall (2013) defines as "screen idea development". Redvall focuses on the scriptwriters' creative work, and her idea is that the scriptwriting process depends a great deal on the actual industry ("field") context; the predominant trends and traditions ("domain"); and the scriptwriter's talent, track record, and training ("individuals"). In relation to the New Nordic Noir project, my focus is less on the scriptwriters' work and more on the way in which the RKS municipality and Filmby Aarhus collaborate with each other.

In relation to the third approach dealing with creative tourism innovation and site-specific interventions related to the Rethinking Tourism project, my work employs participatory observations in screen productions (Caldwell, 2008), practice-based research (Ellström, 2010), and place intervention (Waade et al., 2018) as innovation methods. I will say more about my role as a researcher later in the chapter.

\section{The coastline as a mythological and mediated place}

In many ways, the coastline has a particular position in Danish culture, folklore, and religion. The different imageries of the coastline are embedded in cultural and historical contexts, and together they represent a hybrid landscape (Cosgrove, 1998). The coastline marks the border between land and sea, between life and death, between perishability and infinity. It is a liminal place, a threshold leading to imagined worlds beyond the physical place. For example, some religious rituals (funerals, baptism) take place at the waterfront or on the beach, and mythological creatures live and operate here, with 
some of them only being visible at dusk or dawn (the threshold between day and night). Mermaids and the Norwegian "draugen" (Romano et al., 2005) are two examples of such creatures: they both operate in the water and at the coastline, and in the old fairy tales, the fishermen risked their lives if they did not resist the magic power of the mermaid or the "draugen" monster.

Beside the mythical and mediated imaginations of the beach as a certain place, the coastline has also served as an important workplace for fishing and shipping throughout history. In contemporary culture, the coastal landscapes have been transformed into places for tourism, adventure, and cultural consumption (Urry \& Larsen, 2011). In this process, the beaches, a particular part of the coastline, have become crucial. The tropical dream on which modern Western tourism is based includes a particular way of looking at and using beaches. The European beaches underwent a "polynesification" in which palm trees and tropical plants were planted all the way along the Mediterranean coastline (Löfgren, 1999). The tropical paradise became a popular music and media image, indicating a playful and sensuous life on the beach involving surfing, romance, food, and drink (Meethan, 2012). Parallel to the rapid growth in the tourist industry since the 1960s and the development of new coastal destinations for tourists, a great number of popular films and television series, as well as a great deal of music, have portrayed the beach as a playful and romantic place. Here are just a few examples: the US-based backpacker movie and book The Beach (2000), the television series Baywatch (1999-2001), and the reality show Paradise Hotel (2003-).

\section{The transformation of the west coast of Denmark: from fishing and war to tourism}

Fishing has always been an important occupation in the municipality of RKS, and for the farmers in the area, the coast has served as a source of extra food and income. In general, the west coast has undergone a transformation: from fishing zone to war zone and then to the tourist industry and the energy industry. During the Second World War, the Danish west coast became part of Hitler's Atlantic Wall project, in which massive bunkers were constructed on the beaches and under the sand dunes as a coastal defence network and fortification system to provide protection against military attack. Today the bunkers remain on the beaches as concrete ruins and open wounds impossible to move or destroy.

After the Second World War, this stretch of coastline was transformed again by a new type of invasion: tourism. Today tourism is one of the biggest industries in the municipality, and $80 \%$ of the tourists are Germans (Ehrhorn, 2018). Since the 1970s, Danish families have built summer cottages along the coastal area, and during the summer period, many of these families rent their houses out to tourists. The main attraction for the tourists both winter and summer is the beach, where they can swim, walk, do yoga, go jogging or riding, have a barbecue, play, climb on the bunkers, take 


\section{EXPERIENCE THE BUNKERS IN HOUVIG}

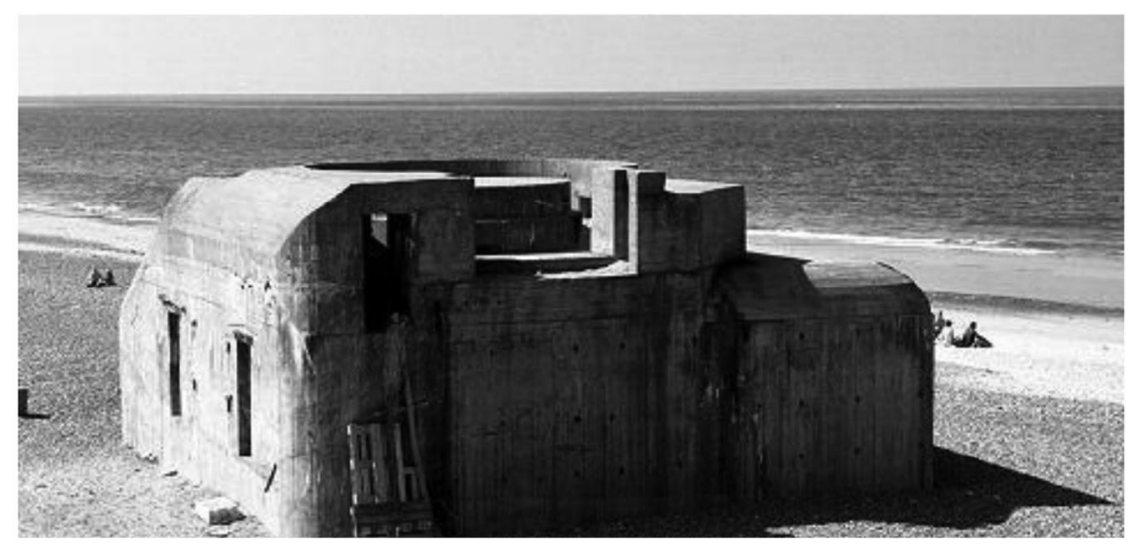

Take a walk in the dunes at Houvig and experience the unique nature and hear the story of the bunker plants from the occupation.

Figure 6.3 Houvig bunker from the Second World War is one of the many bunkers that attract thousands of tourists every year in Ringkøbing-Skjern. This picture appears on the local tourist website and illustrates the way the beach and the bunkers are presented as a destination.

Source: Photo by Jakob Høgel. Søndervig Tourism website. Reproduced with permission.

part in the kite festival, surf, or just gaze. The numerous German bunkers in the area attract and fascinate the visitors: they are like massive concrete sculptural ruins on the beaches (see Figure 6.3). Moreover, in the last two decades, Cold Hawaii, a brand name for the west coast of Denmark among international surfer communities, has attracted the attention of new groups of tourists from all over the world. It can also be argued that another transformation is taking place as well, something which does not replace tourism but supplements it: the wind energy industry. New wind turbines are being constructed along the coastline, and the municipality plans to develop further offshore wind farms a few kilometres from the coastline. Green energy companies in RKS not only produce and export windmill energy but also produce the turbines themselves within the municipality.

\section{Edgelands in Nordic Noir}

In fact, the idea that Filmby Aarhus suggested creating a crime series by using the west coast of Denmark as setting echoes other recent Nordic Noir series also using coastal settings as a distinct narrative and visual element. 


\section{Anne Marit Waade}

This is the case for series such as Inspector Wallander (2005-2013) living at the edge of the Swedish coast (Waade, 2013); The Bridge (2013-2018) taking place in the Öresund region, encompassing both the Danish and Swedish coastal areas (Chow, 2016); and Trapped (2015-) taking place in Reykjavik (Hansen \& Waade, 2017), as well as Nordic Noir series from outside the Nordic regions such as Hinterland (2013-), Broadchurch (2013-2017), and Shetland (2013-). The coastal setting not only works as a visual feature but also mirrors the characters in the stories, the society, and the criminal acts themselves. Gray (2014) explains that the coastal setting in Nordic Noir consists of tropes of negative aesthetics in which exterior darkness mirror the psyche of protagonists, and liminal landscapes stress "isolation and wilderness evoking vulnerability, exposure and insecurity" (ibid: 75).

Liminality ... is characterised by narrative devices that cross thresholds and explore the notion of in/between spaces such as the possibilities for existing in/between fantasy and reality, life and death, being and unbeing.

(ibid: 74)

As the setting for a television crime series, the west coast of Denmark is already loaded with meaning. It is an assemblage of historical, mythological, genre-specific, geographical, and cultural layers. Since the scripts for the New Nordic Noir series still are in development, we do not yet know to what extent these elements are included in the narrative and the aesthetic of the new series. When studying the initial process of developing RKS as a screen production location and a screen tourism destination, I have focused on how these existing practices and cultural meanings of the physical, geographical places, as well as the genre-specific use of settings, are part of the creative process as well as the negotiations between the partners involved in the process.

As we will see in the following, the different partner and stakeholder ideas of how the west coast of Denmark can be exploited as film location and screen tourism destination have not been very clear from the beginning. Rather it has been a process of development in which the different partners involved needed to develop a common language across the sectors (tourism, culture, media production) and understanding related to locations in a screen production as well as an understanding of their respective roles in the process. Furthermore, since this was the very first time that the municipality had been involved in a screen production, it needed to build up competences and professionalize its own involvement.

\section{Location placement: cross-sectoral collaboration}

In general, developing screen tourism requires collaboration across the media and the tourism industry, something that until recently has been quite 
rare. We are talking about two distinct industries with different professional training, mindsets, and values. Already when Filmby Aarhus initiated the New Nordic Noir project back in 2016, the idea of developing screen tourism was part of its ambition. It wanted to develop a transmedia crime drama with the potential to develop screen tourism. So RKS, with its well-established reputation as a popular destination for German tourists and amazing coastal landscapes, was a good choice of partner. For RKS, this was an opportunity to develop a branding strategy as well as screen tourism, despite the fact that the area lacked know-how about the film industry as well as any production facilities. This was the first time the municipality had been engaged in a screen production, so collaboration with Filmby Aarhus on the New Nordic Noir project was a challenge. Two public servants from the culture division took a leading role in the new partnership: project manager Rebecca Molders and the head of culture, Per Høgh Sørensen.

To build up their competence, professionalize their involvement, and attract political support locally, they developed a threefold strategy: 1) strengthen cross-sectoral collaboration and co-creation, 2) build local competences, and 3) develop a local film production policy. This threefold strategy was not defined in a carefully written policy document - it was just something that happened. The modes of collaboration related to the first part of the strategy encompassed new forms of collaboration between the culture, tourism, and strategic planning divisions of the municipality on the one hand and strategic partnerships with commercial players such as media producers and tourism agencies (as well as public partners such as museums and academic institutions) on the other. The great advantage for a small municipality like RKS is that many of the people involved know each other, and it is easy and natural to work across institutions, divisions, and disciplines. The online platform West Coast Universe and the Rethinking Tourism project have paved the way for new collaboration with creative industries and researchers, and during the last couple of years, they have hosted meetings and creative workshops with their new partners focusing on the New Nordic Noir project. The fact that the Rethinking Tourism project is taking place at the same time as the transmedia crime drama project has provided momentum for the partners involved, making it easier to convince the local council to invest funding and engage new partners. The Rethinking Tourism project brought groups of students and international scholars to the municipality, all of them engaging in new ways of seeing and staging the west coast. This process has furthermore inspired RKS to initiate a cocreative strategy involving groups of pupils and creative individuals within the area.

With a view to implementing the second part of the strategy (building local competences), the municipality organized a study trip to Ystad in April 2018 to learn how to develop a sustainable screen tourism and film strategy based on their experiences with the Wallander series. Representatives from the culture division as well as tourism and strategic planning divisions went 


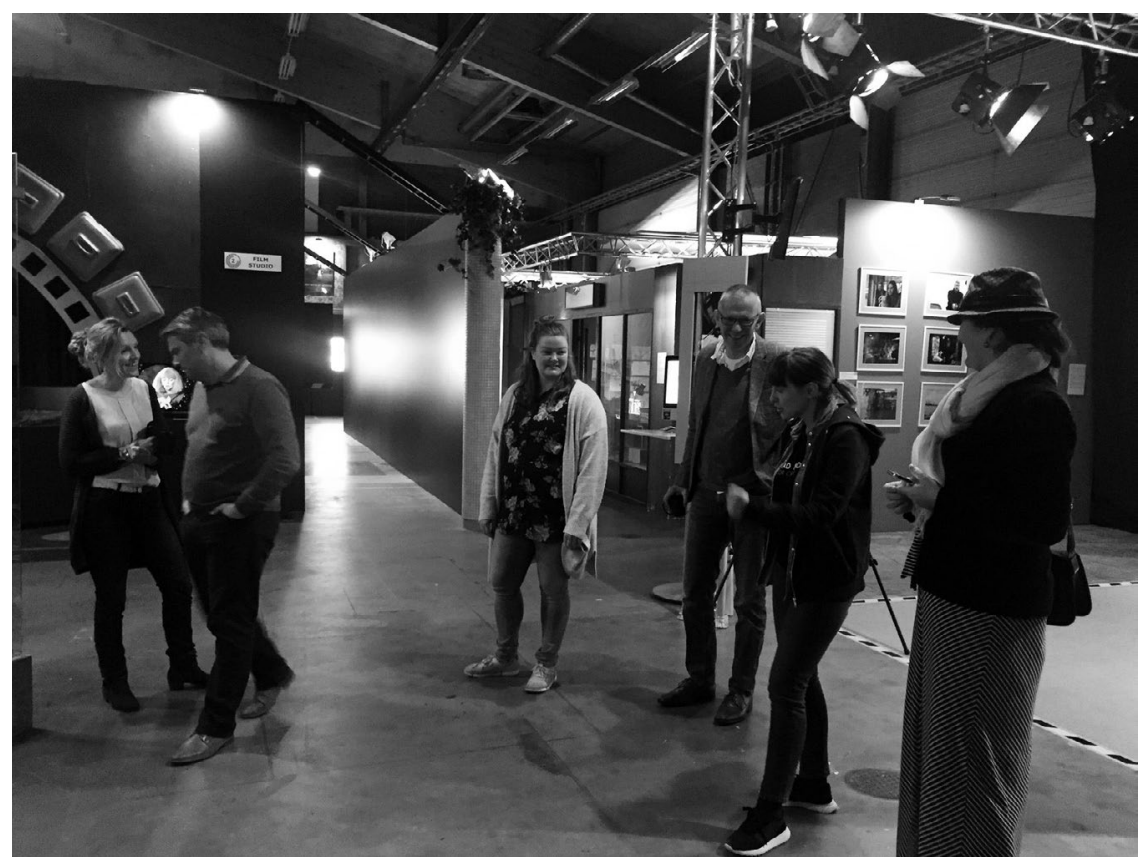

Figure 6.4 Stakeholders from Ringkøbing-Skjern municipality visiting Ystad Studios Visitor Center, April 2018.

Source: Photo by author.

on this study trip, thereby supporting the cross-sectoral collaboration strategy. During the study trip, they met representatives from Ystad municipality, local screen tourism partners and entrepreneurs, strategic planners and film commissioners in the Skåne region, and screen production companies. They achieved an understanding of the wide-scale potential of locally based screen productions and screen tourism, with great locations and local support being identified as key resources. To develop sustainable screen tourism, the stakeholders from RKS that took part in the study trip realized the need for long-term planning as well as a strategy for how to engage citizens, investors, local institutions, and national and international partners.

Inspired by the study trip and the new partnerships, the municipality decided to professionalize its own role in the partnership by appointing Rebecca Molders as a full-time screen production advisor. Furthermore, in August 2018, the local council agreed on a film policy and location placement strategy that aimed to attract more screen productions to the area, invest money in the productions and offer practical support, teach and engage pupils and citizens in screen productions, support a locally based film festival, and take the lead in new innovative projects such as West Coast 
Universe alongside creative partners and researchers. Location placement is a place branding strategy in which the destination (or the city or the nation) places its locations in a film or a series for branding purposes. Location placement can also be part of a local policy aiming to build and strengthen the local creative industry. Moreover, and as part of its film policy, RKS developed a PR strategy to make sure that all initiatives and events were covered in the local news media and thus brought to the attention of citizens, politicians, and institutions in the area.

\section{Creating and negotiating "location imagination": avoid provincial stereotypes!}

So how did the imaginations of the west coast of Denmark as a film location match the screen ideas developed in the pre-preproduction stage of the New Nordic Noir initiative? When Filmby Aarhus first met the local politicians to discuss their potential investment in the New Nordic Noir production, their immediate reaction was that they were worried about the images of the area that the new series would generate: they wanted to avoid comic and dark stereotypes, and they were afraid that murders and crime would have a negative impact on their brand image. The municipality had worked hard to build up a brand image, and the politicians were afraid that a new series could work against this. It is a general challenge for rural municipalities like RKS to prevent economic depression caused by companies closing down, lack of investment, local schools closing down, families leaving, and young people not settling down. In Denmark, these areas have been described as "rotten bananas", "the outskirts of Denmark", and "provincial". When the politicians were asked to invest in the New Nordic Noir series, they wanted to make sure that the series did not confirm any of these discourses and ideas. In addition to the negative branding concerns, the politicians also wondered about the obvious contradiction in the idea of using crime and murders to attract future tourists, new residents, and investors. However, learning more about other crime fiction tourist destinations such as Ystad, Edinburgh, and Gotland made it clear that fictional crime and murders do not affect the brand of a destination - in fact, they are beneficial because good stories will generate media attention.

The first actual visual imagery of the New Nordic Noir series that has been shown is presented on the Filmby Aarhus website (see previously). This image shows the German harbour in Hvide Sande, with the foggy, cold weather being underlined in the green-blue colour palette. This picture echoes the Nordic Noir visual style and settings (Roberts, 2016; Creeber, 2015; Hansen \& Waade, 2017). The German harbour is a very picturesque place, with small, old fishermen's houses lined up in a row, forming the well-known "skyline" imagery shown in tourist magazines and postcards from the area. Many of these houses are still in use; some of them are worn down and have the nostalgic veneer of old paintings and rough weather that appeals to the 


\section{Anne Marit Waade}

tourist gaze (Urry \& Larsen, 2011). Since this is almost the only picture that has been circulated in relation to the New Nordic Noir initiative, it has become a visual icon for the series. The picture is used on the Filmby Aarhus website as well as by the local partners engaged in pre-production.

The last two elements that I will emphasize in this context are related to the creative process. First, screen idea development and the work of the scriptwriters take place on location, so to speak. This idea was part of the project from the very beginning, with the creative workshops involving scriptwriters, producers, and local partners from the municipality meeting in a summer cottage in Hvide Sande. Many television drama series are shot in and based on specific, actual places, but this way of developing sitespecific television drama set in rural areas in which the places themselves inform and inspire the creative process has hardly ever been seen before. ${ }^{1}$ It could be argued that the actual places function as full-scale visual mood boards for the scriptwriting. In addition, and as part of an open creative process, researchers and students have contributed to screen idea development through mapping, playful engagement, and visual productions of possible film locations in Ringkøbing-Skjern. Hundreds of students of architecture, anthropology, experience economy, media studies, and media production have visited the municipality, done on-site fieldwork, and produced visual material and creative ideas for future development as well as potential locations for the crime drama series. Twenty-five international $\mathrm{PhD}$ students also stayed in Hvide Sande for a week in June 2018 to work with Nordic Noir and come up with audiovisual mood boards and creative ideas for the site-specific crime drama series. The process involving students and young researchers has been carried out parallel to the work of the team developing the New Nordic Noir series, although some of the ideas were forwarded to them via teachers and local collaborators.

\section{Location study conducted as co-creative and innovative collaboration}

As mentioned previously, the study reflects a new participatory and collaborative role for researchers involved in screen industry research. My engagement in the New Nordic Noir project has been part of my commitment to the innovation project Rethinking Tourism, the objective of which has been to develop new modes of tourism on the west coast through site-specific intervention. The tourism innovation project has been based on close collaboration between researchers from the fields of architecture, anthropology, culture, and media studies on the one hand and local institutions, entrepreneurs, citizens, and authorities in RKS on the other. The overall ambition has been to develop tourism through site-specific interventions and new modes of cross-sectoral and co-creative collaboration.

In my case, the intervention was related to processes in which I was asked to help the municipality to develop expertise and knowledge on how to be a 
partner in television drama production and how to build up screen tourism from scratch. So rather than studying the practices of others, which is the most common way of doing screen production studies (Caldwell, 2008; Redvall, 2013) and location studies (Hallam \& Roberts, 2014; Hansen \& Waade, 2017), I have engaged in the practice myself and contributed to the development of sustainable new modes of tourism in the municipality. As a result, I initiated meetings with Filmby Aarhus and stakeholders in the municipality, I shared my knowledge with my local partners, I took part in the initial meetings with the local council and gave a talk about screen tourism, I organized the study trip alongside my local partners, I suggested workshops and invited key persons to talk about the project at international research conferences, and I initiated fieldwork for my masters students at Aarhus University.

This way of intervening the processes differs from the other interventions in the Rethinking Tourism project, which generally involved objects and events that took place on particular sites within the municipality. Place interventions and "site-specific provotyping" aiming to engage local stakeholders and citizens is a method which is used in landscape architecture (Waade et al., 2018). However, in my engagement in the New Nordic Noir project, I have instead intervened in the processes with a view to strengthening cross-sectoral collaboration, supporting the role of the municipality in its partnership with Filmby Aarhus, and helping it gain access to knowledge and expertise about how to build screen tourism in relation to screen productions.

\section{Conclusion}

Location imaginations in relation to the New Nordic Noir case illuminate a particular part of the production process: screen idea development. The case study shows how the coastal municipality of RKS, which had no previous screen industry experience, realized during the initial phase of the New Nordic Noir initiative that its coastal landscapes and tourism could be exploited to attract screen productions, develop screen tourism, and engage citizens. In a coastal area and popular tourist destination like RKS, the idea that the landscape and countryside are a commodity with economic value is not new. The coastline has been one of the main sources of income and economic growth throughout history, from fishing and war to tourism and green energy production. But in this case, the municipality is a local partner in a screen production and is also using this initiative to develop a screen production strategy that aims to attract other screen productions, engage in screen productions, use screen productions as windows for place branding, initiate new creative collaborations across sectors, and engage citizens in small-screen productions. One could ask if this initiative will conflict with the existing tourism and the fact that most tourists visiting the west coast seek solitude, exercise, and nature. As such, the Danish west coast is already a mass tourism destination with its more the five million visitors per year, and the New Nordic noir initiative will not change this much. Rather, RKS hopes that screen 


\section{Anne Marit Waade}

tourism can help attract different kinds of tourists from different countries and also maintain the groups of tourists that the region already has.

In general, locations in television drama series have significant economic, narrative, and aesthetics value. The values are related to the landscape imageries and site-specific aesthetics on the screen but also the funding and production facilities that are provided for on-location shooting and locally based productions. However, academic focus on location placement and site-specific television drama has so far been limited. As such, this study aims to contribute to this field and shed light on how location imagination is reflected, negotiated, and practiced in an early stage of a screen production.

\section{Note}

1 One exception is the Danish melodrama Arvingerne (The Legacy, 2014-) (Waade \& Wille, 2016).

\section{Bibliography}

Agger, G. (2016). Nordic Noir: Location identity and emotion. In: A. Garcia (ed.), Emotions in contemporary TV series, pp. 134-152. New York: Palgrave Macmillan.

Beeton, S. (2005). Aspects of tourism: Film-induced tourism. Bristol: Channel View Publications.

Bergman, K. (2014). Swedish crime fiction: The making of Nordic Noir. Milan: Mimesis. Caldwell, J.T. (2008). Production culture: Industrial reflexivity and critical practice in film and television. Durham: Duke University Press.

Chow, P. (2016). Traversing the Øresund: The transnational urban region in Bron/ Broen. In: J. Andersson \& L. Webb (eds.), Global cinematic cities: New landscapes of film and media, pp. 36-58. London: Wallflower Press.

Cosgrove, D. (1998). Social formation and symbolic landscapes. Wisconsin: University of Wisconsin Press.

Creeber, G. (2015). 'Killing us softly': Investigating the aesthetics, philosophy and influence of Nordic Noir television. Journal of Popular Television 3(1): 21-35.

Ehrhorn, M. (2018). Turisme for milliarder: Ringkøbing-Skjern helt $i$ toppen. Retrieved from https://jv.dk/artikel/turisme-for-milliarder-ringk\%C3\%B8bingskjern-helt-i-toppen-2018-1-6 (05-04-2020).

Ellström, P. (2010). Practice-based innovations: A learning perspective. Journal of Workplace Learning: Studies Organizational Learning Organizational Change Innovations Adaptability 22(1-2): 27-40.

Falkheimer, J. \& Jansson, A. (eds.). (2006). Geographies of communication: The spatial turn in media studies. Göteborg: Nordicom.

Fjällbacka Information. (2020). Camilla Lackberg murder mystery tour. Retrieved from https://fjallbackainfo.se/camilla-lackberg-murder-mystery-tour/ (02-04-2020).

Google. (n.d.). Ringkøbing-Skjern Municipality [map]. Retrieved from www.google. nl/maps/place/Ringk\%C3\%B8bing-Skjern+Municipality,+Denmark/@56.017417, $8.2005117,10 \mathrm{z} /$ data $=! 3 \mathrm{~m} 1 ! 4 \mathrm{~b} 1 ! 4 \mathrm{~m} 5 ! 3 \mathrm{~m} 4$ !1 s0x464a539ee50008e3:0xf6f6fed2d $06524 \mathrm{~d} 9$ ! $8 \mathrm{~m} 2$ !3d56.0446887!4d8.50589 (08-08-2018).

Gray, E. (2014). In/between places: Connection and isolation in the bridge. Aeternum: The Journal of Contemporary Gothic Studies 1(1): 73-85. 
Hallam, J. \& Roberts, L. (2014). Locating the moving image: New approaches to film and place. Bloomington: Indiana University Press.

Hansen, K.T. \& Waade, A.M. (2017). Locating Nordic Noir. Basingstoke: Palgrave Macmillan.

Jensen,P.M.(2016).GlobalimpactofDanishdramaseries:Aperipheral,non-commercial creative counter-flow. Kosmorama \#263. Retrieved from www.kosmorama.org/ en/kosmorama/artikler/global-impact-danish-drama-series-peripheral-non-commercial-creative-counter (10-04-2020).

Löfgren, O. (1999). On holiday. Berkeley: University of California Press.

Månsson, M. \& Eskilsson, L. (2013). Capitalising on screen tourism: The attraction of screen destinations. EuroScreen Report, Film London and the EuroScreen Partnership, Pracownia Pomysłów.

Månsson, M. (2015). Mediatized tourism: The convergence of media and tourism performances. PhD dissertation. Lund: Lund University.

McClintock, A. (2010). Wallanders värld/world/welt. Malmö: Roos \& Tegner.

Meethan, K. (2012). Walking the edges: Towards a visual anthropology of beachscapes. In: H. Andres \& L. Roberts (eds.), Liminal landscapes: Travel, experience and spaces in-between. London: Routledge.

Redvall, E.N. (2013). Writing and producing television drama in Denmark: From the Kingdom to the killing. New York: Palgrave Macmillan.

Reijnders, S. (2011). Places of the imagination: Media, tourism, culture. Farnham: Ashgate.

Roberts, L. (2016). Landscapes in the frame: Exploring the hinterlands of the British procedural drama. New Review of Film and Television Studies 14(3): 364-385.

Romano, S., Esposito, V., Fonda, C., Russo, A. \& Grassi, R. (2005). Beyond the myth: The mermaid syndrome from Homerus to Andersen: A tribute to Hans Christian Andersen's bicentennial of birth. European Journal of Radiology 58(2): 252.

Saunders, T. (2017). Peripheries of space, self and literary style in R. S. Thomas's readings of Søren Kierkegaard. Scandinavica 56(1): 59-95.

Sjöholm, C. (2011). Litterära resor - turism i spåren efter böcker, filmer och författare. Makadam: Bulls Graphic.

Søndervig Tourism. (2020). Experience the bunkers in Houvig. Retrieved from https://sondervig.dk/en/experirnce-the-bunkers-in-houvig/ (05-04-2020).

Stougaard-Nielsen, J. (2017). Scandinavian crime fiction. London: Bloomsbury Academic.

Urry, J. \& Larsen, J. (2011). The tourist gaze 3.0: Leisure and travel in contemporary societies. Los Angeles: Sage Publications.

Waade, A.M. (2013). Wallanderland: skandinavisk krimi og filmturisme. Aalborg: Aalborg University Press.

Waade, A.M., Pasgaard, J.C., Nielsen, T. \& Melgaard, M. (2018). Redesigning Nordic landscapes through place intervention. In: C. Cassinger, A. Lucarelli \& S. Gyimóthy (eds.), The Nordic wave in place branding: Constructions, appropriations and articulation. Cheltenham: Edward Elgar.

Waade, A.M. \& Wille, J.I. (2016). Production design and location in the Danish television drama series arvingerne. Kosmorama \#263. Retrieved from www.kosmorama. org/en/kosmorama/artikler/production-design-and-location-danish-televisiondrama-series-legacy (05-04-2020).

Wille, J.I. (2015). Film som design: Design af levende billeder i film og tv-serier. PhD dissertation. Copenhagen: Copenhagen Business School \& The Royal Danish Academy of Fine Arts. 


\title{
7 Flying down to a cosmopolitan- tropical paradise
}

\author{
Bianca Freire-Medeiros
}

\section{Introduction}

Over the centuries, Rio de Janeiro has attracted a polyglot collection of visitors responsible for creating narratives about its peoples and landscapes. If, right up to the first decades of the 19th century, these travellers came mostly from the Old World, from the second half on, the European imagination began to be disputed as travellers from the United States "discovered" their "best neighbour from the south".

For US travellers who were reaffirming their national identities, Brazil seemed to be a particularly interesting counterpoint. Both countries had gone through conquest and colonization, both shared experiences of slavery and immigration, both had a continental-sized land to turn into a nation. And yet each country responded to these common experiences in very different ways. It is Robert Stam (1997: 1) who best summarizes it: "Brazil and the United States are deeply interconnected in a specular play of sameness and difference, identity and alterity. The two countries offer distorting images of each other. Although in no way identical, the two countries are eminently comparable".

This specular game produced, throughout history, tensions between not only sameness and difference but also what could be labelled topophilia and topophobia (see the Introduction to this volume) regarding the physical and human landscape of Rio. In the mid-1920s, while the elites dreamed of Rio as the "Paris of the Tropics" (Benchimol, 1992; Fischer, 2014), Sylvio Gurgel do Amaral, Brazilian ambassador to Washington DC, bemoaned that the US press presented the largest nation in South America as "one vast hospital" with "all the deadly terrors of the jungle," inhabited by dangerous fish, snakes, and insects (Lawrence (1976) quoted in Smith, 1991: 136). Equally upset was the Brazilian audience of The Girl from Rio (1927), for the local residents went by Spanish names, and the capital city was presented as a "squalid Spanish town" (Lawrence (1976) quoted in Smith, 1991: 137). A few years later, the Brazilian government requested the withdrawal from circulation of another Hollywood movie, Rio's Road to Hell (1931). In short, early 20th-century US narratives about Brazil mostly presented the country 
as an undifferentiated, if romantic, Latin hinterland (Amancio, 2000; Woll, 1977; Augusto, 1995; Mendonça, 1999).

A vast literature demonstrates that this overtly prejudicial attitude towards Brazil slowly began to change in the late 1920s and gained momentum with the so-called Good Neighbour Policy (cf. Fishlow, 1984; Pike, 1992). Under Franklin Roosevelt's command and within the context of rise of totalitarian regimes worldwide, this policy clamoured for the cultural industry to help create, at the domestic level, an environment of appreciation and respect for Latin Americans, while mobilizing their public opinion on behalf of the United States' war-related objectives. The Office of Inter-American Affairs used Hollywood within this broader diplomatic machinery to garner support for a political project that also opened business opportunities throughout the region. Meanwhile in Brazil, the socalled "Revolução de 30" (1930s Revolution) imposed a definite identity policy on the nation in a clear attempt to find a new balance between tradition and modernity (cf. Cândido, 1984). Capitalizing on the longing for a new civic and economic order, Getulio Vargas effected a coup d'état which lead to a 15-year Populist regime (cf. Fausto, 1994). He put in motion a program of development which not only doubled Brazil's production of manufactured goods in ten years but also established a national tourist industry.

In the following pages, inspired by the invitation that the editors of this volume pose to identify how fictional imagination intertwines with tourism (see Introduction), I focus on how US narratives produced within the context of an emerging tourism industry placed Rio de Janeiro in an ambiguous location between nature and culture, exoticism and cosmopolitanism. I attempt to understand how the cityscape of Rio, framed for both viewing and visiting, was presented as a "place of the imagination" (Reijnders, 2011). In order to examine this imbrication between imaginative and corporeal mobilities (cf. Urry, 2007), I focus on two narratives that exemplify the launching of Rio de Janeiro as a cinematic tourist destination (see Tzanelli, 2007): Flying Down to Rio (RKO, 1933), a "musical comedy with a tourism related plot" (Schwartz, 2004: 7) and the first Hollywood film which portrayed the city in a positive light, and Hugh Gibson's Rio, the first travel book about Brazil's one-time capital ever written by a US citizen.

Assuming that cinema gives to the audience's imagination a way of mapping the city, offering what Bruno (1997) calls a "modern cartography" and what John Urry (2007) identifies as "the tourist gaze", I am particularly interested to examine how those two cultural products create a cognitive framework that recurrently contrasts both the physical and human landscape of Rio vis-à-vis that of the United States. In a rather influential article on methodological principles for critically examining ethnic images in films, Cortés (1984) advocates in favour of merging different methodologies due to the complexity of the task at hand. Following his steps, I combine both sociological and content analysis in order to understand "not only how 
characters are depicted, but also how they fit into the social structure of the film and how they are involved in various relationships" (ibid: 75).

\section{The travelling city}

Departing from the United States, tourists and travellers, film crews, and fictional characters have travelled to Rio and, in so doing, helped to transform it into a mobile entity, a "traveling city" - a geographic, cultural, and spatial icon that has travelled around the world (Freire-Medeiros, 2002). It was a city where new airports, hotels, and a series of tourism landmarks were created, aiming to position it in the global stage as a desirable destination. In this sense, the Rio that US imagination helped to invent was a "place to play" and also a "place in play" - to use Sheller and Urry's phrase (2004: $1-10)$.

A decolonial approach enables us to better understand the spatiality and historicity of mobility regimes which constitute those "places to play" and are still characteristic of postcolonial metropolises such as Rio de Janeiro. A large amount of Rio's identity has been built on the interconnections between the imagery of modernity, colonization, and coloniality. On the one hand, the "Marvelous City" is trapped into the idea of "Tropicality" (Gerbi, 1973/1996; Arnold, 1996/2000; Livingstone, 2000; Freire-Medeiros \& Castro, 2013), a singular combination of space, "race", nature, and climate, whose significance is deeply ambivalent: a fascinating and opulent landscape but also a strange world of illness and incivility. Coloniality thus defines Rio de Janeiro as the Other that only exists as a mental juxtaposition to the "normality" of the temperate lands.

The manufacturing of Rio as a travelling city has always counted on the sustained complicity of successive Brazilian elites. As happens in other tourist cities, the representations of Rio from the outside have influenced the ways Cariocas themselves have come to understand the city. Engagement in the course of modernity has always been required from this tropical city. Guided by the principles of order and progress, white local elites with European aspirations adhered to aesthetic, cultural, economic, and political values which paradoxically reify their subaltern position vis-à-vis the Metropole.

The Tourist and Entertainment Service, created in 1930, instituted an official tourist season for Rio de Janeiro that started with Carnival and went through the end of September. It was aimed at attracting local as well as international visitors, for whom, by this time, clear rules for entry and stay had finally been adopted. In the following years, the federal government also created the Department of Cultural Publicity and Diffusion, which was responsible for studying and giving guidance on the use of the motion picture projector and other technical devices that served as instruments of cultural diffusion. The Press and Propaganda Department (DIP), which included a division dealing exclusively with tourism, was established, aiming to control and coordinate tourist activities all over the country, to lay down standards 
for spas and mountain resorts, and to coordinate administrative organs connected with those various activities.

In 1932, even before the inauguration of Brazil's first airport (Santos Dumont Airport in Rio de Janeiro in 1936), a PanAm airline route from Miami to Rio was launched. In the following year, RKO's film Flying Down to Rio (from now on FDR) was released, not only promoting the new airline route and the telegraphic services of RKO to South America but mainly inaugurating a long list of Hollywood musicals that acted as thinly disguised travel maps for Rio de Janeiro.

\section{The musical as a map of the tourist city}

Send a radio to Rio de Janeiro

With a big hello just so they'll know

and stand by there;

We'll fly there

Hey Rio

Everything will be okay

We're singing and winging our way to you

("Flying Down to Rio" composed by Kahn, Eliseu, and Youmans; performed by Fred Astaire)

The premiere of FDR was met by high expectations from Brazilian audiences. They saw the new RKO film as Hollywood's final chance to make amends for its earlier cultural gaffes with its South American neighbours. Cinearte, one of the most important Brazilian film magazines at the time and the main thermometer for measuring a film's reception, anticipated with optimism that the film would have "Rio's wonderful scenario rather than alligators, forests, Indians. There will be no castanets, gay caballero, bad man" (quoted in Freire-Medeiros, 2005: 22).

Cinearte readers were not disappointed. On board the plane, flown by the blonde, light-eyed American pilot and maestro, Roger (Gene Raymond), we follow a succession of postcard images. After each shot, the frame slides laterally away to uncover the next image, as though mimicking the motion of actual postcards being fingered by an avid (US) tourist: Guanabara Bay, Copacabana and downtown, the Municipal Theatre, Jockey Club, Sugar Loaf, and Botanical Garden. The seductive attraction of the ocean and the mountains is cleverly blended with fast-paced shots of well-dressed city dwellers in upmarket neighbourhoods, and a dolly shot makes a point of following the hectic sidewalk crowd from left to right while heavy traffic of smart cars traverses in the other direction.

These scenes reveal a clear concern with presenting, in a positive way, the imagery of both a naturally exuberant city as well as an up-to-date, contemporary, civilized metropolis - a challenge that the Municipality of Rio as well as private organizations took rather seriously. The reader should keep in 


\section{Bianca Freire-Medeiros}

mind that it was precisely in 1933 that the mayor, Pedro Ernesto Batista, created the Advisory Council of Tourism, whose main task was to convince the international tourist that Rio was the Paris of the Tropics. By the end of that year, the then-vice president of the Touring Club, Cerqueira Lima, affirmed that over ten years, the organization had struggle "to create something that today is perfectly clear and secure: a tourist mentality in Brazil" (as quoted in Freire-Medeiros \& Castro, 2013: 36). In these efforts to turn tourism into a carefully planned, marketed, and government-promoted business, RKO's musical was to play a fundamental role.

The film tells of a love triangle involving a seductive Brazilian woman, Belinha; the well-intentioned but ineffectual Júlio Ribeiro; and the American hero, Roger. Roger, free-spirited and adventurous, epitomizes what was expected from American men at a time when a combination of business creativity and technological expertise were seen as the only way to surpass the national economic crisis. Júlio, although richer and more educated than Roger, lacks his American's friend restless inventiveness. In this sense, it is possible to see Júlio as representing the old Brazilian oligarchy: highly sophisticated, boasting French manners, but unable to keep up with the new capitalists' way of "doing business", that is, of conquering the world. A conquest that can no longer be based on a big-stick policy, and the producers behind FDR knew that. The film's production team was composed of C.V. Whitney, J.H. Whitney, and M.C. Cooper. Historian Henderson (1982: 4-5) describes them as "aviators, explorers, sportsmen, warriors" who invested in "high-risk, high-profit fields such as high-technology enterprises, aviation, and movies".

Within the new goodwill atmosphere that so enthusiastically celebrated the amicable acquaintance between the two hemispheres, Roger, the self-madeAmerican capitalist, and Júlio, the aristocratic Brazilian, complemented one another. Even when disputing their object of desire, they find no need for fighting or disrespect. Júlio, in honour of his friendship with Roger, simply breaks off his engagement to Belinha, allowing her to marry the American hero. FDR is indeed one of the few films of the 1930s to propose a "legal" outcome to a romance between a white American male and a Latin American woman. ${ }^{1}$ Of course, Del Río's light skin was critical in making her more "acceptable", but one should keep in mind that, just a year before, her portrayal had been much more stereotypically negative: in Bird of Paradise (1932), her role as the savage princess Luana had required that she give up her love for a white man and be burnt to death for transgressing a racial taboo.

Belinha, like the city she lives in, is not only "modern" and "cosmopolitan" but also "hot" and "mysterious". The connections between the colonial city and its women have become so commonplace as to seem to be almost clichéd (Mills, 1991; Pratt, 1992). Colonies, like women, must be both fathered and husbanded. The establishment of a colonial domain, which passes through the founding of the colonial city, is often naturalized through the comparison that equates it with an amorous "conquest". And yet the familiarity of 
the metaphor does not reduce its efficacy. Belinha is so irresistible to men that one of her American girlfriends asks: "What do these South American girls have below the Equator that we haven't?" FDR overtly links Belinha's physical attributes with the cityscape, drawing parallels between the roles that her body plays, via romance and potential procreation, in the foundation of a "new" Rio, one that is the result of the combination between Brazilian femininity and tradition and US virility and technological skills.

Belinha's father plans to launch a new and sophisticated hotel in Copacabana. It should come as no surprise that the Copacabana Palace Hotel, inaugurated in 1923 and an icon to this day of seaside elegance and cosmopolitanism, serves as the setting (O’Donnell \& Freire-Medeiros, 2018: 32). Nevertheless, Belinha's father finds himself the victim of dishonest politicians - another standard US trope to be explored in more recent films - from whom only the intervention of his brave American friends will be able to extricate him. She wants to break off the promises made to her family and fiancé, but only Roger can make her follow her desires. The first kiss between the pair is followed by a dialogue which is heavy with meaning:

“My life has long been arranged", laments Belinha.

"Don't tell me anything so eighteenth century like family arrangements", answers Roger, less skeptical than ironic.

"Would you think so - in my country?"

"Then, I'm going to institute some radical changes in your country", says Roger, threateningly.

"But my fiancé has even built me a beautiful home in Rio Bay", Belinha argues with weak conviction.

"But you love $m e$ !"

"You're taking a lot for granted!"

"And I love you!"

"You don't even know my name!" replies the Brazilian seductress. "You must forget tonight!"

"Now you're taking a lot for granted!" ridicules Roger.

"I'm determined that you'll never see me again", insists Belinha.

"If I have to turn the country upside down, I'll see you!" replies an overconfident Roger.

"I won't permit you".

"We'll see about that".

"You'll do just as I say!"

"Oh, will I?"

"You will!"

"I will not! Your family, your fiancé, the Army, the Navy, all of South America can't stop me! And if you are silly enough ..."

Belinha slaps him on the face. Without hesitation, Roger demonstrates his American masculinity: turns her over on his lap, and slaps her behind. 


\section{Bianca Freire-Medeiros}

It is not surprising that this scene happens before the couple's - and the audience's - actual arrival in Rio, for its main function is precisely to provide the audiences with all the basic elements needed to understand what "Brazil is all about", that is, what meanings - social, sexual, emotional - to invest in the city. The audience is ready to "travel" to Rio knowing it is a city where women are both sensuous and, simultaneously, conscious of their traditional roles; have "undomesticated" personalities, but can always be "tamed" by a powerful male, especially one who is above family traditions, the state, and the law.

The film ends with its most famous scene, the aerial ballet over the city which intercuts shot-on-location images of Rio's landmarks with scenes taken on Malibu Beach, California. While several planes, carrying girls dancing on their wings, write in the sky, "Hotel Atlantico Presents Yankee Clippers", Fred and the band play "Flying Down to Rio" from the hotel's balcony. In the skies of Brazil, Cariocas and Americans unite and save the day. It is interesting to observe that, although the ballet group was supposedly formed by Brazilian and American women alike, there is no way of telling them apart, that is to say, they are equally dressed (and undressed, for when their parachutes open up they are left only with their underwear) and display the same features (light skin, either blondes or brunettes). They are easily interchangeable, reinforcing an idea that permeates the movie as a whole: trade between North and South Americans can be settled based on simple exchange, with no regard to the differentiation of products. Americans offer their creativity; Brazilians offer them job opportunities.

Belinha and Roger's wedding, not by chance, happens on a plane, a neutral territory above the city and its social constraints. Their union celebrates the capacity of the modern white Euro-American male to impose modifications on a traditional social structure. But it also implies that Rio and Miami (where the film begins) are not that far apart, that Brazilians can also be as sophisticated and well educated as their American neighbours to the North.

Both in the United States and in Brazil, Flying Down to Rio was a great hit at the time of its release (Schwartz, 2004; Moura, 1995). American audiences were pleased with the opportunity to fly down to Brazil in a vacation package that included romance, escapism, special effects, and extravagant musical numbers.

\section{From swamp to paradise}

Your first surprise is to find that although their background is exclusively Latin, and they have no antipathy to any race, they are definitely and instinctively friendly toward the United States and toward Americans. When you cast about for an explanation, all sort of reasons are given.

(Gibson, Rio, 1937: 14-15)

Hugh Gibson arrived in Brazil the same year as the film Flying Down to Rio (1933). Although the US ambassador himself did not use the recently inaugurated PanAm aerial services (Gibson and his wife and son came aboard 
the US ship Foreign Legion), ${ }^{2}$ he found a way of welcoming his readers to Rio with an equally privileged view of its scenic landscape: Guanabara Bay is captured in two photographs taken from the top of the hills which have the Sugar Loaf as their focal point.

The opening and recurrent theme of Rio is the seductive, almost mystical, powers of the city's natural landscape. In its very first paragraph, the book advises the reader that the city "is beyond comparison in the strange beauty of its setting" (Gibson, 1937: ii). It is a beauty so "strange" that the recounting of the natural settings had to be left to a whole collection of photographs (31 in all) "in conviction that pictures give a better idea of the beauties of Rio than any amount of written description" (ibid: iii-iv). The final product, more than 260 pages long, is divided into 15 chapters, covering everything from sight-seeing to cultural idiosyncrasies, from fishing to history. Incorporating both a description of the physical aspects of the city (landmarks and climate) and a definition of its social landscape, the book is a guide to the Cariocas' mores and social conduct.

Just like the audiences of the RKO film, Gibson's readers were introduced to the city from the skies, getting a bird's-eye view of its shores. In both cases, the cityscape is reduced to a postcard image and laid at the visitor's feet. Gibson's (1937: 4) description of his first view of Rio's bay could very well be a line from Fred Astaire's character:

As we drew near the harbour for the first time we were ... resigned to disappointment, because, as experienced travellers, we knew the reality could not be up to the standard of the descriptions we had read and heard. And then the haze lifted and a scene met our eyes which made all the written descriptions seem trivial and absurd. It was so much more wonderful than our bravest imagination.

Gibson calls himself an "experienced traveller". But what kind of traveller was he exactly? A career diplomat and writer, ${ }^{3}$ hunter and photographer in his spare time, Gibson started a mobile life quite early in life. Born in Los Angeles in 1883, a still-young Gibson made the transatlantic crossing and joined the École Libre des Sciences Politiques in Paris in the early 20th century. He graduated cum laude in 1907 and joined the US Foreign Service the following year. Part of a new generation of young diplomats whose professional rise had more to do with their personal merits than the influence of their families, he was labelled by the US Foreign Service "America's first real diplomat".

His close friendship with President Hoover would cost him dearly at the end of the Republican president's mandate. Soon after taking office, Franklin D. Roosevelt questioned Gibson's fidelity to the new government and considered his dismissal. Thanks to the intervention of influential friends, Roosevelt agreed to retain Gibson's services, offering him a post in Brazil. After a string of far more prestigious assignments in Europe, Rio seemed an even 


\section{Bianca Freire-Medeiros}

crueller fate than forced retirement. One of his Foreign Service colleagues sent a note of congratulations, reassuring him it would be a "most enjoyable assignment". "I haven't replied to him", Gibson wrote to his friend, Hugh Wilson, "but when I see him I think I'll say that when he has done five years in Central America ...., I'll be glad to receive his congratulations on going back to the swamps. Hu-hu!" (1937, April 14, in Gibson Papers, box 30).

If the ambassador arrived in Rio feeling something of an outcast, in a short time, he would find life in Brazil's capital no less than "enchanting" (1935, September 24, in letter to Wesley Frost). His first impression of the American Embassy as "a hopeless dump", where a night of sleep was denied by noisy crowds on the streets (1933, October 10, in letter to Mrs. Hugh Wilson), was promptly changed with a move to the small and bucolic town of Petrópolis. The American Embassy was mainly kept for the many social events that Gibson would promote during the years he spent in Brazil. In fact, shortly after arriving in Rio, he opened the embassy to the colony of his fellow citizens at the first public reception ever given and patronized by an American ambassador. The event had ample coverage in Brazil's most important newspapers at the time. A Nação, for example, quoted part of Gibson's speech for the 100 people who gathered at the luncheon in his honour: "Although I have never been in Brazil before, I have had many years' experience in dealing with representatives of the Brazilian government, experience which has brought me here with a wholesome respect for their ability, their frank dealing, their high standard of courtesy, and their friendliness for our country" (1937, in Gibson Papers, box 137).

Courtesy, frankness, friendliness - more than mere words demagogically used to praise an audience, these adjectives are either the stock in trade of a seasoned diplomat or reflect Gibson's genuine opinion regarding his new partners. In his first memorandum addressed to FDR, he would state that, although "procrastinating", Brazilians were "gentle, and rather ceremonious" (1933, October 11). Used to the cold distance of the Europeans, Brazilians' warm friendship many times seemed to him "more than one can handle": "This strange people really seem to like us" (1933, September 25, in letter to J. Philip Groves). Surprised by the good manners and culture boasted by the Cariocas (1934, February 27, in letter to Joseph Grew), Gibson wound up creating an image of Brazil and her leaders as unquestionable allies against the might of the Axis. Such understanding, as well as the acritical reception of any data passed on to him by the Itamaraty, many times incapacitated Gibson to assess the manoeuvres and true intentions of the Brazilian government (Hilton, 1975).

Rio was commissioned by the Brazilian Foreign Office of the Vargas government. This fact, no doubt, speaks loudly of the bonds Gibson ended up forming with Brazil's political elite. The book was received with great enthusiasm by the Brazilian media and civic organizations (Swerczek, 1972), ${ }^{4}$ and for the whole period that Gibson was living in Rio, he had always been the object of positive notes from the local press. Community associations such 
as the Association for Christian Youth and the Touring Club paid him high homage due to his constant financial support.

Being emotionally attached to that "strange people", how did Gibson manage to describe them in Rio? Unsurprisingly, Cariocas, once more, are described as "good-tempered" and "friendly" (Gibson, 1940: 17-18). Through a metonymic procedure, they are taken as the "typical Brazilians" and, although Gibson advises the reader that it is not his intention to provide "an exhaustive analysis of Brazilian character, manners and customs" (ibid: 13), he does attempt to contradict some stereotypes he believes had misinformed US perceptions of Rio and Brazilians in general. On one hand, most Americans think "a Brazilian is a multimillionaire who made his money in coffee and spends it in Paris" (ibid: 14); on the other, when visiting Rio for the first time, they expect to land "in a noisy slum" and to have to make their way "over dirty docks and through dirtier streets" (ibid: 7). His fellow citizens will be pleasantly surprised when landing on "a spacious quay" and being conducted through "an airy marble pavilion" (ibid: 7) to meet "the average Brazilian", who has always the well-being of its family in first place and who is always ready to overlook bureaucratic matters in the name of friendship.

Gibson's descriptions match perfectly the images of Rio and the Cariocas displayed in FDR. Both make a point of presenting the city as a sophisticated place where family traditions were strong and smiles were highly valued. What Gibson as well as those involved in the production of FDR obviously did not realize was that they were also building an image of Rio (and Brazil, for that matter) which was equally stereotypical. In the case of both Gibson's book and the RKO film, what is most striking is that the stereotypes displayed by them are based less upon the differences between Americans and Brazilians than they are on what would supposedly be the common traces shared by the two cultures.

Different from other travel narratives of the period, Gibson does not give explicit managerial advice nor discuss any ideological matters. If he reveals a desire to bring some US customs to Brazil, it is limited to generalities such as hunting or gardening practices. In Gibson's own words, his book is a response to both the "insatiable curiosity of travellers" and to "the dearth of published material on Rio" (ibid: vii). The ambassador sees it as a work that could be enjoyed by tourists and general readers alike, presenting knowledge not only of the city but also of its people: "The work ... will be richly repaid if it helps others to share appreciation of the beauties of the place and the charm of the people - either in Rio, or in an armchair before the fire at home" (ibid: xi). Still, "if you want to know what Rio is like you cannot learn it from a book. There is only one way - come and see for yourself" (ibid: 4).

Faced with the limitations of language in his endeavours to grasp and reproduce "the real city" and "the true character" of its inhabitants, Gibson counts on what he considered a more "dependable" form of representation, namely 


\section{Bianca Freire-Medeiros}

photography. As in FDR, a succession of iconic images pass before the reader's eyes: Guanabara Bay, Jockey Club, Botanic Garden, Sugar Loaf, Corcovado, oceans, and mountains. But differently from the spectator of the RKO musical, Gibson's travelling companion has the chance to get a more detailed picture of the city, to visit a fish market, to admire a wood sculpture in the Sacristy of São Bento Church, to gaze at some Carnival merrymakers. It is interesting to note that each time the reader goes a page further, the photographs change from a totally impersonal point of view (the obvious tourist landmarks seen from a distance) to a particular and impressionist frame. Little by little, Gibson unveils the city to those who follow him along the way, giving them mementos of his own experience as a traveller.

In the last chapter, concerned with a panorama of Brazilian history, Gibson (1937) quotes several sources and recommends a list of books. But his narrative is mainly informed by "settled", "agreed" representations of the city constructed by the inhabitants themselves. The description, therefore, obeys a folded logic: it is a representation of a place, but it also creates a new spatiality. The narrative structure basically follows two complementary principles: on one hand, it approaches the city "objectively", offering historical data on Rio's buildings as well as natural landmarks; on the other, it appeals to an "impressionist" depiction, recounting the effects provoked by his contact with colonial churches of "exquisite" architecture, "profuse" markets, the "marvellous" Botanic Garden. In so doing, Gibson assumes he is giving the reader nothing more, nothing less, than "the real Rio", one that "the foreigner rarely gets to know" (ibid: ix). While others offered a partial image of the city, limiting themselves to the description of tourist spots, he is committed to revealing a unique place in between nature and culture, tradition and modernity: "[E]ven modern Rio is a curious mixture of a great metropolis and a summer resort, with odd vestiges of the past. At one extreme you have Cinelandia, with a choice of all the latest productions of Hollywood, Vienna and Berlin; and a few miles away, if you know how to arrange the matters, you can witness a macumba of strange voodoo rites" (ibid: 43).

America, Europe, and Africa: Rio, as perceived by Gibson, is a time map. The presence of cultural elements from the three continents points to a balanced acquaintance between tradition and modernity. Metonymically, this feature of the city is extended to the whole population of the country. There is no conflict between the young and the old: although "up-to-date in most things", the young people "have old-fashioned manners" (ibid: 22). Like the city itself, Brazilians are "a curious mixture of formality and matter-of-fact simplicity" (ibid: 16) and for them, symbolic values and traditional institutions such as family "are more important than money" (ibid: 23).

As in FDR, Gibson's Rio is a spatial form which condenses two apparently irreconcilable principles: the city as a civilized/modern space and city as a primitive/traditional dominion. Although representing Rio as a cosmopolitan city, offering enthusiastic comments on its "modern" side, Gibson is clearly more attracted by its "traditional", "natural" elements, usually rejecting its 
contemporary features and aspiring to discover whatever might be considered vestiges of a "primitive" Brazil. As he summarizes it: Rio is "a great modern city it" with "its boulevards, its skyscrapers and its night clubs," but "when you have the possibilities of a moonlight night on the bay of Rio, who wants to go to an airless night club and listen to airless jazz?" (ibid: 37 ).

The city, for sure, has distinguished itself from nature; however, it is not its opposite but its complement. Not by chance, Gibson's book has chapters titled "Modern Rio" and "Jungles Way in Town", perhaps in an attempt to reproduce in his narrative the same kind of symmetry he believes present in the city. After reading the whole book - and watching the film - one gets the feeling, though, that both narratives ended up prisoners of the same logic employed by most narratives to these days, which transform the city into an exotic good for the "civilized" US consumption.

\section{Conclusion}

It would be no exaggeration to say that a large amount of Rio's history has been built on the real, as well as imaginary, interconnections between the mobilities of colonization, voyaging, and tourism. Both films and travel guides, as I attempted to demonstrated here through two particular cases, are forms of representation which anticipate the cityscape to an audience; they bring a sense of materiality that does not presuppose actual physical mobilities but rather the mobilities of discourse and imagination.

If a fascination between the United States and Brazil had been present, if only informally, the Good Neighbour Policy brought that fascination to the centre of the state's agenda. Under its auspices, Brazilians were increasingly exposed to the full force of the United States' powerful economic, political, and cultural influence. Meanwhile, US investors, leisure travellers, and potential settlers looked southward with mixed hopes of both financial success and sensory delights. Carmen Miranda, the "Brazilian Bombshell", became the highest-paid entertainer in Hollywood in 1942; Hollywood productions accounted for over 70 percent of the films released in Brazil in that same year (Barsante, 1994).

As Tunico Amancio (2000) accurately states, although committed to an exposition of "positive images" of the city, cultural products that were produced under the auspices of the Good Neighbour Policy - FDR included make use of an extensive repertoire of cultural stereotypes and visual clichés. For what I have demonstrated here, the same argument could be made in regard to Gibson's book. It is important to note, though, that the rhetorical tropes that both narratives present can be read as the discursive outcome of a set of specific anxieties about North and South Americans which were in dialogue with the very self-images which Brazilians were attempting to construct of themselves.

For both national and international audiences, Rio was a place in which the presence of cultural elements from Europe, Africa, and America 


\section{Bianca Freire-Medeiros}

pointed to a balanced acquaintance between tradition and modernity, between black rhythms and white bodies. It was, thus, a spatial form that condensed two apparently irreconcilable principles: the city as a civilized/ modern space and the city as a primitive/traditional dominion. Those cities where the power of nature transformed it into a landscape which has overcome man's actions tend to have their geography eroticized and to be considered feminine (Todorov, 1993). In this sense, Rio was seen as conjuring up an ideal balance between a male civilizing power and a female attractive abundance, the symmetry between a domestication of the space by local as well as by foreign males and the preservation of natural landscapes, beautiful and exuberant as its women. While signs of modernity and civilization are brought into the cityscape, Cariocas are shown as having access to the benefits of Western technology (airplanes, radios, and so on), and social rules are posed as being definitely linked to a traditional logic. Exterior time may progress, but the Rio invented by the two narratives examined here always offers a reprieve, an atemporal escape hatch whereby readers and audiences elude modernity and enter an exotic theatrical stage of (male) quest.

\section{Notes}

1 In The Girl of the Rio (RKO, 1932b), del Río's character was fought over by a decent white American male and a greasy Mexican bandit. She finished up with the American, but no marriage was mentioned.

2 The low quality of the ships offering services between the United States and Brazil was a recurrent issue in Gibson's private as well as official letters. The ambassador would even blame the unreliability of those ships for the small number of Brazilians choosing the US as their vacation destination in the 1930s.

3 In 1933, Gibson had written one other book, A Journal from Our Legation in Belgium (1917). He subsequently produced Belgium, The Country and Its People (1939); and The Road to Foreign Policy (1944). With former President Hoover, he wrote The Problem of Lasting Peace (1947), a book that was severely criticized. For an interesting analysis of this, see Harrison Thomson's review (1943).

4 Unfortunately, Rio has never been translated into Portuguese, and today few Brazilians have any knowledge of it.

\section{Bibliography}

Aitken, S.C. \& Zonn, L. (1994). Place, power, situation, and spectacle: A geography of film. Lanham: Rowman \& Littlefield.

Altman, R. (1987). The American film musical. Bloomington: Indiana University Press.

Amancio, T. (2000). O Brasil dos Gringos: Imagens no cinema. Niterói: Intertexto. Arnold, D. (2000). 'Ilusory Riches': Representations of the tropical world, 18401950. Singapore Journal of Tropical Geography 21(1): 6-18.

Augusto, S. (1995). Hollywood looks at Brazil: From Carmen Miranda to Moonraker. In: R. Stam \& R. Johnson (eds.), Brazilian cinema, pp. 352-361. New York: Columbia University. 
Bandeira, M. (1989). Brasil e Estados Unidos: A Rivalidade Emergente (1950-1988). Rio de Janeiro: Editora Civilização Brasileira.

Barsante, C.E. (1994). Carmen Miranda. Rio de Janeiro: Elfos Editora.

Benchimol, J.L. (1992). Pereira Passos, um Haussmann tropical: a renovação urbana da cidade do Rio de Janeiro no início do século XX. Rio de Janeiro: Secretaria Municipal de Cultura.

Berg, C.R. (1988). Images and counterimages of the Hispanic in Hollywood. Tonantzin 6(1): 12-13.

Bruno, G. (1997). Site-seeing: Architecture and the moving image. Wide Angle 19(4): $8-24$.

Cândido, A. (1984). A Revolução de 1930 e a cultura. Novos Estudos 24(4): 27-36.

Clarke, D.B. (1997). Previewing the cinematic city. In: D. Clarke (ed.), The cinematic city. London: Routledge.

Cortés, C.E. (1984). The history of ethnic images: The search for a methodology. MELUS 11(3): 63-77.

Cortés, C.E. (1992). Who is Maria? What is Juan? Dilemmas of analyzing the Chicano image in U.S. feature films. In: C. Noriega (ed.), Chicanos and film: Essays on Chicano representation and resistance. Minneapolis: University of Minnesota Press.

Falcoff, M. (1997). Book review: FDR's good neighbour policy: Sixty years of generally gentle chaos. ORBIS 41(1): np.

Fausto, B. (1994). A Revolução de 1930. São Paulo: Editora Brasiliense.

Fischer, B. (2014). A century in the present tense. In: B. Fischer, B. McCann \& J. Auyero (eds.), Cities from Scratch, pp. 9-67. Durham: Duke University Press.

Fishlow, A. (1984). Brazil: The case of the missing relationship. In: R. Newfarmer (ed.), From gunboats to diplomacy: New U.S. policies for Latin America. Baltimore: Johns Hopkins University Press.

Foulke, R. (1992). The guidebook industry. In: M. Kowalewski (ed.), Temperamental journeys: Essays on the modern literature of travel. London: University of Georgia Press.

Freire-Medeiros, B. (2002). The traveling city: U.S. representations of Rio de Janeiro in travel accounts, films and scholarly writing (1930s-1990s). PhD dissertation. Binghamton: Binghamton University.

Freire-Medeiros, B. (2005). O Rio de Janeiro que Hollywood inventou. Rio de Janeiro: Zahar.

Freire-Medeiros, B. \& Castro, C. (2013). Destino: Cidade Maravilhosa. In: C. Castro et al. (eds.), História do Turismo no Brasil. Rio de Janeiro: Ed. FGV.

Gellman, I.F. (1979). Good neighbor diplomacy: United States policies in Latin America, 1933-1945. Baltimore: Johns Hopkins University Press.

Gerbi, A. (1973/1996). O Novo Mundo. São Paulo: Companhia das Letras.

Gibson, H. (1937). Rio. New York: Doubleday/Doran.

Gibson, H. (1956). Hugh Gibson, 1883-1954: Extracts from his letters and anecdotes from his friends. New York: Belgian American Educational Foundation.

Hannam, K., Sheller, M. \& Urry, J. (2006). Editorial: mobilities, immobilities and moorings. Mobilities 1(1): 1-22.

Henderson, B. (1982). A musical comedy of empire. Film Quarterly 35(2): 2-16.

Hilton, S.E. (1975). Brazil and the great powers, 1930-1939. Austin: University of Texas Press.

Hugh Gibson Papers. (n.d.). Hoover institution on war, revolution, and peace. Stanford: Stanford University Press. 


\section{Bianca Freire-Medeiros}

Jobim, E.C. (1991). O Risco e o Olhar: Sobre a Imagem da Cidade do Rio de Janeiro. Gávea.

Livingstone, D.N. (2000). Tropical Hermeneutics: Fragments for a historical narrative: An afterword. Singapore Journal of Tropical Geography 21(1): 76-91.

Lynch, K. (1984). Reconsidering the image of the city. In: L. Rodwin \& R.M. Hollister (eds.), Cities of the mind. New York: Plenum.

Manthorne, K.E. (1996). O Imaginário Brasileiro para o Público Americano do Século XIX. Revista USP 30: 58-71.

Mendonça, A.R. (1999). Carmen Miranda Foi a Washington. Rio de Janeiro: Record.

Mills, S. (1991). Discourses of difference: An analysis of women's travel writing and colonialism. London: Routledge.

Moura, G. (1995). Tio Sam Chega ao Brasil - A Penetração Cultural Americana. São Paulo: Editora Brasiliense.

O’Donnell, J. \& Freire-Medeiros, B. (2018). Antinomic-complementary landscapes: The beach and the Favela in early-twentieth-century Rio de Janeiro. In: B. FreireMedeiros \& J. O'Donnell (eds.), Urban Latin America images, words, flows and the built environment. London: Routledge.

Pike, F.B. (1992). The United States and Latin America: Myths and stereotypes of civilization and nature. Austin: University of Texas Press.

Pratt, M. (1992). Imperial eyes: Travel writing and transculturation. London: Routledge.

Reijnders, S.L. (2011). Places of the imagination: Media, tourism, culture. Farnham: Ashgate Publishing.

RKO Radio Pictures Inc. (1932a). Bird of paradise. Director: King Vidor. Cast: Dolores del Rio, Joel McCrea, John Halliday, Lon Chaney Jr. Hollywood: USA.

RKO Radio Pictures Inc. (1932b). The girl of the Rio. Director: Herbert Brenon. Cast: Dolores del Rio, Leo Carrillo, Norman Foster, Ralph Ince. Hollywood: USA.

RKO Radio Pictures Inc. (1933). Flying down to Rio. Director: Thornton Freeland. Cast: Dolores del Rio, Gene Raymond, Raoul Roulien, Ginger Rogers, Fred Astaire, Blanche Frederici. Hollywood: USA.

Schwartz, R. (2004). Flying down to Rio: Hollywood, tourists, and Yankee Clippers. Austin: University of Texas Press.

Sheller, M. \& Urry, J. (2004). Tourism mobilities: Places to play, places in play. London: Routledge.

Smith, J. (1991). Unequal giants. Diplomatic relations between the United States and Brazil, 1889-1930. Pittsburgh: University of Pittsburgh Press.

Stam, R. (1997). Tropical multiculturalism: A comparative history of race in Brazilian cinema and culture. London: Duke University Press.

Strain, E. (2003). Public places, private journeys: Technology and the mobilized gaze of the tourist. New Brunswick: Rutgers University Press.

Swerczek, R.E. (1972). The diplomatic career of Hugh Gibson, 1908-1938. PhD dissertation. Iowa: University of Iowa.

Thomson, H. (1943). Book review: 'The problems of lasting peace'. Journal of Modern History 14(4): 557-559.

Todorov, T. (1993). On human diversity: Nationalism, racism, and exoticism in French thought. Cambridge: Harvard University Press.

Tzanelli, R. (2007). The cinematic tourist: Explorations in globalization, culture and resistance. London: Routledge. 
Urry, J. (2000). City life and the senses. In: G. Bridge \& S. Watson (eds.), A companion to the city, pp. 388-397. Oxford: Blackwell.

Urry, J. (2007). Mobilities. London: Polity Press.

Weil, M. (1978). A pretty good club: The founding fathers of the U.S. foreign service. New York: Norton.

Woll, A. (1977). The Latin image in American film. Los Angeles: University of California Press. 


\title{
8 Following Oshin and Amachan \\ Film tourism and nation branding in the analogue and digital ages
}

\author{
Elisabeth Scherer and Timo Thelen
}

\section{Introduction}

The asadora (morning drama) is considered one of the most representative and influential formats on Japanese television. With each series running for half a year, the asadora presents a female heroine in her struggle for personal fulfilment and happiness for 15 minutes every morning since 1961. Yoshimi (2005: 544) noted that "[f]rom the early 1960s, television became a prominent medium linking the family with the state, defining the national consciousness, and dominating people's imaginative views of both the past and the present". This is very true for the asadora: the show's daily presence and the ritualistic habits of many viewers give the asadora steady public attention as well as a prominent place in the collective memory of Japan. Although some critics have diagnosed the slow decline of this format - along with classic television in general - and criticized the sometimes very conservative narratives, the asadora remains an important flagship for the public broadcaster NHK. Furthermore, it also receives notice beyond national borders, especially in East Asia.

Even though various asadora have long been closely linked to specific regions of Japan as filming locations, their impact on tourism has only been investigated recently (e.g. Maruta et al., 2014; Tajima, 2015; Jang, 2016; Scherer \& Thelen, 2017, 2018). Research on media tourism in Japan usually focuses on the genre of anime (Yamamura, 2015) and historical television series (Seaton, 2015). In Japan, the term "contents tourism" is commonly employed, a buzzword initiated by the Japanese government in the early 2000s as an umbrella term for any kind of tourism associated with a transmedially marketed and locally anchored story. This story can be embedded in movies, manga, video games, or literature, though historical personalities and events are also considered "content". The theoretical and methodological approaches to film tourism in Japan are similar to those of film tourism studies in Western research discourse (see also the Introduction to this volume for a discussion on the Western academic perspectives). One peculiarity in the case of Japan, however, is the strong political interest in this kind of tourism, which is regarded as a tool for the economic promotion of peripheral regions and for Japanese "nation branding". Likewise, 
asadora are firmly embedded into the "soft power" (Nye, 2004) strategy of Japan's cultural and foreign policy. In our chapter, we will discuss this political dimension related to the locations of popular media products (see also Chapters 6 and 8 of this volume, which offer case studies of "nationalized" media content in Denmark and Slovenia).

Moreover, our research provides answers to the question of how the phenomenon of film tourism has changed over time. In particular, there is only little research on the effects of the shift from the analogue to the digital age concerning the activities of viewers and their "fan pilgrimages". The examination of asadora as a steady TV format that has run for many decades provides new insights here. We consider film tourism as a part of the phenomenon of media convergence, that is, media content marketed and consumed across multiple platforms. As case studies, we selected two of the most influential asadora in the history of this format: Oshin (1983/1984) as an example of the analogue age and Amachan (2013) for the digital. Additionally, both series relate to narratives of national reconfiguration: the economic boom of the 1980s in the first case and the renewal after the triple disaster of 11 March 2011 (tsunami, earthquake, and nuclear meltdown in Northern Japan) in the latter.

\section{Media convergence and film tourism}

Tourism induced by movies and TV series should no longer be regarded as a phenomenon that occurs more or less randomly and only as a result of the popularity of media products. Rather, it is important to look at tourism in the larger context of media convergence, that is, in the interplay of various media through which a particular story is sold and received.

According to Jenkins (2006: 2), "media convergence" includes the "flow of content across multiple media platforms" and "the cooperation between multiple media industries". In many cases, tourism fits very well into this concept and has become an integral part of the strategy for optimizing all possible sources of revenue: films and series are funded by certain regions in the hope of increasing tourism by representing their cities and landscapes in the media. TV programs, magazines, and online media reports about the filming spread images of the locations. And through licensing, local stakeholders have the opportunity to give a material presence to key figures and symbols from the series that are important to the locations - and thus create a clear link to the story (e.g. Yamamura, 2015).

Visits to filming locations may become part of the strategy of "transmedia storytelling", which, according to Jenkins (2006: 21), means that fans (as "hunters and gatherers") are encouraged to collect fragments from various media to "fully experience any fictional world". Visiting the landscapes of a series or entering the "home" of a fictional character can also be a way for fans to experience all the nuances and dimensions of a given story. 


\section{Elisabeth Scherer and Timo Thelen}

In Japan, marketing of stories across various media channels has long existed, especially in the field of anime. In research on Japan, this phenomenon is usually referred to as "media mix" (Ito, 2008; Steinberg, 2012). As Ito (2008: 52-53) describes, in the 1960s and 1970s, a system evolved in which manga characters wandered into other media such as games, anime, and merchandise, reaching consumers in their everyday lives in a variety of ways. This system did not disappear with digital media but resulted in an "interaction between long-standing and emerging media forms" (ibid: 53).

The audience is conceptualized as a very significant, active part of this system. Consumers access media content through a variety of platforms and can become producers themselves by sharing opinions on their favourite series, writing articles, creating fan art, or simply gathering knowledge that will help them to access the "world" of a story to its farthest corners. Jenkins (2006) calls this principle of fan networking "collective intelligence". Especially when gathering information on filming locations, this principle has proven to be of great value to fans. As Seaton et al. (2017: 221) also stress, one important aspect of marketing filming locations may be not handing over all the information on a silver platter. For fans, it is often the detective work, the meticulous comparison of sceneries on location with stills from films and series, that stimulates their enjoyment.

And as Couldry (2003: 93) noted, when people who have already been to the scene share their experiences on the Internet, it generates further enthusiasm among other fans: "the replication of images of actual pilgrimage sites on the Web reinforces their original significance". Publishing their work is also important for the photographers themselves because they perceive "their travel experiences through the eyes of others" (Sheungting Lo \& McKercher, 2016: 240), and part of the pleasure of their journey is being able to show off their cultural capital as experts. When they watch the series after the trip, they see the places with fresh eyes: they were there; they have become part of something that is "intrinsically significant" (Couldry, 2000: 72), which (in the case of the asadora) millions of people pay attention to every day.

Digital media, and especially social media, are often seen in research as factors that have brought about revolutionary changes - whether as part of media convergence, as a means of connecting the audience, or as a tool for tourism marketing. For example, TV series from Japan are increasingly spreading through Asia and beyond thanks to digital technology - through legal channels, of course, but maybe even more through fan networks that share recordings and create subtitles (Iwabuchi, 2004; $\mathrm{Hu}, 2005$ ) - and it has become easier for fans to connect transnationally. "User-generated content" now has the potential to be received by a large number of people and is often considered more credible than what is distributed via conventional media, making it an important factor in the field of tourism. However, Bird (2011) cautions against an uncritical glorification of the "produser" - as the active consumer is also called - and her power, as the media industry has 
also become quite skilful at instrumentalizing fan activities and controlling the online environment.

In the following sections, we will explore how media convergence and audience activity can be entangled with nation branding strategies and the role digital media plays in this by drawing on the examples of two popular asadora.

\section{Interacting with Oshin and Amachan: audience participation}

The series Oshin (April 1983-March 1984) follows the life of the eponymous protagonist, who rises from a poor peasant daughter from Yamagata prefecture to the owner of a supermarket chain. The plot of the 297 episodes takes place between 1907 and 1983 and thus also deals with the time of World War II. With average audience ratings of $52.6 \%$, Oshin is the most successful asadora of all time and shows how the audience actively participated in a media phenomenon before the Internet age. The reactions and interactions were so far reaching that the audience reached visibility well beyond the abstract numbers of audience ratings. A lively interaction of commercial offers, fan practices, and cultural policy developed, which can still be observed in a similar form today.

According to Harvey (1995: 75), one of the reasons for Oshin's success was that this series was written and produced by women. He sees in Oshin a "powerful statement" that reflects the situation of women in Japan and their position in 20th-century history. The series is also evidence of the successful implementation of the "media mix" principle, which was already highly professionalized in Japan at the time. The so-called "oshindrome" included very extensive marketing beyond the series: music, merchandise, a stage play, and even Oshin toilet paper, for example (Asahi Shinbun, 1983, 27 June; Mainichi Shinbun, 1983, 20 August). As a full-page advertisement in the newspaper Asabi Shinbun shows on 14 January 1984, the target group of Oshin was extended to include children with an anime film and related toys. The slogan "Experience the enthusiasm beyond television" speaks of the underlying strategy of media convergence. Fictional characters thus gain material presence in everyday life and connect the audience even more closely with the series: "The character good functions as a monad or medium through which the consumer can pass into the character's world" (Steinberg, 2012: 188).

Oshin became a morning ritual for many people, a favourite subject of everyday conversation, and a role model. People held meetings where they exchanged views about Oshin, and they even published their own fanzines. According to newspaper articles from the time of the show's broadcasting, Oshin also encouraged the re-enactment of the series' narrative. Oshin's family is portrayed as very poor, so they have to eat rice with radish (daikonmeshi). During the broadcast of the series, it became a popular custom in Japanese families to eat this simple dish together, and even today, one can 


\section{Elisabeth Scherer and Timo Thelen}

find countless recipes on the Internet that refer to the series. This is a simple example of how TV series are integrated into everyday life and how the audience participates in the narrative not just by watching but also through performative acts. Shefner-Rogers et al. (1998: 10) regard Oshin as a series that has produced a particularly high degree of such (parasocial) interaction. NHK and other stakeholders offer manifold opportunities for audience participation, but the viewers do not necessarily enter these predetermined (and commercially viable) paths of interaction.

Much has happened in the more than 30 years since Oshin, and in the digital age, the audience has even more options to become productive and participate in a series. Today, series are often enjoyed independently of a certain TV broadcasting time, which might lead to the conclusion that this destroys the sense of community that comes with experiencing a story simultaneously (and nationwide). On the other hand, the audience is now able to exchange views about the asadora instantly, and new forms of fan communities emerge, such as Facebook groups (called shisetsu òendan, "private support groups") where fans provide each other with detailed information about the series, actors, and so on. These platforms also play a major role in disseminating information about and images from the asadora locations.

With Amachan (April-September 2013), these digital fan activities during the broadcasting became very prominent for the first time. The story follows the life of Aki, a high school student who becomes an $a m a^{1}$ diver in her mother's hometown in Northern Japan (Tōhoku). She is eventually discovered as an idol by the music industry and goes back to Tokyo to pursue her career. After the triple disaster in 2011, which is featured and discussed in the series, Aki decides to return to Northern Japan to help with the reconstruction work.

Amachan, like all asadora, was deeply embedded in the media mix machine, which continues to function much like in Oshin's days. The audience ratings of $20.6 \%$ were rather average. Nevertheless, the series was very present in public discourse, which, as a study by the NHK Broadcasting Culture Research Institute shows, is strongly related to the online activities of the audience (Nihei \& Sekiguchi, 2014). A survey (with 1,298 respondents) on Amachan revealed that audience activity consisted mainly of talking to family $(39 \%)$ or friends $(30 \%)$ about the show, watching TV shows linked to Amachan (13\%), or repeating certain slogans and dialect terms from the series $(11 \%)$. Only $1 \%$ of the respondents said they read or write on SNS about the series (Nihei \& Sekiguchi, 2014: 18). Amachan still had a tremendous online presence: more than six million tweets were posted from 880,000 accounts, about 12 times as many as during the previous asadora broadcast (Nihei \& Sekiguchi, 2014: 24, 28). There is thus a small but extremely committed part of the asadora audience which is increasingly showing its presence on the Internet, exchanging views on social media, publishing fan works (especially illustrations), and thereby strongly shaping the public perception of the series. That these fans are a rather small group among the asadora audience is certainly also due to the fact that today a 
high proportion of viewers are 70 or older, an age group where social media usage is less widespread (Takō, 2012: 285).

In addition to audience ratings, social listening has become an important instrument for measuring the success of an asadora. And, of course, various stakeholders are trying to influence SNS discourse: besides producers such as NHK, numerous interest groups currently employ online media, such as the Kitasanriku Amachan Tourism Promotion Group, which still launches tweets about Amachan and the filming locations on a daily basis, while local people from the region often also comment on social media. As Tajima (2015) explains, the identification of the local population with a series is regarded as an important factor for the success of film tourism in Japan; through the presence in national media, the awareness of the local culture's value grows among the local communities, and with the new self-confidence subsequently gained, they can also succeed in attracting a larger fan base from outside. In the case of Amachan, measures to create enthusiasm among the people of the city of Kuji were involvement in the shooting (for example, as extras or experts for local customs), a local fan magazine, and public screenings of the series. Local people thus became the primary "active audience", a role model for the national audience.

\section{Visiting Oshin and Amachan: film tourism}

Although film tourism has only been studied extensively in Japanese-language research since about ten years ago, the case of Oshin shows that the phenomenon of fan tourism, even in a commercialized form, has existed for a much longer period. Yamagata Prefecture, in particular, where the heroine grows up, was marketed as a tourist destination in the early 1980s and transformed into a "place of imagination" (Reijnders, 2011) for fans. For example, some large advertisements in the daily newspaper Yomiuri Shinbun promoted tours to Oshin's home, including visits to Sakata City and Ginzan Onsen (hot spa) and, depending on the season, a cherry harvest experience or a snowscape boat cruise (Yomiuri Shinbun, 1984, January 17). The leading Japanese tourism agencies sold such tours with great success at that time (Yomiuri Shinbun, 1983, July 25). There are relatively few sources documenting this kind of tourism, but in light of general tourism trends, it can be assumed that the "fan pilgrimage" related to Oshin consisted primarily of group travelling, which means it was characterized by a "collective gaze" (Urry \& Larsen, 2011: 19) shared by all the visitors. This shared travel experience of the filming locations affirms their authenticity for the fans. Moreover, in this era, one can surmise that it must have been much more difficult and time consuming for individual travellers to rediscover the significant spots known from media content on their own in the countryside.

As screenwriter Hashida (1983) reports in a newspaper article, at an early stage of Oshin's production, residents at the filming locations initially doubted the positive impact of the asadora because Yamagata is associated 
in the series with poverty and hard living conditions. Hashida, however, insisted that the series had to be located in Yamagata because of the snow, the Mogami River, and the local dialect. She describes personal memories related to these elements, which support the image of "romantic poverty" in Yamagata, an image that ultimately became very marketable in terms of tourism. Eventually, local authorities in Yamagata also recognized and adapted Oshin's potential: The Bashō Line, which operates on Mogami River, was renamed Oshin Line, and a life-size statue of Oshin was installed in front of Sakata Station (Asahi Shinbun, 1983, July 23). When tourists in Sakata repeatedly asked for the house where Oshin spent her youth, the city government designated a building as an equivalent or model (Yomiuri Shinbun, 1983, July 25). Even in Tokyo, the prefecture drew attention as "Oshin's home" by organizing an apple festival in November 1983 (Yomiuri Shinbun, 1983, November 14).

In Sakata, Oshin sweets, sake (rice wine), wooden dolls (Figure 8.1), straw mats, etcetera, were offered as souvenirs (Asahi Shinbun, 1983, July 23; Yomiuri Shinbun, 1983, July 25). Local specialties and artisan products were enhanced by the label of Oshin and received a new appeal. According to the newspaper Yomiuri Shinbun (1983, July 25), there were also copyright infringements that brought local merchants a complaint from NHK. Copyright is generally a critical issue in film tourism; the often very limited possibilities for the marketing of locally produced souvenirs demonstrate the gap of power between the media producers based in the major cities and the film locations on the periphery (Scherer \& Thelen, 2017: 14-15). NHK does indeed draw much public attention to rural areas, through the asadora itself and by reporting on the filming locations in various shows, but at the same time, the broadcaster carefully protects its own benefits derived from tourism through the licensing of souvenirs (Maruta et al., 2014: 64-65) and thus exploits all opportunities offered by media convergence.

However, the depiction of a certain place in a TV series does not automatically promise benefits. A serious conflict between the heroine Oshin and her mother-in-law plays out in Saga Prefecture, for instance. As a result, the local tourism association of this prefecture worried about the prefecture's image being damaged during the broadcast of Oshin and filed a complaint with NHK. To allay these worries, the producers reassured them that the character of Oshin's mother-in-law would undergo a positive development throughout the narrative (Asahi Shinbun, 1983, September 7). This anecdote illustrates the importance that was attached to Oshin regarding regional development. For Yamagata prefecture, the impact of the series lasts until today, as local tourism promotion illustrates. In addition to the original series, Yamagata Prefecture also advertises itself as a filming location for the Oshin feature film, which was shot in 2013 to celebrate the series' 30th anniversary (Yamagatakanko, 2013). The prefecture invested its own funding in the production of this film in an effort to increase its appeal to visitors, especially in the wake of the triple disaster of 2011. The number of tourists, for example, coming to the Shōnai Movie Village, a large-scale open movie 


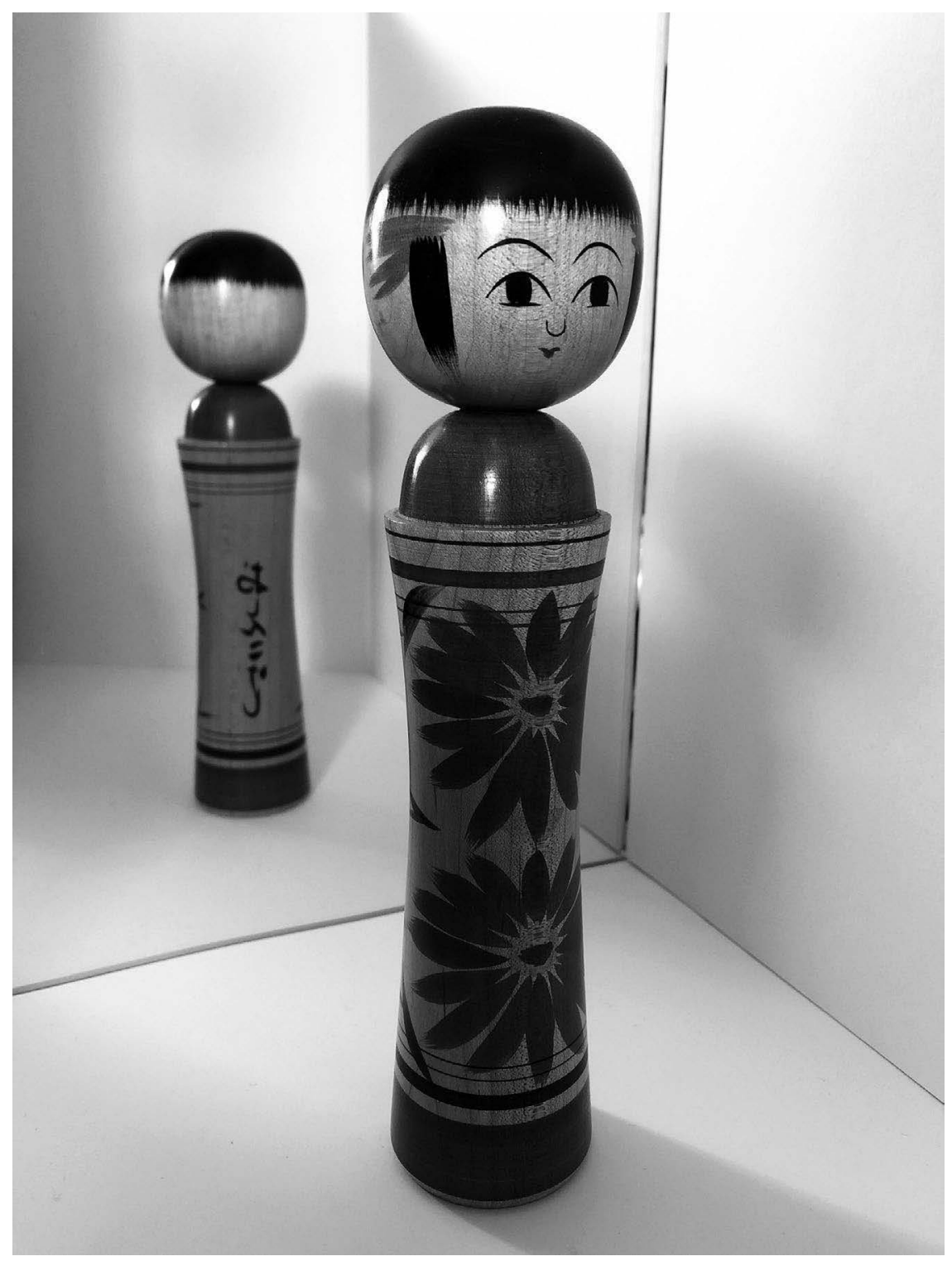

Figure 8.1 Kokeshi (wooden doll).

Source: Photo by authors.

set located in Sakata City, had harshly declined (Yomiuri Shinbun, 2012, September 4) after 2011. In newspaper articles about the feature film, the character of Oshin is now also associated with the strength and endurance of the people of Northern Japan after the catastrophe. 
The triple disaster also played a major role in the production of the asadora Amachan, which was filmed at the same time; it had damaged the region's general image in public, in particular due to the possible risk of radiation. In order to support the region's rehabilitation, the series Amachan was set in the fictitious city of Kitasanriku in Iwate Prefecture, which was heavily damaged by the tsunami. The port city of Kuji, which served as filming location, suffered from serious devastation, but casualties remained relatively low there, with only four people dead. The triple disaster itself as well as the enthusiasm for reconstruction turned into important narratives in Amachan. Comments on Twitter exemplify how much the audience felt affected by the catastrophe's depiction, which probably helped the region acquire greater attention in the public consciousness. One Twitter user wrote that "Kitasanriku became a second home" for him, and another noted that thanks to the series, many people who live outside of Northern Japan realized that the triple disaster affects them as well; thanks to the series, everyone now had "relatives in Kuji", as he put it (Sun Ju Sun, 2013). After the broadcast of the episode in which the tsunami occurred, many tweets compared the depiction in the series (all characters survive) to the actual casualties at the filming location in Kuji. This illustrates the importance asadora viewers attach to authenticity, especially when it comes to the filming locations and regional features.

In addition to a greater interest in the filming locations and the region as a whole, the success of Amachan finally brought a tourism boom. In the year of broadcasting, 2013, Iwate Prefecture recorded an $86 \%$ growth in the number of visitors, which remained at a relatively high level in 2014 compared to the time before the broadcast (Tajima, 2015: 25). Various projects, largely driven by local initiatives, took advantage of Amachan's content and utilized it for touristic means. For example, the facades of closed-down shops in downtown Kuji were embellished with pictures from the series and an "Amachan House" decorated with props from the series was opened.

In the digital age, SNS usage not only diminishes the boundaries between consumers and producers but also greatly influences travel behaviour and trends (Urry \& Larsen, 2011: 59-60). While at the time of Oshin, group travel dominated the tourism market, such organized package tours are rarely offered today. In the case of Amachan, only a three-hour tour with a tourist bus was arranged for visitors (Tajima, 2015: 23). Tourists today act independently, and thanks to technical innovations like mobile devices with GPS, they can now easily explore peripheral filming locations on their own. Such a fan pilgrimage is nurtured by a "romantic gaze" (Urry \& Larsen, 2011: 19): a seemingly individualized and solitary travel experience, which is, however, often significantly pre-influenced by the representations of travel experiences that others have shared on the Internet.

The example of Amachan also illustrates how members of the audience remodel and reproduce certain elements of the media content and then disseminate their own version online. For instance, many fans who came to 


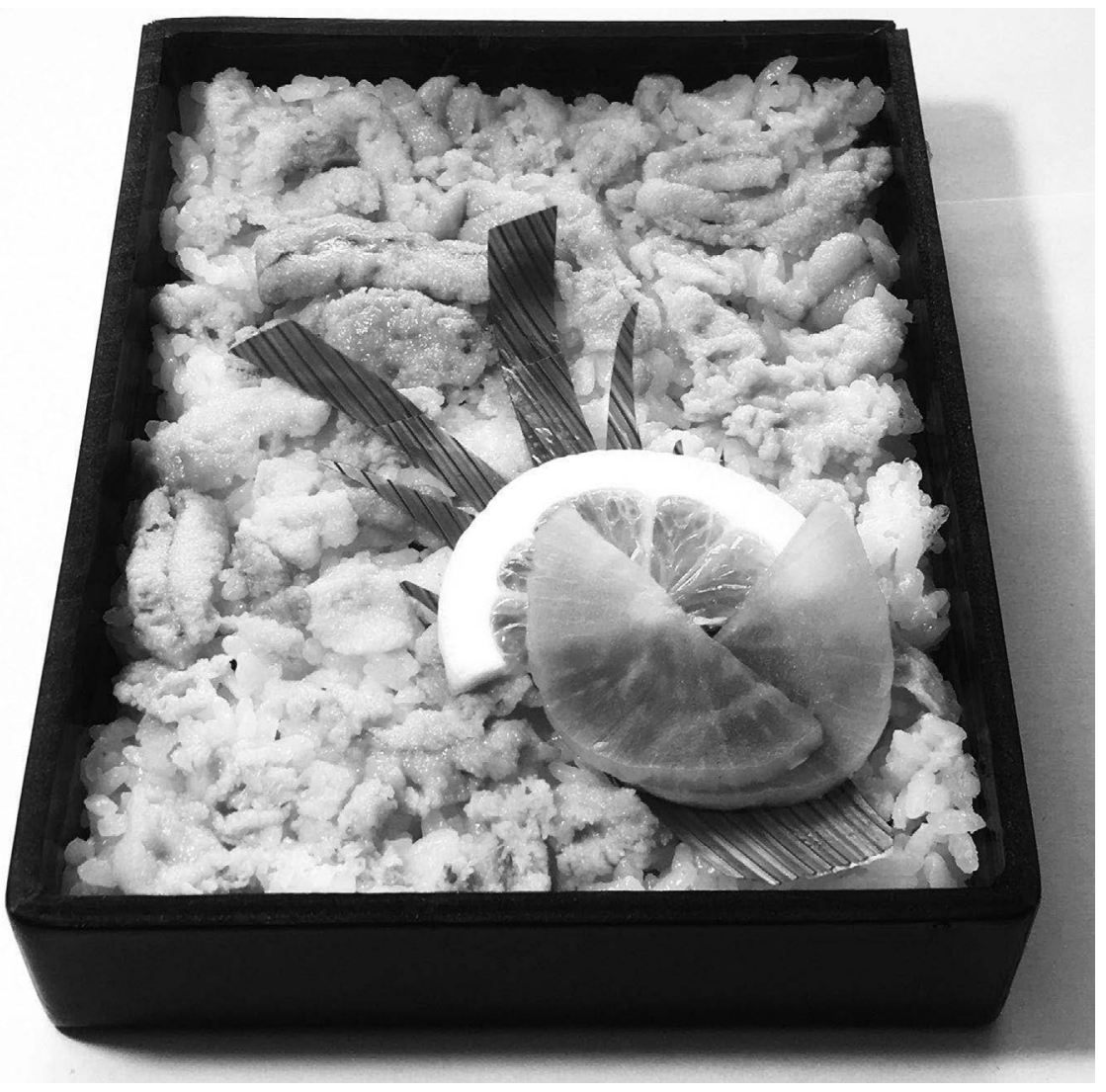

Figure 8.2 Unidon.

Source: Photo by authors.

Kuji visited the Café Moka (the model for Café Rias in the series) or ate a specialty called unidon (rice-based dish with sea urchin; Figure 8.2) that appears in the series. A fan from Thailand even describes on his English blog how he went to a store in Kuji early in the morning to purchase a sea urchin lunchbox, showing many photos of this undertaking and describing the taste in detail (AT1987, 2016). Such accurate reports give other fans a vivid impression of a pilgrimage, allowing for a kind of "vicarious media tourism", which means that one fan is experiencing a location for many others, and his pilgrimage becomes accessible and consumable via social media. The great impact of Amachan fandom became obvious in 2016, when a severe typhoon on the 30th of August caused damage to Kuji City and Café Moka. The café owner obtained many letters encouraging him to continue 
his business, and even fans from Tokyo came to help with the cleanup. Once more, Amachan's legacy supported the reconstruction of the city: the lead actress Rena Nōnen, known as "Non", travelled to Kuji in September to encourage the locals and to re-visit the filming locations of the series (Non, 2006). Non wrote about her travel experience on a blog in cooperation with the instant messaging service Line. On this blog, she regularly declares her attachment to the Tohoku region, which is well received, as many fans' comments show. Non has become an ambassador for the region, and her iconic presence on various media formats (backed by powerful media companies such as NHK and Line) continues to unfold the symbolic power of Amachan even today, years after its broadcast.

As the case of Amachan demonstrates, the media presence of filming locations generates effects beyond the promotion of tourism and sale of local products. The media representation of Northern Japan's landscapes in probably the most influential national TV format, the asadora, created alternative images that possess the power to (at least partially) replace the negative images of destruction that shaped the region's reputation after the triple disaster. The series established a new narrative that linked the coastal area of Northern Japan with thoughts of solidarity and reconstruction. Ultimately, this is embedded in a strategy of nation branding, as we will explain in the next section.

\section{Oshin and Amachan going abroad: soft power}

Since the 2000s, Japan sought to increase its attractiveness and economic power by marketing popular culture - in particular anime, manga, and video games - using the buzzword and label "Cool Japan" (McGray, 2002). However, even before "Cool Japan" gained attention, popular culture served to improve national reputation. In the 1980s, the time of Oshin, Japan had good reasons to polish its international image. Although the Japanese economy experienced a massive growth at that time, Japanese products still had the reputation of being mere copies. Moreover, the Japanese government was interested in establishing new political and economic collaborations in the East Asian region, a complicated undertaking due to the legacy of the Pacific War (Iwabuchi, 2015). In addition, in the face of the Cold War, a positive image of Japan was also important for its relationship to the West, presenting the nation as a reliable ally and strong economic partner, especially for the United States.

The national success of Oshin, a story of renewal after the war, fitted these intentions perfectly. Since 1984, the Japan Foundation (a government-run institution for the dissemination of Japanese culture overseas) provided the series to broadcasters worldwide free of charge as part of its cultural program (Takahashi, 1998: 144). As Iwabuchi (2015: 421) points out, the series thus made a significant contribution to establishing a new international image of Japan, detached from the negative memories of imperialism. The 
heroine Oshin was even considered a kind of symbol for Japan: US President Ronald Reagan drew an analogy between the rise of Oshin and Japan's economic success after World War II in November 1983 (Haberman, 1984).

To this day, NHK proudly points to the great impact and huge success of Oshin worldwide (NHK, n.d.-a), and the female protagonist continues to be deployed as an ambassador of local as well as national identity. The Japan National Tourism Organization (JNTO), for instance, promotes Yamagata Prefecture as the "Home of Oshin" on its English webpage and refers to Oshin as the prefecture's "most well-known person abroad" (Japan Monthly Web Magazine, 2014). Recently, Japanese travel agencies specialized in foreign tourists offer Oshin tours as part of their portfolio (WebTravel, n.d.). NHK also still reports on tourism related to the locations, for example, in a bilingual documentary aired on its international channel NHK World, in which a Malaysian actor explores "Oshin's home" for Japanese and international audiences (NHK, n.d.-b). In addition to attracting visitors from overseas, the media coverage of Oshin's popularity abroad also serves as an affirmation for the Japanese audience: if even foreigners know Oshin and travel to the filming locations, then the series has to be really important. Accordingly, since the 1980s, Japanese newspapers have regularly reported on the success of Oshin in foreign countries and interpreted it as a part of a general "Japan boom". ${ }^{2}$

In the early 2010s, Japan again faced a complicated situation in the global context. The financial crisis of 2008 left the national economy weak and unsteady, while neighbouring East Asian states such as China and South Korea turned into serious competitors, not only in business matters but also concerning the quasi-hegemony of Japanese pop culture in East Asia. Furthermore, the triple disaster of March 2011 and the subsequent nuclear reactor accident raised doubts about Japanese technology as well as about the country's security as a travel destination. Since the mid-2000s, tourists coming from abroad have turned into an important economic force, which the government encouraged with large-scale tourism promotion campaigns (Uzama, 2009). The asadora Amachan clearly reflected this situation: recalling the glorious days of Japanese pop music idols in the 1980s (Johnson, 2018; Tajima, 2018) and at the same time turning the catastrophe of 2011 into a hopeful narrative of resurrection.

Amachan, unlike Oshin, was primarily distributed in Southeast Asia, in Taiwan, Thailand, Indonesia, Myanmar, and the Philippines (Bartolome, 2015). Why has the focus been put on this region? In recent years, Southeast Asia has developed into an important arena for Japanese foreign policy. On the one hand, the number of tourists from these countries travelling to Japan is increasing, and they became an essential target group for inbound tourism (JTB Tourism Research \& Consulting Co., n.d.). This potential was also considered in the case of tourism related to Amachan: Iwate Prefecture advertises the Amachan Museum in its English newsletter (Iwata Prefecture, n.d.), and the Ministry of Economic Affairs and Tourism (METI) published 
an English-language information brochure with the slogan: "Why don't you come to Kuji to experience the world of 'Ama-chan'?” (METI, n.d.). In addition to promoting tourism, a positive image of Japan is certainly beneficial in the competitive race against China for economic partnerships in the emerging ASEAN states (Alegado, 2018) and also for attracting foreign workers, which, despite many reservations, play an increasingly important role in Japanese society, especially in the care sector.

\section{Conclusion}

The digital revolution and media convergence are often considered major turning points in recent media history, and film tourism is thought to have undergone major changes as a result (e.g. Seaton et al., 2017). Drawing on the example of two popular asadora, our chapter showed that many principles have not fundamentally changed with digitization, though they have become more diversified. Viewers were already very active in the 1980s at the time of Oshin, but their fandom at that time was limited to "analogue" media such as fanzines and thus was less far reaching, unless national newspapers reported on it. The marketing machinery, which included merchandise and publications as well as travel packages, was already very much developed by the time of Oshin and very present in the media. At the same time, audience participation was not limited to consumption, and practices such as cooking dishes from the series became so common that the press dealt with it in detail.

In the 2010s, the time of Amachan, the Internet allows fandom to gain higher visibility; through social media, fan art and photos of individual trips to filming locations are spreading, thus expanding the world of the series. Fan activities probably have not increased per se. They are just more directly accessible today, as fans can distribute their works by themselves and do not have to rely on major media companies to get coverage. Local stakeholders, such as tourism promotion groups, can take advantage of this and use the wave of national attention to further strengthen a region's image by spreading their own visual impressions and interpretations of regional identity. Still, only a small proportion of fans are active online, and the number of those who actually travel to the locations is limited. However, a kind of "vicarious media tourism" multiplies the number of those who are involved in the exploration of mediated landscapes, albeit passively.

As we have shown, even though regional landscapes with their special characteristics are presented in the asadora, they always stand for certain aspects of "Japanese identity" and are closely linked to messages related to the prevailing zeitgeist in Japan (Scherer \& Thelen, 2017). The narrative package, which is present on all channels of media convergence also in tourism - always contains an idea of what defines Japanese identity and how it can be presented and marketed internationally. Oshin and Amachan reveal similar tendencies of a nation-branding strategy: both series address resurgence after a difficult time, evoking a sense of 
community and convey perseverance and strength (especially with an eye to the audiences overseas). However, the focus of these branding efforts has changed since Oshin: the target audience is now more likely to be found in Southeast Asia, with the development of international tourism playing an important role alongside economic interests such as a strong investment policy in these emerging countries.

\section{Notes}

1 Ama are professional divers who harvest seafood and seaweed without using air tanks or scuba gear; Martinez (2019) analyzed Amachan with focus on the depiction female ama divers and national identity.

2 For example, in Thailand (Asahi Shinbun 1985, July 25), in Poland (Yomiuri Shinbun, 1985, November 30), and on the occasion of a rerun in Iran (Yomiuri Shinbun, 2013, July 18).

\section{Bibliography}

Alegado, S. (2018, February 8). Japan still beating China in South Asia infrastructure race. Retrieved from www.bloomberg.com/news/articles/2018-02-08/ japan-still-beating-china-in-southeast-asia-infrastructure-race.

Asahi Shinbun. (1983, July 23). 'Oshin’ naze konna ni ninki. Asahi Shinbun, Tōkyō evening edition, p. 3.

Asahi Shinbun. (1983, September 7). Saga no imēji-daun tai. 'Oshin' ken kankōren ga NHK ni kōgi. Asahi Shinbun, morning edition, p. 22.

Asahi Shinbun. (1984, March 14). Terebi ijō no kandō ajiwatte kudasai [advertisement]. Asahi Shinbun, morning edition, p. 18.

Asahi Shinbun. (1985, July 25). Tai no nihon būmu. 'Oshin' no naka ni mizukara hakken. Asabi Shinbun, evening edition, p. 7.

AT1987. (2016, April 11). Amachan location tour: Sea urchin Bento and Amachan corner in Kuji station. Retrieved from https://at1987.com/life/japan-trip-3-sanrikurias-tei-and-amachan-corner-in-kuji-station/.

Bartolome, B.S. (2015, October 12). J-pop show hits local TV. Retrieved from https:// entertainment.inquirer.net/180821/j-pop-show-hits-local-tv.

Bird, S.E. (2011). Are we all produsers now? Convergence and media audience practices. Cultural Studies 25(4-5): 502-516.

Couldry, N. (2000). The place of media power: Pilgrims and witnesses of the media age. London: Routledge.

Couldry, N. (2003). Media rituals: A critical approach. London: Routledge.

Haberman, C. (1984, March 11). In Japan, 'Oshin' means it's time for a good cry. New York Times, p. 25.

Harvey, P.A.S. (1995). Interpreting Oshin: War, history and women in modern Japan. In: B. Moeran \& L. Skov (eds.), Women, media and consumption in Japan, pp. 75-110. London: Routledge.

Hashida, S. (1983, July 8). Kokoro moyō. 'Oshin' no furusato ga naniyue. Mainichi Shinbun, p. 15.

Hu, K. (2005). The power of circulation: Digital technologies and the online Chinese fans of Japanese TV drama. Inter-Asia Cultural Studies 6(2): 171-186. 
Ito, M. (2008). Japanese media mixes and amateur cultural exchange. In: D. Buckingham \& R. Willett (eds.), Digital generations: Children, young people, and new media, pp. 49-66. London: Routledge.

Iwabuchi, K. (ed.). (2004). Feeling Asian modernities: Transnational consumption of Japanese TV dramas. Hong Kong: Hong Kong University Press.

Iwabuchi, K. (2015). Pop-culture diplomacy in Japan: Soft power, nation branding and the question of 'international cultural exchange'. International Journal of Cultural Policy 21(4): 419-432.

Iwate Prefecture. (n.d.). Visit Amachan Museum in Iwate. Retrieved from www.pref. iwate.jp/kokusai/27900/35196/055291.html.

Jang, K. (2016). Kontentsu ga tsukuru 'fūkei': Renzoku terebi shōsetsu no jirei o chūshin ni. CATS Sōsho 8: 83-97.

Japan Monthly Web Magazine. (2014, March). Enjoying yourself in Yamagata: The home of 'Oshin'. Retrieved from https://japan-magazine.jnto.go.jp/en/1404_ yamagata.html.

Jenkins, H. (2006). Convergence culture: Where old and new media collide. New York: New York University Press.

Johnson, D. (2018). Re-collecting old media: The intimate transmissions of Amachan. Critical Studies in Television 13(1): 42-59.

JTB Tourism Research \& Consulting Co. (n.d.). Japan-bound statistics. Retrieved from www.tourism.jp/en/tourism-database/stats/inbound/\#region-courtry.

Mainichi Shinbun. (1983, August 20). Zakkichō. Mainichi Shinbun, p. 23.

Martinez, D.P. (2019). Television and the Ama: The continuing search for a real Japan. East Asian Journal of Popular Culture 5(2): 145-158.

Maruta, K., Kanehama, S. \& Tamayose, A. (2014). NHK asa no renzoku terebi shōsetsu 'Jun to Ai' no hōei to Miyako-jima ni okeru juyō. Okinawa Daigaku Jinbun Gakubu Kiyō 16: 61-69.

McGray, D. (2002). Japan's gross national cool. Foreign Policy 130: 44-54.

METI. (n.d.). Kuji port tourism information brochure. Retrieved from www.mlit. go.jp/kankocho/cruise/detail/087/documents/kanko.pdf\#page=1.

NHK. (n.d.-a). Worldwide success of Ochin. Retrieved from www.nhk.or.jp/archivesblog/genre/drama/9785.html.

NHK. (n.d.-b). Exploring 'Oshin's home'. Retrieved from www3.nhk.or.jp/nhkworld/ en/special/episode/201803250552/.

Nihei, W. \& Sekiguchi, S. (2014, June). 'Sōsharu' ga umu terebi shichōnetsu!? Amachan genshō ga nagekaketa mono. Hōsō kenkyū to chōsa (The NHK Monthly Report on Broadcast Research), 2-17.

Non. (2016, September 19). 久慈へ. Retrieved from https://lineblog.me/non_official/ archives/10868149.html.

Nye, J.S. (2004). Soft power: The means to success in world politics. New York: Public Affairs.

Reijnders, S. (2011). Places of the imagination: Media, tourism, culture. Farnham: Ashgate. Scherer, E. \& Thelen, T. (2017). On countryside roads to national identity: Japanese morning drama series (asadora) and contents tourism. Japan Forum (Online Exclusive): 1-24. Retrieved from www.tandfonline.com/doi/full/10.1080/095558 03.2017.1411378.

Scherer, E. \& Thelen, T. (2018). Drama offscreen: A multi-stakeholder perspective on film tourism in relation to the Japanese morning drama (asadora). In: S. Kim \& S. 
Reijnders (eds.), Film tourism in Asia: Perspectives on Asian tourism, pp. 69-86. Singapore: Springer.

Seaton, P. (2015). Taiga dramas and tourism: Historical contents as sustainable tourist resources. Japan Forum 27(1): 82-103.

Seaton, P., Yamamura, T., Sugawa-Shimada, A. \& Jang, K. (2017). Contents tourism in Japan: Pilgrimages to 'sacred sites' of popular culture. Amherst: Cambria Press.

Shefner-Rogers, C.L., Rogers, E.M. \& Singhal, A. (1998). Parasocial interaction with the television soap operas 'Simplemente Maria' and 'Oshin'. Keio Communication Review 20: 3-18.

Sheungting Lo, I. \& McKercher, B. (2016). Beyond imaginary of place: Performing, imagining, and deceiving self through online tourist photography. In: M. GravariBarbas \& N. Graburn (eds.), Tourism imaginaries at the disciplinary crossroads: Place, practice, media, pp. 231-245. London: Routledge.

Steinberg, M. (2012). Anime's media mix: Franchising toys and characters in Japan. Minneapolis: University of Minnesota Press.

Sun Ju Sun [@sun_ju_sun]. (2013,August 31). 録あまを見た。次週予告 . . . この5 ケ 月間、毎朝海や天野家や喫茶リアスを見続けて来たから北三陸市がもう一つの 地元のようになっていて、胸がざわざわする。\#あまちゃん [Tweet]. Retrieved from https://twitter.com/sun_ju_sun/status/373595677487419392.

Tajima, Y. (2015). NHK asa no renzoku terebi shōsetsu 'Amachan' no Kuji-shi ni okeru juyō. Doshisha University Social Science Review 116: 15-40.

Tajima, Y. (2018). Japanese idol culture for 'contents tourism' and regional revitalization: A case study of regional idols. In: A. Beniwal, R. Jain \& S. Karl (eds.), Global leisure and the struggle for a better world, pp. 117-139. Basingstoke: Palgrave Macmillan.

Takahashi, K. (1998). The impact of Japanese television programs: Worldwide Oshin phenomena. Journal of Regional Development Studies 3: 143-156.

Takō, W. (2012). Taisetsu na koto wa minna asadora ga oshiete kureta. Tokyo: Ōta shuppan.

Urry, J. \& Larsen, J. (2011). The tourist gaze 3.0, 2nd ed. Los Angeles: Sage.

Uzama, A. (2009). Marketing Japan's travel and tourism industry to international tourists. International Journal of Contemporary Hospitality Management 21(3): 356-365.

WebTravel. (n.d.). Travel plan: A visit to the hometown of the popular Japanese TV drama Oshin. Retrieved from www.webtravel.jp/en/21.

Yamagatankanko. (2013). Oshin itinerary. Retrieved from http://yamagatakanko. com/log/?l=334040.

Yamamura, T. (2015). Contents tourism and local community response: Lucky Star and collaborative anime-induced tourism in Washimiya. Japan Forum 27(1): 59-81.

Yomiuri Shinbun. (1983, May 31). 'Oshin' no furusato Sakata, Ginzan onsen to sakuranbo-gari. Yomiuri Shinbun, evening edition [advertisement], p. 7.

Yomiuri Shinbun. (1983, July 25). Oshin: Ninki ichidan to kita ni minami ni. Okuniburi karamete. Kataru kai tsugitsugi, kyōiku rongi mo. Yomiuri Shinbun, evening edition, p. 12.

Yomiuri Shinbun. (1983, November 14). 'Oshin' no furusato PR. Shinjuku de ringo matsuri. Yomiuri Shinbun, morning edition, p. 21.

Yomiuri Shinbun. (1984, January 17). Mogami-gawa yukimisen to Oshin no furusato o tazunete. Yomiuri Shinbun [advertisement], evening edition, p. 2. 


\section{Elisabeth Scherer and Timo Thelen}

Yomiuri Shinbun. (1985, November 30). Oshin. Maikai 70\% no kōshichōritsu. Ura ni ijōna Nihon būmu. Yomiuri Shinbun, evening edition, p. 2.

Yomiuri Shinbun. (2012, September 4). Oshin aratana shūkyakusaku ni. Yomiuri Shinbun, morning edition, p. 30.

Yomiuri Shinbun. (2013, July 18). 'Oshin' Iran de ninki sainen. Yomiuri Shinbun, morning edition, p. 7.

Yoshimi, S. (2005). Japanese television: Early development and research. In: J. Wasko (ed.), A companion to television, pp. 540-557. Oxford: Blackwell. 


\title{
9 Touring the videogame city
}

\author{
Bobby Schweizer
}

\section{Visiting San Francisco virtually}

There is something special about exploring videogame worlds, particularly those that re-create well-known places. These virtual worlds are hybrid spaces that draw on real places to inform their design and are brought to life through computer code that allows us to interact with and navigate them (Bogost \& Klainbaum, 2006; Schweizer, 2013; Whalen, 2006). In games, the activity of tourism is performed within media itself to represent both our fascination with recreating the familiar and our awe at the computer's ability to simulate lifelike worlds to explore. However, the common act of exploring is not always synonymous with touring, which needs to be considered as a meaningfully distinct activity. San Francisco - a place that has captivated media producers of all types - has seen numerous digital recreations in videogames over the years that encourage touristic behaviour. When its iconic geography and architecture are constructed using 3D graphics to be navigated by a videogame player, games set in the Golden Gate City produce a convincing illusion. In one magazine review for a game set in virtual San Francisco, critic Kati Hamza wrote: "What's most impressive . . . is the genuine feel of being in an authentic city. Streets, trees, bridges and 2.429 buildings create a huge environment to suss out - you can have a lot of fun just sightseeing while you fly around" (Hamza, 1991). In another review for a different game set in San Francisco, Philip Kollar wrote that the virtual recreation "captures the flavour of a place I love" (Kollar, 2016). Both of these game reviews marvel at the ability of a virtual world to capture the essence of real place - despite the fact that the two games to which they refer to were made over 20 years apart. Killing Cloud, to which Hamza refers, was released in 1991 for home computers such as the Amiga, Atari ST, and IBM PCs. Watch Dogs 2, on the other hand, was released in 2016 for PlayStation 4, Xbox One, and Microsoft Windows.

The graphical and processing capabilities of the hardware that allowed these games to run may be decades apart, but, at their core, both had the effect of bringing a place to life. Their players seek out familiar landmarks to marvel at the computer representations. In Killing Cloud, the player patrols 


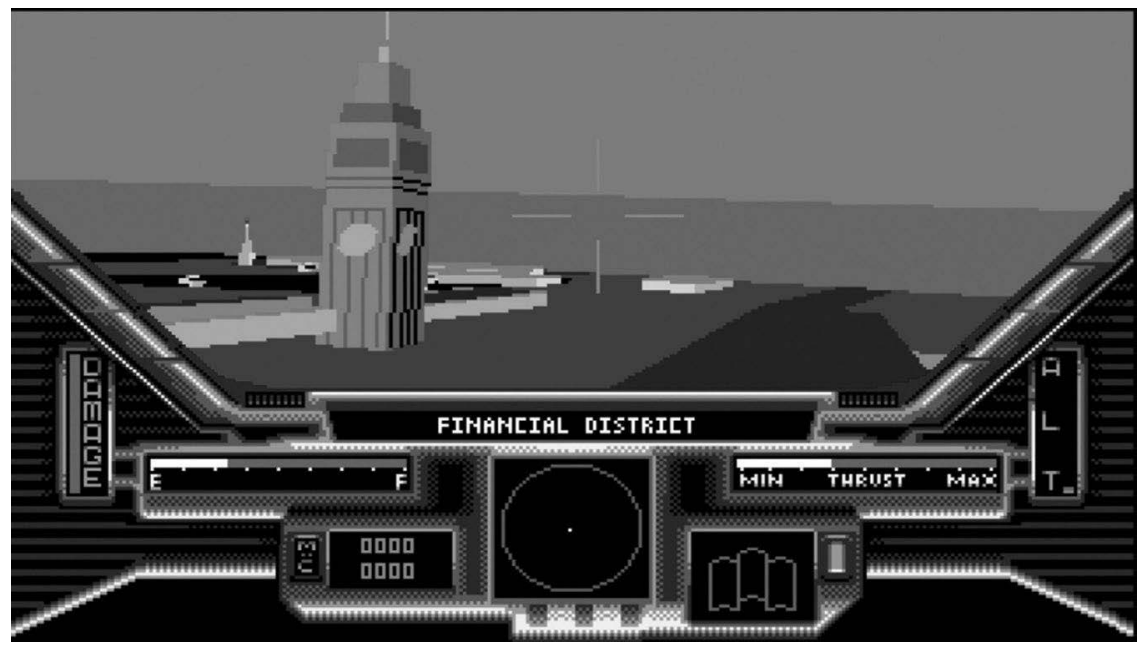

Figure 9.1 San Francisco depicted in Killing Cloud (1991) for the Commodore Amiga.

Source: Image by author.

San Francisco from above on a futuristic hoverbike. San Francisco's tall buildings emerge from the top of the poisonous cloud that hangs low over the city and stand out as distinct landmarks without the visual obstruction typically experienced at ground level (Figure 9.1). The density of San Francisco is abstracted into one or two buildings per city block. A few are modelled to look like their real-world counterparts - the Ferry building, the Transamerica Pyramid, the Hyatt Regency on Embarcadero - but most are placeholders that stand in for a type of building: simple rectangular skyscrapers downtown, Monopoly-piece-shaped houses in residential areas. Compared to other games from the era, the technological novelty of Killing Cloud's polygonal graphics and the freedom to move about the city provided for a touristic experience. In one review of the game, David Upchurch (1991) wrote: “The polygon graphics aren't quite the fastest I've ever seen, but they're more than fast enough, and the ability to set detail level means it's up to you whether you'd rather sight-see or get on with the job at hand". And, in support of this, the game even featured a "touring" mode that allowed players with more powerful computers to enable greater draw distances and more visual detail.

When re-creating real places virtually, it's difficult not to draw comparisons between how we play a game and the way we tour cities. In game reviews from magazines and the Internet, web forum discussions, screenshots shared online, and videos posted to YouTube, players have discussed 
"sight-seeing" Watch Dogs 2. Executive editor Dan Stapleton (2016) of online gaming magazine IGN wrote:

This is a great open world map, and I'm not just saying that because was born in the Bay Area and have lived here for almost my entire life ... it's surreal to be in a car chase and suddenly look up and see something like Moscone Centre, the Palace of Fine Arts, the Painted Ladies, Fisherman's Wharf, or Stanford University. I'd recommend it as virtual tourism, especially if you've been here before and want a refresher.

And Game Spot editor Peter Brown (2016) wrote "Ubisoft does a great job of presenting the Bay Area in an attractive way that feeds intrepid tourists an impressive variety of sights". Tourism, as these quotes and many others allude to, is a frequent part of the conversation about game spaces. The foundational work of tourism in games that this chapter builds upon comes from scholars Michael and Jacqueline Salmond, who proposed that all players are tourists who enact a touristic lifestyle in game worlds that is similar to that in real worlds (Salmond \& Salmond, 2016: 155). The "gamer-tourist" that they describe is motivated by novel experience, adventure, and the feeling of being in a real place. This desire to visit new fantastic virtual worlds is similar to the urge to travel, and visiting new places causes us to look at the environment with a gaze of "interest and curiosity" (Urry \& Larsen, 2011: 1). Yet not all play in videogame spaces is equivalent to tourism because of the goal-oriented structures of games. Tourism is a secondary practice - behaviour that emerges because the videogame city imaginary establishes expectations and produces anticipation about a mediated space. The player in a videogame is able to adopt a touristic mindset through this imaginary, and the act of touring is prefigured by the presentation of something that should be known and is worth exploring (MacCannell, 1999). Thus, Salmond and Salmond's definition of the gamer-tourist needs to be revised to focus specifically on how tourism is performed by players.

\section{Defining tourism in games}

In existing game tourism literature, the idea of encountering new spaces in games - particularly those built in three-dimensional polygonal graphics engines that position a player-controlled figure in a traversable world - is used to draw comparisons to manoeuvring our own bodies through unfamiliar places as if we were tourists. In their most recent edition of The Tourist Gaze, Urry and Larsen (2011) describe nine qualities that typify touristic practices in contemporary society. Three of these qualities put tourism into opposition with work or commuting, one involves journeying to new places, two involve its socially negotiated nature, two others describe how the object of tourist interest is formed by pre-figuring the sight to be seen, and 


\section{Bobby Schweizer}

the final one illustrates how tourists beget more tourism. Yet the figure of the gamer-tourist often conflicts with Urry and Larsen's qualities: games' goal-oriented play actually structures the experience as more laborious than recreational.

The types of games that are open to touristic behaviour, and thus Salmond and Salmond's broad definition of the gamer-tourist, tend to be driven by stories or exploration in a digitally constructed environment navigated by a player controlling a character in three-dimensional space - everything from the open-world cities of Grand Theft Auto and arid landscapes of Borderlands (2009) to the aquatic wonders of Endless Ocean (2008). Urry and Larsen contrast the tourist gaze with "non-tourist social practices", such as those that involve home life and work, noting that what may seem like encountering novel views is not always described by the participant as touring. This tension between player experience and narrative can be seen, for example, in Marvel's Spider-Man (2018). Its version of New York City may be a stunningly modelled 3D environment, but in the diegesis of the game, Peter Parker is hardly on vacation. The game's urban vistas are met with the effort required to progress through the game and the constant forward momentum of the narrative. Playing the game may be a leisure activity, but taking on the role of Spider-Man means facing conflict and challenge while proceeding along a prescribed path. Peter Parker - former photographer for the Daily Bugle - decides it would be useful to "calibrate" the map he uses to track events across the city by taking photos of familiar landmarks. For the player, this is like being a tourist, and the game's "photo mode" allows them to change visual filters and focal length before saving these images to their PlayStation. But for Spider-Man, this is just another day on the job. So, though Salmond and Salmond are right to characterize games as supporting touristic practices, a better definition is required to distinguish goal-oriented gameplay from the other parts of the game that permit and encourage touristic behaviour.

To support touristic behaviour, the game's world needs to be framed for the player as pre-existing and "known by others" to promote the idea that there is something worth touring. For this reason, this chapter focuses on videogame cities that adapt and translate real places in their virtual construction. Navigable space (contrasted with the city as backdrop) also promotes player agency and gives them time to reflect on the world outside of goal-oriented gameplay. For example, although the climactic military battle of the first-person shooter game Homefront (2011) takes place on the Golden Gate Bridge with San Francisco in the background, this scenario is not touring because there, deviation from the prescribe path means failure in the game. By way of contrast, the touristic mindset is well represented in the Yakuza series of games, as illustrated by this quote from game journalist Luke Plunkett (2012):

Tokyo is one of my favourite cities on Earth, and while I've been there plenty of times, I always look forward to going back. It's nine hours and 
$\$ 1000$ away, though, so that's usually out of the question. But when I slide a Yakuza disc into my PS3 I can, for a night, make a half-assed trip, complete with karaoke-laden adventures and endless runs to convenience stores for snacky treats.

It is not just that the game world is a new place for the player to explore it's that some sort of pre-existing knowledge is brought to the game that inspires players to seek out specific locations or experiences. Some are very specific, like Plunkett's knowledge of Tokyo, but other players come to videogame cities knowing that there are sights to see even without having visited the city before. This knowledge is a part of the "urban imaginary" that prefigure our travels because we "negotiate the reality of cities by imagining "the city" as a concept (Donald, 1999: 18). When referring to "the city", the mental image is a conglomeration of the qualities of all urban spaces. And, when referring to a specific city, the imaginary takes into account the "overflow of media images and narratives coexist with personalized memories, historical events, architectural constructions, and lived experiences" (Jaguaribe, 2007: 102). Imaginaries are the convergence point between how "the city affects imagination and how the city is imagined", because the physicality of urban space matters less than the lived spaces of representation (Bridge \& Watson, 2008: 7). Examples of imaginaries include "literary productions, notions of urban myth, memory and nostalgia in the city and its environs, or to the sociological imagination re-cast within the changing realm of new technologies and forms of communication" (Westwood \& Williams, 1997: 1). Imaginaries, as portrayals of the city, convey city-ness beyond their architectural construction. Videogames, as a medium, draw heavily on other forms of mediated cities while providing a unique imaginary of the city whose immateriality is not only visually represented but is experienced through virtual spatial exploration and player agency (Schweizer, 2013). Though not all toured videogame spaces are cities, this frequent form of representation is useful for establishing what constitutes the "touristic mindset" that makes certain kinds of videogame play unique.

\section{Framing the touristic mindset}

The roles we inhabit in games are complex and shape how we understand tourism. Salmond and Salmond extend their exploration-as-travel analogy further by saying that the game itself acts as a tour guide to lead the player through the environment (Salmond \& Salmond, 2016: 154-155). Based on this premise, they suggest that Grand Theft Auto: San Andreas (2005) uses its story, missions/goals, and characters to instruct the player what to do and how to get through the world. The game revolves around a protagonist named CJ who has returned from New York City to the impoverished neighbourhood (based on South Central Los Angeles) in which he grew up. The 


\section{Bobby Schweizer}

character of CJ is a "local", yet the player who controls him is not. If the fiction of the game explicitly defines the player's role opposite to tourist, under what circumstances do we separate the two? On the one hand, researcher Kiri Miller (2008) has described this kind of player as a tourist-ethnographer. Miller takes Grand Theft Auto: San Andreas and highlights how its gameplay and representations of inner-city Los Angeles gang life become a guided form of cultural tourism. We role-play as CJ in order to take this journey and observe with an anthropological gaze. The game, which is set in a faux 1990s California that extensively references popular films such as John Singleton's Boyz $n$ the Hood (1991) and the Hughes Brothers' Menace II Society (1993), provides a specific Los Angeles imaginary to tour. But while the missions in the game provide some sort of guided structure through the world, they don't necessarily encourage tourism in the ways described by tourism studies scholars. Other framing mechanisms are required to position the player as tourist.

It is not unusual for games to be framed by outside paratexts - advertisements, marketing material, instructions manuals - that draw parallels to travel and exploration. Supporting materials such as game walkthroughs (magazines or websites that step by step tell the player how to complete a game) have long been referred to as "guides". Typically, these guides are presented in a utilitarian manner, but creative authors have sometimes recontextualized as tourist guidebooks. For example, the Super Nintendo game EarthBound (1995) came with a strategy guide packaged in the box that depicted the player's journey through the world as an elaborate travel brochure. The "Travel Guide" contained information beyond the usual game walkthrough each of the game's towns and regions had a dedicated two-page spread with a travel brochure on one side and a fake newspaper front page on the other. For example, the starting location of Onett's brochure details the area's temperate climate, "scenic vistas", a "tourist favourite" spot called Giant Step, the arcade, and the library. Some of the images on the page are screenshots of the game's 16-bit graphics, but others are real photographs that help set the tone even though they do not accurately represent anything in the game. At the time of the game's release, strategy guides were typically sold separately, so having it included in every game box exposed the touristic mindset to many more players.

Instruction booklets are another way of preparing the player for the game they are about to encounter. The Grand Theft Auto trilogy of games released during the PlayStation 2 era (Grand Theft Auto III, Vice City, and San Andreas) each came packaged with elaborately themed fold-out maps and instruction booklets. Whereas GTA III (2001) framed this paratext as a general guide to the game's topology, notable characters, and daily life, Grand Theft Auto: Vice City (2002) explicitly titled its manual a "Tourist Guide". The booklet included local facts and history, a guide to "getting around", advice about "what to bring", and points of interest. Any player who chose to read this manual to whet their appetite for the game was provided with a 
neon-Miami imaginary represented in screenshots from the game that emulated photographic composition. The Vice City manual specifically refers to its reader as a visitor - an outsider much like the game's protagonist they are preparing to inhabit.

In-game elements can also promote feelings of tourism. The Assassin's Creed series fills its recreations of real historical cities with pop-up notifications of historical factoids that the player can learn more about by accessing an in-game database. For example, Assassin's Creed II (2009) is set in 15 th-century Italy, and the player visits recreations of cities such as Florence, Venice, and San Gimignano. Although certain elements of these places are anachronistic, the game presents a rhetoric of deep historical simulation by presenting lavish descriptions in an encyclopaedia (Dow, 2013). Wandering into the piazza in front of the Basilica di Santa Maria del Fiore triggers a pop-up message containing a narrative of its construction and history (rather than just names and dates). Though collecting these landmarks is not required for completing the game, the formal, educational presentation lends credence to the authenticity that encourages players to seek out these landmarks as a way of adopting a touristic approach to exploring the game's city beyond goal-oriented gameplay.

\section{Playing tourist}

Whether an individual chooses to call themselves a traveller or a tourist is a process of self-identification that is fostered by elements within the game. This is particularly true when the player and their character traverse the landscape together to perform activities explicitly labelled as "playing tourist". As the story of Grand Theft Auto: San Andreas (2004) unfolds, CJ finds himself leaving Los Santos (Los Angeles) for the city of San Fierro (based on San Francisco). During their time in San Fierro, the player encounters a series of optional game objectives: "snapshot" locations hidden throughout the city that the player can capture using game's camera item. These 50 locations - including the game's versions of the Golden Gate Bridge, Pier 39, Chinatown, and the Castro Theatre - demonstrate the touristic impulse. The objectives are portrayed in the game by round pink icons hovering above the points of interest in order to encourage players to look around and focus on the game's urban architecture. And, because both CJ and the player are new to the island of San Fierro, the idea of sight-seeing here is more appropriate than the Los Santos area of the game that CJ would have called home. Similarly, in Sleeping Dogs (2012), the protagonist character Wei Shen is a native of Hong Kong. However, he (and thus the player) is encouraged to think like a tourist when his American girlfriend asks if he will drive her around and snap a few photos with his phone for her blog. After gathering the shots, the mission concludes with Wei Shen remarking that it's "nice playing tourist in your own town". The use of an ingame camera item replicates our use of digital cameras that allows tourists 


\section{Bobby Schweizer}

to immediately review the activity of the moment (Bell \& Lyall, 2005). Touristic practices can be encouraged diegetically in-game through photography missions that give the option for exploratory play and reflection.

The "possessive spectator", as conceived by media scholar Eric Gordon (2010: 3), acts as an interpreter who reflects on their experience and understanding of a place by recording it. It creates a distinct mindset that transforms space as something to be used by many into space as something to be consumed by one. While paintings and writings have long fixed the image of the city for media consumption, the image of the modern city, as Gordon explains, derives from the development of photographic technology. During most of the 19th century in the United States, urban tourism was a limited category because American cities were spread far apart and had not yet been framed in terms of leisure or historical interest. However, the issue of distance was resolved as the railroad network made passenger travel more accessible and more comfortable such that people with moderate means could make short recreational trips. As a result, the tourism industry began to produce new, cohesive images of the city, including guidebooks and photographs (ibid: 15). The White City of the 1893 Chicago World's Columbian Exhibition was "the first instantiation of a city built to accommodate this emerging possessive spectatorship" in which its visitors "believed they could take control of the Concept-city, consuming it like any other media object" (ibid: 16-17). Most significant to this new way of experiencing the Fair's design was the Kodak "Brownie" camera, which allowed tourists to snap and possess their own views (ibid: 45-47). We can see the same process at work in the various ways videogame technology allows its players to possess space and, as a result, can see how videogame worlds are being reconfigured to accommodate and encourage possessive spectatorship.

Similar to the sight-seeing camera of Grand Theft Auto: San Andreas, game developers have recognized their player's desire to capture moments and have incorporated these tools directly into the game. The player-character's mobile phone in Grand Theft Auto IV (2008) and Saints Row The Third (2011) have camera apps that allow them to document their travels. And, even more recently, open-world games such as Grand Theft Auto V (2013), Yakuza 6 (2016), Watch Dogs 2 (2016), and Marvel's Spider-Man (2018) have incorporated the modern photographic form: the selfie. In Watch Dogs 2, for example, the camera is used as a justification for touring: visiting wellknown landmarks to take character selfies using the in-game camera will earn the player "followers" in the game's fictional social network.

As Dinhopl and Gretzel (2016) describe, selfies afford self-presentation that is "facilitated by distancing or othering the self and looking at oneself from an outside perspective" to situate oneself immediately in the moment. Rather than remove any traces of the player's representation in the world to pristinely capture the landscape, selfie modes inject the player-character's body into the scene. In-game tools that mimic photography, whether a point-and-shoot camera or a selfie mode, encourage players to think like 
possessive spectators as they tour the city's landscape. Players then further undergo their transformation into tourist when the activities of possession encounter methods of sharing their travels with others.

\section{Sharing the journey}

As videogame players become tourists, possessive acts quickly extend into the social practices akin to sharing vacation photos and writing travelogues. The most immediate connection to the long history of the tourist's gaze are screenshots that record individual moment. The practice of capturing screenshots produces a new relationship between player and game similar to tourists who chooses to take photographs. In screenshotting, "layers of identity inform the tourist/traveller in everything they record: what to record, how to record and the language used to describe events" (Salmond, 2016: 191). The ability to easily record moments from a videogame console connected to a TV is relatively recent, but in the early 2000s, players of personal computer games could use the Microsoft Windows "print screen" functionality to save a copy of the image on the monitor. Researcher Betsy Book (2003) described the documentarian impulse of travellers in online virtual worlds who take screenshots to commemorate social interactions, especially when visiting in-game recreations of wellknown landmarks. This practice has also been analysed by videogame scholar Cindy Poremba (2007), who articulated how screenshotting has extended into all manner of games by remediating techniques and conventions of photography. Players could take their screenshots and share them in photo galleries to online fan websites or post them to online discussion forums with narrative accompaniment. The process can be both personal ("look what I did in the game") or empirical ("look at places you can see in the game"). As Orvar Löfgren (2002: 74) says of taking travel photos while on holiday, it's not just the desire to save the memories that drives photography but the pleasure of creating something. For example, artist Raphael Smith (2013) performs elaborate photography in games such as Grand Theft Auto IV by installing software add-ons meant to create images beyond what is immediately available through the built-in screenshot function. These software add-ons can change the view from third to first person in order to remove the player's avatar and user interface; enhance visual features such as higher-resolution textures; create realistic conversions for 3D models like cars and trees; and provide tools that render lighting, colour tone, and saturation of the image as while it is being taken (Grubb, 2013). Smith even hosts these images on the photography website Flickr as a way of equating his digital work with lens-based cameras. The Heterotopias online game magazine is a similar endeavour that collects screenshots and essays that focus on representations of architecture in games. Both forms rhetorically position their game worlds as sites of serious inquiry, like a travel photographer who wishes to reveal the beauty and majesty 


\section{Bobby Schweizer}

of places we take for granted. From fans posting screenshots to forums to self-serious high-resolution, perfectly composed digital photographs, "the recording and preservation of the travel experience is fixed in the idealized performance of what it is to travel" (Salmond, 2016: 192). Deliberate acts of recording become the impulses of tourism.

Home consoles that were connected to televisions at the turn of the millennium, like the Sony PlayStation 2 or original Microsoft Xbox, did not give players easy access to recording technology. This meant that (barring special hardware) players who wanted to save their exploits would need to point a camera at their television. But with the release of the Sony PlayStation 4, the Microsoft Xbox One, and the Nintendo Switch, "share" buttons on the controller have given players quick access to capturing in-game events. Posting screenshots and sharing in-game photos show how the videogame tourist is increasingly engaged in the same kinds of practices as human tourists in physical places sharing their experiences on social media. As these tools and means of disseminating the photographs become more common, players follow Susan Sontag's aphorism that "the camera makes everyone a tourist", and their participation in the game world fluctuates between possessive spectator and sharing actor.

In the last five years, video capture and sharing have become prevalent in the realm of videogames. Gameplay videos uploaded to YouTube, livestreams broadcast to Twitch.tv, and even short clips posted on social media have allowed players to share their game-playing experiences. Game playing is by its nature temporal, and video can capture active performance of the player in a variety of ways. The different modes of capture or streaming can frame the tourism experience as either a record of previous events or a "live" broadcast of the act in real time. The raw footage captured by players may be uploaded in full or edited into highlights and clips. Players may choose to narrate their experiences while playing or compose and edit a video essay afterwards. Live-streaming gameplay may also involve an audience of viewers (typically in a chat room on a separate monitor or windowed alongside the game) discussing the ongoing events of a game. Evidence of these can be found in quantity on YouTube by searching for a game name alongside the term "tour". Searching the phrase "los santos tour" returns a huge number of videos about Grand Theft Auto V (Figure 9.2). In many of these, players seek out the game's real-world Los Angeles equivalents, evocative locations, or even references to the fictional places of the game's prequel Grand Theft Auto: San Andreas. In these videos, the player embodies both the role of possessive spectator and active interpreter. The informal "tours" in these videos cover wide ground: showing off landmarks or impressive visual features, dividing the area up geographically to showcase variety, tours of in-game activities, or even the lesser-known and hidden aspects of the game. Because of the accessibility of recording and streaming tools, these possessive spectators are transforming into amateur tour guides. 

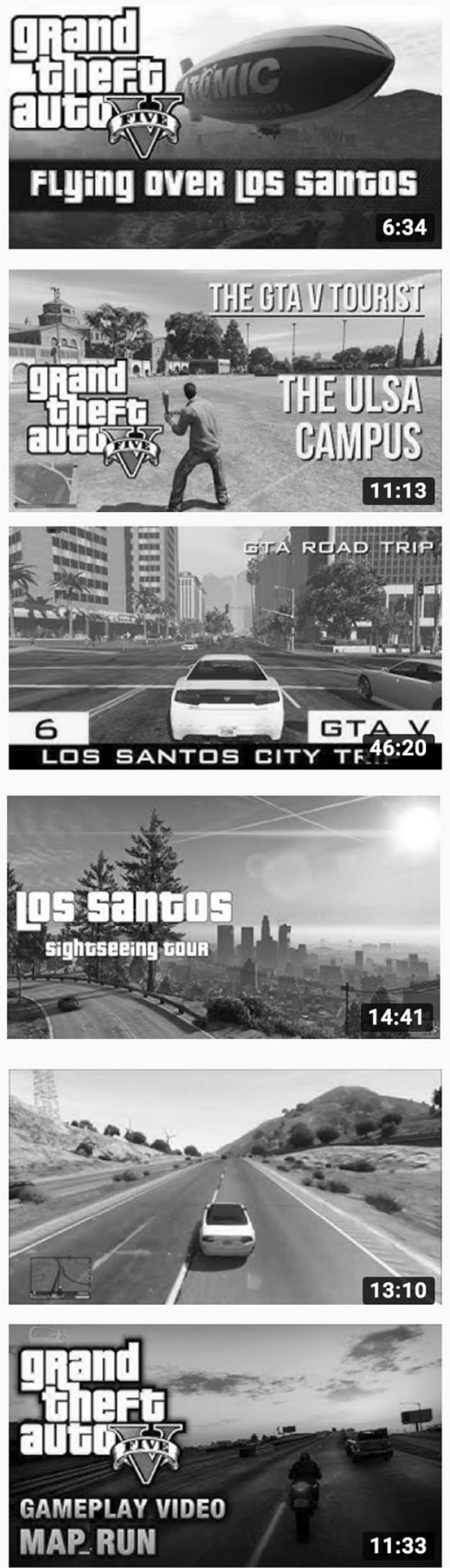

GTA V - A Tour over Los Santos with the Atomic Blimp [PS3] moebotzz $\cdot 2.3 \mathrm{~K}$ views $\cdot 5$ years ago Take a look on the Special Edition DLC Atomic Blimp and a tour over Los Santos and a short

The GTA V Tourist: University of San Andreas, Los Santos... Katzenwagen TV $\cdot 2.3 \mathrm{~K}$ views $\cdot 2$ years ago Hello and welcome to The GTA V Tourist series! :) Today, we'll be checking out the ULSA campus,

\section{The GTA V Tourist: Exploring} the main areas of Los Santos Katzenwagen TV $\cdot 17 \mathrm{~K}$ views $\cdot 2$ years ago Welcome to Episode 6 of Katzenwagen TV's GTA Road Trip series! In this episode, we take a tour

\section{GTA V Los Santos Sightseeing Tour} Cybermax TV $\cdot 913$ views $\cdot 2$ years ago Nice View's from this City.

\section{GTA: V - A Tour of Los}

\section{Santos}

TheVariedGamerHD $\cdot 30 \mathrm{~K}$ views $\cdot 5$ years ago $\mathrm{Hi}$ youtube friends and subscribers, Peter here bringing you another random video and this one

\section{GTA 5 - Map Run: Driving} Around Los Santos \& Blaine... GTA Series Videos $\bigcirc 265 \mathrm{~K}$ views 5 years ago This gameplay video shows how long it takes to drive all the way around the map in Grand Theft Related

Figure 9.2 Player-created tourism videos on YouTube.

Source: Image by author. 


\section{Bobby Schweizer}

\section{The spectator becomes the guide}

In tour videos, players explore with a set of expectations and varying levels of expertise and react spontaneously to what they encounter. A video titled "Touring the Real San Francisco in Watch Dogs 2" produced by online game magazine IGN shows how two players - Alanah from Australia and Marty the long-time San Francisco resident - interpret the game's virtual recreation of San Francisco (Pearce \& Sliva, 2016). The video begins in Dolores Park with Marty explaining that he will be acting as a tour guide to share some of his favourite places in the city. Alanah (and by proxy the viewer) are the audience of this tour, which is motivated by the game's fictional social media platform that rewards players with points for taking selfies in interesting places. Their first stop is the Castro Theatre, which prompts a brief discussion of the significance of the Castro neighbourhood. As they move on to their second location, the two discuss how this version of San Francisco is condensed for the game yet manages to capture "the layers of the city". Much of the tour is conducted while driving a car because it is a quick way to traverse long distances, so Marty is frequently shifting the direction of the viewpoint (which is based in a third-person perspective) to focus on points of interest the car is passing. As the tour continues, Alanah makes an interesting remark: as an Australian, she has not encountered any games about her own cities, so to explore a city that she has just recently moved to reminds her of the feeling New Yorkers or Los Angelinos must have when they see their cities represented in media. As the video tour comes to a close, Marty accidentally runs over a pedestrian, which causes the police to chase after him. He attempts to ignore and evade them but, upon exiting the car to take a selfie on the iconic winding Lombard Street, the police shoot his character to death and the game restarts. The video edits out the restart and the tour continues, but this unexpected event vividly demonstrates how touristic aspirations in open-world city games must always contend with the rules defined in the software's code.

Similar to the city tour of Watch Dogs 2's San Francisco conducted by Marty and Alanah, the persistent novelty of real places re-created virtually is evident in many videos that compare the references and their referents in virtual cities with real-world counterparts. Videos such as GamesRadar's Mafia 3 - New Bordeaux VS New Orleans - The City That Inspired the Game (Jarvis \& Houghton, 2016) and VortexStory's Driver VS Driv3r VS Real Life - Miami Map Comparison (VortexStory, 2017) take photos and footage of the real location and splice them together with in-game footage or screenshots. In the case of a well-known online publication like GamesRadar, the purpose of a comparison tour is to attract attention to the publication's website and YouTube channel to harness hype around of the release of the game. But in the case of VortexStory, an independent video producer with only a small number of YouTube followers and whose channel is focused on sharing the ins and outs of the mildly popular 2004 game 
Driver 3, we can see an earnestness in the desire to act as a tour guide. This genre of video is not limited to comparisons between real-world locations and their videogame counterparts, however. As an example of another kind of mediated imaginary, players of Grand Theft Auto $V$ have documented how its expanded version of Los Santos makes reference to places featured in the version of Los Santos shown in Grand Theft Auto: San Andreas nearly a decade earlier. These videos demonstrate new forms of game tourism in which the object of interest no longer has an index in the real world but rather whose significance is defined within the media culture of games itself.

\section{Game tourism as transformation}

This chapter has focused on videogame cities that were created to replicate or reference existing cities of the world to establish the connection between realworld and virtual-world tourism. Extensive knowledge of these real cities by videogame players is not required for them to be experienced as a tourist even the knowledge that the Seattle of InFamous Second Son (2014) is based on real places is enough to encourage exploration. Yet tourism should not be limited to these urban adaptations. All kinds of fictional game worlds can also be toured. Nintendo's The Legend of Zelda: Breath of the Wild (2017) takes place in the ancient kingdom of Hyrule - a location that has been depicted over the last three decades in various forms across the many games in the series. In the game, players can unlock a camera item that their character Link can use to take photos throughout the land. Functionally, the purpose of the camera is to take photos of "memory" locations related to the story and objects that can be added to an in-game compendium. But though there is no direct way to export the photos outside of the videogame console's ecosystem, players can use the screenshot function of the Nintendo Wii U or Switch to duplicate images of the photographs in their in-game album and share them online. Of course, players could also just screenshot their game without the visual indicators that show while using camera item, but the rhetoric of the diegetic photo or selfie as a specific object associated with memory and spatial experience lends a personal weight to the game's unique vistas. Through possessive spectatorship, curious players document experiences beyond the normal play of the game. In these moments, the game world transcends its functionality, and the gamer-tourist transforms space into place. And, as evidenced by tourism-centred objectives in recent games, recording/sharing functionality, and media being made that captures these experiences, game worlds are increasingly being made with the knowledge that players take pleasure in touring their landscapes.

\section{Bibliography}

Bell, C. \& Lyall, J. (2005). 'I was here': Pixelated evidence. In: D. Crouch, R. Jackson \& F. Thompson (eds.), The media and the tourist imagination: Converging cultures. London: Routledge. 


\section{Bobby Schweizer}

Bogost, I. \& Klainbaum, D. (2006). Experiencing place in Los Santos and Vice City. In: N. Garrelts (ed.), The culture and meaning of Grand Theft Auto, pp. 162-176. Jefferson: McFarland Press.

Book, B. (2003, July 20). Traveling through cyberspace: Tourism and photography in virtual worlds. Presented at the Tourism \& Photography: Still Visions Changing Lives, Sheffield. Retrieved from https://papers.ssrn.com/abstract=538182.

Bridge, G. \& Watson, S. (2008). City imaginaries. In: G. Bridge \& S. Watson (eds.), A companion to the city, pp. 5-17. Malden: John Wiley \& Sons.

Brown, P. (2016, November 23). Watch Dogs 2 review. Retrieved from www.gamespot.com/reviews/watch-dogs-2-review/1900-6416578/

Dinhopl, A. \& Gretzel, U. (2016). Selfie-taking as touristic looking. Annals of Tourism Research 57: 126-139.

Donald, J. (1999). Imagining the modern city. Minneapolis: University of Minnesota Press.

Dow, D.N. (2013). Historical veneers: Anachronism, simulation and art history in Assassin's Creed II. In: M.W. Kapell \& A.B.R. Elliott (eds.), Playing with the past: Digital games and the simulation of history, pp. 215-232. London: Bloomsbury Publishing.

Gordon, E. (2010). The urban spectator: American concept cities from Kodak to Google. Hanover: Dartmouth College Press.

Grubb, J. (2013, September 20). Modder explains how he got $4 \mathrm{~K}$ Grand Theft Auto IV screens that put GTA V to shame. Retrieved from https://venturebeat. com/2013/09/20/these-photo-realistic-4k-gta-iv-screens-put-gta-v-to-shame-gallery/ (03-06-2018).

Hamza, K. (1991, February). The killing cloud. The One (29): 40-41.

Jaguaribe, B. (2007). Cities without maps. In: A. Cinar \& T. Bender (eds.), Urban imaginaries: Locating the modern city, pp. 100-120. Retrieved from http://site. ebrary.com/id/10212637.

Jarvis,J. \&Houghton,D.(2016). Mafia 3:New Bordeaux VSNew Orleans: The city that inspired the game. Retrieved from www.youtube.com/watch?v=8WKX5duy7X0.

Kollar, P. (2016, November 14). Watch Dogs 2 review. Retrieved from www.polygon. com/2016/11/14/13620870/watch-dogs-2-review-playstation-4-ps4-xbox-onepc-windows-ubisoft (05-06-2018).

Löfgren, O. (2002). On holiday: A history of vacationing. Berkeley: University of California Press.

MacCannell, D. (1999). The tourist: A new theory of the leisure class, 2nd ed. Berkeley: University of California Press.

Miller, K. (2008). The accidental carjack: Ethnography, gameworld tourism, and Grand Theft Auto. Game Studies 8(1). Retrieved from http://gamestudies. org/0801/articles/miller.

Pearce, A. \& Sliva, M. (2016). Touring the real San Francisco in Watch Dogs 2. Retrieved from www.ign.com/videos/2016/10/10/touring-the-real-san-franciscoin-watch-dogs-2.

Plunkett, L. (2012, August 29). The joys of using games for virtual tourism. Retrieved from http://kotaku.com/5939108/the-joys-of-using-games-for-virtualtourism (30-03-2014).

Poremba, C. (2007). Point and shoot remediating photography in gamespace. Games and Culture 2(1): 49-58. 
Salmond, M. (2016). The mediation and fetishisation of the travel experience. In: C. Scarles \& J.-A. Lester (eds.), Mediating the tourist experience: From brochures to virtual encounters. London: Routledge.

Salmond, M. \& Salmond, J. (2016). The gamer as tourist: The simulated environments and impossible geographies of videogames. In: P. Long \& N.D. Morpeth (eds.), Tourism and the creative industries: Theories, policies and practice. London: Routledge.

Schweizer, B. (2013, Fall). Moving through videogame cities. Mediascape. Retrieved from www.tft.ucla.edu/mediascape/Fall2013_MovingThroughCities.html.

Smith, R. (2013, February 28). GTA 4 in 4k. Retrieved from www.flickr.com/photos/ 15539352@N02/8517614178/(17-06-2019).

Stapleton, D. (2016, November 23). Watch Dogs 2 review. Retrieved from www.ign. com/articles/2016/11/23/watch-dogs-2-review.

Upchurch, D. (1991, May). The killing cloud. ACE: Advanced Computer Entertainment (44): 60-62.

Urry, J. \& Larsen, J. (2011). The tourist gaze 3.0. London: Sage.

VortexStory. (2017). Driver VS Driv3r VS Real Life: Miami Map Comparison. Retrieved from www.youtube.com/watch?v=Gq4kTvaY3L4.

Westwood, S. \& Williams, J. (1997). Imagining cities: Scripts, signs, memory. London: Routledge.

Whalen, Z. (2006). Cruising in San Andreas: Ludic space and urban aesthetics in Grand Theft Auto. In: N. Garrelts (ed.), The meaning and culture of Grand Theft Auto, pp. 143-161. Jefferson: McFarland. 


\title{
10 Locating the literary imagination Broadening the scope of literary tourism
}

\author{
Nicky van Es
}

\section{Introduction - literature and the imagination}

The tree which moves some to tears of joy is in the eyes of others only a green thing which stands in the way. Some see nature all ridicule and deformity, and by these, I shall not regulate my proportions; and some scarce see nature at all. But to the eyes of the man of imagination, nature is imagination itself. As a man is, so he sees.

William Blake (1777, as cited by Russel, 1906: 62) ${ }^{1}$

Taking a stroll through Peckham Rye park is, for many, a welcome escape from the busy, bustling city of London. Especially on a nice summers' day, the lake, grass, flowers, and trees seem more vibrant, radiating a cacophony of colours as the sunlight bounces off them. Truly a sight to behold; however, apparently, that's not all there is to "see". It was here, in 1765 , that the young William Blake stumbled upon an oak tree in the park. Nothing apparently special, as the park was filled with them at the time, but there was something about this particular one. As eight-year-old William looked up at the tree, he noticed how the tree shined extremely brightly. Not from sunlight. Instead, the tree appeared to be filled with luminous angels, covering the entire canopy of the old oak in front of him. William had just had his first "vision", one which would have a profound influence on his life - and arguably those of many others. Not the least of which was the tree itself through sparking Blake's imagination, it became an object of admiration, a totem or shrine, for his admirers to visit and pay their homage to one of the defining figures of the Romantic Age. Though the actual tree itself is long gone, ${ }^{2}$ to this day, fans and aficionados of Blake visit Peckham Rye park, imagine it being there, and, if only for a moment, might get a glimpse of the trees lighting up if the sunlight hits it just right.

British poet and visual artist William Blake (1757-1827) was known for having a particularly vivid imagination, often composed of religious visions like the one mentioned before. The concept of the imagination runs as a "red thread" throughout his work. His engagement with and explorations of the imagination ultimately led him to the conclusion that on a fundamental 
level, human existence is nothing more - or less, for that matter - than the imagination itself (cited in Maclagan \& Russell, 1907: 51). The cognitive capacity to conjure mental visualizations of matters not physically present is deemed of fundamental importance in shaping one's perception of the outer world at large and one's own place in it. The imagination, as such, colours a perception of experienced reality, essentially characterized by a degree of subjectivity determined by individual agency, emotions, and sociocultural context (Lennon, 2015; see also the Introduction in this volume for a more elaborate phenomenological definition of the imagination).

Though inextricably linked to Romanticism, the cultural significance of the imagination extends far above and beyond the late 18th-19th century as well as the West. Indeed, as is argued in the Introduction to this volume, the imagination appears to be a universal given through which mankind as homo narrans makes sense of, experiences, and give shape to the world around them and their place in it (Berger, 1997). The imagination as source of human creativity, beauty, and the sublime and divine has preoccupied philosophers from nearly all times and places, at least from as far and wide as there exist (written) records of this. From Plato and Aristotle (Chambliss, 1974), to al-Kindi and al-Farabi (Leaman, 2009), and finally Zhuangzi and Confucius (Moeller \& Whitehead, 2019), it is apparent that the great minds from all corners of the globe have preoccupied themselves with the imagination. Travelling was held to be of central importance in engaging the imagination, in turn converted into the many writings and stories produced by (and about) said figures, ultimately immortalizing their philosophies, experiences, and ideas as they continue to live on long after their original thinkers have succumbed to the test of time.

Literature - defined here as literary narratives containing some degree of fictionalization - has proven to be an excellent vehicle for the imagination. It provides a way in which the imagination can be made concrete and conveyed to others through a narration of events that necessarily exist within space and time - ranging from the familiar, mundane, and realistic to the unknown, foreign, fantastical, and abstract. And through the practice of reading, in return, the imagination is stimulated, challenged, and put to work through processing combinations of words and converting them into "mental images" (Hume, 1740/2000). The places and locations which inspired writers and poets alike are turned into compelling "imaginative geographies" (Urry \& Larsen, 2011), so much so that the urge to visit these "places of imagination" (Reijnders, 2011) and experience them in actuality drives tourism to the real-world counterparts of imagined worlds.

And it is here, in the cultural practice of literary tourism - visiting places associated with (in origin) literary narratives, their author(s), and/or their "multimedia afterlife" (Clayton, 2003; Vanacker \& Wynne, 2013; Watson, 2009) - where the connection between the imagination and actual experience becomes the most apparent. But how exactly does literature tie into the mental processes underlying the way(s) in which readers, tourists, and travellers make sense of, experience, and attribute meaning to the world around them? 


\section{Nicky van Es}

\section{Literary tourism}

Literary tourism as the collective, cultural practice it is conceived to be today is commonly held to have its inception in 19th-century Britain, following a simultaneous rise in social conditions as well as the popularization of the realist romantic novel amongst wider layers of society through cultural consecration of their authors (Watson, 2006, 2009). Though still dominated by the upper echelons of society, gradually the practice of literary tourism underwent a process of democratization, where increasingly people from various backgrounds could enjoy the pleasures of visiting literary places. Before this period, however, and arguably up until today, it is more apt to refer to literary travel instead. The earliest records of this lie in the writings of Italian humanist scholar Petrarch, who undertook a "literary pilgrimage" in 1343, visiting places related to the poetry and epics of ancient Roman poet Virgil (Hendrix, 2008). Analogous to a "religious pilgrimage" (Turner \& Turner, 1978/2011), this literary journey was above all an individual one, directed by a distinctively "romantic gaze" (Urry \& Larsen, 2011) and considered a reflexive, educative, contemplative, and "authentic" practice (Fussell, 1980). The concept of tourism, however, comes with diametrically opposed attributes, is often engaged in with (masses of) others, informed by a more "collective gaze" (Urry \& Larsen, 2011) and associated with notions of hedonism, entertainment, commercialism, and superficiality (Fussell, 1980), or "staged authenticity" (MacCannell, 1976/1999).

In combining the popular, collective practice of tourism with the revered tradition of literature as part of "high" culture - evoking associations of personal affinity, refined taste, and critical admiration (Franssen \& Honings, 2014: 244) - one of the fundamental tensions inherent to literary tourism becomes exposed. Following a Bourdieusian field logic (Bourdieu, 1979/1984), the "literary tourist" can be located, if at all possible, on the paradoxical intersection between the "lowbrow", popular practice of tourism and the "highbrow", consecrated status ascribed to literature. One way out of this conundrum, and particularly favoured in a more literary studies approach to literary tourism (Watson, 2006, 2009), has been to engage in a discussion on literary "travel" instead. Another popular alternative is to conflate literary tourism with the arguably less problematic concept of heritage tourism (e.g. Busby \& Shetliffe, 2013; Herbert, 1996, 2001; Pocock, 1992; Squire, 1993, 1994), tying it into romantic conceptions of national or local history conveyed through "classic" literature and their authors and stemming from an apparent "present-day obsession with heritage and cultural memory" (Plate, 2006: 101). However, as argued elsewhere (van Es \& Reijnders, 2016, 2018), this has resulted in a rather one-dimensional and elevated conception of the cultural phenomenon of literary tourism.

Another possible way out, and one favoured in this chapter, would be to broaden the scope, move beyond narrow definitions of literature, and acknowledge the plethora of literary narratives and genres (including adaptations and 
paratexts), each with equally different ways of employing sense(s) of place and time, all with the potential to literally move their audiences across the globe (e.g. Laing \& Frost, 2012; Robinson \& Anderson, 2002). At this point, it is important to emphasize the primacy of narratives and stories in acquiring a sense of place attachment or "sense of belonging" (Morley, 2001). In moving beyond a mediacentric conception (Morley, 2009) in acknowledging that it's above all the "stories that move" (Reijnders, 2016) and not necessarily the particular media which convey them, it is argued that "topophilia" (Tuan, 1974) stems from an extent of "mythophilia". Here, an affective connection to narratives or stories translates into a love for places and locations connected to it. Literature, just like all other media, is merely one of the many possible ways of conveying these narratives which ultimately touch the hearts and minds of people.

Having said that, however, it is at the same time important to keep in mind that different media come with their own traditions and "affordances" when it comes to conveying narratives, stimulating the imagination, and affecting an experience of actual place and locality. Not only that, academic fields of research towards media tourism (as an umbrella concept) have their own distinctive histories and traditions located in literary studies (this chapter, Chapters 15 and 16), music studies and philosophy (Chapter 4), and film/TV studies (Chapter 17). Hence, in order to gain a better understanding of how mediated narratives, in general, stimulate the imagination and instigate travel, attention needs to be paid not only to similarities across media but subtle, nuanced, and meaningful differences encountered between them, too. When it comes to popular stories originally conveyed through literature, the next part of this chapter will continue the discussion through drawing on over four years of ethnographic fieldwork in broadening the scope of literary tourism.

\section{Researching literary tourism}

The research contained in this chapter is based on a four-year period (2013-2017) of ethnographic fieldwork towards unravelling the role and importance of popular literature in contemporary manifestations of literary tourism. In the context of the Locating Imagination project, supported by the Netherlands Organization for Scientific Research (NWO), three case studies were conducted with the underlying aim of offering a critical, timely account, from the tourists' perspective, in an attempt to explore the multifaceted ways in which literature and place are intertwined in an environment increasingly saturated by multimedia and ongoing processes of digitization. This entailed focusing on how, and in which ways, literature and literary narratives tie into 1) imagining, 2) experiencing, and 3) reflecting on place(s) and locality(-ies) from the emic perspective of those directly involved in it: the literary tourists.

Drawing upon insights derived from the intersecting fields of tourism, heritage, and media studies (cf. Pine \& Gilmore, 1999; Reijnders, 2011; Urry \& 
Larsen, 2011; Ehn \& Löfgren, 2010; Laing \& Crouch, 2009; McIntosh, 1999; Connell, 2012; Lean et al., 2014), the "tourism experience" is conceptualized as a process, consisting of pre-visit (i.e. decision-making, imagining), on-site visit (embodied experience), and post-visit (reflections) stages. Though intertwining and flowing in and out of each other in practice, this analytical model acknowledges the importance of the imaginative efforts which are undertaken during and prior to any embodied experience, as well as potentially transformative reflections on this experience which take place during and after the fact. Hence, in order to come to a more multilayered and nuanced understanding of the contemporary experience of literary tourism, the following research aims to assess the role and importance of literature in present-day imaginations, experiences, and reflections on place and locality.

Starting out with the literary imagination, the first case is built on 15 semistructured, in-depth interviews (Kvale \& Brinkmann, 2009; Bryman, 2004) with readers about their beloved stories, how place and locality is imagined through them, and how this subsequently ties back into the participants' actual experiences of their surroundings. The second case dives into the literary experience of "capital crime cities" as the antithesis to its Romantic counterpart, which, instead of providing an escape from the "great, sprawling city" held to be the prime motivation for literary tourists visiting picturesque literary places in the countryside, actually involves a gradual descent into the deepest, darkest, crime-ridden corners of the metropolis. Participation in literary crime-detective fiction tours in Sherlock Holmes' London, Philip Marlowe's Los Angeles, and Lisbeth Salander's Stockholm, in combination with 20 in-depth interviews with participants, provide valuable insights into how, through association and affinity with popular crime-detective fiction, a distinctive "sense of urban place" is provided, negotiated, experienced, reflected upon, and ultimately made sense of.

All data was analysed from a grounded theory perspective through thematic analysis (Glaser \& Strauss, 1967; Charmaz, 2006; Braun \& Clarke, 2006). This entailed the analysis proceeding through gradual stages of coding after transcription of fieldnotes and interviews, an iterative process of moving back and forth between data and theory. During the initial "open coding" phase, particular attention was paid to the ways in which a certain affinity with literature ties into the imaginations, experiences, and reflections as articulated and made sense of by the literary tourists involved, specifically through emphasizing "sensitizing concepts" (Bowen, 2006). Following this, the analyses proceeded through making connections between the initial codes contained in each dataset, grouping together and categorizing those which appeared most prominently across the board while simultaneously remaining receptive to significant and nuanced differences. From this, overarching themes were constructed, aiming to reflect central aspects or dimensions of the literary imagination, experience, and reflection. It is to these themes and the theorizing which explains them that this chapter turns now. 


\section{Findings}

In what follows, the main results of each case study will be provided after a brief introduction to outline the contours of each case, as well as some of the important theories and concepts underlying these. The conclusion towards the end of this chapter will be used to reflect on these cases and engage in a discussion on the "place" of literature in an environment increasingly saturated by digital and multimedia in an age of "media convergence" (Jenkins, 2004).

\section{Armchair travel in a digital age}

During the 19th century, Britain was struck with an insatiable need for "armchair travel", or for "vicarious and simulated travel experiences" (Byerly, 2002: 78). Fortunately, the simultaneous rise in popularity of the realist novel (Watson, 2006) provided those who "preferred to enjoy their newfound knowledge of other places in a highly mediated form" (Byerly, 2002: 78 ) with ample opportunity to do so. To this day, literature is often celebrated (or criticized) for its ability to take its readers on an imaginative journey, through detailed and vivid descriptions of (not-so) far-away places, giving the sensation to the reader as if they were actually there. However, as is postulated in the Introduction to this volume (Lean et al., 2014), the ways in which popular media actually informs, shapes, or contests the imagination and subsequent experience of "being in the world" are often assumed and theorized but hardly researched (notable exceptions to this are Reijnders, 2016; Bolderman \& Reijnders, 2019). How do contemporary readers imagine their favourite literary diegetic worlds, and how does this relate to their perception and experience of actual place and locality? And what place do literature and the imagination it provides have in an increasingly digitizing world?

Towards finding an answer to these questions, 15 people from an diverse range of ages and international backgrounds were interviewed on their favourite books and stories. In making sure the interviews were conducted in a familiar space, most often the respondents' home, and by removing external stimuli as much as possible, it was attempted to stimulate the imagination as much as possible during the interviews (Ehn \& Löfgren, 2010; Reijnders, 2016). Starting from beloved novels and stories, attention was paid to the role of place and locality, how this was imagined through reading, and how this related to their perception of actually existing places or locations.

The results of the study indicate that people's favourite stories first and foremost fall within the realism or magic realism genre, containing realistic depictions of events, characters, and/or places, ranging from the mimetic to diegetic and fantastical narratives. Often, favourite stories were mentioned which were set in the origin culture of respondents, written by nationally corresponding authors, which were often internationally celebrated and known through translation and acquisition of literary awards. Amongst the favourites which were mentioned were Mazu's Bodyguards (2004) by Jade Y. Chen, 
about three generations of Taiwanese women (Y.A., Taiwan, female, 30+); Helping Verbs of the Heart (1985) by Péter Esterházy, a requiem for a dying mother (H., male, Hungarian-Dutch, 35+); and The Misfortunates (2006) by Dimitri Verhulst, on a dysfunctional, alcoholic family of uncles living on the derelict outskirts of a Flemish industrial city (D., male, Dutch, 30+).

Though the translated titles are displayed here, all respondents claimed to read their beloved stories in their native language, which was deemed important due to its argued closest proximity to the imagination of the author. Particularly amongst the respondents with an international background, favourite stories and books evoked sentiments of topophilia (Tuan, 1974), expressing a sense of belonging and connection to an imagined homeland and culture. Place here was often discussed as being atmospherically present, difficult to convey in detail but reminiscent of a situated familiarity or unfamiliarity, for that matter. Working through varying extents of affirmation or subversion of culturally specific imaginations of place and locality, beloved stories and their authors provide a moment of imaginary contact with the Heimat and territories of the "Self".

On the other hand, there were also those whose favourite stories pertained to narratives involving the "Other" (Goffman, 1959; Said, 1978). These were either more related through providing an impressive, subjective account of "lived" experiences of the "Other" as they narrated their experiences of Western culture - such as Americanah by Chimamanda Ngozi Adichie (2013), about a young Nigerian woman who immigrates to the United States (J., female, Austrian, 20+). Otherwise, favourite literature on the "Other" involved stories told from a Western perspective, mainly taking place in territories of the "Other". In the shape of "semi"-autobiographies, the stories of Not without My Daughter (1991) by Betty Mahmoody (M., female, Dutch, 55+) and Lone Survivor (2007) by Marcus Luttrell (J., male, Canadian-Korean, 20+) revolve around intercultural contact (with some extent of conflict) with locals in remote parts of Iran and Afghanistan, respectively. Detailed descriptions of steep icy mountains, deserted planes, and isolated villages as "fearscapes" (Ehn \& Löfgren, 2010) evoke a sense of topophobia (Tuan, 1974), places to explore, especially through the safe confines of the imagination, but ultimately to stay away from. Again showing the importance of socio-cultural context in the imagination (Lennon, 2015), the timing of these interviews coincided with an upsurge in media attention in 2016 for the Syrian refugee crisis (Dearden, 2016), indicative of the myriad of ways in which both the imagination and experienced reality - through varying extends of mediatization - feed on, inform, stimulate, contest, negotiate, and/or enrich each other.

Regardless of the direction of the "imaginative journeys" the respondents undertook in their favourite novels, it was emphasized that it was particularly the extent of "imaginative agency" (cf. Lennon, 2015) that was deemed unique or particular to appropriating narratives through literature. Especially in an environment where the entire "mediascape" (Appadurai, 1990) 
is instantly available at one's fingertips and monitors feed our gaze for the largest part of the day, reading a book is soothing to the eye, albeit arguably requiring a bit more active imaginative engagement. Although literature as the medium par excellence for "armchair travel" is indicated to be losing ground in favour of the moving image and the Internet (Baxter \& Pieszek, 2011), this case has shown several ways in which beloved literary narratives are meaningfully engaged with, negotiated, and appropriated through the imagination.

\section{Chasing sleuths and unravelling the metropolis ${ }^{3}$}

A conventional understanding of literary tourism defines the practice mainly along the lines of its flight away from the "great sprawling cities" (Tuan, 1974) and into the literary places (DeLyser, 2003; Watson, 2006; Westover, 2012) and writers' houses (Hendrix, 2008) located in the countryside. Stemming from an apparent romantic desire to escape alienating urban life, the literary tourist today is drawn to experience the sublime, picturesque, and "authentic" in rurality (Busby \& Shetliffe, 2013; Herbert, 1996, 2001; Pocock, 1992; Squire, 1993, 1994), continuing the tradition as set forth by those during the late Victorian era (Watson, 2009), still visiting the same places tied to the same Romantic, consecrated novelists.

Both the experience of the city as literary place, as well as being conveyed through a distinctively more "lowbrow" realist genre - such as crime-detective fiction - was hitherto largely absent from or not taken seriously in academic research towards literary tourism (with recent exceptions being Mansfield, 2015; van Es \& Reijnders, 2016, 2018; Marques, 2019). Having its origins in the same time as the 19th-century Romantic realist novel, crime fiction's popularity is often attributed to tapping into a cultural fascination for the "unknown" and "uncanny" in the city (e.g. Booth, 2009; Clayton, 2003) through providing realistic and detailed descriptions of urbanity as it works towards exposing the "darker sides" of urban life. How do tourists experience contemporary cities through their participation in crime-detective fiction tours, and what meaning(s) do they attribute to their experiences?

This question becomes more pressing considering the notion that the city is often conceptualized as a "multi-generic" text and hence characterized by an "eclectic simultaneity" (Watson, 2009: 144, 147) of a plethora of fictional and actual narratives instilling urban space with meaning and significance - a development which is frequently held to be driven by ongoing processes of globalization, mediatization, and digitization. Precisely because of this, postmodernists have argued that the contemporary city has become "overexposed" (McQuire, 2008: 11), and, as such, the city has arguably lost its previously more "clear" definable boundaries and identity in favour of adopting a more fluid, ambiguous, and unidentifiable centre, detached from a lucid sense of urbanity - captured in the concepts of the "ageographical city" (Sorkin, 1992) and "postmetropolis" (Soja, 2000). In times of "urban 


\section{Nicky van Es}

placelessness" (ibid), having a meaningful experience of the city becomes an increasingly problematic and less tenable pursuit.

Focusing on the ways in which a particular sense of place was performed on tour through drawing on popular crime-detective fiction, as well as how this was experienced by participants, literary crime-detective fiction tours in Sherlock Holmes' London, Philip Marlowe's Los Angeles, and Lisbeth Salander's Stockholm were participated in, combined with 20 in-depth interviews with literary tourists. In sum, the results show that the experience(s) underlying contemporary crime-detective fiction tourism is more about engaging in a vertical descent into the presumed "heart" of the city instead of a more horizontal, postmodern bricolage of collecting "free-floating" signs and signifiers located on the urban surface.

This "vertical descent" involves a process of getting underneath the "urban façade" in an attempt to gradually approach a presumed core identity of the city. This initially proceeds through recognizing, exposing, and analysing the multiple place-narratives which encapsulate the perceived place-identity. Through the lens of crime-detective fiction, these multiple "layers of significance" (Torchin, 2002) are touched upon in situ, "peeled away", disentangled, and made sense of, illustrating how actual and fictional events, characters, and locations both converge and differ from each other as they are grounded in place. Initially, this entails getting a glimpse of the "other" side of urban life which often lies hidden and obscured underneath a shiny veneer of urban progress and prosperity. As mystery, crime, poverty, and decay are deemed a fundamental part of what makes up a city and life in it, crime-detective fiction provides an initial opening to approach this "grittier" and "uncanny" side or urban place-identity. Instead of opting for a "flight" away from the city, as is characteristic for more romantic literary tourists, the crime-detective fiction tourist chooses to dive in "headfirst", confronting the darker sides of urban life.

After the "urban veil" has been lifted and a glimpse of its "underbelly" is shown, the experience proceeds through further uncovering and unravelling the multiple narrative layers that encapsulate the presumed core-identity of the city. Moving from the starting point of the original fictional narratives, the experiences proceed to touch upon the more factual autobiographical layer connected to the author and actual historical narratives containing the events, characters, and locations which inspired the tourists' beloved stories. Disappointment was expressed in those cases where fictional "spatial discrepancies" (Roesch, 2009), or "diegetic discrepancies" would manifest themselves. This was related to the fact that locations associated with the popular adaptations are often different from those which feature in their literary "origins". Despite both being equally fictional and imaginative, locations associated with the latter were considered more "imaginatively authentic" and subsequently experienced as more "real".

Finally, for those that did manage to come close to the perceived "heart" of the city through having made their way from the "underbelly", several 
respondents expressed strong affection for and identification with the city, acquiring a "sense of belonging" (Morley, 2001). It shows how, through its association with popular crime-detective fiction, the city as a whole is made sense of. In often relying on using metaphors to describe the imagined "capital crime city" as an organic whole, which requires the examination of the interrelations between its various parts which make it up in order to be able to identify the "sum" of its parts, crime-detective fiction tourism is thus best understood as a "modernistic backlash" against a presupposed problematic nature of urban experience in late or postmodernity. It is precisely due to relying on a performance of crime-detective fiction that works through exposing, disentangling, and relating multiple - and at times conflicting - place-narratives that the experience of the city acquires significance and meaning.

\section{Conclusion}

In Japan, there is a saying, 見ぬが花 (“Minu ga hana”), which roughly translates as "Not seeing is a flower", 4 indicative of the notion that the imagination is always better than reality. Maybe it is indeed the case. From that standpoint, the practice of literary tourism - or any (un)mediated narrative tourism, for that matter - is indeed set up for disappointment, and any attempt to locate the imagination in reality might be a futile exercise from the get-go (see also Chapters 15 and 16). At the least, I would argue for the notion that the imagination is simply different, not by definition "better", per se. Even if it would be, the power of the imagination should equally have the power to make experienced reality even better. The imagination has the power to turn run-down or otherwise nondescript locations and "nonplaces" (Augé, 1992/2009) into ones which are imbued with significance and meaning. The stories and narratives we appropriate throughout our lives do seldom remain confined to the interior world. Through the imagination's "transformative potential", the colours of experienced reality can be painted much brighter - like an oak tree filled with angels.

Through the lens of literary tourism, this chapter has illustrated ways in which the role - or "place" - of literature in present-day imagination, experiences, and reflections on place and locality operates in an increasingly multimedia and digitized environment. As such, narratives originally conveyed through literature are said to particularly stimulate the imagination, allowing for relatively more individual agency in creating the "mental images" (Hume, 1740/2000) or "affective textures" (Lennon, 2015) in imagining the story and setting unfolding in the mind. As such, the "imaginative authenticity" (see Chapter 2) of a narrative conveyed through literature is frequently perceived as being more present, especially compared to audiovisual adaptations of said narrative. This, in turn, has its effect on the ways in which actual places tied into the popular narrative are experienced and subsequently reflected upon, where "imaginative authenticity" is 


\section{Nicky van Es}

ascribed to experiencing locations connected to the original literary narrative in cases where there exist diegetic discrepancies, with locations derived from its multimedia afterlife experienced as less authentic. Being able to discern this though prolonged affinity with popular crime-detective fiction narratives across formats, in turn, allows literary tourists to have an "existentially authentic" (Wang, 1999) experience of present-day urbanity - being able to tease out nuanced differences between both fictional and factual place narratives - acquiring a "sense of place" deemed impossible to obtain for those masses of tourists who are unaware of the stories that define a place.

\section{Notes}

1 Published in: Russel, A.G.B. (1906). The Letters of William Blake, Together with a Life by Frederick Tatham, page 62. London: Methuen.

2 A commemorative oak tree was replanted in 2011 (Crown, 2011).

3 Parts of this case study have been previously published in Van Es and Reijnders (2016, 2018).

4 Translation obtained through Wikipedia (n.d.) on Japanese proverbs. Retrieved from https://en.wikipedia.org/wiki/Japanese_proverbs (15 March 2020).

\section{Bibliography}

Appadurai, A. (1990). Disjuncture and difference in the global cultural economy. Public Culture 2(2): 1-24.

Augé, M. (1992/2009). Non-places: An introduction to supermodernity. London: Verso.

Bal, M. (1994). Narrotology: Introduction to the theory of narrative. Toronto: University of Toronto Press.

Baxter, A. \& Pieszek, L. (2011). Armchair tourism: Bringing the world into your living room. In: A. Papathanassis (ed.), The long tail of tourism. Berlin: Springer.

Berger, A.A. (1997). Narratives in popular culture, media, and everyday life. London: Sage.

Bolderman, S.L. \& Reijnders, S.L. (2019). Sharing songs on Hirakata Square: On playlists and place attachment in contemporary music listening. European Journal of Cultural Studies. Advance online publication. https://doi. org/10.1177/1367549419847110.

Booth, A. (2009). Time-travel in Dickens' world. In: N. Watson (ed.), Literary tourism and nineteenth-century culture, pp. 150-163. New York: Palgrave MacMillan.

Bourdieu, P. (1979/1984). Distinction: A social critique of the judgement of taste (R. Nice, Trans.). Cambridge: Harvard University Press.

Bowen, G.A. (2006). Grounded theory and sensitizing concepts. International Institute for Qualitative Methdology 5(3): 12-23.

Braun, V. \& Clarke, V. (2006). Using thematic analysis in psychology. Qualitative Research in Psychology 3(2): 77-101.

Bryman, A. (2004). Social research methods. Oxford: Oxford University Press.

Busby, G. \& Shetliffe, E. (2013). Literary tourism in context: Byron and Newstead Abbey. European Journal of Tourism, Hospitality and Recreation 4(3): 5-45. 
Byerly, A. (2002). Rivers, journeys, and the construction of place in nineteenthcentury English literature. In: S. Rosendale (ed.), The greening of literary scholarship: Literature, theory, and the environment, pp. 77-94. Iowa City: University of Iowa Press.

Chambliss, J.J. (1974). Imagination and reason in Plato, Aristotle, Vico, Rousseau and Keats. Berlin: Springer.

Charmaz, K. (2006). Constructing grounded theory. London: Sage.

Clayton, J. (2003). Dickens in cyberspace: The afterlife of the nineteenth century in postmodern culture. Oxford: Oxford University Press.

Connell, J. (2012). Film tourism: Evolution, progress and prospects. Tourism Management 33: 1007-1029.

Crown, S. (2011, September 20). Blake's vision tree returns to Peckham Rye. The Guardian. Retrieved from www.theguardian.com/books/booksblog/2011/sep/20/ william-blake (15-03-2020).

Dearden, L. (2016, July 30). Refugee crisis: 2016 on course to be deadliest year on record as thousands of asylum seekers drown in Mediterranean. Independent. Retrieved from www.independent.co.uk/news/world/europe/refugee-crisis2016-on-course-to-be-deadliest-year-on-record-as-thousands-of-asylum-seekersdrown-in-a7164271.html (15-03-2020).

DeLyser, D. (2003). Ramona memories: Fiction, tourist practices, and placing the past in Southern California. Annals of the Association of American Geographers 93(4): 886-908.

Ehn, B. \& Löfgren, O. (2010). The secret world of doing nothing. Berkeley: University of California Press.

Fawcett, C. \& Cormack, P. (2001). Guarding authenticity at literary tourism sites. Annals of Tourism Research 28(3): 686-704.

Franssen, G. \& Honings, R. (2014). Literaire fancultuur in Nederland: bij wijze van inleiding. Spiegel der Letteren 56(3): 243-247.

Fussell, P. (1980). Abroad: British literary travelling between the wars. Oxford: Oxford University Press.

Glaser, B.G. \& Strauss, A.L. (1967). The discovery of grounded theory: Strategies for qualitative research. Chicago: Aldine.

Goffman, E. (1959). The presentation of self in everyday life. Garden City: Doubleday.

Hendrix, H. (2008). Writers' houses and the making of memory. London: Routledge.

Herbert, D. (1996). Artistic and literary places in France as tourist attractions. Tourism Management 17(2): 77-85.

Herbert, D. (2001). Literary places, tourism and the heritage experience. Annals of Tourism Research 28(2): 313-333.

Hume, D. (1740/2000). A treatise of human nature: Being an attempt to introduce the experimental method of reasoning into moral subjects. Oxford: Oxford University Press.

Kvale, S. \& Brinkmann, S. (2009). InterViews: Learning the craft of qualitative research interviewing, 2nd ed. London: Sage.

Laing, J. \& Crouch, G.I. (2009). Exploring the role of the media in shaping motivations behind frontier travel experiences. Tourism Analysis 14: 187-198.

Laing, J. \& Frost, W. (2012). Books and travel: Inspiration, quests and transformation. Bristol, Buffalo \& Toronto: Channel View Publications.

Leaman, O. (2009). Islamic philosophy: An introduction. Cambridge: Polity Press. 


\section{Nicky van Es}

Lean, G., Staiff, R. \& Waterton, E. (2014). Reimaging travel and imagination. In: G. Lean, R. Staiff \& E. Waterton (eds.), Travel and imagination, pp. 9-24. Farnham: Ashgate.

Lennon, K. (2015). Imagination and the imaginary. London: Routledge.

MacCannell, D. (1976/1999). The tourist: A new theory of the leisure class, 2nd ed. Berkeley: University of California Press.

Maclagan, E.R.D. \& Russell, A.G.B. (eds.). (1907). The prophetic books of William Blake. London: A.H. Bullen.

Mansfield, C. (2015). Researching literary tourism. Bideford: Shadows Books \& Media.

Marques, L. (2019). The making of the literary city: Edinburgh, Barcelona and Óbidos. In: I. Jenkins \& K.A. Lund (eds.), Literary tourism: Theories, practice and case studies. Oxfordshire: CABI.

McIntosh, A.J. (1999). Into the tourist's mind: Understanding the value of the heritage experience. Journal of Travel \& Tourism Marketing 8(1): 41-64.

McQuire, S. (2008). The media city: Media, architecture and urban space. London: Sage.

Moeller, H. \& Whitehead, A.K. (eds.). (2019). Imagination: Cross-cultural philosophical analyses. London: Bloomsbury.

Morley, D. (2001). Belongings: Place, space and identity in a mediated world. European Journal of Cultural Studies 4(4): 425-448.

Morley, D. (2009). For a materialist, non-media-centric media studies. Television \& New Media 10(1): 114-116.

Pine, B.J. \& Gilmore, J.H. (1999). The experience economy. Work is theatre \& every business a stage. Boston: Harvard Business School Press.

Plate, L. (2006). Walking in Virginia Woolf's footsteps: Performing cultural memory. Cultural Studies 9(1): 101-120.

Pocock, D. (1992). Catherine Cookson country: Tourist expectation and experience. Geography 77(3): 236-243.

Reijnders, S. (2011). Places of the imagination: Media, tourism, culture. Farnham: Ashgate.

Reijnders, S. (2016). Stories that move: Fiction, imagination, tourism. European Journal of Cultural Studies 19(6): 672-689.

Robinson, M. \& Anderson, H.C. (2002). Literature and tourism. London \& New York: Continuum.

Roesch, S. (2009). The experience of film location tourists. Bristol: Channel View Press.

Russel, A.G.B. (1906). The letters of William Blake, together with a life by Frederick Tatham. London: Methuen.

Salazar, N.B. \& Graburn, N.H.H. (2014). Toward an anthropology of tourism imaginaries. In: N.B. Salazar \& N.H.H. Graburn (eds.), Tourism imaginaries: Anthropological approaches, pp. 1-28. New York: Berghahn.

Schmid, D. (1995). Imagining safe urban space: The contribution of detective fiction in radical geography. Antipode 27(3): 242-269.

Soja, E. (2000). Postmetropolis: Critical studies of cities and regions. Oxford: Blackwell Publishers.

Sorkin, M. (ed.) (1992). Variations on a theme park: The new American city and the end of public space. New York: Hill \& Wang.

Squire, S.J. (1993). Valuing countryside: Reflections on Beatrix Potter tourism. Area 25(1): 5-10. 
Squire, S.J. (1994). The cultural values of literary tourism. Annals of Tourism Research 21: 103-120.

Torchin, L. (2002). Location, location, location: The destination of the Manhattan TV tour. Tourist Studies 2(3): 247-266.

Tuan, Y. (1974). Topophilia: A study of environmental perception, attitudes, and values. Englewood Cliffs: Prentice-Hall.

Turner, V. \& Turner, E. (1978/2011). Image and pilgrimage in Christian culture. New York: Columbia University Press.

Urry, J. \& Larsen, J. (2011). The tourist gaze 3.0. London: Sage.

Vanacker, S. \& Wynne, C. (2013). Sherlock Holmes and Conan Doyle: Multi-media afterlives. New York: Palgrave Macmillan.

van Es, N. \& Reijnders, S. (2016). Chasing sleuths and unravelling the metropolis: Analyzing the tourist experience of Sherlock Holmes' London, Philip Marlowe's Los Angeles and Lisbeth Salander's Stockholm. Annals of Tourism Research 57: 113-125.

van Es, N. \& Reijnders, S. (2018). Making sense of capital crime cities: Getting underneath the urban façade on crime-detective fiction tours. European Journal of Cultural Studies 21(4): 502-520.

Wang, N. (1999). Rethinking authenticity in tourism experience. Annals of Tourism Research 26(2): 349-370.

Watson, N.J. (2006). The literary tourist: Readers and places in romantic and Victorian Britain. New York: Palgrave Macmillan.

Watson, N.J. (ed.). (2009). Literary tourism and nineteenth-century culture. New York: Palgrave Macmillan.

Westover, P. (2012). Necromanticism: Travelling to meet the dead, 1750-1860. New York: Palgrave Macmillan. 
$\because$ Taylor \& Francis

Taylor \& Francis Group

http://taylorandfrancis.com 


\section{Part III}

Being there 
$\because$ Taylor \& Francis

Taylor \& Francis Group

http://taylorandfrancis.com 


\title{
11 Toy tourism
}

\section{From Travel Bugs to characters with wanderlust}

\author{
Katriina Heljakka and Pirita Ihamäki
}

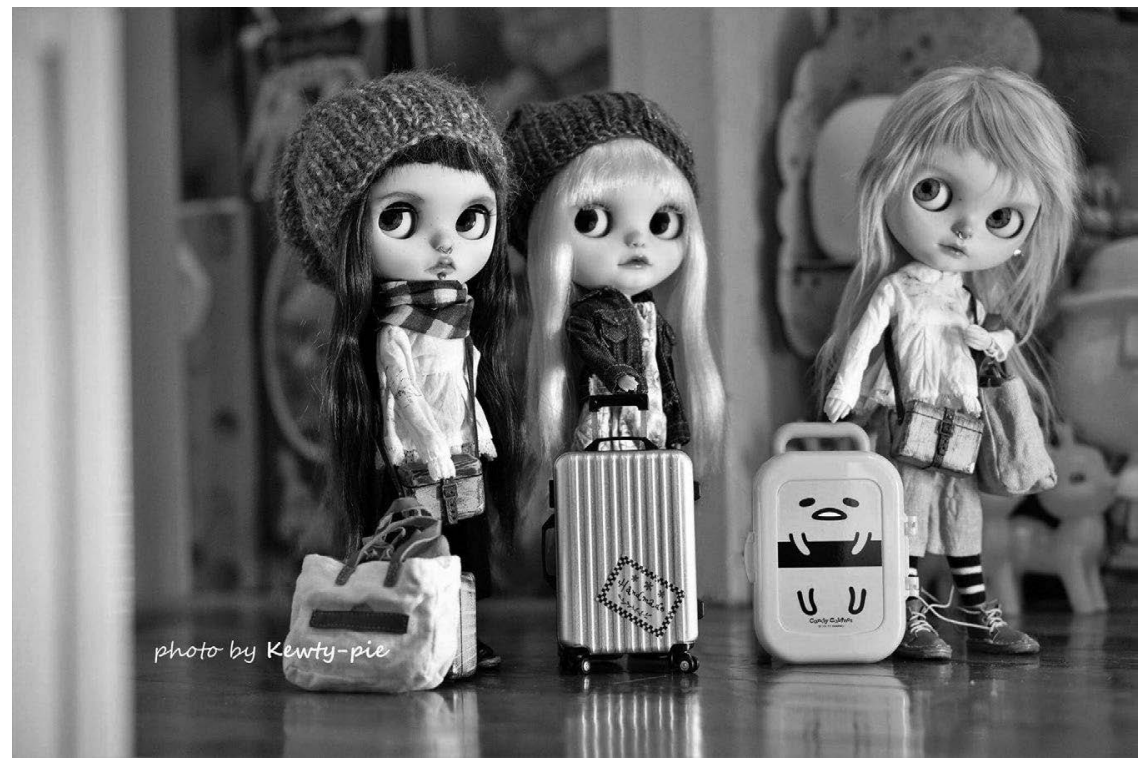

Figure 11.1 Kewty-pie's customized Blythe dolls are all set for travel with their owner.

Source: Photo by Kewty-pie/Simlian (2016). Reproduced with permission.

\section{Introduction}

Tourists become involved in or engage with material cultures because they find them useful (Haldrup \& Larsen, 2006: 278-286). This chapter investigates the significance of playing with toys, or object play, in the context of tourism. Reflecting on the mutual relationship between tourism and play, Heynders and Van Nuenen (2014) noted the role of the tourist as player and the nature of tourism as a form of play. The chapter considers how character 
toys are employed as useful objects in imaginative and leisurely tourist practices, focusing in particular on the toy play of mature players. We examine the phenomenon of travelling toys - toys that travel in the name of toy tourism, either as a part of amateur practices as their owners' companions (see Figure 11.1), single-handedly within hosting programmes or professionally organized toy travel agency services (Heljakka, 2013: 289), or within the game of geocaching.

Character toys (i.e. dolls, action figures, and soft toys) are often portable. For example, the toy company Kenner made their Star Wars figures pocket sized so that they could be carried around and played with wherever the player went (Geraghty, 1996: 213). Even the toy industry encourages toys to travel; for example, there are toys with backstories involving personality traits such as wanderlust (Heljakka, 2013). Moreover, toys are now supplied with accessories associated with human touristic practice, such as miniature cameras.

To examine how contemporary character toys activate the imagination and enable mobile toy play in adulthood, the present chapter explores emerging types of toy tourism through studies of players travelling with their toys, toys travelling by themselves (e.g. Travel Bugs in the context of geocaching), and toys travelling via organized toy travel agencies. Based on a thematic analysis of qualitative interviews and a survey with a toy playing audience - toy fans and geocachers - our aim was to illuminate the motivation behind travelling with toys or sending toys on travels and to contextualize toy tourism practices as a form of contemporary play within human travel and imagination.

In previous studies, the exploration of the various forms of toy mobility focused on non-corporeal elements of toy-related travel experiences, as in Robinson's (2014) research on experimental tourism involving vicarious (experienced through another) travelling with toys as mascots. According to the Oxford English Dictionary (online), a mascot is "a person or a thing that is supposed to bring good luck, especially linked to a particular organisation or an event". The contribution of this study is in highlighting the play-oriented practices of toy tourism that extend beyond the aspects of moving the toys from one location to another. The goal is to analyse the motivations of the toy players to engage with travelling toys, with a particular focus on creativity and contest as well as the relationships developed with the toy characters. Our assumption is that the relationships (human to toy/ human to toy to human) established and strengthened through toy tourism anthropomorphize the toys, which acquire the status of trustees and travel companions beyond mere playthings or portable luck charms.

\section{Photoplaying toy tourism with character toys}

Toy play, as a type of object play, is traditionally associated with children's utilization of toys and other materials in their play scenarios. Adult toy 
players are most often perceived as collectors, but interaction with toys that have a face (i.e. character toys) is not confined to the activity of hunting, gathering, and organizing toys - in other words, building a collection.

Toy play is an activity enabled not only by the toys themselves but also by technologies that extend the playing; mobile technologies and digital platforms (e.g. social media activities) play a fundamental role in both the narrative dimension and goal-oriented elements of adult toy play in terms of documentation, sharing, and reciprocal communication between toys, their owners, and other players. New technologies and social media assist and support in cultivation of the toys' stories and add visibility to adult toy play. Specifically, our studies of toy tourism contest the idea of adult play as reactive (Sutton-Smith, 1997). Adult engagement and relationships with travelling toys include active interaction, creativity, and collective fantasizing. Key aspects of this shared toy play are in imagining, visualizing, and narrating the toys' journeys.

One critical domain of the tourist's imagination is the image - a mental visualization of some kind (Lean et al., 2014: 14). In the case of toys, the imagined is materialized visually, and practices of perceiving and photographing character toys intertwine with patterns of play. Mature audiences actively perform and document toy play in physical environments and then share the visual manifestations of their creative play (e.g. photoplay, toy photography, or toy-related videos) in digital playscapes such as Flickr, Instagram, YouTube, or Facebook. Photoplay is a new form of adult play (Heljakka, 2012, 2017; Heljakka et al., 2017) that Godwin (2015) referred to as "photostories" and categorized as "fannish fiction". As Robinson (2014) reported, carrying a camera as well as the toy legitimizes the activity of adult toy play.

A significant part of the photoplay of adult toy players illustrates travelling with toys and the travel of toys - toy mobility, which is discussed here in relation to play with Travel Bugs and other characters with wanderlust that feature in toy tourism. In the context of tourism, the pictorial image is the most common type of contemporary souvenir (Gordon, 1986: 140). As mixtures of fantasies that feature actual touristic sites, toy-related and visual travel narratives draw inspiration from both popular media texts and other players' photoplay. In that sense, socially shared photoplay involving travelling toys can be seen as the contemporary equivalent of the souvenir - a combination of the nostalgic picture postcard and the social media hashtags that accompany it, as both a greeting and an invitation to play, addressed to a potentially infinite audience.

An early example of a photoplayer is the American fashion model Dare Wright (1914-2001), who became a toy photographer and children's author and was among the first photographers to use toys in a narrative, serial, and perhaps "avatarial" manner. Her first book, The Lonely Doll, was published in 1957 and developed into a series of "toy stories" featuring the doll Edith and two teddy bears called Mr. Bear and Jr. Bear (Heljakka, 2012, 2016). The mimetic potential of character toy mobility 
in Dare Wright's early photoplay or in Jean-Pierre Jeunet's enigmatic 2001 film Amélie, like the images later posted by professional toy travel agencies, are obvious precursors to the photoplay of adult toy fans. In this way, the use value of character toys involved in toy tourism also depends on their photogenicity - oculocentric preferences communicated in toy play. According to Robinson (2014: 162): "the very nature of taking a toy travelling is reliant on imaginative processes, and ... the vicarious sharing and consumption of images is a vital component of the overall experience". For example, toy players say that photographing the toys is just as important as the toys themselves. For some, the toys would not be travelled with if it were not possible to photograph them. Moreover, toy tourism involving photoplay is always performative, as it often happens in public places that are considered culturally or geographically relevant. For example, for some toy players, it is crucially important to photograph famous landmarks, such as the Colosseum in Rome, with toys.

\section{Methodology}

Based on a qualitative approach, the research material includes interview data and survey responses in which toy fans and geocachers shared their experiences with other players of toy tourism on online platforms. The data were collected in seven in-depth interviews conducted face to face and via e-mail with participants from Finland, the United Kingdom, and Singapore, as well as from an international online survey $(N=45)$ in 2017 , including participants from Europe and North America. This material was then subjected to content analysis. Our goal was to understand the motivations of these players and to explore how toy tourism plays out. The interview and survey questions addressed imaginative, creative, and social toy play practices and the physical aspects of toy mobility - the journeys and personal histories of the Travel Bugs and other travelling toys, the relationships between the toys and their owners, and the practice of hosting toys sent on travels by their owners. The multimethod approach also included participatory observation and autoethnographic play - that is, we as researchers actively participated in toy tourism and geocaching practices, either travelling with the toys or sending them travelling.

The first part of our study looks at toy owners who either travel with their own toys or play with other people's toys through host programmes, cultivating the personalities of these toy companions during their trips. We begin by presenting examples of toy play related to the journeys of character toys, which travel in the context of both amateur and professional forms of toy tourism. We then move on to discuss the practices of players travelling with Travel Bugs in the context of geocaching. The second part of the study describes the motivations of the paedic players and the ludic gamers, whose practices are, on the one hand, guided by similar interests and, on the other hand, who play toy tourism for different motivations. 


\section{Paedic and ludic toy tourism: toys and "bugs" as travel companions}

Playing with toys is often associated with more creative freedom than the playing of games. Engagement with character toys, like the playthings discussed in this chapter, is traditionally guided by the imaginative capacities of the player - their ability to narrate personalities, backstories, and dynamics between different toys and the worlds they inhabit. Games, in contrast, most often come with mechanics - predetermined rules for engagement, goals, and winning conditions to motivate the players.

Play theorist Roger Caillois (1958/1961) introduced a classification of games with four main rubrics - agôn, alea, mimicry, and ilinx - depending on how the roles of competition, chance, or simulation present themselves in the games under scrutiny. For example, one may play football or chess (agôn); engage in games of chance, like roulette or a lottery (alea); take on the role of a character in play, such as a pirate (mimicry); or play in ways that bring the player into a state of dizziness and disorder (ilinx). Within each of the different forms of playing, games can also be placed on a continuum between two opposite poles. At one extreme, free improvisation is dominant. It manifests as a kind of uncontrolled fantasy referred to as paidia. At the opposite extreme is ludus, which requires a greater amount of effort, patience, skill, or ingenuity. We are interested in what ways playing with travelling toys reflects Caillois' theoretical concepts of paidia and ludus, leaning on either creative or competitive forms of play. To scrutinize the various dimensions of toy tourism, our goal in the following is to analyse the emerging types of toy play patterns that range from fantasy-guided and free-form paidia to ludus, which resembles play patterns familiar from the context of gameplay.

In the first form of amateur toy tourism, toys travel with their owners in the name of free-form play. The number of toys travelling with their owner may vary depending on whether their owner is travelling for business or pleasure, as Kewty-pie (56 years) explained: "When I travel on work assignments, I bring a couple of my dolls or toys to keep me company. However, when I travel on holiday, I will bring a cabin bag full of dolls and toys with me". Interviewee Les (42 years) said "I always take Murphy and Yewlee on 'proper' holidays" and described her bunny's wanderlust as follows: "I took my Monchichi bunny to San Francisco to visit my brother because bunny always wanted to go there. He had a fab time". In some cases, the toy may become the ultimate "decision maker" about the desired travel destination: "Some places I go only because I think the toy would enjoy it or if I think the toy could create a fun story about it" (Nancy, 35 years). "Adventurous" toys travel to places near and far, often with shared storytelling in mind. In this regard, Nancy talked about her soft toy, Yuuso: "He is very friendly and loves to share travel stories. I have had Yuuso with me on top of $6,000 \mathrm{~m}$ mountains, as well as on 14-hour multi-pitch climbs. He has even been in the cockpit of a passenger plane - in the pilot's seat!" 
In another form of amateur toy tourism, toys are sent out to travel with other players through non-professional hosting programmes. Our examples of this collaborative form of toy play include toys such as a customized Sylvanian Families "cheetah" named Damara DeWildt (Xara, 2016) and the Playmobil figures Hans and Paul the backpackers (n.d.). Both Damara and Hans and Paul have travelled around the world with the help of players who are not their owners. As interviewee Les explained, this play activity is driven by players for players: "I know of Toyvoyagers, a website where you can register a toy and post them to host and/or host toys yourself. I had two toys who travelled by post, and I had a great time hosting other people's toys".

Human players who host travelling toys belonging to other players take the responsibility of organizing valuable experiences for the toys and documenting them. Les described how her own toys have been taken to intriguing locations and how she has used her hometown to produce meaningful photoplay with the toys she has hosted: "My Yeti travelled to Rome and other places, and one of my gorillas went on a Girl Guides camp in Germany. I live in a famous historic town, so it was easy to send interesting photos of the toys I hosted".

Besides relaying the creativity of other players in terms of employment of famous locations and production of clever photoplay in the name of paedic play, some owners of travelling toys have ludic - or game-like - goals, such as reaching a specific number of locations, for example, Damara, "a brave cheetah lady" who wanted to see the world (see Figure 11.2; Xara, 2010). According to the travel plan, Damara was to visit more than ten locations, but the trip remained unfinished at the start of 2016. Damara's trip has taken her from her starting point in South Africa to the United States, Australia, England, and Finland (Xara, 2016). Further, as illustrated by Xara (2016: 17), toy tourism may include parallel projects besides capturing the character toys on camera, to be carried out while exploring the world: "The goal of Damara's trip is to make friends with other Sylvanians and also to collect information on herbs and remedies, because in Lady Lollipop's [the toy owner's] story, Damara works as the healer of her home village, Rooibosch Hill [in South Africa]". During her trip, Damara has tried geocaching, seen kangaroos, shopped at local shops, and seen many local sights.

In addition to amateur practitioners and hosts of toy tourism, there are companies that offer professional toy tourism services. Among these toy travel agencies, which first emerged in the early 2010s, the Barcelona Toy Travel agency and a Prague-based agency are no longer operating. However, Unagi Travel - Japan Travel Agency for Stuffed Animals (n.d.) - still offers tours and promises to "document the trip with photos". One interviewee was aware of the service but was doubtful that the toys would be kept safe: "I've read about [toy travel agencies] in a magazine. But I would never dare to send my toys there in case something happened to them. There would need to be some good insurances for sure" (HanneleK, 52 years). 


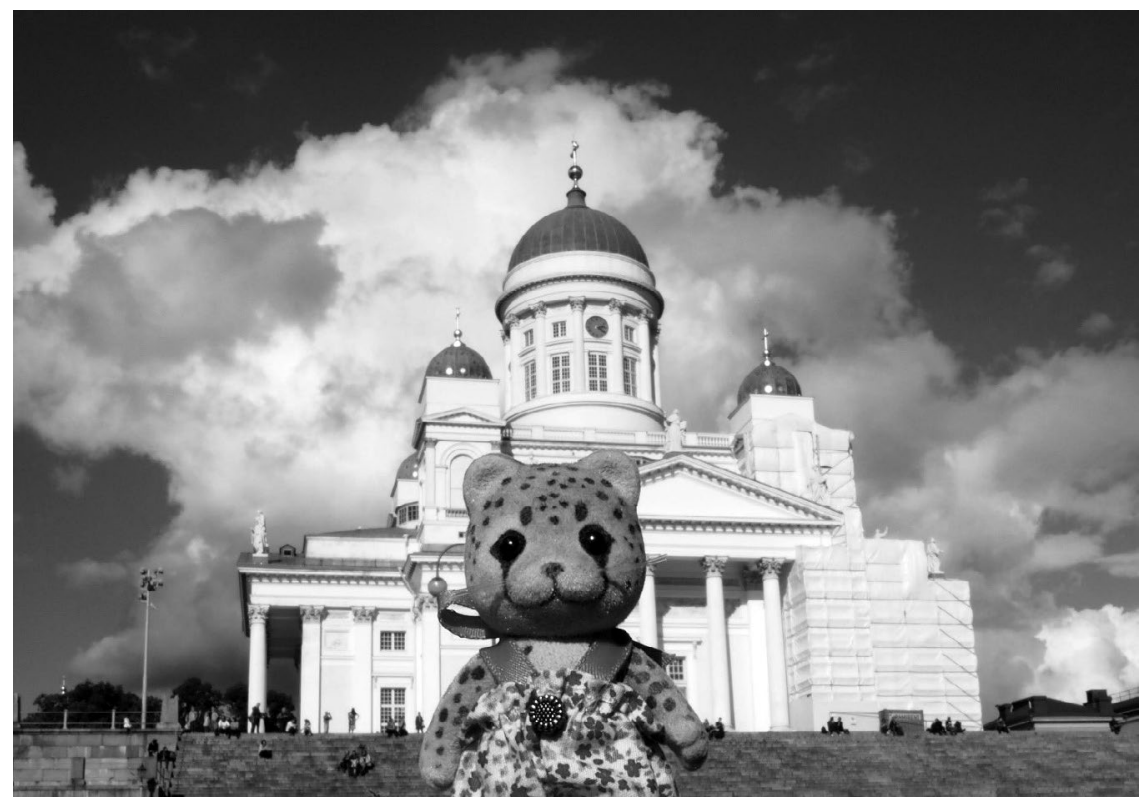

Figure 11.2 Damara DeWildt, a Sylvanian Families “cheetah", has visited Helsinki, Finland, hosted and photoplayed by Xara (2016).

Source: Reproduced with permission.

In parallel to toy tourism in the non-gaming context, toys known as Travel Bugs travel for ludic play within a location-based game in the context of geocaching. Geocaching is a form of digital treasure hunting in which players utilize global positioning system devices or specialized geocaching applications on smartphones to search for geocaches in various environments. Geocaching provides a more competitive platform for what is considered here as the ludic form of toy tourism. Geocaching is currently practised in 185 countries, with more than 10 million registered users on the Geocaching.com online service. Geocaching encourages mobile play in the context of these contemporary "treasure hunts" based on hints about the geocaches, such as coordinates, stories, and even poetical texts.

The geocache is often some form of a box containing a logbook in which each player must write their nickname and the date when they found the geocache. Players get points when they find a new geocache.

Geocaching includes a "game within a game" based on making Travel Bugs mobile. Each Travel Bug, often a character toy of some kind, has its own unique tracking number attached (see Figure 11.3), which is used 
as proof that the player found the item. It also serves as a way of locating the Travel Bug's personal website, where each Bug has its own "diary" recording its movements. The aim is to pick up, drop off, and follow the trackable toys' journeys, and the information on each Travel Bug's website mirrors its real-world adventures. Geocachers who play with Travel Bugs and joined our study employed familiar terminology borrowed from the tourism industry. For example, we were told about a "hotel" provided by Finnish geocachers especially for Travel Bugs, and the Mae West Resort in the United States enables players to acquaint themselves with Travel Bugrelated play patterns.

According to one of our interviewees, the "toyish" dimension of the goal-driven play in geocaching adds practical yet playful ${ }^{1}$ and even transgenerational interest to the location-based game (meaning that individuals representing different generations play together): "[Travel Bugs] can be used to measure the trip that has been taken, and they may play a role in solving a mystery. They make geocaching more interesting and attract children to play geocaching" ( $\mathrm{C}$, female, $41-50$ years).

The Travel Bugs' stories are developed through both written and visual storytelling: "If there is one particularly nice and sympathetic Travel Bug with me, I aim at writing long stories in the log book at each cache and take a lot of pictures" ( $\mathrm{Z}$, female, 31-40 years). The journeys taken with Travel Bugs are then shared online: "Sometimes, I take pictures and write about places I have been with the Travel Bug - at least in the Travel Bug's own log" (X, female, 31-40 years). In this way, it is possible to see how what initiated as ludic forms of play intertwine with paedic play. Moreover, the Travel Bugs as character toys are given similar values as the travelling toys outside of the geocaching game. For example, many Travel Bugs are described as trusted travel companions with magical powers: "A part of the Travel Bugs always travel with me in the backpack. [When I had difficulty finding a cache] I got a Voodoo doll as a TB to bring me luck" (A, female, 41-50 years).

\section{Motivations: storytelling, parasocial relationships, and contest}

Next, we examine the motivational factors behind toy tourism that emerge through paedic and ludic forms of play. Robinson (2014) identified three relevant trends: anthropomorphizing the toys, making them visit famous landmarks, and displaying the photographer's capability and creativity (emphasizing the artistic aesthetic rather than the environment). Robinson characterized these representational trends in toy photography in terms of seeing the world through the toys' eyes. ${ }^{2}$

Our data suggest that both regular toys and Travel Bugs serve narrative purposes as their owners and other players develop their stories through socially shared photoplay and written narratives. Anthropomorphization, 
visits to famous landmarks, and creativity of the photoplayer are all considered important facets of storytelling and motivators of players. Moreover, the interviewees accentuated the role of the toys as the main protagonists, the ambiance of certain travel destinations, and the sociality of play when meeting new "toyfriends" (both human and non-human) at airports.

As storytellers, the travelling toys first function as player extensions; for Kewty-pie, the toys act as stand-ins, taking her place in front of the camera:

I do not like to take pictures of myself, and my dolls and toys take my place in my travel pictures. They are like my picture journal of what I did during my travels. . . . I bring them out with me on my morning walks and stop to take pictures when I see a spot that looks great. Instead of taking a picture of myself in that suitable spot, I take pictures of my dolls in my place.

Interviewee Nancy had a similar agenda, which extended to the toy having its own social media presence: "The toy had a blog and has his own Facebook profile.... I always take pictures of my toy rather than myself".

Second, players wish to photoplay their travelling toys in meaningful locations. "I don't care so much about 'tourist traps' myself, but the dolls need to be taken to them", Pinkkisfun (42 years) claimed. Motivations for Travel Bug photoplay may not be as demanding. For example, a female interviewee (A, 41-50 years) explained the social and communicative aspects of this game:

I always take my own Geo-Buddy - a plush key chain - with me when I travel abroad. At Earth caches, I take a photo of my Geo-Buddy and attach it in the cache and upload it to its own website. I also photograph the most important sights with Geo-Buddy. Once, at the security checkpoint at Heathrow airport, the clerk noticed my Geo-Buddy, which was hanging from my bag. S/he took a photograph of it with his/her mobile phone and logged it online.

Again, female Interviewee A. (41-50 years) said she practised toy photography in urban locations and at touristic sites and photoplayed Travel Bugs during different seasons to enhance the toys' stories, "I photograph fine sights with my own Travel Bug. In Finland, I sometimes photograph Travel Bugs that come from abroad in snowy scenery. I have also photographed at airports, souvenir shops, metro stations (showing the name of the station), in the Czech Republic with a local plush toy etc”.

Players are also motivated by the relationships with their toyfriends; the relationship between a toy-playing adult and a character toy forms an 
intimate bond that tells the tale of the plaything's imagined personality. Parasocial relationships formed with toys resemble the mental investment in the invisible friends of childhood, which now materialize in the form of friendships between adults and character toys with imagined personalities: "My toy is very important to me, kind of like an imaginary friend" (Nancy).

While toys are often considered "buddies", they may be more than that. Their owners point to the toys' capacity to represent their own personalities as well as being extensions of their owners' identities. On the one hand, as Sandy ( 43 years) put it, "The toys are their own personalities. They are characters separate from me that have their own thing"; Interviewee HanneleK stated, "The chimpanzee, is completely its own [personality]".

At times, the personalities of the travelling "toyfriends" may become complex and even demanding, as Pinkkisfun noted when describing her relationship with her doll Molly: "I may not bring Molly along, just because she is so obvious, because there would be a lot of places to photograph her in, and they would be time-consuming and challenging. On the other hand, a doll that does not have a personality is dull and uninspiring".

On the other hand, for everyday players, besides being aesthetically pleasing objects, character toys may also function as "mini-me's" or even as avatarial (in most cases, fantastic and idealized) extensions of oneself. Pinkkisfun reflected, "The toys are maybe more like extensions of myself who encourage me to do things that I otherwise would feel embarrassed about doing".

Nancy emphasized the role of humour in this play with identities: "This (plush toy) persona makes it possible to observe the world and share the notes in a more honest and funny way, so you could call it an alter ego of myself". Toy personalities provide opportunities to explore the player's own aspirations as well, as in the case of Interviewee Heidi (40 years): "Roberta [a Barbie doll, see Figure 11.4] is sort of my ideal me: an Italian donna. I can dress her differently than myself and change the body if needed!”

Finally, players are motivated by contest, the competitive aspect of toy tourism, where toys, like Travel Bugs, are given goals in terms of places to visit or the length of the journey. For instance, a female interviewee (A, 41-50 years) said: "In Budapest, I set off two Bugs to travel, which my children named and chose, and we followed their journeys over one year to see which one would cover more kilometres - that is, who wins the competition. The Travel Bugs are still travelling". Another participant reported owning a Travel Bug that has travelled along with the player "a total of 148.680 miles". Sometimes, as the survey responses in our study illustrate, multiple Travel Bugs are released simultaneously to race against each other. It is in this ludic type of playing toy tourism that Travel Bugs mimic gameplay the most. 


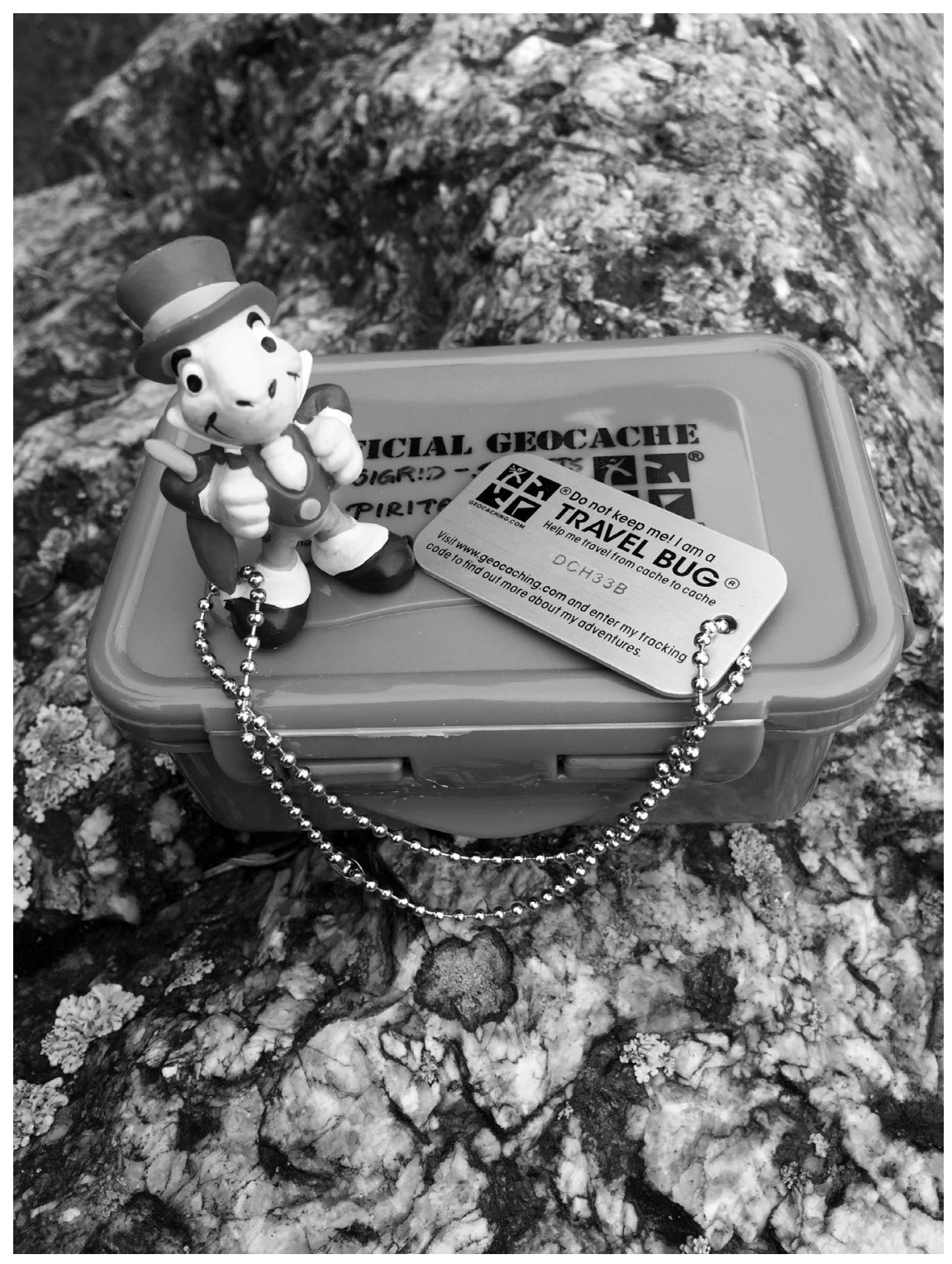

Figure 11.3 A Travel Bug called Dr. Geocacher. Its mission is to travel around the world spreading the word about Pirita Ihamäki's 2015 doctoral thesis: User Experience of Geocaching and Its Application in Tourism and Education.

Source: Photo by second author. 


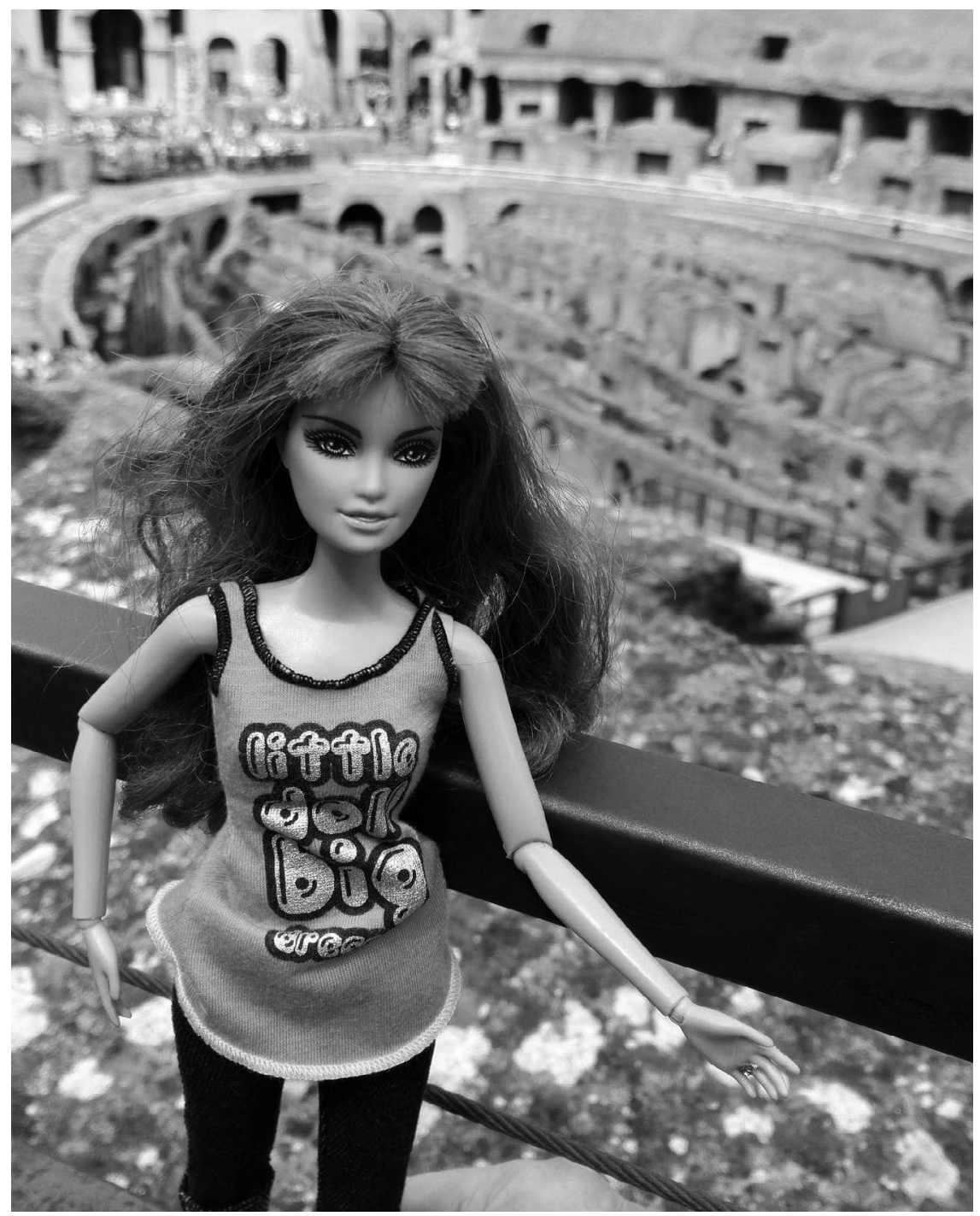

Figure 11.4 Heidi's Barbie doll has travelled to Rome to see the Colosseum. Source: Photo by Heidi Veräjäntausta (2016). Reproduced with permission.

\section{Conclusion}

Character toys have for a long time been regarded as "paratexts" (Gray, 2010). However, toy personalities with their own backstories (both industry driven and player generated) have begun to claim the status of entities with their own agency and wanderlust. This marks a shift in thinking about 
travelling toys from mascots (Robinson, 2014) to personalized objects, as avatarial extensions of players that are mobilized through various play practices.

Toy tourism encompasses all of the interdependent mobilities described by Urry (2007): corporeal travel, the physical movement of things, virtual travel, communicative travel, and imaginative travel. This chapter has explored travelling toys and toy tourism through object play (the physical movement of things) in the context of human leisure and tourism (corporeal travel) and through the activity of photoplay and storytelling (imaginative travel). Sometimes, toys travel to comfort their owners and to keep them company; in other cases, toys travel with their owners to meet up with other toyfriends. Sometimes, toys travel instead with hosts, who function as tour guides. Toys also travel with professional toy travel agencies (if their owners dare to send them out). We identified emerging types of toy tourism through organized toy travel agencies or host programmes (communicative travel) as well as toys travelling "by themselves" - for example, Travel Bugs in the context of geocaching (physical movement of things/virtual travel).

First, our studies of travelling toys reveal the dual nature of toy tourism as a play practice: toys become mobile through the practices of both toy players and gamers. Based on our findings, we suggest that 21 st-century toy tourism can be categorized in terms of Caillois' (1958/1961) distinction between paedic and ludic forms of play. Drawing on Caillois' theory, it is possible to understand how the toy tourism of amateur toy hosts and practitioners - or rather, everyday players (Heljakka, 2013) - relies on creative and imaginative practices that develop the personalities of the toy characters in the name of open-ended paedic play. In contrast, the practices of geocachers lean more towards a ludic domain of play - that is, goal oriented and competitive in nature.

Second, the findings presented in the chapter highlight the common practice of toy tourism with character toys shared by paedic and ludic players. While the travelling toys seem to become mobilized by their players with different motivations, such as storytelling, parasocial relationships, or contest, in mind, their players are similarly interested in documenting and sharing their toys' journeys. The travel stories of toy characters result from the players' collective imaginings around the toys' personalities and ambitions cultivated during their journeys. According to our studies, the portability of character toys may lead to creative photoplay within the public sphere of touristic sites. Functioning as vehicles for creative tourism practices, toys visit popular touristic sites and become "immortalised" there through photoplay, for reasons that relate either to interpersonal storytelling or to intrapersonal sharing of their stories. By becoming anthropomorphized through creatively cultivated and socially shared photoplay and besides acting as protagonists that partake in paedic or ludic play, toys function as stand-ins, extensions, or avatars of their owners. Furthermore, toys also travel to practise their own tourist gaze (Urry, 1990), represented by photoplay as seen through the (camera) lens of the toy through photoplay. 
In taking toys to touristic locations and iconic sites (see Chapters 13, 14 , and 15 in this volume for the significance of visiting famous places), the player playfully enhances their own experience of the place, which will live on through photoplay and storytelling as documented and potentially shared play. As toy players superimpose layers of fantastic narratives on touristic landscapes and landmarks, toy tourism turns touristic sites and ordinary spaces into creative playgrounds where fiction, fantasy, and factual geospace intersect. In many cases, travelling with toys adds to the possibilities of being creative; as interviewee Les put it, "I think that my imagination with toys is more of a creative expression. Like a writer or an artist, it is escapism but also allows me to engage with the world around me in a different way. The toys add spice and purpose to an outing". Just like the fan pilgrim's reading of a city, the toy tourist's playful engagement with a place "can transform even ugly places into sites of wonder and worship" (Brooker, 2007: 434), allowing the player to escape from normal routines, structures, and priorities in an expression of playful liberation. In this way, toy tourism of the 21st century is both oculocentric as well as a mobile and legitimate play activity for adults.

As illustrated in the chapter at hand, motivations to send toys travelling range across solitary and social forms of toy tourism, encompassing personal (identity) play between toy owner and toy companion and social (game) play between a network of players. While the intrapersonal imagination (owner to toy) supports the paedic aspects of play through cultivation of parasocial or avatarial storytelling, interpersonal imaginings orientate players towards socially shared storytelling about the toys' travel adventures and the ludic dimensions of toy tourism, such as collective and game-like playing, to advance the specific goals of a travelling toy such as a Travel Bug. In this way, contest intertwines with creative play - ludic toy tourism with Travel Bugs also includes imaginative or paedic aspects; the players who joined our survey reported conducting both photoplay and written stories for the Bugs.

In sum, toy tourism is a play activity largely supported by the players' imagination, creativity, and shared storytelling that develops from free-form play practices of players travelling with their toys to amateur toy hosting programmes and from more structured and goal-driven play with Travel Bugs in the context of geocaching and professional toy tourism services.

In addition to accentuating patterns of movement among human tourists, character toys, and Travel Bugs with wanderlust, toy tourism makes adult interaction with toys more visible. For that reason, playing toy tourism in any of its various paedic or ludic forms and as presented in our suggested new typology of toy tourism (see Figure 11.5) is not just about turning inward to the intimacy of one's own imagination and story worlds or to mobile object relations with toys but, as interviewee Les further explained, towards the actual world, other players, and "living with your eyes open". 


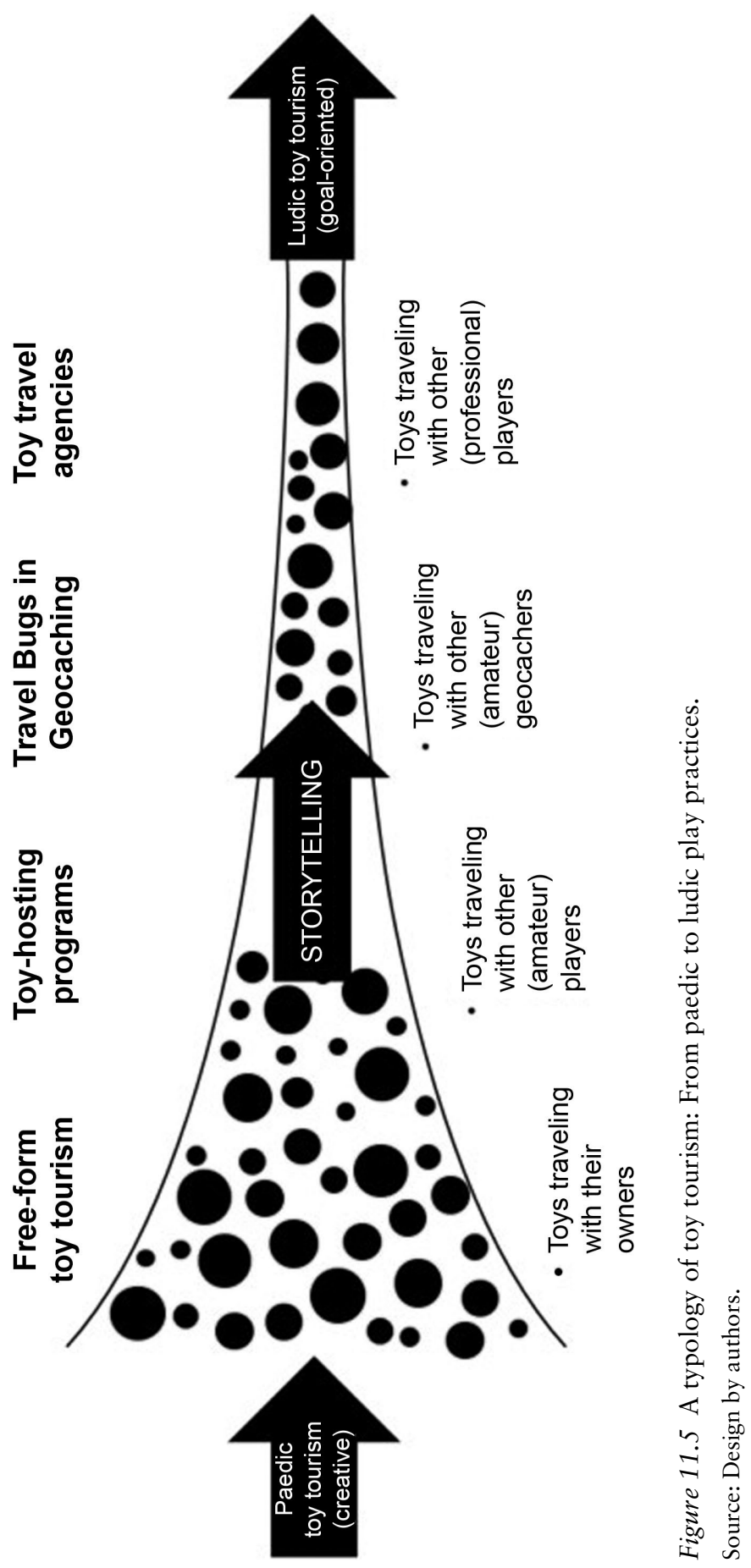




\section{Notes}

1 In previous research, "playfulness" has been associated with individuals characterized, for example, by spontaneity and exuberance (see Sutton-Smith, 2017: 152).

2 For example, many toy characters from the Barbie and LEGO series now come equipped with miniature toy cameras.

\section{Bibliography}

Brooker, W. (2007). Everywhere and nowhere: Vancouver, fan pilgrimage and the urban imaginary. International Journal of Cultural Studies 10: 423-444.

Caillois, R. (1958/1961). Man, play, and games (M. Barash, Trans.). Champaign: University of Illinois Press.

Geraghty, L. (1996). Aging toys and players: Fan identity and cultural capital. In: M.W. Kapell \& J.S. Lawrence (eds.), Finding the force of the franchise: Fans, merchandise, \& critics, pp. 209-223. New York: Peter Lang.

Godwin, V. (2015). Mimetic fandom and one-sixth-scale action figures. Transformative Works and Cultures 20: n.p. https://doi.org/10.3983/twc.2015.0686.

Gordon, B. (1986). The souvenir: Messenger of the extraordinary. Journal of Popular Culture 20(3): 135-146.

Gray, J. (2010). Show sold separately: Promos, spoilers and other paratexts. New York: New York University Press. Retrieved from http://paas.org.pl/wp-content/ uploads/2012/12/02.-Jonathan-Gray-Show-Sold-Separately-excerpts.pdf.

Haldrup, M. \& Larsen, J. (2006). Material cultures of tourism. Leisure Studies 25: 275-289.

Hans and Paul the backpackers. (n.d.). Retrieved from http://hans-the-backpacker. blogspot.com.

Heljakka, K. (2012). Aren't you a doll! Toying with avatars in digital playgrounds. Journal of Gaming and Virtual Worlds 2: 153-170.

Heljakka, K. (2013). Principles of adult play(fulness) in contemporary toy cultures: From wow to flow to glow. PhD dissertation. Helsinki: Aalto University.

Heljakka, K. (2016). All dolled up, then photoplayed: The fashion-oriented practices of adult doll players in the twenty-first century. Catwalk: The Journal of Fashion, Beauty and Style 5(2): 43-62.

Heljakka, K. (2017). Contemporary toys, adults, and creative material culture. In: A. Malinowska \& K. Lebek (eds.), Materiality and popular culture: Popular life of things, pp. 237-249. London: Routledge.

Heljakka, K., Harviainen, J.T. \& Suominen, J. (2017). Stigma avoidance through visual contextualization: Adult toy play on photo-sharing social media. New Media \& Society 20: 2781-2799.

Heynders, O. \& Van Nuenen, T. (2014). Tourist imagination and modernist poetics: The case of Cees Nooteboom. In: G. Lean, R. Staiff \& E. Waterton (eds.), Travel and imagination, pp. 103-118. Farnham: Ashgate.

Lean, G., Staiff, R. \& Waterton, E. (2014). Travel and imagination. Farnham, UK: Ashgate.

Robinson, S. (2014). Toys on the move: Vicarious travel, imagination and the case of the travelling toy mascots. In: G. Lean, R. Staiff \& E. Waterton (eds.), Travel and imagination, pp. 168-183. Farnham: Ashgate.

Sutton-Smith, B. (1997). The ambiguity of play. Cambridge: Harvard University Press. 
Sutton-Smith, B. (2017). Play for life: Play theory and play as emotional survival (C.L. Phillips \& American Journal of Play, Eds.). Rochester: The Strong.

Unagi Travel: Japan Travel Agency for Stuffed Animals. (n.d.). Retrieved from http:// unagi-travel.net/.

Urry, J. (1990). The tourist gaze: Leisure and travel in contemporary societies. London: Sage.

Urry, J. (2007). Mobilities. Cambridge: Polity Press.

Xara. (2016). Matkustava Sylvanialainen - Tässä tulee Damara DeWildt! [The traveling Sylvanian: Here comes Damara DeWildt!]. Nukke \& Lelu 2016(1): 17-19. Retrieved from www.forestfamilies.net/en/The\%20Series/Articles/. 


\title{
12 On (be)longing \\ The Der Bergdoktor phenomenon at the European cultural periphery
}

\author{
Andreja Trdina and Maja Turnšek
}

\section{Introduction}

The convergence of media consumption and tourist practices convincingly refutes Meyrowitz's (1985) argument that media contribute to the emergence of "a placeless culture". Starting from the assumption that place is an experiential accomplishment binding people and environments (Moores, 2012), the present study aims to investigate how a television series' filming location becomes meaningful through the imaginative, practical, and emotional engagements of its audiences. In particular, we analyse how a German-Austrian TV series drama is accepted by the fans at the European cultural periphery in Slovenia. Der Bergdoktor is a German-Austrian TV drama series (2008-), which gained a considerable cross-generational audience in Slovenia when it first aired in summer 2016 and prompted increased interest in Tyrol, Austria, from Slovenian tourists in 2016-2017. We have sought to understand how Slovenian fans of this series make sense of Tyrol by consuming and producing media content, as well as via empirical encounters with place as tourists on tours. We will demonstrate how they reconcile imagined landscapes and topographical reality through their experiences by unravelling numerous intertwined personal, factual, and fictional narratives. We will also explore how these fans acquire a sense of belonging and identity grounded in and beyond the media content itself.

The present study is theoretically informed by and based on qualitative empirical research. In particular, we look at two distinct (albeit interrelated) stages of the spatial appropriation of the Tyrolean countryside and the acquisition of a sense of belonging. First, we discuss the ways in which audiences respond to the series, articulating the sense of "us" or "the symbolic ideas of Heimat" (Morley, 2001). We analyse particular instances of how the TV series engages audiences to comprehend their everyday reality through fictional narratives. We point out that Der Bergdoktor, with its emphasis on tradition, morality, and the romanticization of the idyllic rural lifestyle, addresses a specific "structure of feeling" in post-egalitarian Slovenia. The series' fictional narratives of Tyrolean daily life allow audiences to re-interpret their own post-socialist/post-egalitarian experiences and (be)longings in a multimedia environment. 
Second, we examine how fans, as tourists visiting the series' filming location, connect to the place through embodied interactions, cultivating significant topophilic sentiments and feelings of belonging to an environment. We explore how they are quite aware of and able to navigate through different layers of their experiences of real Tyrol and Der Bergdoktor's Tyrol, combining the place's fictional and factual narratives to create a multilayered construction of the reality they wish to experience.

The accounts of fans/tourists in our study outline the complex convergence between the symbolic and material geographies within which people attach themselves to the world and sustain commonality in the contemporary mediatized world. European media production has traditionally been largely discussed from the perspective of combating the supremacy of Hollywood production in TV programs (e.g. Silj, 1988; De Bens \& De Smaele, 2001). In relation to screen-induced tourism, current literature thus tends to focus on the dominant media culture/Western mediascapes, for example, with the focus on American production. When peripheral areas are addressed in literature on screen tourism, they are most commonly on American productions, for example, in relation to the Game of Thrones series in Dubrovnik, Croatia (e.g. Waysdorf \& Reijnders, 2017), or on the content produced by non-Western culture itself (e.g. Scherer \& Thelen, 2018; see also Chapter 8 in this volume). Audience responses from peripheral, non-dominant Western cultures such as Slovenia have been overlooked in the media and tourism literature, especially in relation to non-Hollywood content. The present chapter tries to fill this gap by exploring the multifaceted ways in which media, culture, and place intertwine in a small locality on Europe's periphery. This study proposes a subtler understanding of the practices of specific pop-cultural tourists with special regard to how their engagements are grounded in interactions between global pop-cultural formats and local cultural conditions.

\section{The television series as a cultural resource in the transmedia age}

As noted, Der Bergdoktor gained a considerable cross-generational audience in Slovenia when it first aired there in summer 2016 on a local commercial TV channel. According to the Pro Plus media company and AGB Nielsen Media Research data (Kotnik \& Cah, 2016), the TV series achieved outstanding ratings, capturing the most summer viewers among domestic and foreign series in the previous ten years. In its target group of 18- to 54-year-olds, it was mostly watched by university graduates over 45 years of age. Furthermore, the series was watched by almost every other Slovenian who watched live TV, that is, $39 \%$ of viewers, including every other Slovenian woman and every third Slovenian man. In general, the highest ratings were among those over 55 years of age. The first episode of the ninth season had a $51 \%$ audience share $(11.8 \%$ rating $)$, and 
it was still most popular among women ('Proplus v jesen', 2016). These numbers are especially impressive in light of the pervasive global trend of TV audience fragmentation.

In 2016 and 2017, Der Bergdoktor's high audience shares and aboveaverage ratings prompted increased interest from Slovenian tourists in the series' filming locations in the Wilder Kaiser region of Tyrol, which is composed of four villages: Ellmau, Going, Scheffau, and Söll. In fact, Slovenian tourist agencies organized commercial travel packages year round. Ellmau and the entire Wilder Kaiser valley have always been tourist areas. Additionally, intensive destination marketing and commercial appropriation of fictional themes occurred after the rise of Der Bergdoktor mania, with the local destination management organization and tourism stakeholders adopting the strategy of eventification. For example, every May and September, Der Bergdoktor Experience Week hosts exclusive fan events in the scenic surroundings of Wilder Kaiser. These events have many synergies across the creative industries, resulting in a wide portfolio of products related to the same pop-cultural phenomenon.

Media has become more mobile, interconnected, and interactive in the transmedia age. From this perspective, it is essential to investigate the entire media ecology in which the Der Bergdoktor audience is immersed. Or, as argued by Sandvoss (2011: 246), "reception practices of a text within one medium need to be analyzed in relation to the inter-textual and inter-medial contexts of such a text". ${ }^{1}$ We not only start from this standpoint but also call for a profound contextualization of the audiences' reception, arguing that historical context is key to the audiences' interaction with the texts. It is here that we follow Reijnders' (2010a: 370) suggestion to understand media-related tourism by taking into account its "cultural embeddedness" and acknowledging its relation to power configurations in society. That is why we turn in the next section to an overview of the cultural context of the series and its Slovenian audiences.

\section{Der Bergdoktor: the Alpine way of life of the once-ruling nation}

Der Bergdoktor focuses on the Alpine way of living, characterized by a bucolic return to tradition and nature, while still enjoying the benefits of modern medicine embodied in a heroic doctor. The modern discourse on the Alpine region idealizes the Alpine way of life. This is probably most recognizable in the 1965 Hollywood production The Sound of Music (Graml, 2004). After its political secession from Yugoslavia, the so-called Alpine culture became a central point of national identity formation in Slovenia (Šaver, 2005). This was manifested in many re-appropriations and re-contextualizations of mythical elements of the Alps in local cultural discourses, most prominently in national (turbo)folk music and Alpine skiing, within which Slovenian nation-imagining has been exercised extensively. 
According to Caramani and Wagemann (2005), nowadays, the concept of the Alpine region refers to a specific political culture: a set of attitudes and values overlapping with religious, rural - urban and centre - periphery (ethno-linguistic) dimensions, including strong anti-modern features and emphases on nature and Heimat in the political discourse and the incorporation of religious and traditional attitudes. These cultural elements are expressed in similar ways across national borders and are most visible in the conservative political party discourses of northern Italy, Bavaria in Germany, Austria, and Switzerland.

The concept of "Heimat" (or motherland) has been widely discussed within works on German national identity and screen production, for example, in relation to the film series Heimat (Silj, 1988; Von Moltke, 2005; Eigler, 2012), which we can count as an important precedent to the Der Bergdoktor series. Not much is known, however, on how non-German or Austrian audiences react to the bucolic and idealized representations within the German-Austrian production. Most importantly, for understanding Slovenian audiences' reactions to Der Bergdoktor, we need to go far back in history to the Habsburg empire that also greatly influenced Slovenian history.

The territory of Slovenia was under Habsburg rule until its dissolution after World War I in 1918. As with other empires, the Habsburg empire had "ruling" and "ruled over" nations. The former were the (Austrian) Germans, making up $24 \%$ of the population in 1910, and the Magyars (20\%), while the latter were mostly Slavs $(50 \%)$. Amongst these, the Slovenians were a small periphery minority, making up only $2.5 \%$ of the overall population of the monarchy in 1910 (Sugar, 1963). At the time, Slovenian society was primarily agrarian and economically less developed compared to the Austrian population, and most of its society were lower middle-class people and peasants led by local clergy and schoolteachers (Cohen, 2007). An important legacy of the empire was the historical positioning of the (Austrian) Germans as the "first", with the Slovenes historically positioning themselves as part of the second-order others (Kreft, 2016). At the time of the monarchy, the (Austrian) Germans were positioned as the rulers, with Vienna as the centre of culture and civilization at the end of the 18th century. This role was ambivalently confirmed but also critiqued in the Slovene literature of the time - literature that is still read in schools today as the canonical works of Slovene literary history (ibid). As demonstrated subsequently, Slovene audiences' readings of Der Bergdoktor are immersed in the wider historical discourse on the idealization of the Alpine way of living and the status of the (Austrian) Germans as the more developed, once-ruling "first".

\section{Research methods}

The present study attempts to understand contemporary fan audiences' readings and engagements with the Der Bergdoktor phenomenon and the Tyrol region. We have used two qualitative research methods: 1) a discourse 
analysis of the Slovenian Der Bergdoktor Facebook fan page and 2) an analysis of three in-depth focus groups of Der Bergdoktor fans who visited Tyrol, conducted in March 2017 and May and June 2018.

The Slovenian Der Bergdoktor Facebook fan page was accessed 6 March 2017, and all topics and discussions were archived. At the time of archiving, the fan page had reached 20,760 likes from Slovenian Facebook users. Approximately 42 pages' worth of written text and visual materials from the fans' posts and comments about Tyrol as a travel destination were analysed - this included the entire available online discussion up to that point in time. Most commonly, travelling to Tyrol was discussed and commented upon via the fans posting their pictures of trips to Tyrol on the fan page, usually consisting of the destination's scenery and/or pictures of fans posing with a cardboard life-sized image of the series' main character. The analysis also included the comments the fans made on such photographs.

The analysis of the online fan discourse was complemented by three indepth focus groups of fans who had travelled to the series' location on their own or via an organized travel-agency package. Information on the participants' age, gender, and place of residence was collected using convenient sampling techniques: snowballing a request sent to the student mailing list of the Faculty of Tourism at the University of Maribor (if the students themselves visited or knew anyone who had visited the location due to the series) and snowballing amongst the researchers' friends and acquaintances. The focus groups included nine participants with an average age of 33 years. Due to the snowballing technique, the average age of participants was lower than the general average age of the audiences. Additionally, many of the included fans visited the site on their own with family or a group of friends and not with an organized travel-agency package. The focus group research is thus limited in that audiences that are younger and more independent in their travelling to the series' location.

In what follows, we avoided structuring our analysis according to the different types of research data provided. We presupposed that the differing background of the data was irrelevant given that our aim was not to grasp the meaning of the Der Bergdoktor series as a self-contained entity but to examine the discourses around the Der Bergdoktor phenomenon and, subsequently, the region of Tyrol, along with the wider range of cultural work that has been conducted around the series.

\section{The borderless Alpine utopia: the evocation of an enchanted village life of order, diligence, and humility}

Many would describe the basic plotline of the Der Bergdoktor series as follows: set in an idyllic mountain landscape, focused on family values and sincere, warm social relationships, Der Bergdoktor is a story full of romantic complications and tense life-and-death situations. The series is centred around Dr Martin Gruber, a charming, resourceful, and attractive doctor, 
who is committed to his work but often turns out to be unstable in his intimate relations. Slovenian fans find the central roles that tradition, family, and morality play in the narrative, which contribute to the idealization of the rural Alpine lifestyle, to be the most significant aspects of the series. Accordingly, in response to the excessive aestheticization of the distinctive mythological attributes of the Tyrolean region in the TV series, ${ }^{2}$ most focus group respondents shared a common perception of Tyrolean values, such as diligence, humility, and order:

There is such order, those houses are so low, they are more like in the fairy tale of Hansel and Gretel, and the grass is so low cut, and those flowers, the whole landscape is, you know, nothing stands out, everything is the same, as if someone would have imagined it, as if someone would have drawn it. ... Warmth, calmness, kindness, that there everyone is connected to others, that there is no everyday madness, well . . . so, everything goes well.

(Participant M.P., age 29)

For the respondents to have an affective affiliation with Tyrol, both aesthetic and ethical renderings of the place (see Savage, 2010: 118) seem to be crucial. Aesthetic statements of the beauty and neatness of the landscape emphasize its physical markers, and ethical statements connect each participant's own identity to Tyrol by accentuating its predominant values and the lifestyle of the local residents, as defined by its social markers. What seems to characterize the respondents' attachment to Tyrol is thus a precarious balance between abstract spatial referents (giving rise to profound topophilic sentiments) and specific ethical motifs referring to traditional cultural elements (family values, traditional gender identities, sincere social relations), grounded in the fictional narrative of Der Bergdoktor and indicative of the rise of re-traditionalism in the Slovenian post-socialist reality.

When asked what makes the TV series so popular, one focus group participant stressed the following: "We lack this warmth, this social sensibility. And this is what the main character offers ... Yes, in this sense of our health system as it is currently ... I think we miss this when we visit our doctor" (Participant M.B., age 53). The series' fictional framework has come to play a substantial role in the process of re-assessment of the changed Slovenian post-socialist/post-egalitarian reality, as the following comments in the Facebook group suggest:

- In Slovenia we would also need one such doctor to do a little order in our health system!!!!

- Indeed, we would need him so much to make it all the same as it used to be!

Fans thus consume Der Bergdoktor in reference to the sociocultural context to which they belong. In various ways, they re-use the meaning of the 
fictional universe of the text to discuss their own personal and social circumstances and make sense of the world in which they live. In their accounts, there is a sense of lost community and withdrawal from a life once known, yet there is also an intense claiming of moral authority on how things should be handled. Slovenian fans have thus largely articulated their relationship to Tyrol with enhanced moralizing about Slovenia's current situation, invoking specific local interpretative repertoires. ${ }^{3}$ Discursive resources actively deployed when discussing Der Bergdoktor in Slovenia seem also to be supplied by the existing folk schemata surrounding the mythology of the enchanted Alpine world.

Such mystification of Tyrol as a promised land by the Slovenian audience can be understood as a double entanglement of the current political and economic situation in Slovenia and the historical semi-colonial position of the country. ${ }^{4}$ In particular, Der Bergdoktor fans on Facebook argued that Austrians know how to turn everything into good business, implicitly referencing the historical position of the (Austrian) Germans as the economically better developed "first" versus the Slovenians as the inferior "Other". Similarly, in the comments, fans compared the Slovenian healthcare system to what they perceived as the better-developed system in Austria. Likewise, Der Bergdoktor tourists shared the same attitude that everything is better across the border in Western countries and that is to what the Slovenians should aspire: "Infrastructure, local roads, these are better than our highways. I mean the order and the cleanliness" (Participant M.B., age 53). The participants continued to engage in this moralizing discourse by describing Slovenia as delayed in development, expressing the need to look up to/ mimic the West: "As regards tourism development they accomplished a lot. We could learn a lot from that" (Participant J.G., age 48). The focus group elaborated on the differences between the tourist destinations of Kranjska Gora, Slovenia, and Tyrol, primarily highlighting the shortcomings of the former. These comparisons depict an attitude where Austria is positioned as the ideal against which Slovenia as the Other is judged. This does not seem to be merely an external imposition. Investigating some of the complexity of the east/west dichotomy, Bakic-Hayden (1995: 922) introduced the notion of "nesting orientalisms", which was evident in the former Yugoslavia and its successor states, demonstrating how "the designation of 'other' has been appropriated and manipulated by those who have themselves been designated as such in orientalist discourse".

The significance of these claims is not so much their content but rather what unfolds within these claims - what they bring into being. In such enhanced moralizing, many respondents regularly contrasted a "clean", "orderly", "successful" Austria with a "sad", "still", "belated", and even "dishonest" Slovenia. In doing so, they performed a self-othering process, reproducing the constructed divide between delayed-in-progress Slovenia and prosperous, reasoned Austria. This is an example of how contemporary neoliberal developmental discourse becomes infused with older 
tropes of colonial discourse. ${ }^{5}$ By being both complicit in and victim to the process of othering, Slovenians occupy an "in-between" space that provides "the terrain for elaborating strategies of selfhood" (Bhabha, 1994: 1) through which cultural value and authority are negotiated and the idea of society is defined. In doing so, they exhibit the nostalgic longing for highly desirable, traditional lives grounded in community and righteousness on the one hand and modern achievements and comfort on the other. The popularity of Der Bergdoktor's Tyrol, with all its attributes, has become a vehicle of historical longing for a home and a sense of community - the idea of Heimat. However, Tyrol seems to paradoxically represent an object of desire for its emphasis on traditionalism (the trope of the idyllic, calm, and bucolic landscape) and an object of fascination for its modernity (the "superdoctor", medical technology, and helicopters to hospital). This leads Slovenian audiences into a precarious oscillation around the mythical core of Alpine imaginary, alternately stretched between glorifying its progress yet simultaneously cherishing its traditionalism, diligence, and humility "simplicity, orderliness and cleanliness" to use the words of one focus group respondent.

The mediated Tyrol in Der Bergdoktor's inter-textual and trans-media context is a symbolic tool with which the audiences' desires and longings are played out and reflections on their own lives are offered. The concept of elective belonging (Savage et al., 2005) can be used to understand the attachment of Slovenian fans/tourists to Alpine Tyrol, as it implies an attachment that has nothing to do with personal history claims or knowledge arising from residence in the locality. Instead, it implies a distinctive ethics of belonging that is premised upon values (ibid: 53). It overstates the importance of symbolic attachment to place, claiming the affiliation and belonging that Slovenian respondents predominantly display in relation to this cultural and historical region of the Alps:

I mean, I would live there right away ... honestly I would live there. If I had the chance to go and live anywhere, that I would have money for it, I would go and live there ... You feel safe in this world. ... Everyone knows each other and they all hang out at that village square.

(Participant M.P., age 29)

Life in Austria is closer to all of us anyway, if you compare, like America or else ... and, of course, you identify easier, there are no big cultural differences, somewhere on this level it is that I think we are alike.

(Participant M.B., age 53)

In this first part of the present study, we showed how a TV series induces a longing for a shared sense of community and belonging to a borderless Alpine utopia. To comprehend how Slovenian audiences use popular culture to shape their identities as members of the historical and cultural region of 
Alpine world (beyond national boundaries), we need to understand that readings and re-constructions of the spatial imageries of the Alps are deeply interwoven into the popular mythical narratives of Alpine culture in Slovenia, feeding on existing meanings from a shared cultural history. ${ }^{6}$ What this suggests is that it is not simply the (properties of) the TV series as text but the specific historically contingent positions from which the Slovenian audiences "read" the text that make the series so popular.

\section{Practical engagements with place: touring Der Bergdoktor's Tyrol}

In the second part of the present study, we would like to identify the practices in which Slovenian fans, as tourists, engage at the filming location and expose how these are determined by their utilization of the fictional Der Bergdoktor universe. The argument unfolds in two analytical sections through exemplary fan testimonials depicting their experiences at the touring site, detailing the many ways of inhabiting the place and reconciling topographical reality with imagined media landscapes.

\section{A road turn that has to be experienced}

The first case highlights the importance of embodied interaction with place. Buchmann et al. (2010: 245-246) claim that film tourists are stimulated by a multisensory encounter with geographical places in ways that are not dissimilar to the embodied performances of adventure tourists. One of our respondents departed from the tour group to experience by herself the road turn that is so often depicted in the series:

For example, I just had to go see that road turn, where he [Martin Gruber, the Bergdoktor] comes down from home and turns to the clinic, the one road turn that is already worn out, right? I said, I have to take a walk here. And I went up to see it. It was the "thing" from the series for me. And I went up on my own on foot and took some photos looking down. There begins the scene when he drives down to the clinic.

(Participant M.B., age 53)

Similarly, other respondents explained how they felt the most connected with the series when they sat down at the exact table where the main character sits with his family and re-enacted a specific scene. Performing certain routines at the locations directly related to the series and photographing these locales intensified the feelings of connection to the place and the series. For fans/tourists, photographs seemed to play a particularly important role in identifying and symbolically marking these meaningful locations and their experiences of them, otherwise liminal and temporary by nature. Other 
travel experiences were similarly depicted as presenting some analogy to the visual imagery or events from the series. Therefore, active participation at site and embodiment seem to be crucial for the overall experience of this "imaginary" place. All these experiences seem to comply with the notion of existential authenticity, as described by Wang (1999) and as elaborated in empirical examples by Belhassen et al. (2008: 684-685): "Experiences of existential authenticity are the result of socially constructed understandings about the places they are touring and the actions they are undertaking in those places, combined with their own direct, empirical encounters". The following quotation shows how this was experienced by one of the travellers.

It was the most beautiful thing to me when we walked across the Village Square. When you look at those little houses and grass. It's so tight, you know, it's all tiny, it's a small road and you walk up, and a bit up and then down. Well, in fact, there are hills everywhere, everything is in order and arranged to perfection.

(Participant M.P., age 29)

Many respondents were also amazed that the Village Square was much smaller in real life, indicating that this made the place feel even more adorable. Counterintuitively, not only the similarities but also the inconsistencies between the series' depiction of the place and the visited site held unique pleasure for fans. For example, participant T.D. (age 22) was surprised that there were so many houses by the clinic that you do not see in the series, while participant A.G. (age 21) acknowledged the clinic house was not so formidable and impressive as the impression one gets from the TV. These insights did not ruin the experience for them; rather they were rewarding in themselves, as they provided additional knowledge about the place and offered fans the challenge to wonder and indulge in speculation about the underlying production process of the series. Participants accordingly wondered how the series producers managed to set up the tables outside the guesthouse and turn cars around at the same spot; they also concluded that a camera angle from below must be what makes the clinic seem bigger and more impressive.

In addition, many described the trip as very intensive and tiring, including a five-hour drive to the location and hiking at the site; however, this physical effort was appreciated as a supplementary validation of their experience as authentic. This echoes the ritualistic participation in activities, which are taken very seriously (one respondent described that the trip felt like a school excursion). In this way, Der Bergdoktor tours should be considered very committed acts that require considerable effort, namely strong personal commitments with the purpose of internalizing values and understandings about the place, which have been absorbed through media representations. 


\section{A fictional funeral and a visit to the real cemetery}

With our second case, we would like to illustrate the intertwining fictional and factual narratives inscribed in a place:

The father of Bergie's ${ }^{7}$ girlfriend Anna has just died. And it was in that episode. Two days later we went on a trip. One acquaintance called me and joked, he said, now I know, you are going to the funeral. Do you have funeral garland? (laughs) Yeah, Arthur died. And we did also go to see the cemetery. And there actually is a cemetery. A nice, great cemetery. It was interesting that, and I was fascinated about it, that there is no marble, it is really a place to calm your soul. Greenery, grass, and everything was so modest, so simple.

(Participant S.B., age 32)

This anecdotal evidence returns us to Meyrowitz's (1985) perspective on understanding physical and media settings as overlapping social environments, making a tremendous impact on our sense of place. As tourists, fans are quite aware of and able to navigate through different layers of their experience of the "real" Tyrol and Der Bergdoktor's Tyrol, such as by experiencing a real/physical cemetery and recalling a fictional funeral taking place there. They may do this with wittiness and humour, as in the previous case. Moreover, the line between fictional and non-fictional elements in experiencing and re-constructing a place is often more nuanced and difficult to discern. The following testimony demonstrates the merging of the physical place and the TV series:

There we stood in front of that restaurant and we were just waiting for Susanne to come out. And that fountain. Wow, here I am. You are expecting that she will come out and do this [putting her hands on her hips] and say something. You can just see her. Perhaps when you're out there you experience the series more than at home, you know? . . . It is there where you feel the series, even though she is not there for real.

(Participant M.P., age 29)

Such a crossover of a specific place and a pop-cultural fictional element reveals the junction of distinctive tangible landscape properties with specific narrative events from the series. To see Susanne from the series as if she is really there resembles a spiritual experience for fans. The fact that Gasthof Wilder Kaiser (Wilder Kaiser guesthouse) at the Village Square in Going, where Susanne, the character of a waitress, works in her traditional Austrian folk costume, is not an operating guest house in real life but a private house does not reduce the attraction this location has for Der Bergdoktor fans. The Village Square is to be considered a specific "lieu d'imagination", a physical point of reference for fans that provides the opportunity to 
construct and cross the symbolic boundary between an imagined and a real world, as described by Reijnders (2010b: 40).

What is more, the real physical setting and the shared collective meanings or ideology of the place that mediate the experiences of the fans/tourists (see also Belhassen et al., 2008) underpin the profound feelings of belonging to the place: "The beauties of the Tyrol . . . I must say it is even nicer than in movies. ... I felt really good there" (Participant M.B., age 53). The respondents formed a connection to the place, revolving from topophilic sentiments to intense feelings of calmness and fitting into place.

All this anecdotal evidence implies that fans' practical engagements with place are, in a way, always pre-structured by particular reference points from the text, such as a road turn, a village square, or a cemetery. According to Hills (2002: 116), these geographical points sustain fantasies of "entering" into the text, and, at the same time, allow the text itself to leak out into fans' spatial and cultural practices. As described previously, fans visiting the filming site do not merely re-live the already established affective relationship with text; they re-use original material from the imaginary Der Bergdoktor universe in various ways beyond the established frames provided by the media producers in the first place. They actively curate a multilayered reality that they wish to experience by selecting and organizing the fictional and nonfictional elements into a unique assemblage with an increasingly eroding boundary between them.

\section{Conclusion}

"Places are not clear and obvious entities", argued Urry (1995: 1). We started from the assumption that place is first and foremost a practical and emotional accomplishment (Moores, 2012: 94). As such, we looked at two distinct (albeit interrelated) stages of spatial appropriation of the Tyrolean countryside and of acquiring a sense of place and belonging by Slovenian fans of Der Bergdoktor, highlighting the ways these stages are informed by local cultural and historical conditions.

Our analysis of Slovenian fans' immersion into Der Bergdoktor's transmedia framework identified concrete patterns of referential engagements with the story that affirm the prevalence of particularly moral interpretative repertoires about Slovenia's belatedness, grounded in a historically specific selfothering process and a comparative/relational metaframe that can be traced back to the semi-colonial historical position of the country. As culturally dominant and recurring patterns of discourse about Der Bergdoktor, these serve as a resource for making claims about the contemporary phenomenal realities of Slovenian post-egalitarian society. They also showcase how the past still permeates the cultural discourses of the present. Clearly, the cultural historical context is important for the engagement with media text and viewing pleasure. Future research could explore how this may also affect the perception of a filming location and the spatial practices related to it. 


\section{Andreja Trdina and Maja Turnšek}

We have demonstrated how culturally specific readings of media representations of place (text negotiations within distinctive local interpretative repertoires, grounded in the historically repackaged self-othering discourse and the folk schemata surrounding the mythology of enchanted Alpine world) and experiences on site (embodied interaction with place) are inextricably embedded in one another, jointly producing a sense of place. Through a multifaceted interplay between mediatization, imagination, and concrete material practices, Tyrol as a place of the idyllic Alpine community-grounded way of life is thus materialized and enacted again and again. The present study refutes the contention that contemporary existence is becoming increasingly placeless (see also Moores, 2012). Rather, it advocates for the ongoing significance of locality in the contemporary mediatized world and promotes investigating related place-making processes at the intersections of the material and the symbolic.

\section{Notes}

1 It is, nevertheless, important to note here that media products were multidiscursive and intertextual long before the arrival of digital technology. See, for example, Bennett's (2017) work on the Bond phenomenon.

2 Similarly, see, for example, Askanius (2019) and Waade (2017) on how the imagery of dark and dangerous post-welfare Scandinavia is constructed through aesthetics of Nordic Noir.

3 As argued by Spasić and Birešev (2012: 141), enhanced moralizing in a postsocialist context could be explained to some extent by radical structural transformation and sudden shifts in patterns of social reproduction.

4 See, for example, Owczarzak (2009) on examining the post-socialist context through the lens of postcolonial studies.

5 For Buchowski (2006: 465-466), contemporary European orientalism is a "refraction, a derivative or correlate of a phenomenon covered by such concepts as globalization, the expansion of multinational capital, flexible capitalism, transgressions, migrations, transnationalism or the media-covered global village".

6 On how audiences in dialogue with popular culture shape their identities as border crossers between geo-cultural entities, see also Askanius (2019).

7 "Bergie" is a pet name for Martin Gruber, der Bergdoktor, among many fans in Slovenia.

\section{Bibliography}

Askanius, T. (2019). Engaging with the bridge: Cultural citizenship, cross-border identities and audiences as 'regionauts'. European Journal of Cultural Studies 22(3): 1-20.

Bakic-Hayden, M. (1995). Nesting orientalisms: The case of former Yugoslavia. Slavic Review 54(4): 917-931.

Bhabha, H.K. (1994). The location of culture. London: Routledge.

Belhassen, Y., Caton, K. \& Stewart, W.P. (2008). The search for authenticity in the pilgrim experience. Annals of Tourism Research 35(3): 668-689.

Bennett, T. (2017). The Bond phenomenon: Theorising a popular hero: A retrospective. The International Journal of James Bond Studies 1(1): 1-34. 
Buchmann, A., Moore, K. \& Fisher, D. (2010). Experiencing film tourism: Authenticity and fellowship. Annals of Tourism Research 37(1): 229-248.

Buchowski, M. (2006). The specter of orientalism in Europe: From exotic other to stigmatized brother. Anthropological Quarterly 79(3): 467-470.

Caramani, D. \& Wagemann, C. (2005). A transnational political culture? The Alpine region and its relationship to European integration. German Politics 14(1): 74-94.

Cohen, G.B. (2007). Nationalist politics and the dynamics of state and civil society in the Habsburg monarchy, 1867-1914. Central European History 40(2): 241-278.

De Bens, E. \& De Smaele, H. (2001). The inflow of American television fiction on European broadcasting channels revisited. European Journal of Communication 16(1): 51-76.

Eigler, F. (2012). Critical approaches to Heimat and the 'spatial turn'. New German Critique 39(1): 27-48.

Graml, G. (2004). (Re)mapping the nation: Sound of Music tourism and national identity in Austria. Tourist Studies 4(2): 137-159.

Hills, M. (2002). Fan cultures. London: Routledge.

Kotnik, B. \& Cah, K. (2016, August 30). On je Bog, ki ga vsi potrebujejo. Delo. Retrieved from www.delo.si/prosti-cas/on-je-bog-ki-ga-vsi-potrebujejo.html (01-05-2018).

Kreft, L. (2016, July 4-15). Razdvojenost v drugosti: slovenstvo med narodi. Conference Procedure: 52: seminar slovenskega jezika, literature in kulture. Retrieved from http://centerslo.si/wp-content/uploads/2016/06/52_Kreft.pdf (01-05-2018).

Meyrowitz, J. (1985). No sense of place: The impact of electronic media on social behavior. Oxford: Oxford University Press.

Moores, S. (2012). Media, place and mobility. Hampshire: Palgrave.

Morley, D. (2001). Belongings: Place, space and identity in a mediated world. European Journal of Cultural Studies 4(4): 425-448.

Owczarzak, J. (2009). Introduction: Postcolonial studies and postsocialism in Eastern Europe. Focaal 53: 3-19.

Proplus v jesen z nadpovprečno gledanostjo. (2016, September 9). MM Marketing Magazine. Retrieved from www.marketingmagazin.si/novice/mmediji/13260/proplus-v-jesen-z-nadpovprecno-gledanostjo (01-05-2018).

Reijnders, S. (2010a). On the trail of 007: Media pilgrimages into the world of James Bond. Area 42(3): 369-377.

Reijnders, S. (2010b). Places of the imagination: An ethnography of the TV detective tour. Cultural Geographies 17(1): 37-52.

Sandvoss, C. (2011). Reception. In: V. Nightingale (ed.), The handbook of media audiences, pp. 230-250. Malden: Wiley-Blackwell.

Savage, M. (2010). The politics of elective belonging. Housing, Theory and Society 27(2): 115-135.

Savage, M., Bagnall, G. \& Longhurst, B. (2005). Globalization and belonging. London: Sage.

Šaver, B. (2005). Nazaj v planinski raj: Alpska kultura slovenstva in mitologija Triglava. Ljubljana: Fakulteta za družbene vede.

Scherer, E. \& Thelen, T. (2018). Drama off-screen: A multi-stakeholder perspective on film tourism in relation to the Japanese morning drama (asadora). In: Film tourism in Asia, pp. 69-86. Berlin: Springer.

Silj, A. (1988). East of Dallas: The European challenge to American TV. London: British Film Institute. 


\section{Andreja Trdina and Maja Turnšek}

Spasić, I. \& Birešev, A. (2012). Social classifications in Serbia today between morality and politics. In: P. Cvetičanin (ed.), Social and cultural capital in Serbia, pp. 139158. Niš: Centre for Empirical Cultural Studies of South-East Europe.

Sugar, P.F. (1963). The nature of the non-Germanic societies under Habsburg rule. Slavic Review 22(1): 1-30.

Urry, J. (1995). Consuming places. London: Routledge.

Von Moltke, J. (2005). No place like home: Locations of Heimat in German cinema, vol. 36. Berkeley: University of California Press.

Waade, A.M. (2017). Melancholy in Nordic Noir: Characters, landscapes, light and music. Critical Studies in Television 12(4): 380-394.

Wang, N. (1999). Rethinking authenticity in tourism experience. Annals of Tourism Research 26(2): 349-370.

Waysdorf, A. \& Reijnders, S. (2017). The role of imagination in the film tourist experience: The case of Game of Thrones. Participations 14(1): 170-191. 


\title{
13 Live event-spaces \\ Place and space in the mediatized experience of events
}

\section{Esther Hammelburg}

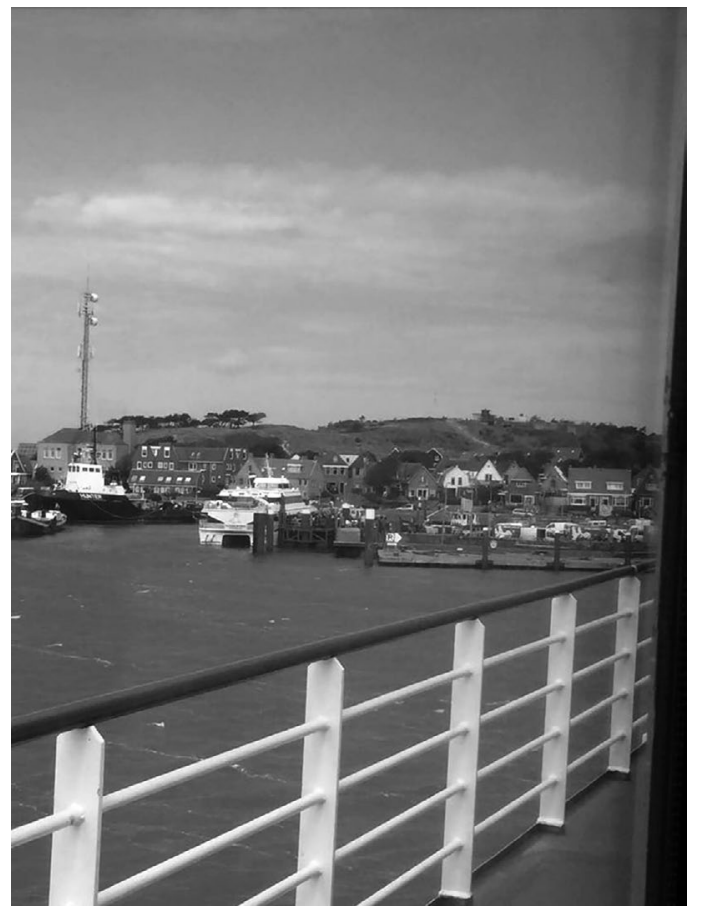

\author{
Yesssss \\ \#Oerol \\ \#Terschelling \\ \#sea-sun-wind \\ \#beautiful things \\ \#excited
}

When arriving by boat ... you see the island approach, and in that moment I think: "Yes, wonderful!" And then I have a photo, and I say [on Facebook]: "Oerol, yes, beautiful things". And that has to go [on Facebook] immediately, because then I am just totally... you get excited by it [clenches fists].

I want to share that immediately.

Figure 13.1 Quotes and photo by Simone, taken at Oerol Festival (2017).

Source: Reproduced with permission.

Arriving on the Dutch island of Terschelling for Oerol, Europe's largest festival for location-based theatre and art, has a special feel to it. You enter a space in which you know that you will be surprised and touched - by unique theatrical performances and installations, by special encounters with other visitors, and by the majestic landscapes of the island. The sensation of leaving the mainland behind and stepping into the atmosphere of the festival 


\section{Esther Hammelburg}

evokes that special "Oerol feeling”. As Monica, a returning festival visitor, explains: "I always feel it when I am there. . . . For a whole week I don't think about anything else; I am really only there on the island". Being in the "Oerol bubble", as this feeling is often described, makes the mainland seem far away. You are simply there on the island. But are you really?

From the boat, you post a photo of your view on Instagram: "\#Oerol here we come!" A video story on Snapchat shows your friends that you are entering the port. When landing on the island, a WhatsApp message comes in from a colleague wishing you a good time. And on your way to the campground, you stop to photograph the familiar view of the beach with low tide for your friend who cannot be there. These anecdotal examples illustrate that we are never just "here"; even in an event such as Oerol, organized within the geographically confined space of a small island, (deep) mediatization leads us to be here, there, and everywhere all at once.

This chapter takes up the challenge set forth in the Introduction of this volume and investigates the deeply mediatized experience of place and space within lived practice by studying two annual cultural events in the Netherlands as cases, Oerol Festival and 3FM Serious Request. Substantial participatory fieldwork during these events reveals how deep mediatization concurrently gives rise to more complex experiences of space and generates a real sense of a shared "here". The study addresses the question of how participants in these events navigate spatial complexity and experience spatial unity. I will demonstrate that - through a dialectical multitude of translocal connections within eventspheres - fluid and temporal event-spaces are constructed in which participants have a clear sense of "here" and "there". Using the concept of liveness as a theoretical vantage point helps to better understand this dialectical experience of space: liveness addresses how, through media, spatial fragmentation is overcome and proximity is created. I argue that it is the sense of liveness that creates the closeness between the near and the far elements within the mediatized eventsphere and binds it all together into one event-space.

\section{Understanding space within deeply mediatized eventspheres}

Due to the current degree of digitalization, former levels of mediatization have been surpassed such that "[n]o matter which domain of society we consider, its formation is in one way or another related to the technologically based media of communication" (Hepp \& Hasebrink, 2018: 17-18). Couldry and Hepp (2016) introduce the concept of deep mediatization to address this current intrinsically mediatized situation in which every element of society is co-constructed with media, as are the ways in which we form meaningful connections. Continuing from the premise that the world is deeply mediatized, an event cannot be regarded in itself, isolated from the media through which the event is experienced, shared, and envisioned. In their seminal work Media Events: The Live Broadcasting of History 
(1992), Dayan and Katz describe how broadcast media function to express belongingness by creating moments of shared focus on an event. Volkmer and Deffner (2010: 220) address the experience of events within a further mediatized situation, arguing that these events are "'reciprocal' processes of mediation where the meaning of 'experienced' events is reconstructed". This conceptualization of the experience of events is aptly captured by their term "eventsphere" (ibid). The eventsphere encompasses the field of experiences, happenings, and media texts connected to the event through which it is discursively re-mediated.

The move from event to eventsphere entails an extension of its spatial realm. As my introductory example of arriving at Oerol illustrates, lived space is never a straightforward experience. Human geography understands space as a continual construction on various levels. Henri Lefebvre's (1974/1991) concept of "social space" points out that space is constructed through the social relations brought to a place by the actors in it. Thrift (2003: 96) has analytically distinguished four types of space, empirical, unblocking, image, and place space, and argues that "the exciting thing ... is that we are learning how to put them together in combinations that are beginning to produce unexpected insights". Exploring the experience of space in the lived practice of deeply mediatized eventspheres does that exactly.

Media technologies play an important part in the production of space. Several authors convincingly argue that mediated communication has led to a pluralized, layered experience of space consisting of a variation of specific places (Evans, 2015; Urry, 2002). This view is supported by Shaun Moores (2004: 23), who conceptualizes "place as pluralised . . . by electronic media use" building on Scannell's (1996: 76) observation that mediated events occur simultaneously in "the place of the event itself and that in which it is watched and heard".

Moreover, another spatial layer is added to the eventsphere by our constant communicative connections to others, whether physically near or far away. These distant others are often perceived as more proximate than someone who might sit next to you (Meyrowitz, 1985). In eventspheres, we, as Hjorth (2013: 111) writes: "are seeing different tapestries involving a variety of modalities of presence (co-presence, tele-presence, net-locality)". Madianou (2016) even claims that, due to the ubiquity of media technologies, we have a constant "awareness of the everyday lives and activities of significant others", which she names ambient co-presence (ibid: 183). Consequently, the experience of the "here" of the eventsphere is accompanied by the awareness of a variety of distant elsewheres. Arguably, a wide spectrum of event locales are featured within the eventsphere, and proximity and distance are conjoined.

These lines of thought raise the question of how all the event-places are woven together into one shared space of the eventsphere: the eventspace. I argue that a sense of liveness - defined as the potential connection, through media, to events that matter to us as they unfold (Hammelburg, 


\section{Esther Hammelburg}

2015 ) - creates proximity between the near and the far elements within the eventsphere and binds it all together into one event-space. As Feuer (1983: 19) claims: "notions of 'liveness' lend a sense of flow which overcomes extreme fragmentation of space". In the 90s, Dayan and Katz (1992) eloquently described how live media events create a shared experience of a centre. Although our current intensive, fragmented media use entails that these mediated centres are constructed differently, I agree with Couldry and Hepp (2017) that media still (co)create mediated centres. For instance, Bruns and Burgess (2011) and Papacharissi (2015) have identified unifying practices in networked media by showing how publics are formed through the use of hashtags. Also, although mobile and digital media seem to be more placeless, this chapter will show the importance of place and the way this is enacted in current deeply mediatized eventspheres.

Liveness has been extensively theorized in the study of mass media and large media events as an ideological construct in which spatial borders are diminished (Berenstein, 2002; Feuer, 1983; White, 2004). The notion is raised herein that media technology has "triumphed over spatial distances, the far is reduced to the near, the elsewhere is both here and everywhere" (Allon, 2004: 265). Alongside the process of deep mediatization, it is conceivable that this concept stemming from the study of (broadcast) media proper can be used to better understand our lived practices in deeply mediatized eventspheres.

\section{Methods}

The central cases in this study - Oerol 2017 (Oerol17) and 3FM Serious Request 2017 (SR17) - are both in their own way distinctive eventspheres with respect to their spatial organization. Oerol is Europe's largest festival for location-based theatre and art. Since 1982, it has been organized every year in June on the Dutch island of Terschelling and attracts over 50.000 visitors. The festival is closely tied to the physical space of the island, as the performances are tailor-made for the locations in the landscape of Terschelling. In contrast, 3FM Serious Request, an annual Red Cross fundraiser organized in December by the Dutch national radio station 3FM, which reaches approximately 10.000 .000 people and brings approximately 500.000 visitors, is inherently a media event. Three radio DJs are locked up in a transparent studio named the Glass House for a week to make radio 24/7. Thus, the main event is the radio show, and people are invited to join in this event in several mediated ways. There is a physical location, the Glass House studio placed in a different Dutch city every year, but the event itself is spatially more distributed, since the scenes also include the media streams that are made, television broadcasts, and fundraising initiatives carried out by individuals to raise money. Thus, whereas the Oerol festival programs performances intended to be experienced without media in specific locations, the "programme" of 3FM Serious Request consists predominantly of 
media content. These dissimilarities make the combined material very rich in creating a view on spatiality in the mediatized event experience. My analysis of the two cases is not comparative; rather, the objective is to see whether and how certain practices recur in different situations. Furthermore, since each case shows a distinct combination of used media, studying both cases sheds light on a broad range of media use, including both broadcast and networked media. The studied events were organized in the Netherlands, yet both have an international character. Oerol has an international outreach, attracting both artists and visitors from all over the world, and Serious Request is a format that is not only implemented in the Netherlands but also in eight other countries worldwide.

I have explored these two eventspheres using both ethnographic and digital methods for data collection. Both methods have led to three datasets for each case (see Figure 13.2), the first of which consist of observations. These unstructured participant observations carried out at event sites and online were used to familiarize myself with the places and activities of the events as well as to glean a general sense of the media use of participants in the eventspheres.

\begin{tabular}{|c|c|c|}
\hline $\begin{array}{l}\text { DATA } \\
\text { SETS }\end{array}$ & $\begin{array}{l}\text { OEROL - } \\
\text { June } 2017\end{array}$ & $\begin{array}{l}\text { 3FM Serious } \\
\text { Request - Decem- } \\
\text { ber } 2017\end{array}$ \\
\hline $\begin{array}{l}\text { Collected } \\
\text { with eth- } \\
\text { nographic } \\
\text { methods }\end{array}$ & $\begin{array}{l}\text { - Observation } \\
\text { - } 59 \text { short inter- } \\
\text { views (in situ) } \\
\text { - Ten in-depth } \\
\text { interviews }\end{array}$ & $\begin{aligned} \text { - Observation } \\
\text { - } 59 \text { short inter- } \\
\text { views (in situ) } \\
\text { - } 19 \text { in-depth } \\
\text { interviews }\end{aligned}$ \\
\hline $\begin{array}{l}\text { Collected } \\
\text { with } \\
\text { digital } \\
\text { methods }\end{array}$ & $\begin{array}{l}\text { - Observation } \\
-5.784 \text { Insta- } \\
\text { gram posts } \\
-12.332 \\
\text { Tweets }(5.879 \\
\text { unique users) }\end{array}$ & $\begin{aligned} \text { - Observation } & \\
- & 3.750 \text { Insta- } \\
& \text { gram posts } \\
- & 85.052 \text { Tweets } \\
& (34.235 \text { unique } \\
& \text { users) }\end{aligned}$ \\
\hline
\end{tabular}

Figure 13.2 Overview datasets.

Source: Design by author.

The ethnographic material further comprises two datasets of semi-structured qualitative interviews, that is, short in situ interviews (averaging three minutes) held with one to six persons at a time at an event location or activity and longer in-depth interviews (averaging 30 minutes) carried out with one to four persons, but predominantly individually, at the periphery of event locations or at home via video conference. Where the short in situ interviews provide unique insight into the multitude of live experiences in place, the longer interviews offered room for more in-depth exploration of these experiences. A total of 248 people participated in the interviews, 120 in the Oerol17 study and 128 in the SR17 study. These qualitative interviews form the core material for the analysis in this chapter. For the design of the ethnographic part of the research and the first phase of analyses, I followed a grounded theory approach (Charmaz, 2014; Strauss \& Corbin, 1998). This inductive approach offers an effective way of truly gaining insight into lived practices. Audio recordings of interviews were transcribed and initially 


\section{Esther Hammelburg}

coded using MaxQDA (2018). The analysis that followed was performed using grounded theorizing and discourse analysis looking for interpretative repertoires (Wetherell \& Potter, 1988). Working with the research material, clustering initial codes and finding my way through what people had shared with me, I continuously aimed to work with my datasets in an iterative way, going back and forth between my developing ideas and the data (Hammersley \& Atkinson, 2007).

Additionally, digital methods were used to gather and analyse posts from Instagram and tweets from Twitter to get a sense of how these platforms were employed to join in the eventsphere. The tools used - Visual Tagnet Explorer (VTE) (Rieder, 2015) for Instagram and Twitter Capture and Analysis Tool (TCAT) (Borra \& Rieder, 2014) for Twitter - were developed within the Digital Methods Initiative of the University of Amsterdam. Both tools provide the option to gather content from the platforms searching by hashtags or location. The digital datasets lend themselves to various forms of analysis, both quantitative and qualitative. Considering the scope of this chapter, they have been used here in an exploratory way to gain an understanding of the content that is created in the eventspheres.

In the following three sections, I will address how my interviewees skilfully navigate spatial complexity and experience spatial unity in the eventspheres of Oerol17 and SR17. The first section will show that the embodied experience of being-in-place is essential in their event experiences, the second part will explore how deep mediatization entails spatially complex practices, and the third will focus on my interviewees' experience of spatial unity in the eventsphere: the event-space. Following from my interest in lived practices and apposite choice of method, the complete analysis is very much grounded in the experience of my interviewees. It was often when thinking aloud during the interviews that interviewees became conscious of their media behaviour and the logic behind it. In the following analysis, I have tried to stay as true as possible to the lived event experiences of my interviewees, ${ }^{1}$ often quoting to let them speak for themselves, since it is in these practices that place is made.

\section{Being-in-place}

When speaking of their event experiences, my interviewees notably often mention specific places. In my material from Oerol17, for example, many locations on Terschelling are mentioned, and the island seems to be important for my interviewees' connection to the festival. As Gretchen, who was organizing a photo of herself with her friends at an event location on the island, said: "I like that I can show it to my husband when I get home because he knows this place, we enjoy coming here. So, then I think: look what a nice installation they have built here. I find that very important". Since the Oerol festival is closely connected to Terschelling, it was not surprising to me that experiences of the festival and the island mutually influence each other. 
Nevertheless, even though 3FM Serious Request can be considered more placeless and is organized in a different town every year, my interviewees from SR17 spoke of very similar experiences. As Kirsten says: "it was more enjoyable because it was [organized in a town] nearby, so it is also closer to you". Another interviewee, Maya, comments: "It feels like home . .., because it is so close by". Often this proximity to the eventsphere is accompanied by a sense of pride. Joey tells me, reflecting on taking a "selfie" with his girlfriend at the Glass House: "Well, it is kind of special that it is placed in our city. So, I wanted to photograph that". The event taking place in his hometown of Apeldoorn was what Joey wanted to capture. Frequent Terschelling visitors join in Oerol, Oerol visitors develop a love for Terschelling, and many of my interviewees in SR17 state that their involvement with the event grew after it visited their town or region. The eventsphere thus comprises various event-places.

Furthermore, as we are always situated in a spatial context, in our specific personal environment, the eventsphere appears to be a conglomerate of a range of locales of embodied experiences. Being-in-place is an embodied experience that is "multisensory, corporeal and active" (Rakić \& Chambers, 2012: 613). As Rakić and Chambers have argued, it is through this embodied experience that place is concurrently taken in and created. In both the longer and the short in situ interviews held at Oerol17, embodied experiences of very specific locales were prominent: seeing the sun go down over a field, feeling the sand touching your feet while dancing on the beach, hearing the sound of a band playing while biking through the forest. As the photo and quote at the start of this chapter exemplify, the boat trip to and arrival at Oerol, seeing, hearing, and feeling the sea, the wind, and Terschelling, are mentioned as being "Oerol-moments" in nearly all of the in-depth interviews. In the interviews from SR17, similar embodied experiences of locales were specified: seeing the Glass House, being in the hustle and bustle of the crowd in the square in Apeldoorn, talking to the DJs through the main microphone, and donating money in the mailbox at the Glass House. It is in all of these locales that, through the embodied experience of being-in-place, event-places are consumed and produced.

\section{Spatial complexity}

In deeply mediatized eventspheres, this variety of event-places is further extended by locales that are not obviously identifiable as such. Firstly, as media let us join in eventspheres as witnesses-at-a-distance (Dayan \& Katz, 1992; Peters, 2001), a multitude of sites of reception are added to the eventsphere. In both my interviews and my Instagram dataset from SR17, in which many people join partly or solely through radio and television, I noticed many private spatial contexts functioning as event-places, such as the car, the couch, and the living room. As Hetty tells me: "For me it [the event] is just at home on TV. [Outside] the weather is grey, and then I really enjoy it 


\section{Esther Hammelburg}

[in my home]. I also have a little Christmas tree. So, for me, it is also a bit of the feeling of Christmas in these dark days". From the way my interviewees describe their joining in eventspheres as witnesses-at-a-distance, often using descriptions of specific elements of their home, it becomes clear that their physical sense of the place that they are in is very present and taken into the experience (cf. Scannell, 1996). This is their embodied experience of beingin-place in the eventsphere.

A second way in which deep mediatization multiplies place in the eventsphere is by including all those places that we imagine or visit due to our communication with others (also see Chapters 14 and 17 in this volume) often referred to by scholars as mediated co-presence. When being-in-place, whether at an event location or in our living room, we are simultaneously present in several other places, such as the park where a friend is walking, the office where colleagues are working, or your own home where your partner is while you are at the event. One story, of two individuals named Walter and Lenny, at Oerol17 nicely illustrates this. They tell me how they are involved in a tongue-in-cheek battle on Instagram. They attach the hashtag "\#FuckIbiza" to their posts to address the location of two friends who cancelled their Oerol plans to go to Ibiza instead. This awareness of Ibiza being another place to be in, choosing here while their friends are there, seems to co-constitute their experience of being at Oerol17. In this example, it re-affirms the fun that they are having. In other situations, interviewees explain that the awareness of other locales takes away from the experience of "being there". Emma explains why she put her phone away during an "Oerol expedition": "I think that you experience it differently when you take a picture of it. You would be thinking of [everything going on in] the present again and of home and for whom you take the picture. While when you are sitting there, you are just with your own thoughts, without the photo". Thus, reflexive awareness of "distant others" and "distant elsewheres" can re-affirm or lessen the embodied experience of being in the eventsphere.

These experiences of being witness-at-a-distance and our awareness of distant others and distant elsewheres also influence the embodied experience of being-in-place "on the ground" at an event. Many of my interviewees express their excitement about being in places that they have seen before through media or that gain importance in relation to distant others (see also Chapters 12 and 17 in this volume). For instance, being at the Glass House is co-constructed by expectations raised by all of the images that visitors have seen of it before coming there. As Thrift (2003: 100) argues: "images are a key element of space because it is so often through them that we register the spaces around us and imagine how they might turn up in the future". Many interviewees describe their being-in-place at the event location in contrast to earlier experiences as witnesses-at-a-distance and state that it feels "more real to be there in person". When asked to reflect on this realness, they refer to senses that are not transferable via media technologies, such as the bodily 
closeness of others, touch, smell, and vibe. As Oerol17 visitor Sasha says: "of course you can take a selfie, but that won't reflect the feeling, you know".

Furthermore, many of my SR17 interviewees recounted that, where they were restricted by the camera view before, now they can look where they want to look and see everything that the television director may not focus upon. This - almost freeing - embodied experience of being-in-place "without" media is something that I have also noticed at Oerol17, where many interviewees expressed that they prefer to go offline or minimize their smartphone use. In both case studies, interviewees described these "media free" practices by using the word "live", a term they also used for several mediated participations in the eventsphere. This shows that "liveness" is experienced in a diversity of ways. As we will go on to see, the "live experience" is very often affirmed by media use. And even when media technologies are deliberately put away in favour of the presumed "pure" experience of the moment, this deliberate non-mediation co-articulates the moment (cf. deep recursivity in Couldry \& Hepp, 2016; and the paradox of dis/connectivity in Hesselberth, 2017). Media technology, whether used or deliberately not used, always plays an important part in the live experience of being-in-place.

Another way in which media technologies co-articulate being-in-place is by asserting the embodied experience of being there and affirming the importance of this. The authoritative power of the broadcast media institutions of radio and television was especially evident during my participant observations at SR17: people waved at the cameras, situated themselves perfectly in front of them, and eagerly looked at my recording device asking me if I did radio interviews. My interviewees in SR17 tell me that seeing themselves on TV provides enjoyment and pride. Seeing yourself, a friend, or a familiar place on the screen strengthens the experience of being there, and the visibility of cameras and screens awakens the desire of your presence to be captured by them. As Hetty tells me, she stays put on the couch in front of the television for at least two hours after sending an SMS to SR17 just so she can see her message appear on TV. Joyce shows me a picture of a television screen showing herself in the crowd in front of the Glass House, taken by a friend who noticed her when watching SR17 on TV, telling me that it makes her happy to "be seen". And then there is Pif, who was filming the live stream on the large screen next to the Glass House. Explaining why she chose to film the screen instead of the actual scene that was taking place on the other side of the Glass House, her boyfriend speaking to the DJs, she told me: "Well ... he is on TV, so you have to show that, right. A bit of showing off your man, that does add to it".

Notwithstanding this authoritative role of broadcast media, connective media also work to assert and affirm being in the eventsphere. In all of my datasets, it is clearly visible that people want to show where they are, commonly by posting pictures and videos on various connective platforms or sharing them within closer social networks through direct messaging services such as WhatsApp. As Jason tells me about letting his friends know that he 


\section{Esther Hammelburg}

is in Apeldoorn for SR17: "Well, you are there, so then I send a quick Snapchat video to friends. Because yeah, they are jealous that they can't be here". This was a really prominent theme in my material from both case studies and appears to be deeply normalized behaviour, as became apparent by the frequent use of words such as "just" and "of course". Participants often noted that they had never thought about it but just do it. Jane at Oerol17 states: "I find it important that people know that I am here, I guess. . . . You never really think about that, but now that I do I do find it important". Some interviewees even speak of proving that they are there, such as Claudia at SR17: "Just to say that you were there. A little bit of proof or so. It doesn't make sense to do it, but I like it". In my Instagram datasets, this is evident; many images - often using the platforms' vernacular forms of selfies and first-person and point-of-view perspectives (Gibbs et al., 2014) - essentially show being-in-place. Selfies in front of the Glass House, first-person views of boating to Terschelling, and couch point-of-view shots of living rooms with SR17 on TV can be seen as a practice of visual presencing (Meese et al., 2015; Richardson \& Wilken, 2012) as people visually place themselves in event locales. Whether stemming from a personal desire, from an expectation of media, or from a prompt given by the platforms in use, I would argue a combination of these, people love sharing where they are (see Chapter 11 in this volume for a reflection on how this is done in toy tourism). And by doing so, they add yet another spatial layer to the eventsphere.

\section{Spatial unity: the event-space}

Both the multiple locales in the eventsphere and the experienced spatial unity between these locales are recognizable in the prominence of the word "here" in my interviews. By "here", my interviewees refer concurrently to the locale of embodied experience - the being-in-place on the couch, the festival ground, the boat - and to "the event" as one central de-spatialized eventsphere. Throughout my interview material, the various event locales do not stand out as separate places but rather as parts of a meaningful whole: the event-space. This event-space becomes especially apparent when my interviewees identify its borders. While they are apt to seamlessly include housework, WhatsApp messages, and phone calls in the event-space, at other moments, the smallest disturbance can annoy them because it takes them out of it. Where Gretchen's husband is included as a distant other in the event-space of Oerol17 (as described earlier), Hetty explains that she can better enjoy SR17 when her husband is out of the house. Many speak of being distracted by their phones while joining in the eventsphere, whether via television or on the festival grounds. My interviewees' annoyance with "elements" that disturb the flow of the eventsphere shows us that the eventspace is constructed and requires active upkeep.

Being a witness-at-a-distance through live broadcasts and streams creates a privileged position in the event-space, since it enables us to take positions 
in and see aspects of the event that are difficult to witness on the ground, such as a drone shot of the party on the beach or a close-up of an emotional radio DJ inside the Glass House, and all this from the comfort of your own home or mobile phone. As my interviewees portray their domestic event locales as cosy, warm, and comfortable, "being there" becomes an intimate situation in which proximity is experienced. Here we see a "classical" notion of liveness in which, in the words of Berenstein (2002: 33), "[ $\mathrm{t}]$ he combination of the site of reception (the home) and the mode of transmission (immediacy) creates a powerful means of engaging". Joining in the event-space as a witness-at-a-distance is experienced as truly participating in the eventsphere. As Anita describes watching SR17 on TV with her family: "You experience it. Well, we are all fully engaged [laughs]. I find it wonderful. . . . You see the people [at the Glass House] enthused, cheering, etc. [laugh] We cheer along". Joining in the event from the couch provides for an equally valid event experience as, for instance, standing in front of the Glass House during SR17 (cf. Scannell, 1996). As Dennis speaks about his participation in SR17 through the live stream: "It [the location of the Glass House] is always so far away. . . . But to be able to follow it closely, watching the 24/7 stream, you get the idea as a viewer that only by watching you contribute to Serious Request as a whole". As a witness-at-a-distance, your living room becomes deeply entangled with other event-places, and you join the event-space.

Writing yourself into the event-space through connective media is afforded by platforms through specific functionalities. Each platform has its own way of letting the user share where she is: Snapchat has locationbased filters, Instagram and Twitter use locations, and on Facebook you can "check-in". These functionalities not only afford the sharing of concrete locations, they also enable my interviewees to connect to the event-space as these functionalities overlay it you can use the "SR17 filter" or add "location Oerol". This can be seen as a more abstract placing or (visual) presencing, referring not to a specific locale but to the eventspace as a whole. As mentioned before, adding location is often more of a habit than a deliberate choice. It is a simple way to clarify the context of a story or photo, as Janice at Oerol17 explains: "When I post an Instagram-story, there is the option to add location, and I actually always do that. And then I don't add text because then I think: okay, people know why I post it, because I added the

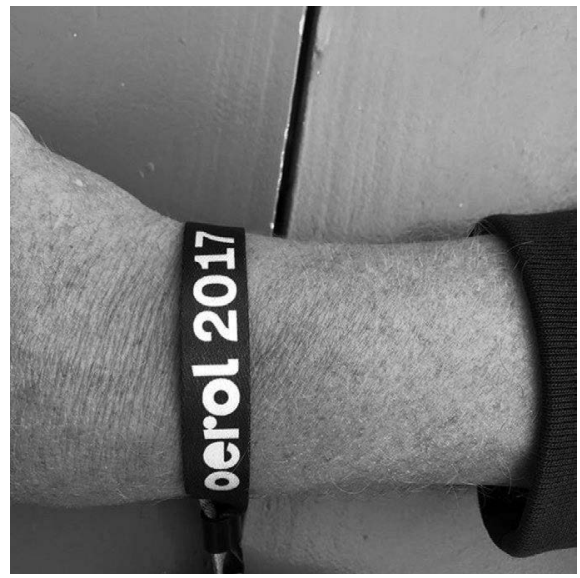

Figure 13.3 Visual presencing at Oerol17. Source: Photo by author. 


\section{Esther Hammelburg}

location". Here location is more than coordinates and also more than an event-place. These functionalities are used to assert and affirm being in the event-space. This positioning in the event-space through social media platforms clearly stands out in both my interview material and my datasets from Instagram and Twitter. As we have seen, most often, event locales are used to do so. However, one recurrent visual trope is de-spatialized - meaning it has no tangible reference to a place - and still places you firmly in the eventspace: the I'm-in photo (as I call it), which employs merchandise of the event for visual presencing. For instance, at Oerol17, as at many other festivals, people visually "chain" themselves to the event by photographing their own wrists with the wristband that provides entrance to Oerol activities. For many people, this practice is an annual photo tradition.

And then there is the hashtag, the most common functionality used on both Instagram and Twitter. Much like the "I'm-in" photo, the hashtag places you in the event-space without referring to a physical place. This placelessness makes the hashtag, and its birthplace Twitter, a perfect tool to join in media events or comment on television content. Many of my interviewees explain that they use hashtags so that people will find their comments or photos when searching for the event hashtag, others tell me that they join in the event-space by searching for hashtags, and nearly all say that the hashtag connects their content to the event. Hashtags do more than just presencing; as performative statements (Bruns \& Burgess, 2011), they co-create the event-space. Hashtags such as \#sr17 and \#oerol17 co-shaped the event-spaces of SR17 and Oerol17. Although we have to bear in mind that these hashtags may not all be used intentionally for the formation of the event-space (Bruns \& Burgess, 2011), they do shape the eventsphere and its space. Hashtags not only represent the event; they also form the event and event experiences. \#sr17 assembles myriad types of content and people (cf. Papacharissi, 2015), as well as a range of locales spanning from podiums to living rooms, into one meaningful event-space.

\section{Conclusion}

Let us return to where we began and examine Simone's arrival at Oerol Festival. By referencing Terschelling in both her Facebook post and her account of the experience - sharing a point-of-view shot of the island and mentioning the environmental elements of sea, sun, and wind - Simone shares a very embodied experience of being-in-place. She places herself in a specific physical place with sensate, affective, and cognitive experiences, some of which even resurface as she clenches her fists when recounting the experience. By sharing her experience on Facebook, she adds spatial layers to it. Similar to what we have seen in other examples from both case studies, Simone is noticeably aware of distant others and feels the desire to instantly share her excitement with them. By using \#beautifulthings, she also refers to other places, distant elsewhere, in the eventsphere of Oerol17 which she 
expects to encounter. Simone's mediated experience of arrival encompasses multiple places and is concurrently a unified event experience, conspicuous in the way she speaks of Oerol as a meaningful whole and the unifying use of \#oerol. She is "there".

Diving into the two eventspheres of Oerol17 and SR17 - through participant observations, qualitative interviews with 248 participants, and the exploration of 9.534 Instagram posts and 92.384 tweets - has uncovered the importance of place and space in the mediatized experience of events. I have demonstrated that media concurrently de-spatialize, in the sense that they diminish spatial borders, and affirm embodied experiences of being-in-place. My interviewees experience a flow and coherence in these eventspheres, as well as disruptions thereof, which I argue are best understood in terms of liveness. Liveness - the mediatized connection to unfolding events - assembles our embodied experiences of being-in-place and de-spatialized notions of "being there" as dialectical partners. Through these dialectics, eventspheres such as Oerol17 and SR17 become fluid and temporal event-spaces within which participants skilfully navigate spatial complexity and experience spatial unity - meaningful event-spaces in which "being there" and "being here" are experienced as one.

\section{Note}

1 Interviewees quoted in this chapter have been anonymized.

\section{Bibliography}

Allon, F. (2004). An ontology of everyday control: Space, media flows and 'smart' living in the absolute present. In: N. Couldry \& A. McCarthy (eds.), MediaSpace: Place, scale, and culture in a media age. London: Routledge.

Berenstein, R. (2002). Acting live: TV performance, intimacy, and immediacy (19451955). In: J. Friedman (ed.), Reality squared: Televisual discourse on the real, pp. 25-49. New Brunswick: Rutgers University Press.

Borra, E. \& Rieder, B. (2014). Programmed method: Developing a toolset for capturing and analyzing tweets. Aslib Journal of Information Management 66(3): 262-278.

Bruns, A. \& Burgess, J. (2011). The use of Twitter hashtags in the formation of ad hoc publics. In: A. Bruns \& P. De Wilde (eds.), Proceedings of the 6th European Consortium for Political Research (ECPR) general conference 2011, pp. 1-9. Colchester: The European Consortium for Political Research (ECPR).

Charmaz, K. (2014). Constructing grounded theory, 2nd ed. London: Sage.

Couldry, N. \& Hepp, A. (2016). The mediated construction of reality. Cambridge: Polity Press.

Couldry, N. \& Hepp, A. (2017). The continuing lure of the mediated centre in times of deep mediatization: Media events and its enduring legacy. Media, Culture \& Society 40(1): 1-4.

Dayan, D. \& Katz, E. (1992). Media events: The live broadcasting of history. Cambridge: Harvard University Press. 


\section{Esther Hammelburg}

Evans, L. (2015). Locative social media: Place in the digital age. London: Palgrave Macmillan.

Feuer, J. (1983). The concept of live television: Ontology as ideology. In: E.A. Kaplan (ed.), Regarding television: Critical approaches: An anthology, pp. 12-21. Los Angeles: American Film Institute.

Gibbs, M., Meese, J., Arnold, M., Nansen, B. \& Carter, M. (2014). \#Funeral and Instagram: Death, social media, and platform vernacular. Information, Communication \& Society 18(3): 255-268.

Hammelburg, E. (2015). \#stemfie: Reconceptualising liveness in the era of social media. Tijdschrift Voor Mediageschiedenis 18(1): 85-100.

Hammersley, M. \& Atkinson, P. (2007). Ethnography: Principles in practice, 3rd ed. London: Routledge.

Hepp, A. \& Hasebrink, U. (2018). Researching transforming communications in times of deep mediatization: A figurational approach. In: A. Hepp, A. Breiter \& U. Hasebrink (eds.), Communicative figurations: Transforming communications in times of deep mediatization. London: Palgrave Macmillan.

Hesselberth, P. (2017). Discourses on disconnectivity and the right to disconnect. New Media \& Society 20(5): 1994-2010.

Hjorth, L. (2013). The place of the emplaced mobile: A case study into gendered locative media practices. Mobile Media \& Communication 1(1): 110-115.

Lefebvre, H. (1991). The production of space (D. Nicholson-Smith, Trans.). Hoboken: Blackwell.

Madianou, M. (2016). Ambient co-presence: Transnational family practices in polymedia environments. Global Networks 16(2): 183-201.

MAXQDA, software for qualitative data analysis. (2018). VERBI Software-ConsultSozialforschung GmbH.

Meese, J., Gibbs, M., Carter, M., Arnold, M., Nansen, B. \& Kohn, T. (2015). Selfies at funerals: Mourning and presencing on social media platforms. International Journal of Communication 9: 1818-1831.

Meyrowitz, J. (1985). No sense of place: The impact of electronic media on social behavior. Oxford: Oxford University Press.

Moores, S. (2004). The doubling of place: Electronic media, time-space arrangements and social relationships. In: N. Couldry \& A. McCarthy (eds.), MediaSpace: Place, scale, and culture in a media age. London: Routledge.

Papacharissi, Z. (2015). Affective publics: Sentiment, technology, and politics. Oxford: Oxford University Press.

Peters, J.D. (2001). Witnessing. Media, Culture \& Society 23(6): 707-723.

Rakić, T. \& Chambers, D. (2012). Rethinking the consumption of places. Annals of Tourism Research 39(3): 1612-1633.

Richardson, I. \& Wilken, R. (2012). Parerga of the third screen: Mobile media, place and presence. In: R. Wilken \& G. Goggin (eds.), Mobile technology and place, pp. 181-197. London: Routledge.

Rieder, B. (2015). Visual Tagnet Explorer, version 1.1. Retrieved from https://tools. digitalmethods.net/netvizz/instagram/.

Scannell, P. (1996). Radio, television and modern life: A phenomenological approach. Hoboken: Blackwell.

Strauss, A.L. \& Corbin, J.M. (1998). Basics of qualitative research: Techniques and procedures for developing grounded theory, 2nd ed. London: Sage. 
Thrift, N. (2003). Space: The fundamental stuff of human geography. In: S. Rice $\&$ G. Valentine (eds.), Key concepts in geography, pp. 95-108. London: Sage.

Urry, J. (2002). Mobility and proximity. Sociology 36(2): 255-274.

Volkmer, I. \& Deffner, F. (2010). Eventspheres as discursive forms: (Re-)negotiating the 'mediated center' in new network cultures. In: N. Couldry, A. Hepp \& F. Krotz (eds.), Media events in a global age. London: Routledge.

Wetherell, M. \& Potter, J. (1988). Discourse analysis and the identification of interpretative repertoires. In: C. Antaki (ed.), Analysing everyday explanation: A casebook of methods. London: Sage.

White, M. (2004). The attractions of television: Reconsidering liveness. In: N. Couldry \& A. McCarthy (eds.), MediaSpace: Place, scale, and culture in a media age. London: Routledge. 


\title{
14 Fans and fams
}

\section{Experience and belonging aboard a cruise ship music festival}

\author{
David Cashman
}

\section{Introduction}

Imagine the excitement of being at an outdoor rock festival with your favourite band or genre. Think of the smells and sights and sounds of being front and centre a few feet from the stage where metal band Cannibal Corpse is shredding. You feel the vibrations of the subs in the pit of your stomach. The light show illuminates musician after musician, audience member after audience member. You are there with some of your best friends. But it is muddy from earlier rains, and you are sleeping in a tent. You have to queue for drink and food, which is expensive. And the less said about the toilets, the better. Now imagine that same festival, but this time you are sleeping in a small but luxurious room. You have a room steward to make your bed each night and to bring you room service at your whim. Food is plentiful and included in the festival admission. There are a multitude of bars and staff to wait on you. You have more than one stage and can move between your favourite acts. The cost of the festival is reasonable and all inclusive. You still have your friends there, but you meet strangers that become friends and call you their family. You have a much greater chance of meeting your musical idols. You still get to listen to Cannibal Corpse, but this time you do it from a jacuzzi at the side of the stage.

Sounds good, doesn't it? Such experiences are common to thousands of festivalgoers who attend popular music festivals on cruise ships. Dozens of these festivals now ply the waterways of the world servicing fans of bluegrass, metal, indie rock, and a plethora of other genres. There is an intense feeling of camaraderie, and participants refer to each other and the artists as "ship fam". This intense feeling of belonging is somewhat at odds with the location, which is a mobile geography and a non-place where it is not physically possible to "belong".

There are three concepts of import to successful music festivals on cruise ships. First, cruise festivals celebrate a specific but wide variety of music genres, including alternative rock (The Rock Boat); metal (70,000 tons of Metal, Monsters of Rock); dance music, also known as EDM (Holy Ship!, Mad Decent Boat Party); country music (The Country Music Cruise, Cruisin' Country); jazz (Blue Note at Sea, The Jazz Cruise); Soul (Soul Train 
Cruise); and more. Other festivals celebrate a particular band, such as the KISS cruise, the Kid Rock cruise, or the Weezer cruise. Festivalgoers are passionate about the music or band and understand and celebrate the cultural signifiers and performance conventions of the genre. Second, the cruise environment is a desirable place to hold a music festival. Many of the issues that plague promoters of land-based festivals, such as accommodation, security, the provision of food and drink, the construction of performance spaces, technical equipment, and staff, are already present on cruise ships. Cruises are regarded both by general cruise tourists (Hosany \& Witham, 2010; Huang \& Hsu, 2009; Hung \& Petrick, 2011; Kwortnik, 2008) and interviewed festivalgoers as a luxurious and desirable holiday. Third, interaction between festivalgoers and also between festivalgoers and musicians within this hedonistic, intense, and neotribal (Maffesoli, 1996) festival experience results in a constructed and artificial closeness and sense of belonging. Participants in this research reported staying in contact with fellow "ship fam", sometimes meeting up between cruises, attending land-based concerts, and generally experiencing a warm and unusually intimate experience with fellow cruise passengers during the festival.

This chapter considers how belongingness is co-opted by festival organizers to create a socially and commercially successful ocean-going festival experience. These festivals have no need to interact with the region or culture in the manner of a land-based festival but can focus entirely on the music, on the musicians, and on the festivalgoers and their temporary society. These festivals are of increasing significance on the world festival circuit, providing employment to musicians, engaging fans, and opportunities to belong, if only for a few days, to a collective dedicated to music and experience. Data were drawn from a series of nine interviews undertaken in 2016 augmented by an open-ended survey, which captured 129 respondents. This sample incorporated 19 different festivals, including The Rock Boat (58\%), 70,000 Tons of Metal (23\%), Ships and Dip (10\%), Live Loud (6\%), Rombello (6\%), and Mad Decent Boat Party (5\%). These data were analysed using a grounded theory methodology. The research finds that festival organizers co-opt the mobile geography of the cruise ship and the sensory tourism of the festival to construct a purposeful experience that creates a fabricated sense of belonging and camaraderie. This hyperreal belonging makes return visits more likely, thereby increasing the financial viability of the enterprise.

\section{The tourist experience of cruise festivals}

Cruise festivals combine two tourist models: cruise tourism and festival tourism. Cruise tourism is one of the success stories of the tourism industry. From 2000 until 2010, passenger numbers have grown at $8 \%$, more than three times the growth rate of international arrivals on air transport (Clancy, 2017: 43), though this has slowed somewhat since (Cruise Line International 


\section{David Cashman}

Association, 2016: 7). Cruise ships generate enormous profits, mainly from onboard revenue (Becker, 2006; Vogel, 2017). Onboard revenue includes the costs of cruising not contained in the ticket price, notably gambling, consumption of alcohol, and spa treatments. A cruise ship has been likened to a cocoon (Vogel, 2004), a mobile tourist enclave (Weaver, 2005), and an extended "tourist bubble" (Jaakson, 2004). These models are variations on the steel capsule of the cruise ship, which firmly defines the tourist area of the ship and the area outside the ship: ports and ocean. By creating a solid boundary point, tourists' attention is pointed inwards, and onboard revenue thrives. While little research has been undertaken on the social and cultural aspects of cruise ships, there is general agreement they are postmodern and hyperreal tourism products (Kulhanek, 2012; Vogel \& Oschmann, 2013; Williams, 2012) and consequently encourage guests to playfully engage with their surroundings (Feifer, 1985). This encapsulation and the resultant onboard revenue is the key to the success of the cruise industry.

Festivals on cruise ships sit between several established paradigms. They are clearly music festivals in that they celebrate a genre or a person; however, there are several conflicting models for festivals (Getz, 2010) all of which contribute to our understanding. Falassi (1987: 2), for example, describes festivals in anthropological terms as "a sacred or profane time of celebration, marked by special observances", a definition that clearly applies to cruise music festivals. To Pieper (1965), only religious celebrations are festivals. There are certainly processes akin to religious ceremony in cruise festivals, such as ritual, worship, and celebration. Arcodia and Robb (2000) note that festivals are public, celebratory, and embedded in community. The community of the "ship fam" is central to cruise festivals. However, most festivals are strongly connected with and invested in place (De Bres \& Davis, 2001; Derrett, 2003; Lau \& Li, 2015; McClinchey \& Carmichael, 2010; Quinn, 2003) to the extent of "eventrification" of geographical place (Jakob, 2013). Cruise ships are placeless festivals, existing only within the placeless (Augé, 1992; Relph, 1976) and unnamed ocean. MacLeod's (2006) work on placeless festivals, which she calls "postmodern festivals" or "post-festivals" is pertinent. To the festival attendees, geographical place is less relevant than engaging with the experience.

The experience between festivals is remarkably similar. They begin with pre-parties the day or so before the festival. The ship will be boarded from about midday after the previous passengers disembark and will depart at about $5 \mathrm{pm}$. Once at sea, a routine establishes itself. Performances commence at $10 \mathrm{am}$ in various venues around the ship, especially the main theatre and a large stage on the lido deck. They may dock in a port, one of the specially altered islands leased by the cruise line, or may stay at sea. In their pursuit of abandon, festivalgoers may consume large amounts of alcohol and participate in traditional cruise ship activities such as belly-flop competitions and bingo (albeit with a rock and roll twist). There are theme nights where attendees dress up in pre-organized costumes. Performances end a few hours 
before sunrise, and the last stalwart partiers go back to their cabins before to crash for a few hours before awakening to do it all again.

Cruise festivals tend to be comparatively small and intimate, with numbers limited by the physical capacity of the cruise ship, often around 2,000 for midrange ships. Participants comment positively on this aspect, describing "All the awesomeness of non-stop music, with none of the hassles of huge crowds, mud, port-a-potties, camping”, and

No worries about noise bothering the neighbours, no curfews, no worries about drinking since your cabin is so close, all of your friends and musician friends are close by, food is ready for you any time of the day or night to easily grab something on the run if there's a show to get to.

Festival interactions occur within the magical tourist space of the cruise ship. This encapsulated space functions as the delineator of festival space, as a barrier to casual departure, as luxurious space, and as the container for an experience.

\section{Theory}

Cruise music festivals are a relatively new model of tourism and have not yet attracted great amounts of research. However, there are several relevant areas that shed some light. Belongingness sheds light on the processes of onboard community. Sensory tourism considers the way that cruise tourists interact with the festival. Finally, experiential tourism considers the actual experience of the festival.

Belongingness is a key human motivation (Baumeister \& Leary, 1995). It is the third aspect of Maslow's hierarchy of needs, indicating the belief that one cannot achieve self-esteem and self-actualization without social belonging. Lee and Robbins (1995), basing their work on Kohut (1971) and Patton et al. (1982), argue that belongingness is composed of three incremental aspects companionship, affiliation, and connectedness (Lee \& Robbins, 1995: 232). Companionship is the relationship with close family and is the first aspect of belongingness. Affiliation is about peer relations while growing up. Connectedness refers to the adult feelings of being "human among humans" (ibid: 233). Cruise ship festivals encourage this sense of social belonging via the adoption and promotion of the concept of the "ship fam". The stoking and manipulation of Lee and Robbins' three aspects are of considerable import to the aesthetic and financial success of cruise ship music festivals.

The friendships that develop deeply and quickly between festival participants, as well as participants and musicians, with egalitarian and community implications, can be understood within the model of communitas. "Communitas", a concept proposed by Turner (1969, 1974), involves a close, temporary bonding generated by shared experience. Many scholars have noted the relationship of festivals, liminality, and the generation of 


\section{David Cashman}

communitas (Arcodia \& Whitford, 2006; van Heerden, 2009; Rutherdale, 2008). This became a key concept within tourism studies (Cohen, 1979; Duffy et al., 2011; Franklin, 2003; Wang, 1999; Yarnal \& Kerstetter, 2005). Urry and Larsen (2011: 11) note that "an intense bonding communitas" is experienced by a tourist who finds him/herself in an "anti-structure ... out of time and place - conventional social ties are suspended". Connell and Gibson (2003: 228) further note that

music tourism sub-cultures have emerged around the tours of particular artists, with groups of highly committed fans (even "groupies"), who follow performers around from concert to concert, even generating a sense of communitas through shared experiences, fan clubs and traditions maintained on-tour.

This focus on the collective experience of cruise festivals can be also contextualized within Maffesoli's (1996; Maffesoli \& Foulkes, 1988) concept of "neo-tribalism". Maffesoli argues that as the social institutions of modernism have transformed into those of postmodernism, their ability to fuse large groups of people towards a common goal has been lost, replaced by small groups bonded by common experience, emotions, and aesthetics. Certainly, festivalgoers share a common aesthetic desire for the music celebrated by the festival. Words and phrases used to describe the "ship fam" are affectionate: music lovers, friendly, nice, broad demographic, family, international, partiers, like-minded, and there to have a good time.

Cruise festival tourism is a product of sensory tourism. Humans broadly construct their experience through interpreting the world, based on sensory input. Some of the senses have received significant academic attention, including sight (Franklin, 2001; Gillespie, 2006; Urry, 1990, 2008), taste (Cohen, 2004; Kivela \& Crotts, 2006; Richards, 2002), and, to an extent, smell (Dann \& Jacobsen, 2003). However, the traditional senses of touch and hearing (and non-traditional senses such as chronoception and thermoception) have received little study. As Gottschalk and Salvaggio (2015: 11) note, "it is not sufficient to 'just add' smell, touch, taste, or chronoception to the panoply of senses one attends to when conducting mobile ethnography; the challenge is to understand their dynamic interplay". While the interplay between the various senses is of import to this discussion, the process of sound as a semiotic symbol, as a device for engaging tourists, and as promoting a profitable tourism product is of particular importance. The constructed and humanly fabricated space of a cruise ship is devoid of meaning until culture is poured into it by the cruise line and co-opted by the festival organizers. It is this inherent meaninglessness meaning that provides cruise operators with the opportunity to musically enculture the space. In so doing, they focus their clients' attention on the music, the "ship fam", and the experience without the distraction of engaging with the specific geography in which tourists find themselves. 
Hyperreality theory, pioneered by Umberto Eco (1987) and Jean Baudrillard (1994) posits that there exist instances of consciousness whereby an individual is unable to perceive the difference between reality and fabrication. The tourism industry regularly co-opts this postmodern idea to create engaging experiences that permit participants to playfully bend the nature of reality. As noted, cruise ships are prime examples of hyperreality (Kulhanek, 2012; Vogel \& Oschmann, 2013; Williams, 2012) in that they are fabricated environments bearing the illusion of social and cultural reality. The Royal Caribbean ship Voyager of the Seas

is a classic example of simulacrity and hyperreality, the loss of authenticity and the becoming real of what was previously a simulation, artefacts from a bygone era becoming part of the décor, with designers recycling them as sculpture and other art. Thematic elements, including photographs, ship's compasses and navigational equipment are pinned to the wall. Voyager of the Seas has a theatre called La Scala, it also has an art collection valued at some $\$ 7.5$ million and a shopping mall, the Royal Promenade, modelled on Burlington Arcade.

(Williams, 2012: 195)

Hyperreality in tourism utilizes and informs the concept of experience. The cruise industry generally and the cruise music festival business specifically are in the business of staging experiences. Early models for tourist experience included the SERVQUAL model (Parasuraman, Berry \& Zeithaml, 1991; Parasuraman et al., 1985, 1988) and Bitner's Servicescape model (1992); however, the most broadly influential model is that of Pine and Gilmore $(1998,1999,2011)$. Pine and Gilmore state that there are two axes for participation in the experience economy. The first is that of participation, defining how audiences affect the touristic performance. In passive participation, guests do not directly affect the performance, but active participation means that they do. The second axis, connection, discusses the connection of the guest to the performance. An absorbed guest is occupied by a touristic performance from a distance, but an immersed guest physically becomes a part of the touristic performance. Combining these axes results in the realms of an experience. An experience enjoyed ...

- ... from a distance (absorbed connection) without being affected by guests (passive participation) is entertainment;

- ... from a distance (absorbed connection) but directly affected by guests (active participation) is educational;

- ... by being immersed (immersed connection) without being affected by guests (passive participation) is aesthetic;

- . . . by being immersed (immersed connection) but directly affected by guests (active participation) is escapist. 


\section{David Cashman}

In the centre is the "sweet spot", representing the richest of possible experiences. To attain the sweet spot, all aspects must be equally weighted and evident. Pine and Gilmore (2011: 59) state that "to design a rich, compelling and engaging experience, you don't want to incorporate only one realm". All aspects must be considered in designing an experience. Pine and Gilmore (1998: 102-105) further note that an experience should be themed, should harmonize impressions with positive cues, should eliminate negative cues, should mix in memorabilia, and should engage all five senses. The geographical space of hyperreal spaces is entirely constructed. Humans turn space into place by naming it (Relph, 1976). If this is the case, cruise ships are constructed and are mobile geographies in a way like no other. They are enormous, with the largest the formidable Royal Caribbean Oasis-class. Populated by humans, they are named in the traditional nautical fashion (port, starboard, aft, stern), but also by location, for example, the Blue Sapphire Lounge, the lido deck, the main restaurant. Yet these geographies move from place to place in a manner like no other human community, among the unpopulated and largely unnamed oceans. Thus, as well as being geographical places by being named, they are also not places by virtue of being unfixed. Two scholars in particular discuss this. Relph (1976) talks of the concept of "placelessness", a process by which place is experienced "inauthentically" by the concept of "kitsch" - an uncritical acceptance of presented values. Augé (1992) discusses the concept of non-place (non-lièges), anthropological spaces of transience. One of the participants said that she

couldn't think of anything better than seeing some of my favourite bands in the middle of the ocean with people who loved them as well. And cocktails.

This simultaneous duality of place means that ships can be engaged with by festival participants, but the focus is turned inward towards the festival, because there is no "outside" with which to engage.

\section{The festivals}

The experience of a cruise festival falls well within a Pine and Gilmore experience. It is clearly themed according to the focus of the festival. Theme nights are incorporated into the event. Musical memorabilia and souvenirs are available onboard, photos are taken by ship photographers and participants, and autograph seekers are catered to. All five traditional senses are engaged almost to the point of sensory overload. Moreover, the careful planning of the festival and the inclusion of the four realms of the experience place it very close to the sought-after sweet spot.

Because of the careful and experiential planning of the festival, the generation of belongingness and communitas is particularly strong in these oceanborne festivals. Festival planners purposely design it to be so. Music festivals 
often generate communitas of their own accord, but by hosting a music festival on a ship, the festival has no distracting geographical place outside the festival to distract from the actual festival. Participants noted that the environment of the ship was more amenable to the construction of friendship. As one participant forthrightly put it:

Holy fucking shit! A cruise ship is the optimal environment for a music festival. First off, you're safe: there's a doctor on board and tons of staff that care about your well-being. If you're feeling sick, you can go back to your cabin and rest. If you're hungry, you can walk five minutes and grab free food. If you're dehydrated, you go to a water station and grab a glass of water. Outdoor festivals have none of those things, and if they have those things, they're expensive, inconvenient, or difficult to access. A cruise ship is so, so insanely safe. A cruise ship is also great for noise concerns. No complaints from local residents or police, because you're on an ocean. A cruise ship festival is also all-inclusive. You never have to worry about getting back to your hotel, or finding food, or making public transportation before the show ends. Everything exists on the cruise ship, and it's incredibly peaceful.

The temporary inhabitants of the liminal space within a cruise ship are encouraged to "dress differently, eat and drink differently, sleep differently, act differently, play differently, and feel differently" (Yarnal \& Kerstetter, 2005: 370). Festivalgoers certainly do all these things. They undertake fancy dress, outfitting themselves as giant pigs or pieces of fruit, or jockeys astride a horse. They consume large quantities of alcohol and excellent food. They stay up until the bands stop playing and wake late to do it all again. One participant described it as

the most atypical experience of my life. I'd wake up at 1PM, crawl to the buffet and snag a disgusting amount of pizza and return to my room. Chill out with the boyfriend, chill out with friends, and just enjoy the time on the boat. Then, an event would start around 5PM, and we'd check that out. With great music starting at 6PM, we'd party for a few hours, grab some food, party, grab some food, and repeat all of that until 5AM. Also scattered throughout there: drinking heavily, costume changes, twerking, and generally weird stuff.

Festivalgoers act, feel, and play completely differently to how they do on land.

Fans are also likely to engage with star performers at a cruise festival. Musicians are encapsulated in the festival experience, enclosed in a placeless space for the duration of the cruise rather than being whisked away at the end of their show; the band that fans saw onstage one night is lining up at the breakfast buffet the next morning. One attendee reported having 


\section{David Cashman}

dinner with Ed Robertson, lead singer, guitarist, and songwriter of Barenaked Ladies. Another guest recounted that

Wintersun's first performance in the indoor arena . . . brought me to tears, it was so technically brilliant. Here I was, the mother, crying in the pit. I got to tell Jari [Mäenpää, singer and guitarist] that too and he was touched. He took my hand and put it on his heart and said "That means so much to me. Thank you".

These encounters are described as "parasocial" by Horton and Wohl (1956). This term describes the relationship of fans to stars that is seemingly intimate but actually mediated by television, radio, or the distance of the performance hall. Certainly this relationship is mediated; an interviewed festival organizer revealed that in many festivals, mingling with the guests was written into musicians' contracts. However, to participants, it seems natural and authentic. One respondent recounted

sitting around in a hallway with members of Collective Soul, other bands and other fans singing oldies while someone played guitar. The chance to sit next to my favourite rock stars and sing songs was a dream come true.

I am not suggesting that artists do not react genuinely to fan encounters; clearly they do. However, fan-artist meetings in a fabricated and hyperreal space that neither can escape from, and in a system that mandates interactions between the two groups, is a hyperreal encounter. By promoting and managing parasocial encounters between star performers and festivalgoers, organizers create an unusual level of intimacy between the two groups in the pursuit for the construction of belongingness.

A further level of belongingness is manifest in the construction of "ship family", usually abbreviated to "ship fam". After the music, participants regarded the family-like intimacy within the festival participants as of great import. Many festivalgoers that met on the ship, or perhaps shared a cabin, maintained contact between festivals by meeting for concerts (if possible), or through social media. One festivalgoer reported,

With the ship-based festivals, you are on the boat with all these people. You may not see them all, but they're there and you can run into random people and know you'll see them at some other point. I think there's a stronger camaraderie with the ship-based festivals.

Festivalgoers contrasted the more intense sense of belonging in a cruise festival and the relative anonymity of a larger festival. One participant noted:

I think I'm getting a bit too old for regular music festivals. By the time the boat party was over, everybody knew each other. Everybody was 
friends on the boat whereas you don't really get that at land-based music festivals anymore. Obviously it was a lot smaller, so there was only about 2.000 people on the boat as well. So after being on there for four or five days you kind of knew everyone's faces.

\section{Implications and concluding remarks}

As with hyperreal tourism products, there is a disconnect between fabrication and authenticity in cruise festivals. On the one hand, the festival occurs in an entirely fabricated and hyperreal geography. Encounters between fans and star performers are managed and constructed. The relationships between festivalgoers and between festivalgoers and star performers are temporary and parasocial. Yet the experience is perceived as "real" and "authentic". Fans (and potentially musicians) feel that these temporary relationships are real enough to call each other "family". Festivalgoers seemingly "belong", but there is no place and no one to belong to.

Belongingness and connectedness are key to tourism. Many scholars (such as Cohen, 1979; Crompton, 1979; Dann, 1977; Pearce, 1993) have written on how tourism enhances family and connectedness. However, increasingly, tourists are using different methods to achieve a sense of belonging (Gössling et al., 2016; Krohn, 2012). The production companies that run these festivals are well aware of the importance of the sense of belonging and connectedness to the financial and aesthetic success of cruise festivals. They do whatever they can to ensure that festivalgoers achieve this. They mandate interaction between fans and musicians. They purposely construct a liminal space that is separate from everyday space, where festivalgoers undertake unusual activities such as dressing up in wild costumes, undertaking cheesy cruise ship events, and partying non-stop from $10 \mathrm{AM}$ until 4 AM.

Cruise music festivals construct a facsimile of belongingness so guests will feel engaged and empowered by the temporary society of the festival. This becomes obvious upon a consideration of Lee and Robbins' (1995) three aspects of belongingness: companionship, affiliation, and connectedness. Companionship (the relationship with close family) is overtly fabricated by the employment of terms such as "ship fam" and "family" by both festivalgoers, organizers, and star performers throughout the festival. Festivalgoers spoke constantly of their ship family during interviews. Affiliation (peer relations while growing up) is fabricated by the performance of music from the youth of participants: the median ages of festivalgoers on The Rock Boat were 36-40, metal festivals were 31-35, and EDM festivals were 21-25. The engagement of music from their youth (even if that was just a few years ago) allows festivalgoers to regress into this time and, by proxy, their fellow festivalgoers become their teenage peers. The additional engagement of childish and unrestrained behaviour adds to this feeling of temporal disconnect. Finally, connectedness (the adult feelings of being "human among humans") 
is created by the proximity of humans sharing an intensely sensory experience on the dance floor, while eating, while engaging in hero worship, and the other aspects of the festival. It is hard to get away from other humans while attending the festival. The resulting belongingness is, in a way, hyperreal and facsimile, a fabrication and construction of real belongingness. Yet it feels very real to the participants.

The net result of this fabricated belongingness is repeat visits: an annual pilgrimage - a term Turner may have found interesting - to attend the festival next year with fellow "ship fam". Slightly more than two-thirds of the sample attended more than one cruise festival, with the average being five festival attendances. One respondent reported attending 14 festivals. Belongingness, while it creates an engaging and memorable festival experience, also ensures the financial viability of the festival. Some festivals, among them Holy Ship!, are now so successful they are having to schedule multiple annual sailings.

By holding festivals on a placeless cruise ship, by managing star/fan interaction, and by creating a strong sense of communitas, cruise festival organizers tap into the need for people to belong to a community. In this case, it is a community brought together by love of a genre of music or of a particular artist. Perceived as authentic and real, this sense of belonging occurs in a fabricated and hyperreal fashion in a fabricated and hyperreal environment. Participants are regarded as "family", yet they are almost all strangers brought together perhaps once, perhaps annually. The entire tourist experience is a temporary and ephemeral community lasting only a few days before scattering across the world. Yet this managed belongingness is seductive and personal. It creates festivals that are financially and aesthetically successful, encounters that are fabricated but perceived as genuine, and tourist experiences that are memorable. Despite the disconnect between the authenticity of the experience and the manufactured and fabricated reality, the festivalgoers do not complain. And they will return next year.

\section{Bibliography}

Arcodia, C. \& Robb, A. (2000). A future for event management: A taxonomy of event management terms. Events beyond 2000: Setting the agenda: Proceedings of conference on event evaluation, research and education, 154-160. Sydney, Australia.

Arcodia, C. \& Whitford, M. (2006). Festival attendance and the development of social capital. Journal of Convention \& Event Tourism 8(2): 37-41.

Augé, M. (1992). Non-lieux: Introduction à une anthropologie de la surmodernité. La librairie du XXe siècle. Paris: Seuil.

Baudrillard, J. (1994). Simulacra and simulation (S.F. Glaser, Trans.). Ann Arbor: University of Michigan Press.

Baumeister, R.F. \& Leary, M.R. (1995). The need to belong: Desire for interpersonal attachments as a fundamental human motivation. Psychological Bulletin 117(3): 497-529. 
Becker, B. (2006, October). Onboard revenue takes centre stage. International Cruise and Ferry Review: 17-18.

Bitner, M.J. (1992). Servicescapes: The impact of physical surroundings on customers and employees. Journal of Marketing 56: 57-71.

Clancy, M. (2017). Power and profits in the global cruise industry. In: R. Dowling \& C. Weeden (eds.), Cruise ship tourism, 2nd ed, pp. 43-56. Oxford: CABI.

Cohen, E. (1979). A phenomenology of tourist experiences. Sociology 13(2): 179-201.

Cohen, E. (2004). Tourism and gastronomy. Annals of Tourism Research 31(3): 731-733.

Connell, J. \& Gibson, C. (2003). Sound tracks: Popular music identity and place. London: Routledge.

Crompton, J.L. (1979). Motivations for pleasure vacation. Annals of Tourism Research 6(4): 408-424.

Cruise Line International Association. (2016). 2017 cruise industry outlook. Press Conference Presentation. Retrieved from www.cruising.org/docs/default-source/ research/clia-2017-state-of-the-industry.pdf.

Dann, G. (1977). Anomie, ego-enhancement and tourism. Annals of Tourism Research 4(4): 184-194.

Dann, G. \& Jacobsen, J.K.S. (2003). Tourism smellscapes. Tourism Geographies 5(1): 3-25.

De Bres, K. \& Davis, J. (2001). Celebrating group and place identity: A case study of a new regional festival. Tourism Geographies 3(3): 326-337.

Derrett, R. (2003). Making sense of how festivals demonstrate a community's sense of place. Event Management 8(1): 49-58.

Duffy, M., Waitt, G., Gorman-Murray, A. \& Gibson, C. (2011). Bodily rhythms: Corporeal capacities to engage with festival spaces. Emotion, Space and Society 4(1): 17-24.

Eco, U. (1987). Travels in hyperreality. London: Pan Books.

Falassi, A. (1987). Festival: Definition and morphology. In: A. Falassi (ed.), Time out of time: Essays on the festival, pp. 1-10. Albuquerque: University of New Mexico Press.

Feifer, M. (1985). Going places: The ways of the tourist from imperial Rome to the present day. London: MacMillan London Limited.

Franklin, A. (2001). The tourist gaze and beyond: An interview with John Urry. Tourist Studies 1(2): 115-131.

Franklin, A. (2003). Tourism: An introduction. London: Sage.

Getz, D. (2010). The nature and scope of festival studies. International Journal of Event Management Research 5(1): 1-47.

Gillespie, A. (2006). Tourist photography and the reverse gaze. Ethos 34(3): 343-366.

Gössling, S., Cohen, S.A. \& Hibbert, J.F. (2016). Tourism as connectedness. Current Issues in Tourism 21(14): 1586-1600.

Gottschalk, S. \& Salvaggio, M. (2015). Stuck inside of mobile: Ethnography in nonplaces. Journal of Contemporary Ethnography 44(1): 3-33.

Horton, D. \& Wohl, R.R. (1956). Mass communication and para-social interaction: Observations on intimacy at a distance. Psychiatry 19(3): 215-229.

Hosany, S. \& Witham, M. (2010). Dimensions of cruisers' experiences, satisfaction, and intention to recommend. Journal of Travel Research 49(3): 351-364.

Huang, J. \& Hsu, C.H.C. (2009). Interaction among fellow cruise passengers: Diverse experiences and impacts. Journal of Travel and Tourism Marketing 26(56): 547-567. 


\section{David Cashman}

Hung, K. \& Petrick, J.F. (2011). Why do you cruise? Exploring the motivations for taking cruise holidays, and the construction of a cruising motivation scale. Tourism Management 32(2): 386-393.

Jaakson, R. (2004). Beyond the tourist bubble? Cruise ship passengers in port. Annals of Tourism Research 31(1): 44-60.

Jakob, D. (2013). The eventification of place: Urban development and experience consumption in Berlin and New York City. European Urban and Regional Studies 20(4): 447-459.

Kivela, J. \& Crotts, J.C. (2006). Tourism and gastronomy: Gastronomy's influence on how tourists experience a destination. Journal of Hospitality and Tourism Research 30(3): 354-377.

Kohut, H. (1971). The analysis of the self. New York: International Universities Press.

Krohn, B.D. (2012). Social motivations for attending in event tourism. Athens Tourism Symposium. Athens, Greece.

Kulhanek, I. (2012). Hyperreality in post-tourism: An analysis of fun, space and the experience of "hyperreality" aboard Carnival's cruise ships. MA thesis. Vienna: Universität Wien.

Kwortnik, R.J. (2008). Shipscape influence on the leisure cruise experience. International Journal of Culture, Tourism and Hospitality Research 2(4): 289-311.

Lau, C.Y.L. \& Li, Y. (2015). Producing a sense of meaningful place: Evidence from a cultural festival in Hong Kong. Journal of Tourism and Cultural Change 13(1): 56-77.

Lee, R.M. \& Robbins, S.B. (1995). Measuring belongingness: The social connectedness and the social assurance scales. Journal of Counseling Psychology 42(2): 232-241.

MacLeod, N.E. (2006). The placeless festival: Identity and place in the post-modern festival. In: D. Picard \& M. Robinson (eds.), Festivals, tourism and social change: Remaking worlds, pp. 222-237. Clevedon: Channel View Publications.

Maffesoli, M. (1996). The time of the tribes. London: Sage.

Maffesoli, M. \& Foulkes, C.R. (1988). Jeux de masques: Postmodern tribalism. Design Issues 4(1-2): 141.

McClinchey, K.A. \& Carmichael, B.A. (2010). The role and meaning of place in cultural festival visitor experiences. In: M. Morgan, P. Lugosi \& J.R. Brent Ritchie (eds.), The tourism and leisure experience: Consumer and managerial perspectives, pp. 59-80. Clevedon: Channel View Publications.

Parasuraman, A., Berry, L.L. \& Zeithaml, V.A. (1991). Refinement and reassessment of the SERQUAL scale. Journal of Retailing 67(4): 420-450.

Parasuraman, A., Zeithaml, V.A. \& Berry, L.L. (1985). A conceptual model of service quality and its implications for future research. Journal of Marketing 49(4): 41-50.

Parasuraman, A., Zeithaml, V.A. \& Berry, L.L. (1988). SERVQUAL: A multiple-item scale for measuring consumer perceptions of service quality. Journal of Retailing 64(1): 12-40.

Patton, M.J., Connor, G.E. \& Scott, K.J. (1982). Kohut's psychology of the self: Theory and measures of counselling outcome. Journal of Counseling Psychology 29(3): 268-282.

Pearce, P.L. (1993). Fundamentals of tourist motivation. In: R.W. Butler \& D.G. Pearce (eds.), Tourism research: Critiques and challenges, pp. 85-105. London: Routledge. 
Pieper, J. (1965). In tune with the world: A theory of festivity. New York: Harcourt Brace.

Pine, J. \& Gilmore, J. (1998). Welcome to the experience economy. Harvard Business Review 76(4): 97-105.

Pine, J. \& Gilmore, J. (1999). The experience economy: Work is theater \& every business a stage. Boston: Harvard Business School Press.

Pine, J. \& Gilmore, J. (2011). The experience economy. Boston: Harvard Business Review Press.

Quinn, B. (2003). Symbols, practices and myth-making: Cultural perspectives on the Wexford Festival Opera. Tourism Geographies 5(3): 329-349.

Relph, E.C. (1976). Place and placelessness. London: Pion.

Richards, G. (2002). Gastronomy: An essential ingredient in tourism production and consumption? In: A. Hjalager \& G. Richards (eds.), Tourism and gastronomy, pp. 3-20. London: Routledge.

Rutherdale, R. (2008). Canada's August Festival: Communitas, liminality, and social memory. Canadian Historical Review 77(2): 221-249.

Turner, V. (1969). The ritual process: Structure an antistructure. Ithaca: Cornell University Press.

Turner, V. (1974). Pilgrimage and communitas. Studia Missionalia 23: 305-327.

Urry, J. (1990). The tourist gaze. London: Sage.

Urry, J. (2008). Globalising the tourist gaze. In: Tourism development revisited: Concepts, issues and paradigms, pp. 150-160. London: Sage.

Urry, J. \& Larsen, J. (2011). The tourist gaze 3.0. London: Sage.

van Heerden, E. (2009). Liminality, transformation and communitas: Afrikaans identities as viewed through the lens of south African arts festivals: 1995 - 2006. DPhil dissertation. Stellenbosch: University of Stellenbosch.

Vogel, M.P. (2004). Kreuzfahrt: Reisen im dreifachen kokon. Am Bord 5: 17-20.

Vogel, M.P. (2017). Economics of cruise shipping: The need for a new business model. In: R.K. Dowling \& C. Weeden (eds.), Cruise ship tourism, 2nd ed, pp. 124-137. Wallingford: CABI.

Vogel, M.P. \& Oschmann, C. (2013). Cruising through liquid modernity. Tourist Studies 13(1): 62-80.

Wang, N. (1999). Rethinking authenticity in tourism experience. Annals of Tourism Research 26(2): 349-370.

Weaver, A. (2005). Spaces of containment and revenue capture: 'Super-sized' cruise ships as mobile tourism enclaves. Tourism Geographies 7(2): 165-184.

Williams, A. (2012). Understanding the hospitality consumer. Oxford: ButterworthHeinemann.

Yarnal, C.M. \& Kerstetter, D. (2005). Casting off: An exploration of cruise ship space group tour behaviour, and social interaction. Journal of Travel Research 43(4): 368-379. 
$\because$ Taylor \& Francis

Taylor \& Francis Group

http://taylorandfrancis.com 


\section{Part IV}

Returning home

Memory and belonging 
$\because$ Taylor \& Francis

Taylor \& Francis Group

http://taylorandfrancis.com 


\title{
15 Strange spaces of mediated memory The complicating influence of Roots on heritage tourism in The Gambia, West Africa
}

\author{
Jason Grek-Martin
}

\section{Introduction}

Early in the spring of 1750, in the village of Juffure, four days up-river from the coast of The Gambia, West Africa, a man-child was born to Omoro and Binta Kinte.

- Alex Haley, Roots (1979)

So begins Roots: The Saga of an American Family (1976), one of the most culturally significant literary works of the 20th century. The product of 12 years of research on three continents, Roots was more than a novel. For author Alex Haley, the book was a work of "faction" (Delmont, 2016), a genealogical narrative that blended documented facts with fictional details to tell the compelling story of his maternal ancestors' multigenerational struggles with slavery and its aftermath. Much of the narrative focuses on Kunta Kinte, whose birth is recorded in the first line of Roots and whom Haley would identify by book's end as his own great, great, great, great grandfather. Haley's opening line also irrevocably bound Africa's smallest mainland nation to the Roots phenomenon. By devoting the book's first 32 chapters to a detailed depiction of young Kunta Kinte's life in Juffure, Haley ensured that Roots readers had an extended imaginative encounter with an actual village in an actual West African nation. As a result, visitors to The Gambia have long been encouraged to follow in Haley's footsteps and visit the real Juffure in order to experience first-hand the fabled land of Roots.

Yet the Roots connection is not the region's only draw. Situated in the middle of the River Gambia's broad estuary, within sight of Juffure, James Island has long attracted heritage tourists to explore the ruined fort that served for several centuries as a vital defensive stronghold and active transshipment point for the British slave trade before becoming an early bulwark against that trade after the British outlawed the practice in 1807. This multifaceted historical significance was prominently acknowledged in 2003 when UNESCO collectively inscribed James Island and six other heritage structures in the region as The Gambia's first World Heritage Site (UNESCO, n.d.-a). Not long after, however, James Island was targeted by the Gambian 
government in a plan to further entrench the Roots legacy in this heritage district. During a high-profile ceremony at the site in 2011, Gambian Vice President Isatou Njie-Saidy explained that the time had come to give James Island a new name, honouring a more worthy figure: "the island . . . will henceforth be called Kunta Kinteh Island, ${ }^{1}$ to keep alive of course the memory of this great symbol of resistance, bravery and the resilient spirit of the African person" (Mendy, 2015: 22-51). This act of renaming reflected Kunta Kinte's stature as both a favoured native son and, thanks to Roots, the human face of slavery for millions, making his name doubly resonant in this prominent place of Gambian heritage. UNESCO soon endorsed the name change (UNESCO, n.d.-b), and two distinct worlds became officially intertwined at these Gambian heritage sites: a UNESCO-inscribed World Heritage-scape (Di Giovine, 2008) associated with the long and difficult history of the trans-Atlantic slave trade and the quasi-fictional land of Roots made famous by Alex Haley.

The fascinating relationship between these overlapping heritage/media landscapes had captured my imagination during previous visits to The Gambia and was on my mind once more in the autumn of 2015, as I prepared to lead a dozen undergraduate students on a geography field course to the country. After learning that none of my students were familiar with Roots, I designed a modest and rather experimental research project to investigate the relationship between heritage and media tourism at these sites. Recruiting my students as voluntary research participants, I divided them into two nearly equal groups: "Non-Readers" were asked to refrain from reading (or watching) Roots ahead of our trip; "Readers", meanwhile, were asked to work through at least the opening 250 pages of the book, covering Kunta Kinte's first 17 years in Juffure as well as his eventual capture and transport to America. Following Haley's lead, I framed Roots as a work of creative non-fiction, purposefully avoiding any mention of the numerous questions that have emerged about the book's veracity since its release (Delmont, 2016). With this groundwork established, our group visited Kunta Kinteh Island and several heritage sites in and around Juffure during a day-long excursion near the end of the field course. Upon our return to Canada, I conducted a series of interviews to learn whether my participants considered the Roots narrative a prominent feature of these heritage sites and whether knowing a key component of that narrative in advance made these sites more comprehensible and resonant for Readers in comparison to Non-Readers. Ultimately, my goal was to determine whether my participants felt that the Roots narrative complemented or complicated the UNESCO-endorsed heritage narratives at these sites.

\section{Strange spaces of memory and imagination}

As we shall see, many of my Readers, especially, were confused and frustrated by what they saw and heard that day, suggesting that they experienced 
these Gambian heritage sites as "strange spaces": highly mediated sites that leave visitors feeling bewildered and out of place because of the "interpretive conflict" they generate (Jansson \& Lagerkvist, 2009: 2). As Jansson (2002) asserts, we are increasingly immersed in mediascapes, "the multitude of mediated texts surrounding people in their everyday lives - television programmes, magazines, advertisements, postcards and so on," which provide us with "both realistic and phantasmagorical visions of the world" (ibid: 432). These representations shape our sense of place in especially potent ways when we travel, since we are apt to consume an abundance of media about our chosen destination prior to departure. As a result, it becomes increasingly difficult to distinguish representation from reality, and traditional notions of authenticity rooted in the lived history of a place give way to a more relativistic "symbolic authenticity" (Wang, 1999), defined by how well the destination conforms to the tourist's preconceived and highly mediated expectations about what they will experience during their visit (Jansson, 2002: 439; see also Chapter 17 of this volume). This muddling of reality and representation can transform travel destinations into strange spaces: "the harbours of interlaced dreams and memories - heterotopian spaces of discontinuities, disproportions and dislocations," marked by "the co-existence [emphasis added] of familiar and phantasmagorical elements" (Jansson \& Lagerkvist, 2009: 10).

This ability of strange spaces to simultaneously evoke memories and dreams, the familiar and the phantasmagorical, resonates with Reijnders' (2011) analyses of media tourism: the spectrum of travel targeting real-world sites associated with popular culture (ibid: 4-5). Reijnders adapts Nora's concept of lieux de mémoire - heritage sites designed to instil and perpetuate collective memory to assess what he calls lieux d'imagination: "physical locations, which serve as a symbolic anchor for the collective imagination of society" (Reijnders, 2011: 8). ${ }^{2}$ Nora (1996) suggests that our collective sense of historical continuity and equilibrium has been disrupted in the modern age, resulting in a mounting quest to create and venerate "places in which memory is crystallized". Museums, archives, monuments, cemeteries, heritage properties - such sites of memory constitute complex combinations of the material, the symbolic, and the functional, "partly official and institutional, partly affective and sentimental," which provide a "residual sense of continuity" with the past (ibid: 1, 7, 14). As Reijnders notes, such sites of memory reflect our inherently "topophilic" disposition (Tuan, 1974), which compels us to create "places which can function as symbolic moorings in a turbulent world" for intangible yet deeply felt phenomena (Reijnders, 2011: 13).

Of course, the fictional worlds we embrace through popular media can also be linked to real-world places of the imagination, "which for certain groups within society serve as material-symbolic references to a common imaginary world" (Reijnders, 2011: 14). This geographical linking of the familiar to the phantasmagorical is a logical outgrowth of the fact that many cultural producers make overt reference to actual places in order to lend 
their fictional narratives greater verisimilitude. At the same time, numerous travel destinations have eagerly promoted themselves as celebrated places of the imagination to garner tourist dollars (Reijnders, 2011: 17-18). In both cases, the blending of the imagined and the real has considerable power to attract visitors. Such sites allow some media tourists to escape into their imagination - to take a holiday within a beloved story; for others, the point of the visit is to playfully (re)construct and negotiate the boundary between the real and the imagined (Reijnders, 2011: 51, 92).

Considering Reijnders' places of the imagination as a media-driven analogue to Nora's sites of memory raises an interesting question: what differentiates collective memory from collective imagination? Collective memories - especially those that operate beyond the local scale and the realm of lived experience may simply be another form of imagination, albeit one primarily focused on the documented past. While the imagination that animates media tourism can also look to recorded history for inspiration, it additionally encompasses fantastical realms frequently set in some alternative past, parallel, diegetic worlds of today and fictional projections into near and distant futures (Reijnders, 2011: 14). In effect, we might consider Nora's sites of memory to be a particular kind of place of the imagination, albeit one that draws on different forms of authenticating source materials, evinces different narratives concerning the meaning and significance of the site, and perhaps attracts quite different types of visitors.

But what happens when the same destination serves as both a site of memory and a place of the imagination? There are numerous heritage sites that draw on the historical record to "crystallize memory" in ways envisioned by Nora but which also function as a "material-symbolic reference" to fictional worlds embedded in our collective imagination, as discussed by Reijnders. To take one example, two recent releases in the Star Wars film franchise included a number of scenes shot amidst the ruins of the 7th-century monastery on the Irish island of Skellig Michael. As a result, the island has received increasing attention from media tourists, raising important concerns about ecological sustainability and cultural authenticity at this UNESCO World Heritage Site (Allen \& Lennon, 2018).

As this example suggests, it is important to consider how heritage dissonance is likely to manifest at such overlapping sites of memory and imagination. As Tunbridge and Ashworth assert, heritage dissonance can take many forms, including incongruent or contradictory transmissions generated at the same site or between related sites (Tunbridge \& Ashworth, 1996: 28). Dissonance can also stem from the presentation of heritage narratives that some visitors may find distasteful, distressing, or inflammatory, particularly those emanating from destinations associated with past conflicts, tragedies, and atrocities (Tunbridge \& Ashworth, 1996: 29). Visiting such destinations - including numerous sites connected to the trans-Atlantic slave trade - is increasingly framed as "dark tourism", which focuses on "the act of travel to sites associated with death, suffering and the seemingly macabre" (Stone, 2006: 146). 
Crucially, as considerable dark tourism scholarship reveals, sites associated with tragedy and death are especially likely to function as both sites of memory and places of the imagination (Ashworth \& Hartmann, 2005; Dann, 2005; Lennon \& Foley, 2000; Seaton, 1996; Stone, 2013; Walter, 2009; Wight, 2009). After all, major tragic events often receive widespread media coverage, in some cases followed by a series of (quasi-)fictional treatments of the tragic story across a number of media platforms, including fiction and non-fiction writing, television, documentaries, feature films, popular songs, and more. As a result, sites of memory that commemorate actual tragedies can also attract media tourists for whom the fictionalized accounts of these dark events provide the predominant impetus for visiting. As Strange and Kempa (2003) have suggested in their analysis of Alcatraz Island, widespread public fascination with highly mediated sites of trauma and tragedy can pose significant interpretive challenges for "memory managers," who often "struggle to set the record straight" when confronted with tourist expectations shaped by myriad "cultural files of sound, images and stirring plots” (Strange \& Kempa, 2003: 399).

Drawing on these insights, this study constitutes a preliminary attempt to trace the contours of a particular form of heritage dissonance, which I propose arises when "darker" sites of memory (in this case, Gambian heritage sites associated with the tragic history of the trans-Atlantic slave trade) intersect with places of the imagination (in this case, a literary landscape associated with Roots), producing strange spaces of mediated memory. Before turning to my case study, however, I need to expand on the impact of Haley's celebrated magnum opus, in order to better contextualize the potential risks and rewards the Roots narrative offers to the "memory managers" at these Gambian heritage sites.

\section{The Roots phenomenon}

Upon its 1976 release, Roots became an instant sensation, spending 22 weeks atop the New York Times bestseller list and winning a special Pulitzer Prize. In addition, the eight-part television mini-series adaptation became a landmark in broadcasting history upon airing in January 1977, attracting record-breaking audiences and winning nine Emmy Awards. Additional television adaptations followed in 1979, 1988, and 2016, demonstrating the remarkable staying power of the Roots franchise.

The success of Roots can be attributed to several factors. First, it offered a widely accessible and compelling narrative of perseverance and eventual triumph in the face of substantial adversity. Crucially, Roots also put a human face on the pernicious institution of slavery, providing enough specific details to give the story purchase while speaking to the universal traumas endured by the ancestors of millions of African Americans. The timing of Roots was also fortuitous: in 1976, the enduring legacy of the Civil Rights Movement, the rise of Black History programs at a number of universities, and the 
national mood of commemoration surrounding the American Bicentennial all provided the fertile cultural soil in which Roots took root. The final, vital ingredient was that Haley had seemingly achieved the impossible: he had undone the erasures of slavery and traced his own family lineage two centuries into the past, back to a specific ancestor living in a specific village in West Africa (Athey, 1999; Delmont, 2016). At the same time, Haley's rich and detailed descriptions of Juffure provided American popular culture with some of its first positive depictions of traditional African life, fuelling the place-based imaginations of millions of readers and viewers (see Chapter 5 of this volume).

Yet a number of controversies soon began to swirl around Roots. Two plagiarism suits were filed soon after publication and, while one was dismissed, Haley was forced to settle the other out of court (Delmont, 2016). Soon thereafter, a pair of American genealogists cast doubt on several key details pertaining to Haley's account of his pre-Civil War family history (Mills \& Mills, 1984). Meanwhile, a British journalist returned from The Gambia with serious questions concerning the credibility of the "griot" who had supplied Haley with much of his information during a 1967 research trip to Juffure. This reporting challenged the pivotal ancestral link between Haley and Kunta Kinte, even casting doubt on whether an individual by that name had actually existed in Juffure during the period in question (Ottaway, 1977). Finally, a number of scholars took issue with Haley's idyllic depiction of Juffure and his simplistic characterization of the slave trade in this region at the time of Kinte's capture, further casting doubt on the story's veracity (Blayney, 1986; Courlander, 1986; Delmont, 2016; Gamble, 2000; Wright, 2011).

These controversies undoubtedly tarnished the work's standing among historians, literary critics, and certain segments of the public. Still, for many, while Haley's facts could be questioned, the overarching truth of his story remained intact. As one commentator argued, "although poor in historical accuracy, Roots is indeed so rich in rhetorical and symbolical power that in the 1970s it started a new dialogue about black families in the United States and created a greater and expanding curiosity about one's ancestry" (Bordin, 2014: 7-8). Roots indeed sparked a notable surge in genealogy (Athey, 1999; Delmont, 2016) while also prompting numerous African Americans to travel in search of their heritage, initiating a pronounced wave of "roots tourism" to sites connected to the trans-Atlantic slave trade (de Santana Pinho, 2008; Mensah, 2015; Mowatt \& Chancellor, 2011).

Surprisingly, despite the story's overt connection to Juffure, The Gambia had only limited success in its early attempts to capitalize on the Roots phenomenon (Gijanto, 2011; Bellagamba, 2009). In 1996, the National Council for Arts and Culture (NCAC) specifically targeted African American diaspora tourists by launching the inaugural Roots Homecoming Festival, which culminated in an emotional pilgrimage to Juffure and James Island (Gijanto, 2011; Bellagamba, 2009). Now known as the International Roots Festival, this biennial celebration has had some success in attracting roots tourists 
over the last two decades. Yet, beyond these occasional festivals, the promise of a Roots-centred diasporic tourism industry has never fully materialized. As a result, these sites are now predominantly marketed to northern European beach holiday-goers as an enriching day trip providing escape from the familiar tourist bubble enveloping the coastal resorts.

\section{Visiting the land of Roots}

Our own heritage excursion came at the end of the 2015 field course, following more than a week of intensive, environmentally focused programming throughout The Gambia. To reach these sites, we travelled by boat from the south bank village of Brefet, stopping first at Kunta Kinteh Island (see Figure 15.1). After an hour-long tour of the island, we crossed to the river's north bank to explore the adjacent villages of Albreda and Juffure, home to several UNESCO-inscribed heritage sites built by the Portuguese, French, and British over a period of 300 years. Only a few of these structures remain intact, most notably the Maurel Frères Building in Juffure - a former British warehouse that the NCAC transformed into the modest but compelling Museum of the Slave Trade in 1996 (Bellagamba, 2009). We spent nearly two hours

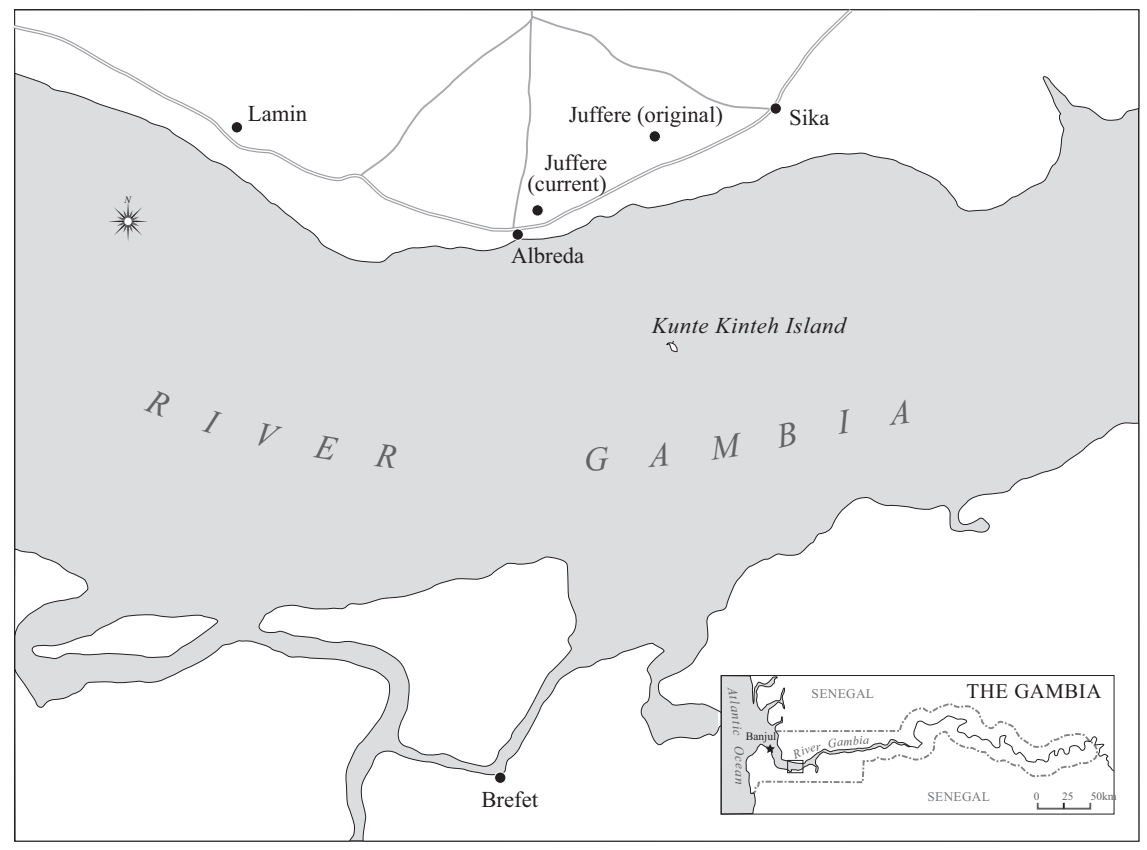

Figure 15.1 Kunta Kinteh Island and vicinity.

Source: Map created by Jennifer Grek-Martin for author. 


\section{Jason Grek-Martin}

exploring the museum and its surroundings before re-boarding our pirogue and returning to Brefet.

After the field course was completed, I conducted open-ended, semistructured interviews with each of my 12 undergraduate student participants, followed by a group interview with 8 of my participants. My participants were mostly female (10 of 12 ) and predominantly Canadians of European ancestry, although I did have two international students with African ancestry: one from the Caribbean and one from West Africa. None of my students had visited The Gambia previously. Most were enrolled in geography or environmental studies/science programs, while some also had a background in international development studies. They ranged in age from 19 to 32 years old, and they varied considerably in terms of travel experience some had never left Canada prior to the field course, while others had spent extensive periods of time travelling abroad, including considerable time in developing countries. In the context of my study, five of my participants had volunteered to be Readers (assigned the first 250 pages of Roots, to be read prior to departure), all of whom were Canadian females between the ages of 19 and 32 years old. Six of my participants were Non-Readers, and this group consisted of two males and four females between 20 and 27 years of age, five of whom were Canadian. In addition, I interviewed one student who had elected not to take part in this excursion because, as someone with African ancestry, they had been understandably reluctant to visit a site that had a direct and tangible connection to the history of the trans-Atlantic slave trade - an important reminder that not all members of the African diaspora are keen to incur the emotional toll associated with roots tourism.

To avoid influencing my students' expectations, I was careful not to discuss Roots or provide any details about these heritage sites prior to our visit. As a result of these precautions, and in light of the natural rapport I was able to establish with these students over the course of an eventful and intensive trip, I feel confident that my participants' responses were candid and genuinely reflected their experiences that day. However, the narrow scope and experimental nature of my project mean that caution needs to be exercised when drawing conclusions from these interviews. Indeed, it is important to note that our group did not follow the standard tourist itinerary when visiting these heritage sites, which likely affected how they were experienced. In addition, my students came from diverse backgrounds, meaning that the expectations and perceptions that each participant brought to their experiences that day were undoubtedly shaped by many factors beyond their reading (or not) of Roots. Moreover, my Readers were assigned Roots rather than selecting the book out of interest, which may have influenced how they approached both the narrative itself and its connections to these heritage sites. Ultimately, given these factors, the findings that follow are intended to be suggestive rather than conclusive.

To begin, I asked my participants whether they felt that the Roots narrative had featured prominently at these Gambian heritage sites. The prevailing 
response was "no", which runs counter to recent scholarship asserting that the Roots narrative dominates these sites, often at the expense of official heritage narratives. For example, Gijanto (2011: 228) argues that while "multiple competing narratives are visible in the modern-day heritage landscape" centred on Juffure, "the Roots landscape . . . is recreated on a daily basis by local guides who are able to subvert the larger created heritage-scapes ... of UNESCO and the NCAC" (ibid: 234). Bellagamba (2009) paints a similar picture when she argues that the heavily promoted Roots narrative fills up the "historical imaginary" of tourists "without leaving room for alternative readings" of this region's complicated historical relationship with the transAtlantic slave trade (ibid: 465).

Yet, in contrast, my participants felt that our Gambian guides were actually quite reticent to directly engage with Haley's famous narrative. On Kunta Kinteh Island, our guide did not address the recent name change or make any reference to Roots beyond an obligatory name-check at the outset of the tour. Likewise, while the interpretive signs had been updated to reflect the new name, the rationale behind the renaming was not provided, and there was nothing that explicitly linked this place to Kinte himself. This clearly puzzled my students, with one noting:

I thought they'd actually mention Kunta Kinte a bit more than they did. I was kind of wondering, since I only read portions of the book, . . . what made this guy so special that he had an island named after him?

Nor did our guides make overt reference to Roots during our time in Albreda and Juffure. Notably, we were not directed to the Kinte family compound to pay our respects - a pilgrimage that both Bellagamba (2009) and Gijanto (2011) describe as a standard obligation for tourists visiting Juffure. Meanwhile, the name Kunta Kinte is nowhere mentioned in the Museum of the Slave Trade, which focuses instead on the documented history of slavery in the region. Indeed, the museum contained only a single, small display devoted to Alex Haley, which was rather inconspicuously integrated into a room full of photo-collages featuring prominent African Americans. Overall, then, the Roots narrative was strangely downplayed at each of the heritage sites we visited that day, despite the recent renaming of Kunta Kinteh Island and the ongoing cultural relevance of Roots in popular culture. Nonetheless, my Readers still found that their perceptions of these heritage sites were strongly imbued with the lingering traces of Roots, colouring their experiences on the island, in the villages, and at the museum that day.

\section{The Island}

Turning first to the island (Figure 15.2), I was curious how my participants experienced this place as a site of memory highlighting its role in the 


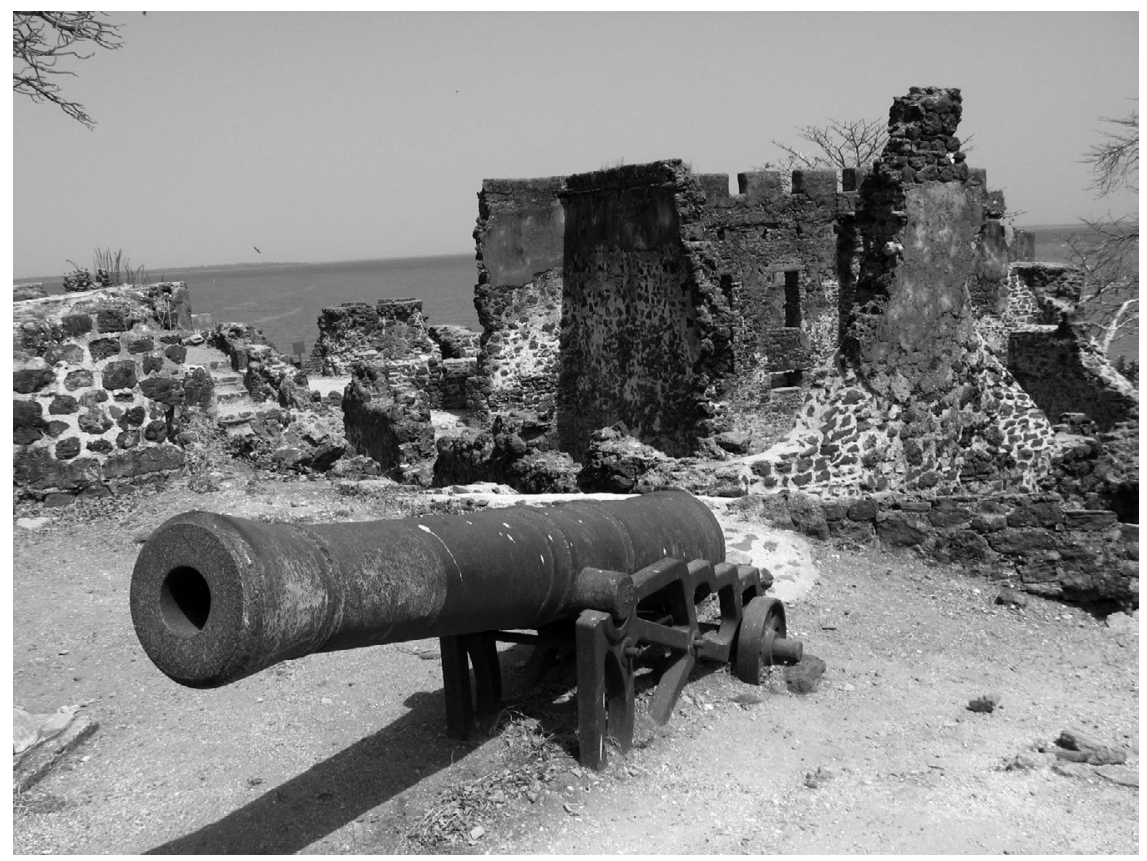

Figure 15.2 Ruined fortifications on Kunta Kinteh Island.

Source: Photo by author.

trans-Atlantic slave trade. Based on the responses I received, it was clear that many Non-Readers struggled to make sense of this narrative:

I was kind of feeling confused for most of it and I didn't really understand a lot of it. So, I was getting disappointed and I was getting frustrated because I was like, "oh, I should have known, I should have read, I should have, you know, had this previous knowledge so that it would be more meaningful".

This remark, echoed by other Non-Readers, indicates that the primary source of confusion was a general lack of background knowledge on the history of the slave trade rather than a specific lack of familiarity with Roots. Indeed, as one Reader noted, even fellow Readers were confused by their tour of this site:

[E]ven the people who had read Roots didn't really seem to have a solid appreciation of what the purpose of the fort was.

This observation was confirmed by several Readers during our group interview and proved reassuring to Non-Readers, who had presumed that the 
historical details they had struggled to grasp during the tour had been covered in the book. As a site of memory, then, all of my participants found the island to be strangely disappointing.

But what of its role as a place of the imagination? Did Kunta Kinteh Island resonate more strongly with Readers thanks to the Roots connection? Not really. The main point of contention was the fact that this island - recently renamed after the central character in Roots - was barely mentioned in the book. The only reference appears early on, as Kunta listens to his father tell the story of the journey he and his brothers had taken years before to spy on the great "toubab" (European) ships at anchor in the River Gambia. "Nearby was an island," the elder Kinte recalled, "and on the island was a fortress" (Haley, 2014: 75). Curiously, Haley does not mention the island at all during the brief but gripping account of Kunta Kinte's capture near Juffure and his short journey to the hold of the waiting slave ship, the Lord Ligonier. This omission generated considerable confusion for my Readers, who struggled to comprehend why the island had been renamed after a character who had never set foot upon it:

I was trying to find that [Roots] connection constantly ... trying to draw these specific connections to the places and then was confused why they weren't talking about Kunta Kinte and ... why the island was named that.

Another Reader was more cynical, wondering whether the name change was merely a re-branding exercise designed to attract more tourists:

On the one hand, you could consider it the reclaiming of a name that was colonial and, you know, getting rid of James Island, which is obviously an English name, and then taking this [name] Kunta Kinte, which is representative of Gambian people. I understand it from that perspective but I'm inclined to think that it was more of a tourism marketing tool in that they were trying to encourage people to come to the island because of Roots rather than to appreciate the history that took place there and to have kind of a solemn experience there.

Given the amount of confusion and mistrust the Roots connection generated for my Readers, it is clear that Haley's account fundamentally complicated what for them was an already problematic heritage narrative on Kunta Kinteh Island.

\section{The villages}

Further confusion arose when we crossed to the river's north bank to tour the adjacent villages of Albreda and Juffure. Despite the presence of several UNESCO heritage sites scattered around these villages, our tour guide offered only a perfunctory overview of the region's rich heritage from the central vantage point of the Albreda town square. This 
underwhelming interpretation was consistent with Gijanto's (2011) recent field observations, suggesting that the full commemorative significance of these sites of memory is no longer being effectively conveyed to visitors. Gijanto feels that such omissions are the result of Gambian tour guides privileging the Roots narrative instead but, again, this was not our experience.

We next left Albreda and entered Juffure proper - a place name that meant relatively little to Non-Readers but was full of significance for Readers, given that Haley had devoted 200 pages to Kunta Kinte's childhood home. In the book, Haley characterizes Juffure as a "small dusty village of round mud huts," situated some distance "inland" and at least three days' journey upriver "from the nearest place on the Kamby Bolongo [the River Gambia] where slaves were sold" (Haley, 2014: 1, 5, 72). Haley's Juffure was thus an isolated village, set back in the bush and well removed from the main slave-trading hub of James Island - an island, recall, that is fully visible from present-day Juffure. One of my Readers picked up on this locational discrepancy right away:

I was curious about whether Juffure, the town that we visited, was indeed the same Juffure that existed in the book? Because, in the book, it was described as being ... a little bit of a journey away from the river.

Another perplexed Reader wondered whether this Juffure was once known by another name or was simply the continuation of the neighbouring village of Albreda:

I question whether or not it even is the same Juffure or [whether] they just renamed some village Juffure so that people could go to Juffure because they were there for Roots tourism.

Thus, the locational discrepancy between Haley's village and the current village, coupled with the latter's all-too-convenient proximity to Kunta Kinteh Island and its undifferentiated continuity with Albreda, led some Readers to question the authenticity of the Juffure we visited that day.

In fact, Juffure had been moved to its current location long ago, well before Haley made his breakthrough research trip in 1967. Our group thus visited the same Juffure where Haley had met several living members of the Kinte clan and first heard the story of Kunta Kinte. It remains unclear precisely when this relocation occurred but, in truth, it matters little, since the original Juffure existed only a kilometre east, and slightly inland, of the village's current location. Moreover, records show that the British had established a trading house at Juffure by 1727 (Gijanto, 2011). Thus, by the time of Kunta Kinte's putative birth in 1750, the real Juffure was a sizeable settlement and pivotal trading centre, well integrated into Britain's triangular trade network, rather than the remote and idyllic village depicted in Roots - a misrepresentation noted by a number of critics (Delmont, 
2016; Gamble, 2000; Wright, 2011). Haley acknowledged the discrepancy but rationalized his decision as necessary myth-building: "I know Juffure was a British trading post and my portrait of the village bears no resemblance to the way it was. But ... I, we, need a place called Eden. My people need a Plymouth Rock" (Young, 1977, cited in Delmont, 2016: 189).

Unaware of Haley's mythopoetic aspirations, my Readers had considerable difficulty reconciling the real Juffure with the bucolic village that had been embroidered across those early chapters of Roots:

[The] Juffure in my mind is still the Juffure from the book and the Juffure in The Gambia ... they're different things.

In contrast, several of them indicated that our earlier visit to an ethnographic museum outside the coastal village of Tanji had spontaneously stimulated a number of Roots-related imaginings, thanks to its collection of hand-crafted cultural artefacts and its life-sized facsimile of a traditional Gambian compound. As one remarked:

I didn't feel immersed in the book when I was there in Juffure. I didn't feel like I was immersed in "Roots-land" when I was on James Island because . . . Roots didn't take place on James Island, you know what I mean? And I didn't feel like I was in Kunta Kinte - . . like I was looking at his hut or anything like that. Maybe, if anything, it was in the Tanji Museum, where it was this historical representation of what the huts would have looked like back then. ... I felt, again, a little bit more of a connection to the book when I was there than I actually did when I was in Juffure or James Island.

The Tanji Village Museum thus proved to be a powerful place of the imagination for several Readers, whereas the actual village of Juffure left them bewildered and suspicious; another indication that the Roots narrative seems to complicate the heritage narratives associated with this place.

\section{The museum}

Our final stop was the Museum of the Slave Trade in Juffure (Figure 15.3), a site which seemed to resonate with all of my participants in meaningful ways. For Non-Readers, the museum provided the all-important context that they found lacking at other sites:

When we went to the museum itself, that's when I got hit with it most. ... Like, "oh yeah, this, this really happened. This is real".

Another Non-Reader found the museum powerful because it provided a local frame of reference for understanding the slave trade: 


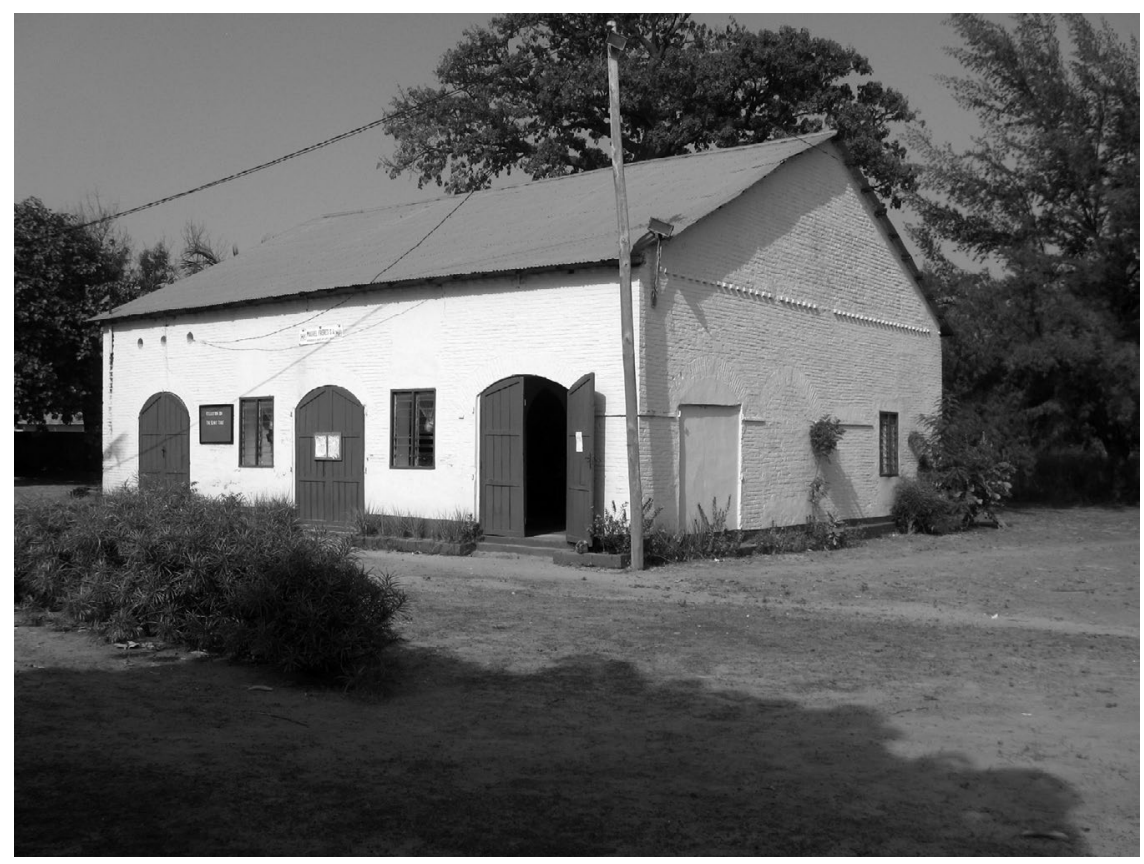

Figure 15.3 The Museum of the Slave Trade, Juffure.

Source: Photo by author.

I really enjoy learning from the Gambian perspective. . . . So, seeing it from this side definitely gave me a whole new perspective. . . . So, I definitely benefitted from going to the museum.

Thus, while several students found the museum's evident state of disrepair troubling, many considered our visit to this site of memory to be their most meaningful experience that day.

The museum proved to be even more evocative for Readers, with several noting that the challenging history interpreted there felt much more poignant thanks to the emotional potency of the Roots story:

At least for me, the whole journey he [Kunta Kinte] went through really took the museum to, like, an awful but really important place. Because the museum gave me the facts about what happened and the book gave me the feelings.

This was especially true for the exhibit addressing the horrors of the Middle Passage. Haley's visceral account of Kunta Kinte's time aboard the Lord Ligonier provides some of the book's most challenging material, making 
these particular displays much more emotionally charged for Readers. Thus, while a strong familiarity with Roots had complicated their impressions of Kunta Kinteh Island and the village-scape of Juffure, my Readers found that knowing the story effectively complemented the narratives presented at the Museum of the Slave Trade.

\section{Conclusion}

While the Roots narrative featured less prominently than expected at these Gambian heritage sites, its pervasive influence nonetheless marked these destinations as both sites of memory and places of the imagination. As places of the imagination, however, these sites offered a rather superficial and geographically distorted set of linkages to Roots, which failed to transport my Readers to the Edenic African landscapes so richly depicted by Alex Haley. Given these circumstances, it is not surprising that my participants found that the Roots story frequently complicated rather than complemented the UNESCOendorsed heritage narratives at these sites, heightening their sense of dissonance and transforming these sites into strange spaces of mediated memory.

Yet, as Reijnders (2011: 19) asserts, places of the imagination "offer the opportunity ... to construct a symbolic distinction between 'imagination' and 'reality" ' in ways that allow visitors to downplay and even delight in any dissonance that may arise. For some visitors, then, it is precisely the challenge of unravelling the intertwined threads binding "the realistic and the phantasmagorical" (Jansson, 2002) that makes these strange spaces appealing. However, while this playful engagement with dissonance may be common at many places of the imagination, it is perhaps less likely to arise at those combined sites of memory/places of the imagination that - like these Gambian heritage sites - are directly associated with past suffering, tragedy, and death. At many such "darker tourism" destinations (Miles, 2002), the grim realities of the historical record almost require an attitude of solemn contemplation from visitors, which may limit the more playful engagements that Reijnders has documented in other media tourism contexts. Indeed, if my Readers are any indication, media tourists who visit sites associated with a dark past may very well expect that the popularized accounts of this past hew closely to the documented historical narrative in both detail and tone. Under these circumstances, any perceived gap that opens between the documented and the imagined past at these heritage sites can render such spaces of mediated memory uncomfortably or even unacceptably strange.

In the case of these Gambian sites, this troubling sense of dissonance is heightened by the fact that Haley marketed Roots as a work of "faction" rather than fiction, leading Readers to expect considerably more congruency between the heritage-scape and their imagined land of Roots. Ironically, then, the less familiar a visitor is with the details of Roots, the more complementary its associations with these sites may seem. Yet, if Gambian officials were prepared to honestly and overtly reframe Roots as evocative fiction rather than erroneous faction, taking care to differentiate fact from 


\section{Jason Grek-Martin}

myth when engaging Haley's narrative, the historical resonance of these sites could be enriched while still acknowledging the ongoing cultural significance of Roots in shaping our perceptions of this region and its history. Such an approach would seem more capable of harnessing the emotional power of the Kunta Kinte story to make the vast and multifaceted enterprise of the trans-Atlantic slave trade even more relatable and poignant to visitors.

\section{Notes}

1 Gambians habitually include or remove the letter "h" at the end of names and places otherwise ending in the letter "e". For the sake of consistency, I have adopted Haley's spelling of "Kunta Kinte" and "Juffure," while also employing UNESCO's designation "Kunta Kinteh Island" when discussing this specific heritage site. Note also that The Gambia is one of only two countries (along with The Bahamas) that officially uses a definite article in its name (Central Intelligence Agency, 2019).

2 For convenience, I will refer to lieux de mémoire as "sites of memory" and lieux d'imagination as "places of the imagination" for the remainder of the chapter.

\section{References}

Allen, A. \& Lennon, M. (2018). The values and vulnerabilities of 'Star Wars Island': Exploring tensions in the sustainable management of the Skellig Michael World Heritage Site. International Journal of Sustainable Development and World Ecology 25(6): 1-8.

Ashworth, G. \& Hartmann, R. (eds.). (2005). Horror and human tragedy revisited: The management of sites of atrocities for tourism. New York: Cognizant Communications.

Athey, S. (1999). Poisonous roots and the new world blues: Re-reading seventies narration and nation in Alex Haley and Gayle Jones. Narrative 7(2): 169-193.

Bellagamba, A. (2009). Back to the land of Roots: African American tourism and the cultural heritage of the River Gambia. Cabiers d'Études Africaines 49(193-194): 453-476.

Blayney, M.S. (1986). Roots and the noble savage. Tennessee Historical Quarterly 45(1): 56-73.

Bordin, E. (2014). Looking for Kunta Kinte: Alex Haley's Roots and African American genealogies. Iperstoria - Testi Letterature Linguaggi 4: 3-9.

Central Intelligence Agency. (2019). The world factbook: Africa: Gambia. Retrieved from www.cia.gov/library/publications/the-world-factbook/geos/ga.html.

Courlander, H. (1986). Kunta Kinte's struggle to be African. Phylon 47(4): 294-302.

Dann, G.M.S. (2005). Children of the dark. In: G. Ashworth \& R. Hartmann (eds.), Horror and human tragedy revisited: The management of sites of atrocities for tourism, pp. 233-252. New York: Cognizant Communications.

Delmont, M.F. (2016). Making Roots: A nation captivated. Berkeley: University of California Press.

de Santana Pinho, P. (2008). African-American roots tourism in Brazil. Latin American Perspectives 35(3): 70-86.

Di Giovine, M.A. (2008). The heritage-scape: UNESCO, world heritage, and tourism. Toronto: Lexington Books.

Gamble, D.P. (2000). Gambian studies no. 39: Postmortem: A study of the Gambian section of Alex Haley's Roots. Brisbane: David P. Gamble. 
Gijanto, L. (2011). Competing narratives: Tensions between diaspora tourism and the Atlantic past in the Gambia. Journal of Heritage Tourism 6(3): 227-243.

Haley, A. (2014). Roots: The saga of an American family, 30th anniversary ed. New York: Da Capo Press.

Jansson, A. (2002). Spatial phantasmagoria: The mediatization of tourist experience. European Journal of Communication 17(4): 429-443.

Jansson, A. \& Lagerkvist, A. (2009). What is strange about strange spaces? In: A. Jansson \& A. Lagerkvist (eds.), Strange spaces: Explorations into mediated obscurity, pp. 1-26. New York: Routledge.

Lennon, J. \& Foley, M. (2000). Dark tourism: The attraction of death and disaster. New York: Continuum.

Mendy, C. [In the Name of Our Ancestors]. (2015, February 9). Roots festival 2011: The inauguration of Kunta Kinteh Island. Retrieved from www.youtube.com/ watch? $=0$ oUmVvQ9_tos.

Mensah, I. (2015). The roots tourism experience of diaspora Africans: A focus on the Cape Coast and Elmina Castles. Journal of Heritage Tourism 10(3): 213-232.

Miles, W.F.S. (2002). Auschwitz: Museum interpretation and darker tourism. Annals of Tourism Research 29(4): 1175-1178.

Mills, G.B. \& Mills, E.S. (1984). The genealogist's assessment of Alex Haley's Roots. National Genealogical Society Quarterly 72: 35-49.

Mowatt, R.A. \& Chancellor, C.H. (2011). Visiting death and life: Dark tourism and slave castles. Annals of Tourism Research 38(4): 1410-1434.

Nora, P. (1996). General introduction: Between memory and history. In: L.D. Kritzman (ed.), Realms of memory: Rethinking the French past, vol. 1, pp. 1-20. New York: Columbia University Press.

Ottaway, M. (1977, April 10). Tangled roots. Sunday Times of London.

Reijnders, S. (2011). Places of the imagination: Media, tourism, culture. Farnham: Ashgate.

Seaton, A.V. (1996). Guided by the dark: From thanatopsis to thanatourism. International Journal of Heritage Studies 2(4): 234-244.

Stone, P.R. (2006). A dark tourism spectrum: Towards a typology of death and macabre related tourist sites, attractions and exhibitions. Tourism 54(2): 145-160.

Stone, P.R. (2013). Dark tourism scholarship: A critical review. International Journal of Culture, Tourism and Hospitality Research 7(3): 307-318.

Strange, C. \& Kempa, M. (2003). Shades of dark tourism: Alcatraz and Robben Island. Annals of Tourism Research 30(2): 386-405.

Tuan, Y. (1974). Topophilia: A study of environmental perception, attitudes, and values. Englewood Cliffs: Prentice-Hall.

Tunbridge, J. \& Ashworth, G. (1996). Dissonant heritage: Managing the past as a resource in conflict. Chichester: John Wiley.

UNESCO. (n.d.-a). Kunta Kinteh Island and related sites. Retrieved from http://whc. unesco.org/en/list/761.

UNESCO.(n.d.-b). Decision: 35 COM 8B.1: Changes to names of properties inscribed on the World Heritage list: Kunta Kinteh Island and related sites. Retrieved from http://whc.unesco.org/en/decisions/4272.

Walter, T. (2009). Dark tourism: Mediating between the dead and the living. In: R. Sharpley \& P.R. Stone (eds.), The darker side of travel: The theory and practice of dark tourism, pp. 39-55. Toronto: Channel View Publications.

Wang, N. (1999). Rethinking authenticity in tourism experience. Annals of Tourism Research 26(2): 349-370. 


\section{Jason Grek-Martin}

Wight, C. (2009). Contested national tragedies: An ethical dimension. In: R. Sharpley \& P.R. Stone (eds.), The darker side of travel: The theory and practice of dark tourism, pp. 129-144. Toronto: Channel View Publications.

Wright, D.R. (2011). The effect of Alex Haley's Roots on how Gambians remember the Atlantic slave trade. History in Africa 38: 295-318.

Young, A.S. (1977, April 21). Roots: Tangled and untangled. Los Angeles Sentinel. 


\title{
16 How stories relate to places? Orhan Pamuk's Museum of Innocence as literary tourism ${ }^{1}$
}

\author{
Marie-Laure Ryan
}

\section{Introduction}

Literally implementing the title of the present volume - Locating Imagination a sign at a busy intersection in Istanbul that reads "Pamuk, Kemal" points towards a museum created by Orhan Pamuk, the Turkish Nobel prize-winning author, and devoted to a novel whose hero, Kemal, is a product of Pamuk's imagination. There are many museums in the world that commemorate the life and work of real authors, and there are some fictional or legendary characters who inspired museums (Don Quixote, Sherlock Holmes, William Tell), ${ }^{2}$ but Pamuk's Museum of Innocence is unique among literary museums and consequently as a target of literary tourism in that it does not fit into either category. It was not conceived as a collection of Pamuk memorabilia but as a companion piece to a novel of the same name, and, unlike the aforementioned characters, the hero of the novel is not a popular transfictional character who appears in many texts and media. In this chapter, I will discuss the museum in terms of its relation to the plot of the novel, actual subject matter (for "innocence" is a subjective characterization of that which it is about), and type of experience that it offers to visitors. But before I address these questions, I will explore the foundations of literary tourism (Bulson, 2009; Reijnders, 2015) by asking how stories relate to space, what attracts fans of fictional stories to real-world locations, and how narrative theory can be made to account for such fan behaviour, which goes against much of the teachings of the schools of literary theory that dominated academia in the second half of the 20th century, from new criticism to deconstruction.

\section{How stories relate to space(s) and place(s)}

Locating imagination means tying stories to certain points in space, thereby turning these points into special places. The place-making potential of stories, duly noted by proponents of the space/place distinction (Tuan, 1997), can hinge on a variety of features. First and foremost among them are stories of personal memories. Our recollections from childhood or from happy moments spent in a certain location mark some coordinates as a place on the 
map of our life. Second, certain locations are singled out in a culture because they are the setting of important historical events narrated by factual stories. People may want to visit Saint Helena, Omaha Beach, Auschwitz, or Ground Zero in New York City because of their historical significance.

Moving from the factual to the fictional, certain points in space can be turned into places through traditional tales. Of all the genres of folklore, legends are the most deeply anchored in space. They may tell how certain landscape features came into being or they may associate the deeds of saints and heroes with specific locations.

Last, but not least, real places can be singled out because they are the setting of famous narratives. Sometimes these places are independently well known, such as the Dublin of James Joyce (Bulson, 2009); other times, they are obscure places that a certain narrative puts on the cultural map under a pseudonym, such as the village of Illiers, which inspired the Combray of Marcel Proust and is now officially named Illiers-Combray.

To illustrate the power of narrative to create a sense of place, let me tell a personal anecdote. It concerns a novel by Alan Lightman titled Einstein's Dreams (2004). The text describes various conceptions of time that can be derived from Einstein's theory of relativity. Since Einstein's ground-breaking paper on relativity was written while he was living in Bern, Switzerland, working by day as a clerk in the patent office, all the examples are set in Bern or elsewhere in Switzerland. When I read the novel, I felt transported to Bern, a city I know fairly well. The book awakened memories and gave me a wonderful sense of place.

A few weeks after reading Einstein's Dreams, I attended a conference on physics and literature, and I met the author Alan Lightman. I told him how perfectly his book captures the unique essence of Bern, what the Romans would call the genius loci, or spirit of the place. He replied that he had never been to Bern, and had no intention of ever going there. Why not? Because Bern was a mythical place for him, something he had built in his imagination, and he did not want this idealized image to be compromised, or even destroyed, by reality. The book never really offered the kind of lengthy place descriptions that one finds in 19th-century fiction, for instance, in Dickens and Balzac. All it did was mention a few street names, a few landmarks, and my imagination did the rest.

Readers who have never been to Bern construct the setting in their mind rather than recalling it from memory, and for some people, this image is more vivid, more fulfilling than any direct sensorial experience, so that, like Alan Lightman, they will have no desire to go to Bern. But for other readers, merely imagined places cannot replace a lived experience, and for them, going to Bern and retracing Einstein's walk from his house to the patent office will complete the sense of place created by the book. It is this kind of readers who engage in literary tourism.

The whole idea of literary tourism rests on a paradox. On one hand, tourists are driven by their desire to see with their own eyes the real-world 
counterparts of fictional places. They want to experience these places "as they really are", in their unmediated presence. If people were satisfied with picturing in their mind the settings of stories, they would not go to the trouble of physically travelling to these locations. On the other hand, the tourist's experience is heavily mediated by the text, so that what is being seen is less a place in itself than a place as seen by the author, who is credited with the ability to capture the essence of the place (or criticized for the inability to do so if the tourist is disappointed). The conflicting desires of seeing places in themselves and of seeing them through the author's eyes are inextricably linked in the experience of the literary tourist.

When I first started studying literature, in the 60 s and 70 s, the idea of literary tourism would have been considered sacrilegious. The desire to visit the places mentioned in a novel would have been regarded as the mark of a naive reader who fails to understand the essence of literary language. For a long time, beginning in the 50s, the study of literature was dominated by schools such as new criticism, structuralism, deconstruction, and poststructuralism, schools that I call "textualist", because they regard the literary text as an autonomous, self-enclosed system that should not be studied in terms of its relations to the real world but in terms of the internal relations between its elements. Talk about content was considered illegitimate because it presupposes that meaning can be conceived independently of its linguistic representation. If content cannot be distinguished from form, this means that literary texts cannot be paraphrased (Brooks, 1947) and interpretation is necessarily a betrayal, because it says what the text means in different words.

In a purely textualist conception of literary meaning, when a fictional text uses the name of a place that exists in the real world, this place possesses only the properties that are mentioned in the text. According to Ruth Ronen (1994: 128), when Stendhal mentions Paris in his novel Le Rouge et le noir, this Paris loses its geography, because none of the iconic places of the real Paris are mentioned in the novel: the Seine, Notre Dame, and the Louvre do not feature in this Paris. So what does Paris represent in the novel? It has a social and political significance, it is a site of power, and above all, it is the place where people can realize their highest ambitions (cf. the expression monter à Paris). Le Rouge et le noir is indeed a story of social climbing but a climbing that ends in a spectacular fall for the hero Julien Sorel. If the Paris of Le Rouge et le noir is a purely political and social entity, it would make no sense for readers of Stendhal to travel to Paris to deepen their experience of the novel: our imaginary tourist would have no idea where to go within Paris. But there are other novels that do a much better job than Stendhal in bringing Paris to life. For instance, many of the episodes of Proust's $A$ la recherche $d u$ temps perdu are located in Paris landmarks, such as the Champs Elysées or the Bois de Boulogne, and for the Proust lover, these places will be haunted by the characters of the novel.

For literary tourism to be justified, we need a theory of literary meaning that restores connections between narrative fiction and the real world but 
without endorsing a narrowly mimetic view of fiction as representation of reality, for obviously, there are many fictional worlds that differ in important ways from the real world. In other words, we need a theory that accounts for both resemblance and difference between real locations and their fictional counterparts.

These conditions are fulfilled by a theory of fiction that relies on the concept of possible world (Pavel, 1986; Ryan, 1991; Doležel, 1998). The philosophical notion of a possible world rests on the idea that "things could have been different from what they are" (Lewis, 1986). In another possible world, you could have been a billionaire, and Hillary Clinton could have been elected US president in 2016. There exists an infinity of possible worlds, one of which is the actual world where we live, and the others are non-actualized possible worlds. These worlds are created by mental acts, such as imagining, dreaming, or writing fiction. When we read a text of narrative fiction, we relocate ourselves in imagination into its world, and, suspending our disbelief in its existence, we regard it as real, or actual, though an act of make-believe (Walton, 1990). This gesture of relocation, which I call recentring (Ryan, 1991), explains how we can get immersed in a fiction, be caught in suspense, and experience emotions for the characters, even though we know that they never existed.

Possible worlds are never totally identical to the actual world, but they can resemble it to variable degrees. For instance, the fictional worlds of fantasy or science fiction are very distant from the actual world, while the worlds of realistic novels are fairly close. They mostly differ from reality through the existence of fictional characters, but they may contain the same locations and the same historical individuals. When readers construct the worlds of fictional texts, they apply what I have called the principle of minimal departure (Ryan, 1991: 48-60): this means that when the fictional text refers to an entity or a kind of entity that also exists in the real world, readers can project upon this entity everything they know about it from their experience of the real world, except when the text contradicts this experience. Therefore, we can imagine the Dublin of James Joyce's Ulysses as sharing the geography of the real-world Dublin, but it differs from it because it has citizens named Leopold Bloom and Stephen Daedalus who do not exist in reality. The possible worlds approach to fiction thus supports the idea of literary tourism by maintaining a connection between real-world locations and their fictional counterparts without insisting on an absolute identity between the two.

Stories can relate to space and place in three ways: true stories that take place in real geography, such as the narratives of historiography or personal memories; fictional stories that take place in (counterparts of) real-world settings, such as James Joyce's Ulysses or Dostoevsky's Crime and Punishment; and fictional stories that take place in imaginary geographies, such as Lord of the Rings, or in a split, partly real and partly imaginary geography, such as Harry Potter, which combines London with the fantastic world of the Hogwarts School of Witchcraft and Wizardry. As shown in Figure 16.1, 


\begin{tabular}{|c|c|c|}
\hline & Real geography & Imaginary geography \\
\hline \multirow{2}{*}{$\begin{array}{c}\text { Story told as } \\
\text { true }\end{array}$} & $\begin{array}{c}\text { Normandy beaches; Auschwitz; } \\
\text { Ground Zero in New York. }\end{array}$ & $\begin{array}{c}\text { Holy Land Experience; } \\
\text { Stations of the Cross. }\end{array}$ \\
\hline \multirow{2}{*}{$\begin{array}{c}\text { Story told as } \\
\text { fiction }\end{array}$} & $\begin{array}{c}\text { Joyce's Dublin; Dostoevsky's St } \\
\text { Petersburg; Reichenbach Falls; sites } \\
\text { of myths \& legends. }\end{array}$ & New Zealand as Lord of the Rings' \\
& & Middle Earth; \\
& & Universal's Islands of Adventure. \\
\hline
\end{tabular}

Figure 16.1 Real and imaginary geographies as targets of narrative tourism.

Source: Design by author.

each of these three categories inspires a form of narrative tourism (I write narrative rather than literary tourism because the stories that motivate people to visit their setting are not necessarily considered literature).

Square 1 is represented by the busloads of visitors who are taken to Auschwitz every day; by the numbers of American tourists who regard the Normandy beaches of World War II as a necessary stop on their tour of France; or, more spontaneously, by the people who travel to their family's place of origin, inspired by their elder's stories. ${ }^{3}$ Square 2 corresponds to the classical cases of literary tourism: retracing the itinerary of Joyce's Leopold Bloom in Dublin; taking an organized tour of Dostoevsky's Saint Petersburg; or visiting Reichenbach Falls in Switzerland, where Sherlock Holmes fell to his death (there is even a sign that commemorates the "event"). Square 3 is more problematic in terms of narrative tourism because there is no real place to visit, but fictional geographies can be reached through a simulation that makes real space pass as imaginary space. For instance, fans of Lord of the Rings may want to visit New Zealand because this is where the movies were shot. The real landscape becomes in their mind the fictional space of MiddleEarth. But the most important form of tourism inspired by narratives with a fantastic setting is the theme park (Waysdorf \& Reijnders, 2016). Many theme parks are deliberately designed to recreate the settings of popular narratives. For instance, Universal's Islands of Adventure in Orlando, Florida, has sections representing the worlds of the Dr. Suess stories, Harry Potter, Jurassic Park, TinyToons, and Marvel superheroes comics. In these cases, we have a doubling of space: the real space of the theme park represents the imaginary landscape of a narrative, and the visitor's movement in that space simulates a visit to the fictional space. To quote computer game designer 
Brenda Laurel (1993: 14), the virtual reality of theme parks allows visitors to "take their body with [them] into worlds of the imagination".

In the cross-classification of the axes real/fictional story and real/imaginary geography that produces Figure 16.1, one possibility is missing: a true story that takes place in an imaginary geography. If the setting is fictional, so is the story. But there are forms of narrative tourism that come close to illustrating the paradoxical combination of Square 4. If a theme park can be devoted to a fictional story, why couldn't it represent a story that at least some visitors regard as true? Think of the Holy Land Experience in Florida (Holy Land Experience, n.d.). Or, as a predecessor of the designed experience of theme parks, think of the Stations of the Cross that one finds in the Alpine countries of Europe. They consist of little chapels on a steep trail that represent the episodes of the Crucifixion. Pilgrims are supposed to re-enact the passion of Christ by following the trail and stopping at each station to pray. For the pilgrims, the story is true; it is, in fact, more than true, it is the foundation of their faith. But the space where the re-enactment takes place is not the real setting, it is a simulated space - in contrast to the places in Jerusalem where the original events took place. Hence we can perhaps say that for believers, the ritual of the Stations of the Cross re-enacts a true story in a simulacrum of geography.

\section{Pamuk's Museum of Innocence}

Orhan Pamuk's Museum of Innocence is part of a triptych that includes a novel, an eponymous real-world museum that has become a significant Istanbul tourist attraction ${ }^{4}$ (shown in Figure 16.2), and a partly autobiographical text titled The Innocence of Objects (2012) that mediates between the novel and the museum and functions as catalogue. The novel narrates the creation of a fictional museum; the museum displays objects that bring to life the historical, geographical, and social setting of the novel; and the autobiographical text (henceforth referred to as the catalogue) describes the contents of the actual museum and how it came into being.

Set in Istanbul from 1975 to 1984, the novel tells the story of an unhappy love affair that turns into a fetishist obsession. The narrator, Kemal, belongs to the upper crust of Istanbul society, a class that tries to emulate European culture at all costs. He is engaged to Sibel, a heavily Westernized young woman. One day he walks into a store to return a gift that Sibel rejected because it is an imitation of a famous brand, rather than a genuine article, and he falls in love with Füsun, the salesgirl, a stunning beauty who is a distant relative of his. They engage for a short time in a passionate sexual relation, but after Kemal's formal engagement to Sibel, Füsun disappears and Kemal is heartbroken. His strange behaviour leads Sibel to break the engagement. When Füsun renews contact with Kemal a few months later, she is married to Feridun, a fat boy and aspiring screenwriter whom she married without love because by giving up her virginity, she has compromised her 


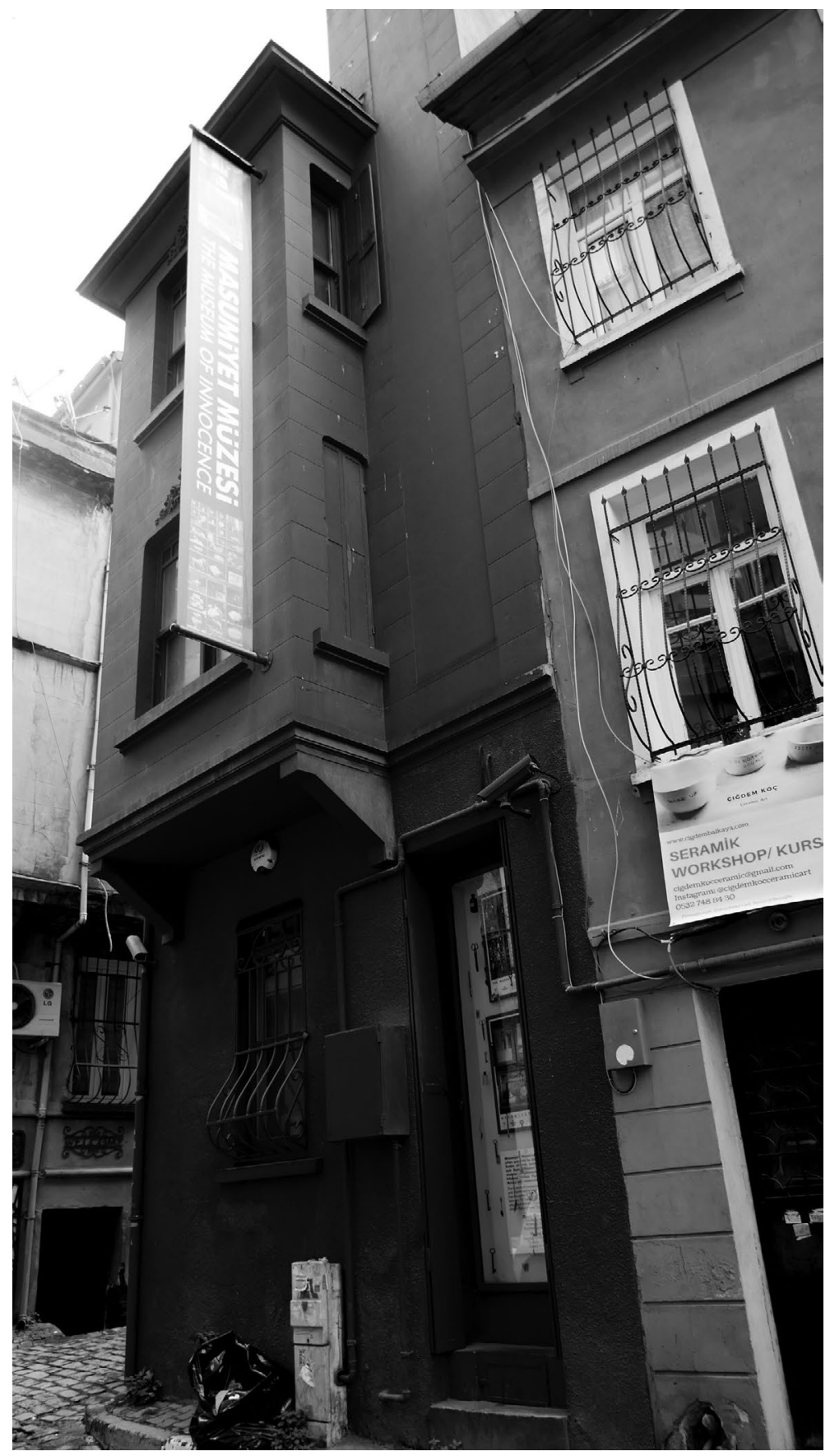

Figure 16.2 The Museum of Innocence in Istanbul (the dark, narrow building on the left).

Source: Photo by author. 
marriage prospects. For eight years, Kemal visits Füsun four times a week for supper in her parents' house, where she still lives with her husband, and he spends his evenings watching TV with the family. He also steals various objects from the house, because they bear the imprint of Füsun's presence. Finally Füsun gets a divorce from Feridun (who has become in the meantime a famous film writer and now has an affair with an actress) and she agrees to marry Kemal on the condition that he take her to Paris. During the trip, they renew their physical relation, but the next day, Füsun drives Kemal's car into a plane tree, killing herself and seriously wounding Kemal. The text is ambiguous as to whether it is an accident or a suicide. After Füsun's death, Kemal creates a museum with all the objects he has stolen from her house, and he asks his friend Orhan Pamuk to writes his life story. Pamuk accepts, for he, too, was in love with Füsun, but rather than writing a regular biography of Kemal, he will write a novel told in the first person by Kemal. This future novel is the one we have just read, so that the text of The Museum of Innocence curls back upon itself, through an effect reminiscent of Proust's $A$ la recherche du temps perdu.

The museum comes in two versions: the fictional and the real one. The fictional museum is Kemal's creation, and it is described in the novel, while the real museum is Pamuk's creation, and it is described in the catalogue. But while the two museums exist in different worlds, there is a lot of overlap between them and a lot of interplay between the discourses that describe them. Many times in the novel Kemal mentions objects that play a role in the plot and then says: "I exhibit it here", referring to the fictional museum. This is (almost) true of the real-world museum, since one can see a similar object in one of the displays. The novel also contains a map locating the actual museum and a free ticket. On the other hand, the catalogue, which is as a whole a non-fictional account of how and why Pamuk created the museum, contains many passages lifted (rather than openly quoted) from the novel, it refers to Kemal and Füsun as if they actually existed, and it contains a literary map of Pamuk's Istanbul that shows the settings of events not just from The Museum of Innocence but from several of his other novels. The fiction contains true information about the real-life museum, and the catalogue contains fictional statements about the characters in the novel.

Kemal's decision to create a museum develops in three stages. It begins with an attempt to conjure Füsun's presence through the objects that have touched her body. He retreats regularly to the apartment where he used to make love to her, and he tries to pick up her scent in the sheets or the trace of her hand in the objects that she used to touch. This leads to the second stage of Kemal's obsession - stealing objects that belong to Füsun. During the eight years when he visits her four times a week at her parents' house, he steals her earrings, barrettes, and combs, including those that he gave her as presents, and he brings them back to the apartment, where he tries to reassemble her body through the things that belonged to her. His kleptomania soon expands to other kinds of objects found in Füsun's parents' house, such as glasses, 
bottles of cologne, salt shakers, and a quince grater. He often replaces the stolen objects with new ones, only to steal them again. In a third stage of his obsession with objects, the fetishist lover turns into a compulsive collector of objects of the same kind: he religiously picks up Füsun's cigarette stubs, and after eight years, he has collected 4.213 of them. He also manages to steal numerous examples of the China dogs that sit on top of the TV, creating a unique collection of a kind of item that symbolizes an important turning point in middle-class culture - the moment when television replaced radio and became the centre of domestic life. After Füsun's death, Kemal continues his gathering of mementos that represent Turkish everyday life in the 70s and 80 s by getting objects from other obsessive collectors. To find room for his growing collection, he buys the family house of Füsun and sends her mother to live elsewhere. The museum that displays Kemal's mementos is much more than a mausoleum to Füsun (Kemal reminds us that mausoleum is the etymology of museum); it is also a tribute to the passion that led to the creation of many small, private museums around the world: the passion of collecting for its own sake. Compulsive hoarding is turned into a labour of love and into a work of art. To explain the displays of the museum, Kemal asks Orhan to write his life story, because individual objects can only represent isolated atoms of present moments, and it takes the line of a narrative plot to turn a series of moments into time. In the end, the museum plays the same role for Kemal as the writing of a novel does for the narrator of Proust: the museum gives meaning to Kemal's life, a life that most people consider wasted. To parody Proust, the museum recaptures the lost time.

Pamuk's museum is in many senses the opposite of Kemal's. It is a real museum that tells a fictional story, while Kemal's museum is a fictional museum that tells what is from Kemal's point of view a true story. In Kemal's museum, objects are in a sense de-realized, since they stands for Füsun and the memories they evoke, while in Pamuk's museum, they stand primarily for themselves, projecting a mute presence that combines strangeness and familiarity. While Kemal first falls in love with Füsun, then becomes an obsessive collector of objects connected to her and ends up with a museum, Pamuk starts as a passionate collector of objects and ends with the simultaneous creation of a museum that hosts the objects and of the fictional characters of Kemal and Füsun as the thread that connects the objects. In the catalogue, Pamuk tells us that starting in the 1990s, he began collecting objects from antique shops that represented daily life in Istanbul in the 70s and $80 \mathrm{~s}$, a time when a Westernized elite was trying to erase any trace of the Ottoman past, and also any trace of the Greek, Armenian, Jewish, and Kurdish minorities that left Istanbul in the 50s. Therefore, what one sees in the museum is not typical Turkish artefacts, the kind that tourists adore, but mass-produced objects similar to those found everywhere in the West.

Pamuk first thought of writing a novel in the form of a museum catalogue; he would show objects and then describe the memories that the objects evoke in the protagonist, but the novel eventually developed as a classic 
self-standing narrative without illustrations. The catalogue is the bridge that connects the museum to the novel. The novel consists of 83 short chapters, and each of them is represented in the museum by a box that shows some of the objects mentioned in the chapter (see Figures 16.3 and 16.4).

There are four types of relations between the text of the novel and the objects shown in the museum. First, objects important to the story that are collected in the real world and shown in the museum. It was for instance easy for Pamuk to find 4.213 cigarette butts and to present them as having been smoked by Füsun. Second, objects that play an important role in the plot and are specially manufactured for the museum. Pamuk asked a craftsman to create the fake brand-name bag that Sibel rejects and that leads to the meeting of Kemal and Füsun. Third, objects found by Pamuk in antique shops around which he builds episodes or that he inserts into the text through casual mentions, not because they are important to the plot but because he was in love with them. For instance, there is a display that contains only one object, a quince grater, that Pamuk found in an antique shop. To insert it in the novel, he invents a rather convoluted episode where the police stop Kemal on his way home, search him, find the grater, and suspect it of being a weapon. And fourth, objects shown in the museum that could not be fitted in the novel, such as the belongings of Kemal's and

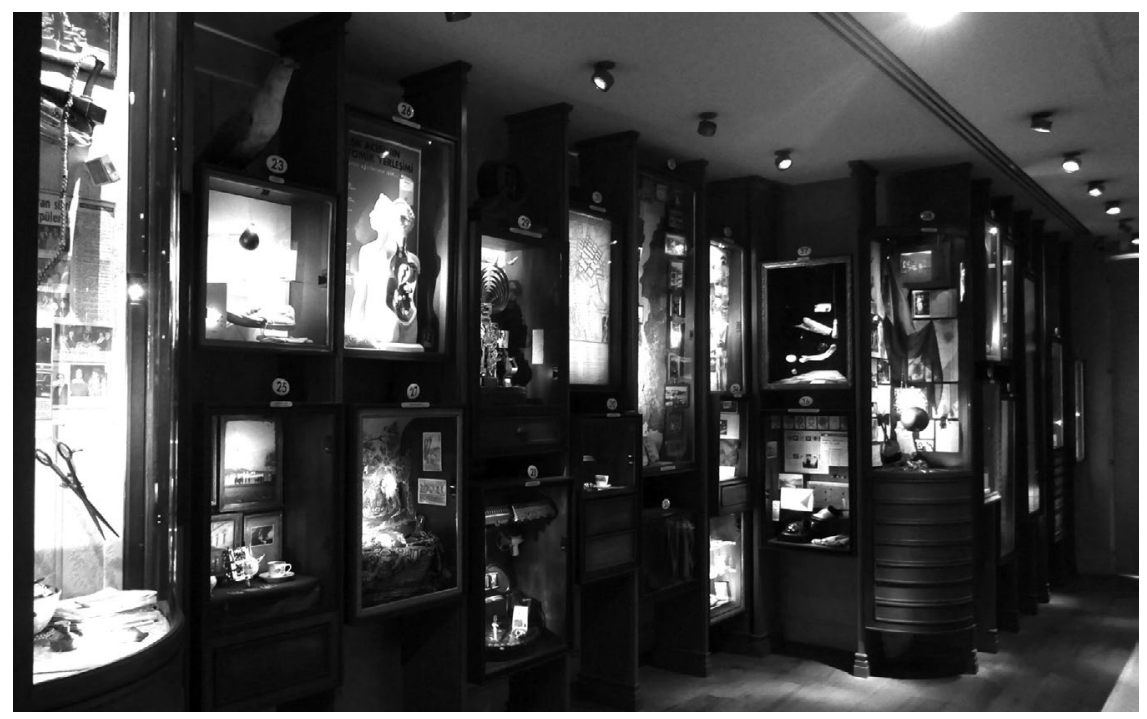

Figure 16.3 General view of the Museum of Innocence. Each of the boxes corresponds to a chapter in the novel.

Source: Photo by author. 


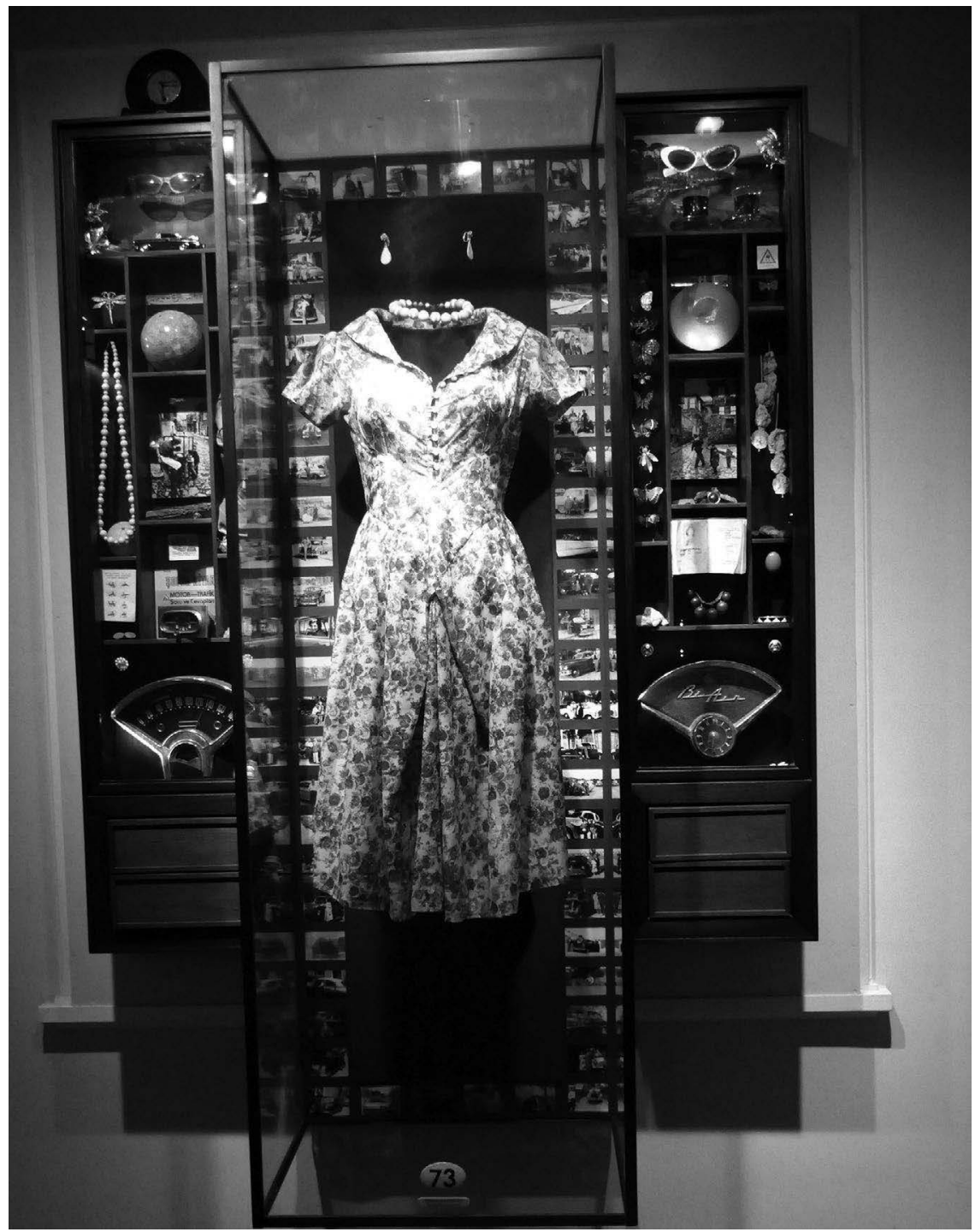

Figure 16.4 One of the displays of the Museum of Innocence. This one shows Füsun's dress and various belongings, with photos of families proudly posing with cars. It refers to a chapter titled "Füsun's driving licence." In the novel, Kemal teaches Füsun how to drive, then she is killed in a car crash. The furniture that holds the objects is strikingly similar to the 17 th- and 18th-century Wunderkammer.

Source: Photo by author. 
Füsun's fathers, both of whom die during the narrative. The museum shows complete collections of all the objects that they used during their daily lives, as if these collections captured the essence of the living person.

Even when the objects in the museum correspond to objects mentioned in the novel, they are much more than illustrations. About a frame that shows junk crammed under the metal frame of a bed, Pamuk (2012: 83) writes in the catalogue: "As they gradually found their place in the museum, the objects began to talk among themselves, singing a different tune and moving beyond what was described in the novel". And also: "I was trying to make a sort of painting with the objects, but they were telling me something different" (ibid). What they tell Pamuk in their stubborn resistance to being turned into a painting is that their meaning resides in their pure presence, not in their relations to Kemal and Füsun. If objects are declared innocent, it is because of their insistence in being themselves and in telling their own story.

The creation of the displays that correspond to the various chapters was an opportunity for Pamuk to reconnect with an early vocation as a visual artist that he later abandoned to become a writer. The museum consists of a series of frames, or boxes, reminiscent of the work of the artist Joseph Cornell, who pioneered the practice of arranging objects in a box in an aesthetic and meaningful way. In these boxes, the objects truly talk among themselves, and the whole is more than the sum of its parts. While Pamuk does not mention Cornell as influence in the catalogue, he acknowledges another important source of inspiration: the so-called cabinets of curiosities, or Wunderkammer, that displayed disparate collections of exotic objects in the 17th and 18th centuries. The Wunderkammer treads a thin line between a disciplined collecting of objects representing specific categories and indiscriminate hoarding. Similarly, the Museum of Innocence is part highly selective display of mementos from a certain period in Istanbul's history and part random collection of objects that happened to strike a chord in Pamuk's imagination.

An important difference between Kemal's and Pamuk's museums is the importance of Füsun. While Kemal conceives his museum as a mausoleum to Füsun, she is only represented in the real Museum of Innocence through her earrings, one of her dresses, her shoes, socks, panties, combs and barrettes, and her cigarette butts. It would have been easy to include photos of her (or rather photos of a woman posing as her), but this would have turned the museum into some kind of cheap photo novel, and it would have detracted attention from the objects. The museum is not really a memorial to the fictional character of Füsun; it is a tribute to that which she represents, namely the city of Istanbul. The love of Kemal for Füsun is an opportunity for the novel to explore Istanbul in its diversity, from Nişantaşı, the rich neighbourhood where Kemal's family lives, to Çukurcuma, the ethnically diverse, occasionally run-down, but vibrant neighbourhood where Füsun's family lives and where the actual museum is located. To quote a favourite cliché of literary critics, Istanbul is truly the main character in the novel. After 
Füsun's death, "Istanbul [becomes] a very different city" (Pamuk, 2009: 492), a city of paved streets and concrete buildings rather than the sensory feast of noises, sights, and smells that it was before.

Let's now turn to what the museum has to offer to tourists and to literary tourists in particular. The catalogue is in a sense more informative than the museum, because it shows all the displays (minus a few that were not finished at the time of publication), it comments upon them either with original text or with text from the novel, it presents many enlargements of the details of the frames, and, most importantly, it lets users read and watch at their own pace. But the catalogue does not entirely replace the museum, first because the museum contains data that cannot be reproduced in a book (such as sounds and videos) and second because the space has been carefully arranged to give meaning to the visitors' itinerary. The museum is housed in a very narrow building that occupies three stories. When visitors climb the stairs in a spiral movement to the top story and look down at the other stories, they will see all the displays simultaneously (or rather, the tops of the boxes), together with a large spiral drawn on the bottom floor (Figure 16.5). This spiral symbolizes the Aristotelian conception of Time, which links all the moments together, just as a story links isolated objects and characters into a meaningful sequence of events (Pamuk, 2012: 253). When the visitor reaches the top and contemplates the collection below, the elusive experience of time is turned into visible space, and the whole is truly more than the sum of its parts.

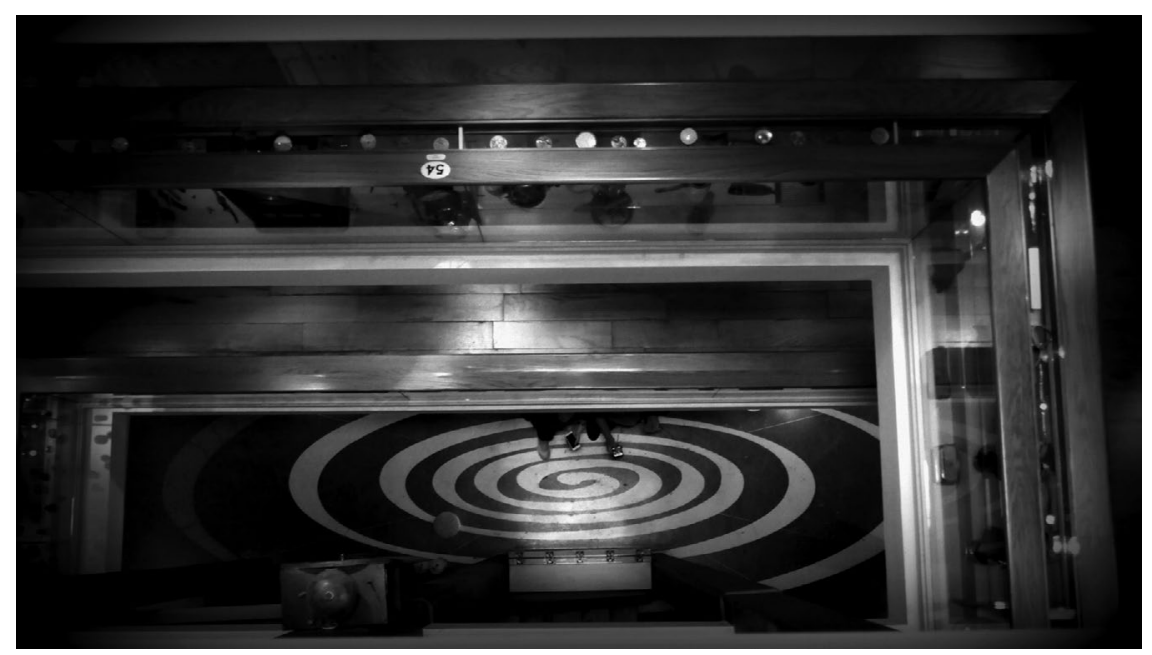

Figure 16.5 The spiral, symbol of the unity of (narrative) time, on the ground floor, that people see from the third floor at the end of their visit.

Source: Photo by author. 
Pamuk denies having created the museum for the readers of the novel exclusively. In the catalogue, he writes: "And yet just as the novel is entirely comprehensible without a visit to the museum, so the museum is a place that can be visited and experienced on its own. The museum is not an illustration of the novel, and the novel is not an explanation of the museum" (Pamuk, 2012: 18). So what kind of people will visit the museum, and what will they get from it? First one must consider the possibility that nobody will ever visit it. Pamuk tells us that he would not be upset. "When I set up a museum in one of these shabby neighbourhoods, displaying the objects that had characterized daily life in Istanbul, I would not mind the absence of visitors but would be comforted by the poetic aura that the empty museum would bring to the environs" (Pamuk, 2012: 28). In other words, the outside of the museum contributes to the genius loci of Çukurcuma as much as the genius loci of Istanbul contributes to the inside of the museum. If there are any visitors, they will have to walk through the same streets as the characters in the novel in order to reach the museum, and even if they have not read the text, they will imbibe the atmosphere that inspired it.

Many people will treat the museum as an art museum devoted to the artistic creations of Orhan Pamuk. These visitors will typically spend 20 to 30 minutes in the museum. Those interested in what drove Pamuk to create the museum can listen to an audiotape, in either Turkish or English, in which Pamuk comments on the displays and links them to the novel. In contrast to the audio guides of most museums, Pamuk's commentaries are so extensive, and they slow down the walk-through so much, that it would take several visits to listen to all of them.

What kind of experience will the museum provide to those people who have read the novel? Will they feel a special emotion, as Kemal would, by seeing a sneaker or a dress and thinking "this is Füsun's shoe", "this dress once enveloped her body"? I doubt it. One may be filled with awe when one sees the relics of saints or the dresses of Marilyn Monroe, but Füsun is an imaginary character, and visitors are aware of it: the museum does not break the ontological divide between fiction and reality. Moreover, Pamuk doubts that visitors will be able to connect the objects in the displays to specific details in the novel: "From watching visitors to the museum who had also read the book, I realized that readers remember no more than six pages of descriptive detail in the six-hundred pages of the novel. Readers who look at the displays were more likely to remember the emotions they'd felt while reading the novel than the objects in it" (Pamuk, 2012: 121).

Are the objects in the displays really able to evoke the affective reactions we experience while reading the novel? Judging by the responses on Amazon, the reader's emotions are mainly directed at the characters. They consist of irritation or even contempt for Kemal, a rather self-deluding, unreliable narrator who does not see the harm he does to Füsun, who wanted to be an actress, but Kemal does nothing to help her realize her dream, even though he has enough money to produce a film in which she could star. Readers 
also feel pity or puzzlement for Füsun, whose true feelings toward Kemal are impenetrable. While the emotions of the readers of the novel are directed at the characters, the emotions of museum visitors are mainly object oriented. The objects in the displays speak of Istanbul much more than they speak of Kemal and Füsun, and even more importantly, they speak to the visitor of a past that is perceived at the same time as very remote and very close. Very remote, because technology steadily accelerates the rate of change of the world, and the world of our youth seem to be centuries away. But also very close, because some of us can actually remember using the kind of objects displayed in the boxes. This is why a museum like Pamuk's creates much more personal emotions than, say, a museum devoted to medieval artefacts or to objects from antiquity. This emotion has a name: it is called nostalgia. It makes us cherish any object that evokes personal memories, even though we may have been indifferent to these objects when the past was the present. ${ }^{5}$

If Pamuk is right about the limitations of memory, about the fact that what readers remember from the 600 pages of the novel can be held in 6 pages, the best way to experience the relation between the book and the museum is not during a visit to the physical museum but by revisiting the museum through the catalogue and by re-reading the novel at the same time. As they look at the photos of the frames and then read the corresponding chapters, readers will become aware of many details that they had not noticed during their first reading. Their second reading will be like an Easter egg hunt for the objects that Pamuk inserted in the novel not because they are important to the plot but because he felt mysteriously attracted to them when he found them in a junk store.

How does Pamuk's project fit within the table displayed in Figure 16.1? As already noted, by locating the museum in Çukurcuma, where the house of Füsun's family is located in the novel, Pamuk invites visitors to experience the vanishing genius loci of Istanbul: steep and narrow streets where children play football (a recurrent theme in the novel), some traditional wooden houses still standing, and numerous antique stores where many of the museum's objects must have been purchased. The trip to the museum provides the sense of place that literary tourists seek out, and it fits within Square 2. But once people have reached the museum, they find a space that no longer corresponds to the setting of the novel. The itinerary of the visitor through the narrow three floors of the museum does not reproduce the movement of the plot through Istanbul; rather it reproduces the chronological sequence of the narrated events, since it follows the novel chapter by chapter. It is a movement that corresponds to narrative time rather than to narrative space, though at many of the stops in this journey - this is to say, at many of the displays - narrative space is evoked through photos of Istanbul. Many museums are organized in such a temporal way, especially history museums. As Azaryahu writes,

In recent years storytelling has become increasingly important in the design of these museums. ... Museum planners and designers arrange 
text and stories along circulation paths that direct the movement of visitors and invest museum space with a sense of sequential, narrative order. Indeed, some contemporary museum buildings have been designed around the stories they are designed to tell.

Narratively organized museums normally represent true stories, ${ }^{6}$ but there is no reason why they could not tell fictional stories.

Getting back to the table, the museum does not fit into Squares 1 and 4 because it tells a fictional, not a true story. It does not fit into Square 2 because the space of the museum is not literally the space of the narrative. The closest fit is Square 3, which is exemplified by theme parks, because just as visitors move through the simulated space of theme parks to experience imaginary stories, so does the visitor who has read the novel move through the Museum of Innocence, connecting each box to a chapter and aided in this task by the audio track. The main difference between theme parks and Pamuk's project is that the real space of most theme parks suggests a fictional story that takes place in a fictional geography, while in Pamuk's museum, the visitor who walks through the display travels in imagination through a fictional story that takes place in real geography. The Museum of Innocence does not consequently fit comfortably into any of the squares that make up the table in Figure 16.1. Yet insofar as the table prompts us ask what prevents an easy classification it its categories, it fulfils a heuristic function that reveals fined-grained distinctions in how stories relate to space and places.

Whether people stumble upon the Museum of Innocence or deliberately seek it, whether they are fans of this particular novel or haven't read it, whether they are looking for evidence of Pamuk's artistic talent or for a nostalgic collection of kitschy objects, Pamuk's combination of novel and museum represents a unique literary experiment and a new form of literary tourism. While most examples of literary tourism are developed bottom up, in response to the success of a certain work (preferably of popular culture) and are not planned by the author, the actual Museum of Innocence was conceived top down by Pamuk, in the sense that the ideas of the museum and of the novel were inextricably entwined in his mind, and the museum is not a commercial exploitation of the success of the novel. Like most works of art, the museum fulfils an obscure personal desire, and it is in order to understand this desire that Pamuk wrote the story of Kemal and Füsun.

\section{Notes}

1 A modified version of section 2 of this article was presented at the 7th conference on Narrative and Language Studies, Karadeniz University, Trabzon, Turkey, in May 2018. It appeared under the title "On the Eloquence and Silence of Objects: Orhan Pamuk's Museum of Innocence" in NALANS, the journal of the association. www.nalans.com/index.php/nalans. 
2 For Don Quixote, see www.spain.info/en_US/que-quieres/arte/museos/ciudad_ real/museo_del_quijote.html; for Sherlock Holmes, www.sherlock-holmes.co.uk/; for William Tell (whose actual existence is doubted by historians), www.tellmuseum. $\mathrm{ch} /$ ?lang=en.

3 It could be argued that people visit these places because of the events that took place there, not because of stories, but it is through stories that they are aware of the events.

4 A detailed description of the museum can be found in the Lonely Planet's guidebook Turkey (Bainbridge et al., 2015: 96-97).

5 A museum that cultivates the nostalgia created by everyday objects is the Museum der Dinge (Museum of Things) in Berlin, which Pamuk quotes as a source of inspiration. The museum captures the passing of time by collecting objects from the 20th century, such as cooking ranges, TV sets, dolls, or Nivea boxes, and showing the changes that their design undergoes over the years. These objects elicit emotional responses by making the visitor think: "I had one like that" or "this is the kind of thing that my grandmother used".

6 Examples of narratively organized museums that tell a true story are the German Historical Museum in Berlin and the United States Holocaust Memorial Museum in Washington, DC. An example of a museum specifically designed around the story to be told is the Berlin Museum of Jewish History, designed by Daniel Libeskind (Azaryahu, 2016: 199-202).

\section{Bibliography}

Azaryahu, M. (2016). Museum narratives. In: M.-L. Ryan, K. Foote \& M. Azaryahu (eds.), Narrating space/spatializing narrative, pp. 181-206. Columbus: Ohio State University Press.

Bainbridge, J., Atkinson, B., Butler, S., Fallon, S., Gourlay, W., Lee, J. \& Maxwell, V. (2015). Lonely Planet Turkey (travel guide). Franklin: Lonely Planet Global, Inc.

Brooks, C. (1947). The well wrought urn. New York: Harcourt Brace.

Bulson, E. (2009). Novels, maps, modernity: The spatial imagination, 1850-2000. London: Routledge.

Doležel, L. (1998). Heterocosmica: Fiction and possible worlds. Baltimore: Johns Hopkins University Press.

Holy Land Experience. (n.d.). About the experience. Retrieved from https://holylandexperience.com/about/ (02-02-2020).

Laurel, B. (1993). Art and activism in VR. Wide Angle 15(4): 13-21.

Lewis, D. (1986). On the plurality of worlds. Oxford: Blackwell.

Lightman, A. (2004). Einstein's dreams. New York: Vintage.

Pamuk, O. (2009). The museum of innocence (M. Freely, Trans.). New York: Vintage Books.

Pamuk, O. (2012). The innocence of objects (E. Oklap, Trans.). New York: Abrams.

Pavel, T. (1986). Fictional worlds. Cambridge: Harvard University Press.

Reijnders, S. (2015). Stories that move: Fiction, imagination, tourism. European Journal of Cultural Studies 19(6): 672-689.

Ronen, R. (1994). Possible worlds in literary theory. Cambridge: Cambridge University Press.

Ryan, M. (1991). Possible worlds, artificial intelligence and narrative theory. Bloomington: Indiana University Press. 


\section{Marie-Laure Ryan}

Tuan, Y. (1997). Space and place: The perspective of experience. Minneapolis: University of Minnesota Press.

Walton, K. (1990). Mimesis as make-believe: On the foundations of the representational arts. Cambridge: Harvard University Press.

Waysdorf, A. \& Reijnders, S. (2016). Immersion, authenticity and the theme park as social space: Experiencing the Wizarding World of Harry Potter. International Journal of Cultural Studies 21(2): 173-188. 


\title{
17 Placing fandom \\ Reflections on film tourism
}

\author{
Abby Waysdorf
}

\section{Introduction}

From 2013-2017, I was lucky enough to research film tourism as part of the Locating Imagination project. Over those four years, I conducted three case studies around tourism associated with film and television shows - Game of Thrones-related tourism in Belfast, Northern Ireland and Dubrovnik, Croatia; The Wizarding World of Harry Potter theme park in Orlando, Florida; and The Prisoner and its main filming location, Portmeirion in North Wales. In this chapter, I review the results of this project, reflecting on what these three cases, in combination, suggest about film tourism and its future.

As Karpovich (2010) discusses, the focus on meaning-making and representation in many of the qualitative studies of film tourism means that they dwell on whether the tourist is experiencing the "media" or the "reality". The disjuncture between what is on screen and what actually is, and how this difference is interpreted, has proven to be an intriguing way to investigate what authenticity, a key issue in tourism studies, means for tourists today (Beeton, 2016; Buchmann et al., 2010; Brooker, 2007; Edensor, 2001; Månsson, 2011; Rojek, 1997; Torchin, 2002). If, as the seminal work of MacCannell (1999) argues, we become tourists in order to seek out "authentic" experiences denied to us in our everyday lives, what does it mean for tourists to increasingly seek out experiences that are entirely inspired by the media? There has also been a focus on motivations of tourists - what brings them to these sites and what they look for while there (Carl et al., 2007; Macionis \& Sparks, 2009), where the question of experience is based around what the wished-for experience is and the implications of it being met or not. For media researchers, film tourism provides a way to investigate concerns about how we as audiences interact with and make sense of a pervasive media culture. This has been discussed in terms of power relations between audiences and industry, in terms of enforcing the industry's power through the construction and control of these spaces (Booth, 2015; Couldry, 2000; Garner, 2016; Peaslee, 2011) or in terms of the experience of "entering into" the textual world through tourism and challenging the lines between imagination, the media, and reality (Aden, 1999; Brooker, 2005; Hills, 2002; Lee, 2012; Reijnders, 2011; Roesch, 2009). 
What was missing from both these perspectives is how these places are actually experienced, beyond the issue of whether they are authentic, and how, once experienced, they are incorporated into the practices and lives of their visitors. It was this niche that I focused on in my research. The use of three case studies means that I was able to consider different examples of film tourism against each other using their similarities and differences.

This involved two main research questions. The first was how, and in what different ways, do film tourists experience places related to their object of fandom? This built on prior research on the film tourist experience (Buchmann et al., 2010; Kim, 2010; Lee, 2012; Reijnders, 2011; Roesch, 2009) as well as on fan tourism (Aden, 1999; Booth, 2015; Brooker, 2005, 2007; Garner, 2016; Hills, 2002; Sandvoss, 2005), with a larger focus on how fandom impacts the tourist experience.

This then moved into the second main research question: What role do film-related places play in contemporary fan practices? Since the beginnings of the Internet, fans have made use of its capacities to bring people into conversation with each other, using its affordances to build strong communities (Baym, 2000; Jenkins, 1992, 2006). In the digital age, fandom is largely seen as centred around these spaces. However, following the wider spatial turn in media studies (Ek, 2006; Falkheimer \& Jansson, 2006; Moores, 2012), I was interested in seeing how the existence and increasing relevance of film tourism affects fan practice today. What uses do fans find for these places, and how does having them available to visit affect their practices?

These questions were investigated and eventually answered by three case studies. These cases are all examples of "fantastic" film tourism: essentially, film tourism for places that don't exist in the real world. Focusing on fantasy highlights the tensions between reality, imagination, and the media that are at the heart of film tourism. Fantasy worlds are "unreal" on multiple levels, being not only fictional but departing from our own world. In these cases, reality and fiction can't be compared directly, as might be the case for more mimetic screen fictions (Torchin, 2002; see also Chapters 6, 8, and 12 in this volume). That fans wish to visit these places at all raises important questions about the way in which we as audiences see the borders between fantasy and reality. Understanding how these places are experienced, and what role they serve for fans, also allows us to actually see how these borders function today.

\section{Understanding film tourism}

I believe that film tourism can only be understood by understanding the discourses of both tourism and fandom studies. Contemporary tourism, as argued by Urry (2002; with Larsen, 2011) and MacCannell $(1999,2011)$ is constructed around seeing important sights of elsewhere - the great works of art, spectacular landscapes, and so forth. This has a long history in Western practice (Adler, 1989), beginning as a way in which to learn about other 
cultures and shifting to a Romantic conception of being emotionally moved by exposure to important places and objects. This moved from being an integral elite practice to a just-as-important mass practice in the late $1800 \mathrm{~s}$ and early 1900s with the rise of the railroads, steamships, and workersrights movements that granted holiday time (Urry \& Larsen, 2011). The practice of gazing, as well as what is worth gazing upon, is based in culturally formed ideas of what is proper practice and what is important to look at. The practice and the objects of the gaze are constantly circulated through different media, creating and reinforcing the idea that it is important to see and experience certain sites "for oneself". Visiting confirms their importance to us.

The "for oneself" is an integral part of this. As Urry and Larsen (2011) argue, tourism is built not only on gazing but on co-presence with a site. Our understanding of places is embodied (Crouch, 2000, 2001), and to truly know one, we must be physically present with it, experience it with our bodies in a multisensory fashion. In a time when we have become accustomed to audiovisual media, it is through the other senses that we confirm reality (Rodaway, 1994). Tourism, and "really experiencing" a place, therefore needs to be done in a multisensory fashion. Film tourism builds on this "being there" is different than seeing it on screen, and can be incorporated into existing patterns and practices of tourism (Beeton, 2016; Buchmann et al., 2010; Edensor, 2001; Kim, 2010; Roesch, 2009). It is also, potentially, more important on a personal and social level than "traditional" tourist locations, connecting to the Romantic ideal of sightseeing.

This is because of fandom. Here, I use Sandvoss' (2005: 8) definition of the term, "the regular, emotionally involved consumption of a given popular narrative or text". These narratives and texts matter to fans - they not only give pleasure but shape the fans' identity by connecting to important aspects of themselves (Hills, 2002; Sandvoss, 2005; Williams, 2015). Fandom is a way of finding ones' place in the world, both internally and, increasingly, externally through the formation of fan groups. The contemporary age has made this process almost synonymous with digital media, but as this research shows, physical place matters as well. They provide a mode of connection.

On one level, these places are sought out to give a sense of "reality" to what is only, if vividly, imagined. Objects of fandom matter to fans and often "feel real" (Jenkins, 1992; Saler, 2012), occupying space in the fan's head in the way that "real" people and places might. There is a clear understanding that these places are fictional, yet, as Reijnders (2011) notes, reality and imagination are interwoven in a way that fans especially wish to pick apart. Visiting physical places tests and plays with the boundaries of what is real and what isn't, showing the differences between the two while allowing the pretence, even if just for a moment, that it has collapsed.

However, the idea of "entering into" another world is only part of a larger issue of how film tourists and fans relate to the multiple worlds we inhabit. This idea of using tourism to encounter the fictional and fantastic is now a 
standard practice, recognized across fandoms. This suggests that it is enacted not only for its own sake but because of what participating in it represents. Visiting these spaces not only plays with the interrelation between our world and the text's but provides a way to reflect on ones' fandom. It becomes a ritual practice that acknowledges the role it has played in shaping the fans' life and identity. Therefore, it is also important to look to another aspect of tourism in order to understand film tourism in full: that of commemoration. Reijnders' (2011) concept of "places of the imagination" makes the link between sites connected to popular landmarks and historical monuments, while Couldry (2000) suggests that visiting the Coronation Street set served as a way to commemorate the act of watching television. To this, I suggest that visiting film-related locations serves to commemorate not just the text but being a fan of it.

Therefore, both fandom and tourism need to be considered when making sense of film tourism as a phenomenon. This has implications for the tourism industry - which might want to capitalize on the rise of film tourism - but also for the way in which we understand the relationship between (fan) audiences and the media industry. Place, while not new itself, is a new opportunity for a media industry increasingly interested in creating and controlling fandoms, one that they have begun to make use of.

\section{The experience of film tourism and its role in fandom}

My exploration of film tourism was based on two main research questions. They were based on a desire to understand the experience of film tourism for the tourists and from there, what this experience can tell us about the ways in which media, popular culture, and place interrelate today. Here, I present my answers to these questions.

\section{The experience of fantasy film tourism}

The first question I asked was: How, and in what different ways, do film tourists experience places related to their object of fandom? The fans involved in each case I investigated have their own way of experiencing and making sense of the places involved, utilizing their history with the text, their own interests, and their relationship with the fan community.

However, we can still see important commonalities. I defined film tourism as an "imaginative experience", (Waysdorf, 2017) building on Reijnders' (2011) centring of imagination in the media tourist experience and McGinn's (2004) concept of "imaginative seeing". An imaginative experience is an experience shaped by the imagination (in that it is an experience tied as much to the fictional narrative as what is actually perceived), which in turn influences the imagination as well. It is this reciprocity that is crucial here, in that the experience of film tourism has as much potential to influence the imagination as the imagination does the experience. 
I further divided this into three main "modes" of imaginative experience hyperdiegetic, production, and historical. The hyperdiegetic mode, based around Hills' (2002) concept of hyperdiegesis, was about experiencing the locations as their fantasy counterparts, performing actions like the characters or imagining themselves in their world. The experience of tourism not only let them feel like they were part of the story but allowed them to imagine the narrative world beyond the screen. This mode was joined by the production mode, which was based around imagining the production of the show. Fans were not only interested in imagining how the show came to be but appreciated the work and effort that went into the process as a symbol of how much HBO had invested in making it a quality production (especially compared to the negative way that fantasy is usually considered). Finally, fans were interested in the history of the places they visited for Game of Thrones, a historic mode of imaginative experience. Game of Thrones created a frame for understanding the "real" histories of Dubrovnik and Northern Ireland, making this history more interesting while also confirming some of the "historical accuracy" of Game of Thrones.

These can be seen, in some fashion, in each of the three cases, but shifting in a way that indicates the differences between these locations and their fandoms. For fans of The Prisoner, the hyperdiegetic mode is seen not only in the re-enactments but in the way that fans still often draw on the show to describe the locations or in use of specific terminology. However, with Portmeirion being so well established to these fans, it is slightly more in the background compared to the production and historic modes. Here, understanding Portmeirion and its impact on series creator and star Patrick McGoohan is seen as a crucial part of understanding The Prisoner. The diegetic world of The Prisoner is less coherent than that of Game of Thrones or Harry Potter, while its fans consider the thematic and philosophical questions it raises to be of high importance. Therefore, understanding and commemorating McGoohan, as the "auteur" of The Prisoner, is just as important as its story-world.

At the same time, and particularly among the most long-term fans, the historic mode of imagination is very important. Many fans are equally passionate about Portmeirion itself and its creation by architect Clough WilliamsEllis as they are about The Prisoner. They have put a great deal of effort into learning more about Williams-Ellis and his vision and value this kind of knowledge highly. As with Game of Thrones fans, this is often put into a framework that works with The Prisoner and its production. WilliamsEllis becomes a fearless iconoclast, much like both McGoohan and his character Number 6, and Portmeirion an example of a (cultishly) successful yet uncompromising artistic vision, much like The Prisoner itself. As with Game of Thrones tourism, the three modes work with each other rather than against each other. That the place can be imagined in multiple ways doesn't confuse the fantasy fan but instead enhances the experience.

In looking at the Wizarding World of Harry Potter (WWOHP), a recreation rather than a filming location, the imaginative experience is a bit 
different. Here, I build around Saler's (2012) concept of the "ironic imagination", in which fans treat an imaginary world "as if" it were real, while knowing it isn't. It is this that allows fans to be emotionally invested in a fictional world and to work at filling in the spaces that the author does not. I moved this concept to the space of the theme park, showing how its affordances as a medium work as a physicalization of the ironic imagination. It is this physical experience that is at the heart of WWOHP - a concentrated version of the "hyperdiegetic" mode of imagining - and one of the reasons that it has become so beloved by fans of the Harry Potter series. However, fans are aware that WWOHP is a construction and therefore also use the production mode of imagination. Imagining and contemplating the production of WWOHP makes them think that their fandom is valued, as Universal put so much effort into making it right, similar to how Game of Thrones fans discussed what its high production values meant.

Yet the historical mode is almost entirely absent. This can perhaps be explained by WWOHP being a section of a theme park. As I have discussed (Waysdorf \& Reijnders, 2018), theme parks are considered "set-apart" spaces, outside of normal life. Constructed away from their host cities, on isolated land, this set-apart character is both part of their appeal and why they are critiqued so heavily. They are considered artificial, without the weight and history of "real" places, but also places where outside the park doesn't matter. As a result, fans at WWOHP are less likely to be interested in and discuss the non-text-related history of their surroundings. What matters when visiting WWOHP is how credibly it fulfils the medium potential of the theme park - whether it successfully simulates being in the Harry Potter story-world - which means that it is the hyperdiegetic and production modes that dominate.

The imaginative experience at a filming location is therefore built upon a sense of what "happened" in a location, where the imagination imparts a meaning to an archway or rock that would otherwise be any other, a meaning that can be interpreted in different ways. By contrast, the (ironic) imaginative experience of a place like WWOHP is more clearly about deepening the connection to the fictional world, based around strengthening the sense of how the imaginative world would feel if it wasn't fictional. It is an official transmedia expansion that adds to the story-world, deepening the fans' knowledge of it in a way that was intended by the series' creators, rather than the unofficial understanding of it for Game of Thrones fans. Dubrovnik was used to depict King's Landing, but is not supposed to "be" it in a textual sense, while the Diagon Alley of WWOHP "is" the textual Diagon Alley.

Despite these differences, what is most important in any imaginative experience is that the fan is having the experience in their own body. The physical experience of being at the location enhances and shapes the fan's understanding of the text when they return to it, either via watching it again or even just thinking about it. It is this physicality that I ultimately come back to as my final answer to how film tourism is experienced. As shown in the 
imaginative modes previously, it is impossible to come up with one totalizing answer to how these places are imaginatively experienced. However, there is one commonality to all parts: the importance of the embodied experience of the location - of physically being there.

For Game of Thrones fans, this embodiment is discussed in terms of getting a "sense" of and gaining knowledge about the show. Having an embodied experience with the locations involved in creating the show is the crucial part of the exploratory nature of its tourism. They learned more about a show that is still shrouded in mystery, supplementing what they know from the screen with this physical knowledge. At WWOHP, where many fans are already very familiar with the finished narrative, embodiment is expressed in terms of a long-wished-for immersion within it through the park's affordances. Here, they can eat, drink, smell, and move as if they were part of it, their imagination enhanced by the fully embodied experience. It is this feeling that underpins the other relationships that fans develop with WWOHP. For the Prisoner fans interviewed, the embodied experience of being in Portmeirion cements their understanding of its importance to The Prisoner and supports their fandom of it. They feel that they more fully understand the mindset of the show's creator by being where he was and feel that they are closer to the text and fellow fans by visiting it as they have. In moving to and through Portmeirion on a regular basis, re-enacting scenes of The Prisoner at their exact place of filming, and walking through familiar pathways, it becomes a beloved place and the "home" of their fandom.

This kind of co-presence and embodiment are considered crucial parts of the tourist experience. The multisensory, embodied experience of tourism is how we confirm the reality of a place. Film tourism serves to do this for films and television shows. In visiting places associated with them, as we visit other types of landmarks and locations, these films and television shows become more than screen fantasies - they become real (Hills, 2002; Sandvoss, 2005). This has often been discussed in terms of an immersion fantasy (Brooker, 2005; Hills, 2002; Roesch, 2009), of putting oneself into the textual world, with embodiment as part of this fantasy.

As these cases show, however, immersion in the textual/filmic world itself is only part of the way in which fans, even the most devoted fans, experience film-related locations. The experience can be as much extra-textual as it is textual. But all parts of the film tourism experience are embodied. Visiting these locations not only creates new knowledge about the text and its spaces but connects the fan personally to it. That they have been in the same place as the text, or in a place that allows them to be physically immersed in the text, creates a different connection to it than watching does. It is often one that fans find difficult to put into words, as it is entirely contained within the body. It is this embodied experience that allows the imaginative modes to function. They experience their object of fandom at the most personal - the bodily - level.

What this suggests is that embodiment is as crucial to film tourism as it is to other forms of tourism, even if film tourists are visiting a place that 
doesn't actually exist. They experience the location as a personal connection to the film or television show they visit it for. This separates them from nonfilm tourists, as the place is never entirely "itself" but experienced in relation to this external presence. It also means that the question of authenticity and the search for an "authentic experience", which is so prominent in tourism studies, is different here. Film tourists are less concerned with whether these locations are an "authentic" representation of the cultures they are hosted in or even if they are entirely like they are on screen. What matters is whether they can have this personal connection with the text. Film tourism can even be seen as sort of non-representational geography (Thrift, 1996), but a different sort than is commonly meant by the term, as it is based in connecting to a particular form of representation rather than the everyday experience of place. However, in that film tourism is essentially embodied, and that the experience is based in the practices and performances of physicality, gives it more common ground than one might think. Explicitly foregrounding the embodied nature of film tourism is therefore necessary. It is not an incidental part of film tourism, but it forms the heart of the experience.

\section{The role of film places}

Following this first question, I asked: What role do film-related places play in contemporary fandom? Fandom, both in terms of the community of other fans and the experience of being a fan, is not an isolated moment. It is something that the fan brings with them to the location they visit and something they carry with them once they leave. As film tourism has grown, becoming an established practice in tourism and fandom circles, it is worth asking how these places affect the practices of fandom today. The existence of places that fans can visit in order to connect to their fandom, and the visits that tourists make to them, undoubtedly play a role in how their fandoms operate.

First and foremost, what film-related places do is locate the fandom. They give the fandom presence in the physical world, as much as they do for the film and television show itself. Fandom is largely thought of as free-floating, particularly in the contemporary era where much of its practices take place online, but film-related places tie it to a specific place. This is not unique to film and television fandom - as Rodman (1996), Hills (2002) and Sandvoss (2005) discuss, places like Graceland and stadiums play similar roles for music and sports fans, respectively, providing an anchor in the physical world. They "provide a form of permanence to what would otherwise be a potentially fleeting pre-verbal experience" (Hills, 2002: 153). Film-related places, whether they are filming locations or created and adopted locations like WWOHP, do this for fans of films and television shows. In this, the fandom, in addition to the text, becomes more real. It has a specific place and therefore the stability and groundedness that place provides.

Consequently, that the fandom has a place engenders specific effects. There is the experience of physical connection to the object of fandom, as I discuss 
previously. It is also useful, however, to consider these places as sites of commemoration - as places that the fandom and the experience of being a fan, and not just the object of fandom, can be paid tribute to. This is something that is particularly visible in the long-developed fan culture at Portmeirion, but it is also seen at the other locations. Fans visiting WWOHP frequently spoke of their visits as a culmination of their long-term fandom, especially when they could share it with other fans, while the Game of Thrones fans saw visiting as recognition of a new interest in their lives and the lives of their friends and family back home who also watched the show. For some, visiting also provided their first experience of "being" a fan, in the sense of participating in fan practices with others.

Being at a place of fandom means that fans can experience their fandom, as well as the text, at the embodied level. Being at a filming location that is frequently visited by fans links the fan to this history. The fans that perform in re-enactments at the site of filming connect themselves not only to The Prisoner but also to the fans that have performed these re-enactments over the decades. They personally connect to their fellow fans and, in many cases, to their own memories. At WWOHP, the sheer volume of other fans meant that the Harry Potter fans interviewed felt that they were physically surrounded by their fandom - they could feel the weight of its worldwide popularity. While this made the park crowded and the lines for attractions long, it also made them feel that they were not alone in their passion. Because of this established presence, a place of fandom provides a place to be a fan - to perform fandom and fan practices in a way that the fan might not feel able to do elsewhere.

In my research, I also encountered many fans who do not act as fans when outside of these locations. While they might discuss their favourite show or film with family members and friends, they rarely ventured into the online (and offline) spaces of discussion and community that are considered emblematic of contemporary fandom. They are not "participatory" in the same way that these more frequently studied fans are. There were many reasons given for this, but it was clear that when in these places, and while on holiday, they were more willing to perform fandom than they would be otherwise. The structures and rhetoric of being "on holiday" support acting as a fan in a way that "everyday life" does not. The tourist has time to spend on more frivolous pursuits, such as fandom, and has the freedom to act as they might not do at home (Hennig, 2002). While in everyday life, they might be afraid of being considered "dorky", or perhaps not "dorky" enough, while on holiday, they can fully act like fans.

This is enforced by the places they visit. If they are places of fandom, they are the correct place to act as fans. Within these spaces, fans can do what would be inappropriate or strange elsewhere. These kinds of performances are perfectly appropriate, even expected, at places of fandom. At WWOHP, for example, fans felt that they should wear Harry Potter-related clothing, while fans at Game of Thrones-related sites were more willing to proclaim 


\section{Abby Waysdorf}

their fandom - and perform it with others - while there than they admitted to doing in their daily lives. Even the fans of The Prisoner I interviewed, who were often archetypal "participatory" fans, felt that some activities were far more appropriate in Portmeirion than elsewhere. This not only includes the full-scale re-enactments, which some felt would be "silly" elsewhere even if they enjoyed doing them in Portmeirion, but the general activities of their fandom. While they might be able to gather, talk about The Prisoner and its themes, and make references to it outside of Portmeirion, it was in Portmeirion that this felt the most natural. Additionally, in visiting Portmeirion, they could devote their time and attention fully to their fandom in a way that they could not while surrounded by the concerns of everyday life. This is similar to how Harry Potter fans felt about WWOHP - they could "geek out" with impunity, shutting out the stresses that they experienced while at home and focus on this part of themselves, while also avoiding the censure that acting in this way might engender elsewhere. These film-related places therefore become the place to be fans most fully, whether the fan participates in fandom on a regular basis or only when at these places.

That these places attract fans to them means that they are a place to encounter other fans. This can be in a diffuse way, such as Harry Potter fans enjoying the feeling of being around so many other fans within the space of WWOHP, or in a more concrete way, such as Prisoner fans building deep bonds with the other Prisoner fans they have come to know through visiting Portmeirion regularly over the years. It must be noted that these places are not the only gathering points of contemporary film and television fandom or even the only place where fans can "be fans". The fan convention, one of the oldest fan traditions, continues to provide this role to fans, as it has done throughout the decades of organized fandom (Jenkins, 1992; Porter, 2004; Geraghty, 2014). At the convention, fans can meet with each other in person and perform their fandom, hence their continued popularity even as they cease to be the only way in which to participate in the fan community. Their free-floating nature, as they are often held in the generic spaces of hotels and convention centres, can, as Porter (2004) discusses, put the focus on the community and the text, as well as allowing it to be reproduced and encountered seemingly everywhere.

However, as my interviewees discuss, meeting in these places is not "the same" as meeting in a place of fandom. Being at a place of fandom, where they feel like the space is theirs and where they can act fully as fans, is considered more special than meeting elsewhere. For "non-participatory" fans, the space of the fan convention is also confusing in a way that places of fandom are not. They have their own social norms and modes of behaviour that non-participatory fans are unfamiliar and uncomfortable with. They require participation rather than encourage it, and the genericness of the environment does not make them feel that they are in a unique enough situation to perform fandom. While they overlap, particularly for very popular fandoms, there is a difference in the role that they play in contemporary fandom. 
The specificity of places of fandom, compared to convention spaces, also creates a sense of permanence. That fans of The Prisoner can return to Portmeirion, which has not changed significantly since its filming in the 1960s, and connect to both The Prisoner, and their fandom of it there gives these fans a sense of ontological security (Giddens, 1991; Williams, 2015). As long as Portmeirion stands, The Prisoner will exist, and the fans can visit it and recall both the show and the times they have spent there with fellow fans. A specific place gives a sense of permanence.

This potential also speaks to the way that the role of these places of fandom for fans changes over time. For Game of Thrones fans, while they did serve as a gathering point and place to perform fandom, they primarily served as a way to gain knowledge about the show, knowledge that they could not get elsewhere. They could explore different aspects of it by being there and come home with different perspectives and new information. Visiting filming locations was a way for them to enhance and build up their fandom of this newer, but quite popular, show. For Harry Potter fans, where the story-world is something that many of the fans have carried with them since childhood, there is still this sense of a new kind of experience with it (as the way of interacting with the Harry Potter universe at WWOHP is quite different from reading the books or watching the films), but being at the place is more about committing themselves again to their fandom, which had not had new content in a while, rather than building it up. Additionally, in establishing a dedicated, and at least semi-permanent, place for Harry Potter fandom, a specific gathering point for the fandom is also created, meaning that fans have a dedicated place to continually meet. At Portmeirion, most fans' engagement with The Prisoner and Portmeirion itself is long term and sustained but would perhaps drift away without the rhythms of the regular visits. In returning to Portmeirion, they re-immerse themselves in their lives as fans, keeping the fandom alive over the years. These visits are thus a "homecoming" - a return to this long-established and familiar home of fandom, the focal point of The Prisoner. Place can therefore serve different roles throughout the life course of both an individual fan and a fan community.

What this all suggests is that specific places are an important, but frequently overlooked, part of how fandoms operate. While not every fandom has a place - as the Prisoner fans were keen to point out - that some fandoms have one, and that it can be created as WWOHP was, is significant. The increase in film tourism and special events, particularly for objects of fandom that don't always fit into the fan convention space, indicates that there is a desire among fans to have a place and to have that place fill this role, or at least that this desire can be created. There is every indication that in the future, a specific place, and the roles it fulfils for fans, will be an important part of most fandoms. As Beattie (2013), Booth (2015), and Garner (2016) indicate in their studies of the Dr. Who Experience in Cardiff, it is equally likely that these spaces will be explicitly part of the media industry's management of fans. These developments mean that fandom 
researchers need to take place into consideration when studying a contemporary media fandom. The way in which place is used and controlled is an important aspect of how audiences and the media industry relate to each other today.

\section{Conclusion}

I think of this research as not the end of the discussion on fandom and film tourism but a beginning. What I have shown here is how fantastic film places can be experienced by some fans, and what role being there at these places can play in their fandom. They are examples of the potential relationships that can be built between individual fans, fan groups, and specific places and worth taking into consideration in the future as we look to understand shifting fan practices and experiences today. Ultimately, what I have shown here is that place is important, even, or maybe even more, in a digital and transmedial age, as the physical, "real" experience is still one that can't be duplicated. Being there, however we define "there", even if "there" doesn't truly exist, matters.

\section{Bibliography}

Aden, R.C. (1999). Popular stories and promised lands: Fan cultures and symbolic pilgrimages. Tuscaloosa: University of Alabama Press.

Adler, J. (1989). Origins of sightseeing. Annals of Tourism Research 16(1): 7-29.

Baym, N. (2000). Tune in, log on: Soaps, fandom, and online community. London: Sage.

Beattie, M. (2013). The 'Doctor Who experience' (2012) and the commodification of Cardiff Bay. In: M. Hills (ed.), New dimensions of Doctor Who: Adventures in space, time, and television. London: I.B. Tauris.

Beeton, S. (2016). Film-induced tourism, 2nd ed. Bristol: Channel View Publications.

Booth, P. (2015). Playing fans: Negotiating fandom and media in the digital age. Iowa: University of Iowa Press.

Brooker, W. (2005). The Blade Runner experience: Pilgrimage and liminal space. In: W. Brooker (ed.), The Blade Runner experience: The legacy of a science-fiction classic, pp. 47-107. London: Wallflower Press.

Brooker, W. (2007). Everywhere and nowhere: Vancouver, fan pilgrimage, and the urban imaginary. International Journal of Cultural Studies 10(4): 423-444.

Buchmann, A., Moore, K. \& Fisher, D. (2010). Experiencing film tourism: Authenticity and fellowship. Annals of Tourism Research 37(1): 229-248.

Carl, D., Kindon, S. \& Smith, K. (2007). Tourists' experiences of film locations: New Zealand as 'Middle-Earth'. Tourism Geographies 9(1): 49-63.

Couldry, N. (2000). The place of media power: Pilgrims and witnesses of the media age. London: Routledge.

Crouch, D. (2000). Places around us: Embodied lay geographies in leisure and tourism. Leisure Studies 19(2): 63-76.

Crouch, D. (2001). Spatialities and the feeling of doing. Social \& Cultural Geography 2(1): $61-75$. 
Edensor, T. (2000). Staging tourism: Tourists as performers. Annals of Tourism Research 27(2): 322-344.

Edensor, T. (2001). Performing tourism, staging tourism: (Re) producing tourist space and practice. Tourist Studies 1(1): 59-81.

Ek, R. (2006). Media studies, geographical, imaginations and relational space. In: J. Falkheimer \& A. Jansson (eds.), Geographies of communication: The spatial turn in media studies, pp. 43-64. Göteborg: Nordicom.

Falkheimer, J. \& Jansson, A. (eds.). (2006). Geographies of communication: The spatial turn in media studies. Göteborg: Nordicom.

Garner, R.P. (2016). Symbolic and cued immersion: Paratextual framing strategies on the Doctor Who experience walking tour. Popular Communication 14(2): 86-98.

Geraghty, L. (2014). Cult collectors: Nostalgia, fandom, and collecting popular culture. London: Routledge.

Giddens, A. (1991). Modernity and self-identity: Self and society in the late modern age. Cambridge: Polity Press.

Hennig, C. (2002). Tourism: Enacting modern myths. In: G. Dann (ed.), The tourist as a metaphor of the social world (A. Brown, Trans.), pp. 169-187. Oxon and New York: CABI Publishing.

Hills, M. (2002). Fan cultures. London: Routledge.

Jenkins, H. (1992). Textual poachers. London: Routledge.

Jenkins, H. (2006). Convergence culture: Where old and new media collide. New York: New York University Press.

Karpovich, A.I. (2010). Theoretical approaches to film-motivated tourism. Tourism and Hospitality Planning and Development 7(1): 7-20.

Kim, S. (2010). Extraordinary experience: Re-enacting and photographing at screen tourism locations. Tourism and Hospitality Planning \& Development 7(1): 59-75.

Lee, C. (2012). 'Have magic, will travel': Tourism and Harry Potter's United (magical) Kingdom. Tourist Studies 12(1): 52-69.

MacCannell, D. (1976/1999). The tourist: A new theory of the leisure class, 2 nd ed. Berkeley: University of California Press.

MacCannell, D. (2011). The ethics of sightseeing. Berkeley: University of California Press.

Macionis, N. \& Sparks, B. (2009). Film-induced tourism: An incidental experience. Tourism Review International 13: 93-101.

Månsson, M. (2011). Mediatized tourism. Annals of Tourism Research 38(4): 1634-1652.

McGinn, C. (2004). Mindsight: Image, dream, meaning. Cambridge: Harvard University Press.

Moores, S. (2012). Media, place, and mobility. New York: Palgrave Macmillan.

Peaslee, R.M. (2011). One ring, many circles: The Hobbiton tour experience and a spatial approach to media power. Tourist Studies 11(1): 37-53.

Porter, J.E. (2004). Pilgrimage and the IDIC ethic: Exploring Star Trek convention attendance as pilgrimage. In: E. Badone \& S.R. Roseman (eds.), Intersecting journeys: The anthropology of pilgrimage and tourism, pp. 160-179. Chicago: University of Illinois Press.

Reijnders, S. (2011). Places of the imagination: Media, tourism, culture. Farnham: Ashgate.

Rodaway, P. (1994). Sensuous geographies: Body, sense, and place. London: Routledge. 


\section{Abby Waysdorf}

Rodman, G. (1996). Elvis after Elvis: The posthumous career of a living legend. London: Routledge.

Roesch, S. (2009). The experiences of film location tourists. Bristol: Channel View Publications.

Rojek, C. (1997). Indexing, dragging, and the social construction of tourist sites. In: C. Rojek \& J. Urry (eds.), Touring cultures: Transformations of travel and theory, pp. 52-74. London: Routledge.

Saler, M. (2012). As-if: Modern enchantment and the literary prehistory of virtual reality. New York: Oxford University Press.

Sandvoss, C. (2005). Fans: The mirror of consumption. Cambridge: Polity Press.

Thrift, N. (1996). Spatial formations. London: Sage.

Torchin, L. (2002). Location, location, location: The destination of the Manhattan TV tour. Tourist Studies 2(3): 247-266.

Urry, J. (2002). The tourist gaze, 2nd ed. London: Sage.

Urry, J. \& Larsen, J. (2011). The tourist gaze 3.0. London: Sage.

Waysdorf, A.S. (2017). Placing fandom: Film tourism in contemporary fan culture. $\mathrm{PhD}$ dissertation. Rotterdam: Erasmus University. Retrieved from https://repub. eur.nl/pub/102767.

Waysdorf, A.S. \& Reijnders, S. (2018). Immersion, authenticity and the theme park as social space: Experiencing the Wizarding World of Harry Potter. International Journal of Cultural Studies 21(2): 173-188.

Williams, R. (2015). Post-object fandom: Television, identity, and self-narrative. London: Bloomsbury. 


\title{
18 The National Theatre, London, as a theatrical/architectural object of fan imagination
}

\author{
Matt Hills
}

\section{Introduction}

Stijn Reijnders has argued that "memory seems to play an important part in the way in which places of the imagination are experienced. In other words, one can identify a certain reciprocity between memory and imagination" (2011: 113). This chapter builds on such a recognition by focusing on the "mnemonic imagination" (Keightley \& Pickering, 2012) within place-making affects. At the same time, I am responding to the question of whether it is "possible to be a fan of a destination?" (Linden \& Linden, 2017: 110). As Rebecca Williams (2018: 104) has recently argued, we need a greater understanding of

what places can do to visitors who may not bring particular media or fan-specific imaginative expectations with them and yet may respond strongly to a particular place. . . . What confluence of affective, emotional and experiential elements may cause them to become fans of that site ...?

By focusing on the Royal National Theatre on the South Bank of London usually referred to as the "National Theatre" or the "NT" - I am deliberately taking a case study which multiplies some of these questions, since the NT has acted as the site for both theatre fandom (Hills, 2017) and what has been termed "architectural enthusiasm" (Craggs et al., 2013, 2016). Indeed, the National Theatre has been marked by a related doubling throughout its history (having opened in 1976 after a much-delayed construction process). For, as Daniel Rosenthal (2013: 845) observes in The National Theatre Story, it represents "what [playwright] Tom Stoppard termed coexistent institutions: 'One was the ideal of a national theatre; the other was the building"'. As such, it has also given rise to two "co-existent" forms of fandom and imaginative place-making, one focused on its theatrical status, and one focused on its distinctive brutalist architecture - "brutalism" coming from the French for "raw concrete", or béton brut, which makes up much of architect Denys Lasdun's stark building. However, these co-existent responses to the NT should not be seen as installing a binary of (theatrical) 
textuality versus (architectural) materiality - as Cornel Sandvoss (2014: 116) has noted in his work on fandoms articulated with locations, "places, and in particular places of pleasure and affect, are also always texts". This is certainly true for the NT's monumental public architecture, which is aligned with artistic/consumerist branding and mediated in a range of ways, not just through the "architectural gaze" of photography (Aigner, 2016: 190) but also via the consumption of souvenirs and merchandise (Garduño Freeman, 2018: 133, 136; Grindrod, 2018: 139). And, of course, the NT's theatrical and architectural fan imaginings also intersect: as a building located in a specific part of London and situated by the bank of the River Thames, it can operate as a "pilgrimage theatre" for visitors (Carlson, 2003: 157) and as an example of "architourism" (Ockman \& Frausto, 2005), interweaving architectural materiality with theatregoing recollections. As a site that is celebrated by "brutalist fans" (Grindrod, 2018: 139), the cultural meanings of the NT - especially as a publicly funded project pre-dating the culturalpolitical normalizations of neoliberalism - can also be textually mapped onto the building's enduring physicality.

Having accepted that both text/matter and theatre/architecture slip across each other, I will nonetheless structure my analysis in terms of first exploring theatre fandom before then turning to architectural enthusiasm. This is because the two practices often occur in different cultural spaces (e.g. forums such as Theatreboard) and through different social organizations (e.g. the Twentieth Century Society). Although it would be experientially possible for one person to combine and integrate theatre and architecture fandom, nevertheless the communal expressions and articulations of these fandoms tend to be sequestered and hence more singularly, artificially bounded - at the Theatreboard forum, for instance, there are subforums to share one's interest in specific plays (usually those about to be staged) and theatrical performers, but there is no sustained focus on theatres in terms of their architectural design. Similarly, in the Twentieth Century Society's magazine, $\mathrm{C} 20$, there is a concentration on buildings and their design, but even where these buildings may be theatres, there is no significant focus on their dramatic output. In each case, the fandom is enacted as relatively bounded and concentrated, its proper objects ("material" theatres; the art of theatrical productions) being implicitly defined and centred for other members of the fan community. Curiously, it is perhaps the National Theatre Shop which places architecture and theatre fandom most visibly side by side, each being rendered as a contiguous consumerist target market and thus represented via items shared (Kershaw, 1994: 174).

I will begin by introducing the "mnemonic imagination" (Keightley \& Pickering, 2012) in relation to theatre fandom. This concept refuses to view memory merely as a "trace", against which imaginative processes can be viewed as somehow more creative or productive, arguing instead for the need to theorize memory as intertwined with imagination, without becoming somehow false. The mnemonic imagination, for Keightley and 
Pickering, is what enables the imaginative leap of connecting experiences, hence underpinning forms of ongoing self-narrative. It can therefore give us a way of newly understanding the repeated experiences (return visits; mediated encounters and "being there") which become threaded together in fans' narratives of self, and their associated attachments to places (Waysdorf \& Reijnders, 2018: 3). Critic Matt Trueman (2016) has argued that

It's very hard to be a fan of a building. ... You can get to know an artist or a company, in a way you can't a venue. Their personality shines through [in] their shows. . . . Buildings shift with each show they host. They might have a manifesto, a set of values, maybe even something like personality, but it's abstract and detached. It's not tied to individuals.

But if this is so, how does the National Theatre let "us become fans" (ibid)? And following the "mnemonic imagination", how might this be an imaginative process, as much as one based on fan memory?

\section{Theatre fandom: ventriloquized and materialized}

If media tourism, or visiting a pilgrimage theatre, involves negotiating "between a realized imagination and an imagined reality" (Reijnders, 2011: 114), then we surely need to address how this sifting occurs. As Reijnders reminds us, it is precisely "[b]ecause imaginations and realities are interwoven, [that] people feel the need to unravel them" (ibid: 15). And in terms of repeated theatregoing by "theatre mavens" (Bennett, 2005: 409), we cannot split this dialectic of imagination and reality into buildings merely treated as the "real", and plays/performances presumed to proffer the "imagined". For, as Marvin Carlson (2003: 143) has pointed out, contra Matt Trueman's notion that buildings shift with every show:

[E]lements of theatre ... tend to be reinforced by their association with specific physical buildings. Certain dramatists, certain companies, certain actors, certain designers, often remain for years or even decades at a particular location, and so the audience memories of the previous work of those various theatre artists are reinforced by the fact that much or all of that previous work was experienced in the same physical surroundings.

There is hence a "ghosting" or layering of theatre fans' memories over each new visit to a theatre building, not only in terms of previous productions seen there but also "where ... the memories ... of that part of the city help to provide a reception context for any performance seen" (ibid: 140).

Bringing together the insights of Reijnders and Carlson means, in turn, that memory and imagination are necessarily articulated here; theatre fans engage with particular theatres as places of the imagination simultaneously through memory traces, narratives of producers/performers, geocultural 
associations, and aesthetic experiences of imagined worlds. Keightley and Pickering's (2012) notion of the "mnemonic imagination" therefore offers a valuable theoretical resource, one which emphasizes how memory and imagination are intertwined (ibid: 3 ) and thus how memory can itself be creatively narrated (ibid: 6). As they have argued,

It is through the mnemonic imagination that our engagements with the past move through a series of interactive dualities: . . . the interplay between experience and expectation, memory and possibility; the relations between lived first-hand experience and mediated ... second-hand experience. Exploring the movement between these dualities is crucial.

(ibid: 7)

Keightley and Pickering emphasize how the mnemonic imagination "makes possible the grasping together of the past, present and future in ways that create new meaning" (2012: 63), since it allows for the past and the present to be sifted, contrasted, and narrated within ongoing self-identity, affirming the theatre fan's self-narrative as someone who repeatedly visits particular venues and recalls that history (through first-hand and mediated experience) as meaningful in the present.

As Sandvoss (2014: 134) notes, such memories - products, I am arguing, of the mnemonic imagination - provide "important bookmarks ... in fans' reflexive constructions of personal narratives ... that mark a means through which ... enthusiasm becomes a narrative resource in fans' life courses". At the same time, such "memories foster a sense of attachment and security ... [to] a place where fans . . belong - a form of emotional home" (ibid). The metaphor used in the Handbook of Imagination and Culture for this is actually one of "trails of the imagination" (Glaveanu \& Zittoun, 2018: 360), where the imagination is culturally channelled into iterated "beaten tracks" (media franchises, brands, major venues, etc.) and personally "familiar paths" (ibid: 361) within which places such as the National Theatre can become points of attachment and Heimat experiences for fans/enthusiasts. This very much resonates with well-established work on place and belonging, for example, by Yi-Fu Tuan (1977: 82) and David Seamon (1979: 57), which argues for the importance of repeated visits and familiarity in relation to feelings of place-oriented attachment. Heightened and especially "intense" experience (Tuan, 1977: 185) can also provoke new "trails of the imagination", however - this could be a first experience of monumental architecture such as the NT or a first experience of (located) theatrical artistry. Here, though, it is being suggested that repeated or habitual experiences may also be repeatedly imagined and thus connected and cathected into the groove of fans' self-narrative.

Such "bookmark" memories or "familiar path" of recursive, revisited imaginings are richly evident in the National Theatre programme for its 50th anniversary event (Haill, 2013). Here, NT staff, playwrights, and politicians 
were invited to commemorate the theatre's half-century (extending back to the National Theatre company's beginning in 1963, then based at the Old Vic). Contributors tended to affirm personal early memories and/or memories of taking their children to the National for the first time:

In my teens in the late 1970s I fell in love with the National Theatre. I loved the building, the plays, the cafes and the bookshop. It seemed to me the most glamorous and civilized place on earth. It became my hangout. The place I went to read, watch, listen, write, learn and dream. ... . I am as thrilled as ever to be able to enter via the Stage Door. I met my wife Debra fifty yards from that door. When our first child became of play-going age we took him, of course, to the NT. . . Thank you NT for the life you have given me.

(Marber in Haill, 2013: 17; see also Miller in Haill, 2013: 39)

There is a sense of passing the NT on to offspring as a sort of parental gift, whilst this also acts, in sociological terms, not only as part of a self-narrative of home/belonging (Waysdorf \& Reijnders, 2018) but also as the intergenerational transmission of cultural capital. This notion of belonging at the National is also present in playwright David Hare's account, Hare having been extensively associated with the National (Billington, 2007: 327). He recalls that when "we moved into the South Bank, ... it was so huge that ... I would run into friends I hadn't seen for years, but who turned out to be working somewhere in the building" (Haill, 2013: 23).

John Grindrod interviewed National Theatre staff in his study Concretopia, and there was a similar sense of blending past and present through the mnemonic imagination. These staff members again recall early experiences of the NT - crucially, before they worked there professionally - cementing self-narratives of "familiar paths":

Paul, who had joined the lighting department in 1982, had similarly warm feelings about the building from the start. "I always loved the building", he told me. "I live in central London, just down the river, and I watched it being built. I used to come down here and get excited, and I always thought it was a wonderful space, a wonderful structure. Always liked it. Always fascinated by it."

(Grindrod, 2014: 420)

Though it can be argued that "fans ... are more likely to share their experiences and thus contribute to the wider 'story' of a destination" (Linden \& Linden, 2017: 113), these are "theatre professionals-as-fans" (Tulloch, 2018: 426), meaning that the expressions of NT fandom which tend to have been officially recorded do not hail more broadly from outside theatre's professional world (Haill, 2013). Those who "reside" at the NT, if you like, are valued above tourist or pilgrim fan audiences, who remain somehow an 
"alien culture" (Bennett, 2005: 409), spoken for by staff: “The NT rewards repeated visits.... It grows on you. Once, in a meeting of NT technical staff, [a] theatre consultant ... asked how many loved the building. A forest of hands went up" (Dillon, 2015: 85). Those within the professional theatre field act as a substitute voice for external fans, providing a kind of ventriloquized fandom that can more securely discursively anchor the value of the NT's activities. The aberration or unexpectedness of "outsider" fan voices is sometimes acknowledged, as when former NT Artistic Director Nick Hytner recounts how people would approach him to say how much they loved the NT before then mentioning the lack of queues for the ladies' toilets or "exceptional" meatballs in the Terrace restaurant. Hytner (2017: 273-274) acknowledges that "I learned to be as happy to hear about interval activity ... as I was to hear about the play", indicating that when fans are not ventriloquized via professional accounts, then they do not stick to aesthetic discourses of theatrical appreciation.

Seeking testimonies from ordinary fans of the NT would also risk exposing just how little they might represent "the nation" - whatever that could mean in terms of multiple constructs - but it nevertheless seems culturally safer to leave the nation, precisely as an imagined community, very firmly imagined behind the figures of NT staff, playwrights and actors, allowing the NT to "maintain the illusion of its reconstruction of a ... public sphere" (Jones, 2007: 128). As Ross Garner has noted, limiting "discussion of anniversaries and affect to institutionally controlled examples results in fans' affective responses becoming marginalized" (2018: 67).

For the ordinary, non-professional theatre fans who gather at Theatreboard (theatreboard.co.uk), a forum formerly linked to the publication What's On Stage but run independently since 2016 by "a group of dedicated fans" (MyTheatreMates, 2016), the NT is discussed in relation to its specific productions, and its new seasons are also communally pored over. Fan comments in "New Season" threads display the mnemonic imagination's "interactive dualities" of experience and expectation, drawing on previous encounters with the National and positioning theatrical knowledge as bound up with consumerist expectations. Here, the NT is represented primarily as an organization that forum members want to interact with as well-served consumers; NT website crashes are reported on, and posters share their adventures in terms of trying to secure tickets, as well as sharing tips on when/how to get cheap but decent seats, sometimes at the front of the stalls. The NT as an architectural space is backgrounded, with the emphasis falling on how well run (or not) online ticket sales are, as well as on debates surrounding the composition of each new season immediately it's announced.

Non-professionalized theatre fandom has been othered as excessively consumerist in versions of theatre studies (though this situation is changing as work on theatre fandom continues to develop). For example, Baz Kershaw (1994: 174) laments how "wearing . . . a National Theatre peaked cap may be even more culturally charged than an evening in the stalls watching the 
show", with consumption supposedly being substituted for authentic theatrical experience. Set against this, Caroline Heim's (2016: 133) audience studies' work on "mainstream theatre", based on interviews with theatregoers, stresses how the "theatrical programme, more than any other souvenir, stirs the memory of the event. . . Some audience members cherish and almost deify their programmes. ... For some ..., the programme subsumes all the memories of the suspended moments of the production ... and becomes 'a time capsule to capture a special moment in time"”. And even where fans are not attending the National Theatre building on the South Bank, instead watching productions beamed live to a local cinema as part of the "NT Live" scheme, a "physical reminder of the event in the form of a programme was desired by 22 per cent of respondents... . The importance of physical items is also evident in the 14 per cent who said they would consider buying NT Live official merchandise after watching the broadcast" (Abbott \& Read, 2017: 181). Retail is thus a normalized part of contemporary theatre fans' expectations (Heim, 2016: 132), with souvenirs such as programmes acting as tokens of cultural capital that "place ... the work, the production, and the audience member into a nexus of ... cultural significance. The program can act as a guarantee of the cultural experience, and can help to authenticate it" (Atkinson, 2006: 155), akin to other (media) tourist memorabilia.

The programme is thus a marker of having been there, providing "materialized traces of the imagination ('souvenirs from the road')" (Glaveanu \& Zittoun, 2018: 361). But more than that, it also iterates the sense of attachment to a venue such as the NT, aiding the mnemonic imagination in stitching together memories, present affective relationships to the theatre-as-location, and a fannish self-narrative anticipating future theatrical productions (or revivals) yet to be experienced. Collecting programmes can also interweave biographical self-narrative with the shared historical narrative of a theatre. Fans can memorialize attending the NT during the eras of artistic directors or in relation to different directors' "brands" (Mermikides, 2013) and playwrights' careers: "Many of the National's most acclaimed shows have hinged on pairings who appear as recurring characters in The National Theatre Story: Peter Shaffer and John Dexter; Harold Pinter and Peter Hall; David Hare and Richard Eyre; Tom Stoppard and Trevor Nunn; Alan Bennett and Nicholas Hytner" (Rosenthal, 2013: xii). To date, the NT has had only six artistic directors since its formation in 1963 (all men); this lineage provides a way of readily narrating different historical moments. In addition, the NT's artistic directors have tended to publish their recollections of leading the institution (e.g. Hytner, 2017), and these have been supplemented by the memoirs of leading directors and playwrights (e.g. Blakemore, 2013; Hare, 2015). As a result, the NT's less formal public documentation proffers a series of not always on-brand anecdotes, differing in tone from published recollections linked to brand anniversaries such as Britain's Royal National Theatre: The First 25 Years (Goodwin, 1988) or National Theatre: 50 Years on Stage (Haill, 2013), as well as the institution's "authorised biography" (Rosenthal, 2013: xiii). 
Fans' programme-buying and souvenir consumption is therefore one way for the mnemonic imagination "to connect personal and public remembering ..., with each being implicated in the other. The work of the mnemonic imagination produces the synthesis of our first-hand experience with . . . culturally mediated second-hand experience" (Keightley \& Pickering, 2012: 199). However, as I have noted, it is not only via theatre fandom that the National Theatre becomes an object of (located) fan imagination, for it also has a dedicated following of brutalism fans, for whom its building - and architect Denys Lasdun - are more central to processes of the mnemonic imagination than specific theatre productions, directors, and playwrights. I will conclude by considering this second aspect of the NT's "co-existent" doubling (Rosenthal, 2013: 845).

\section{Architectural enthusiasm: publicized and merchandized}

The rise of Web 2.0 has moved an array of fan practices into the mainstream of cultural participation. The concept of participatory culture - initially discussed by Jenkins as an aspect of fan communities (1992) - has now been used to analyse post-show theatre engagement (Conner, 2013,2016) and interpretive communities' interactions with "iconic" architecture (Aigner, 2016; Garduño Freeman, 2018). Taking the Sydney Opera House as her case study of an architectural icon, Garduño Freeman argues that tourists and visitors "contribute to the building's representation in culture" (2018: 78 ) by sharing their photographs, videos, blogs, and material productivity. Although we might assume that participatory culture - communities producing and sharing their own media texts - democratizes the "official" mediation of architecture, Anita Aigner demonstrates that this is not always the case. Even participatory media shared online can replay the dominant cultural-industrial "architectural gaze" which

presents a building as an autonomous object viewed for its own sake. It does not show the use . . . of the object, . . . but instead . . captures the object from its best side. . . . It is characteristic for . . . [this] legitimate imaging mode, especially as regards exterior shots, that the objects are shown in full size and without much environment. ... This artefact-centred image type also assigns ... recipients a position: one of a spectator distanced and separated from the object, like a visitor to a museum opposite an exhibit.

(Aigner, 2016: 190)

As well as sharing this "authorised heritage discourse" (ibid: 183), what has been termed the "architectural enthusiasm" of organizations such as the UK's Twentieth Century Society (Craggs et al., 2013) also intersects with official governmental practices, as the Society is involved in the conservation of valued architecture. Indeed, as Craggs et al. (2016) have shown, 
architectural enthusiasts have tended to discursively police their own emotional, fannish investments in architecture by splitting communal activities into education/socializing, which can be passionate, and conservation or campaigning, which are instead very much presented as professional and rational (ibid: 1). Associations with "fandom, obsession, geekiness, or amateurism" are therefore denied by members of the Twentieth Century Society when they are involved in conservation work (ibid: 2), as "it is not always helpful to be seen as the "anoraks of concrete architecture"” (ibid: 6).

Enthusiasts have been categorized as distinct from fans on the basis that media fans focus their attention directly on media texts, whereas enthusiasts are interested in a material hobby which then leads to specific media consumption (Abercrombie \& Longhurst, 1998: 148-150). However, this binary has been relaxed in subsequent scholarship, with Longhurst (2007: 104) using "enthusing to capture the idea of some degree of investment in forms of culture be they directly media related or not". Drawing on this latter sense, architectural enthusiasm as defined by Craggs et al. (2013) - like the participatory cultures identified by Aigner (2016) and Garduño Freeman (2018) - can be thought of as a type of fandom, making sense of Grindrod's (2018: 139) description of "brutalist fans".

However, I want to suggest that the National Theatre is not so much an "icon" but rather an architectural monument that is valued by its concrete devotees. Sklair (2017) has suggested in The Icon Project that contemporary iconic architecture operates within a neoliberal framework, promoting consumption and reinforcing the dominant power of a transnational capitalist class. Sklair defines "monumentality" as belonging to an older era in the "public expression of architectural representation", with iconicity replacing this as a central discourse. The result is that "architectural iconicity has been socially produced by the corporate fraction of the transnational capitalist class in architecture and has begun to replace monumentality as a marker of the global hegemony of the capitalist class" (ibid: 53-54). Iconic architecture is usually privately funded, typically acting as a component of place-branding within the experience economy (Klingmann, 2010; Lonsway, 2009).

The National Theatre is a product of 1960 s and 1970 s UK politics, though, having opened in 1976. Architecturally, it belongs just before our intensified neoliberal era where such "[1]eft modernisms of the 20th century continue to be useful... [as] a potential index of ideas ... [that] can still offer a sense of possibility which decades of being told 'There is No Alternative' has almost beaten out of us" (Hatherley, 2008: 13). The National Theatre, as befitting its status, was designed as monumental public architecture rather than as a privatized consumer-cultural "icon". It was part of a "last push to create exciting and experimental public spaces, before responsibility for these kinds of projects shifted decisively away from public and into private hands" (Grindrod, 2014: 403). Its architect Denys Lasdun conceptualized the NT as a space that was "open" to the city and the public, comparing flows of audiences in and out of auditoria to the adjacent River Thames (Dillon, 2015:36, 
45). Lasdun also intensely valorized the NT's public spaces - foyers, walkways, and terraces - as a kind of "fourth auditorium" alongside the building's three theatre spaces (ibid: 45). Indeed, this "fourth theatre" notion (Jones, 2007: 126 ) is repeatedly emphasized in official NT publications (see also Goodwin, 1988: 99), working as an ongoing narrative legitimation of the theatre's public and "national" status. Such is the prevalence of this authorized NT discourse that the Open House London 2019 event even included a talk on the topic of "Social Spaces at the National Theatre" (Open House London, 2019).

This dominant discourse of the NT's "public" architecture, where in-between spaces of transit inside the building are generously proportioned and where interior and exterior are demarcated in "open" ways (Carlson, 1989: 161162 ) - even more so after the National's restoration project led by architects Haworth Tompkins (Grindrod, 2018: 125, 127) - vehemently positions the NT against London's more recent architectural icons (Tompkins \& Todd, 2007: 3-4). And this publicizing discursive practice - performing the NT as a resolutely public space even as it is branded and de facto commercialized in terms of having to justify its public subsidy (Kershaw, 1994: 168) - is frequently recapped in the accounts of architecture enthusiasts. Grindrod (2014: 403) says of the Barbican and the National Theatre that "[s]ince my teenage years I've spent so many hours hanging around in their concrete foyers and balconies, theatres and bars. ... To me they are ... comfortable, welcoming . . . and entirely life-enhancing”. Barnabas Calder (2016: 326) produces a similar self-narrative in Raw Concrete: The Beauty of Brutalism when he observes of the NT that there

is abundant unprogrammed space for theatregoers to mill around, passers-by to drop in ... or have a sit-down ... or any other function people might choose for what amounted to free, warm, indoor space. As a teenager without much cash I was one of countless beneficiaries, over the decades, of a place where I could read for hours, wait for or talk to friends, or just watch the world go by without having to buy and force down pints of tea or coffee.

Reminiscent of the NT regulars quoted by Nick Hytner (2017: 273-274), who appreciated the facilities in the interval as much as the plays being staged, and resembling NT staff accounts of loving to spend time in the building before they worked there (Grindrod, 2014: 420), this publicizing fandom values the NT not just for its spectacular brutalism which underpins the "architecture geek's pleasurable game" of appreciation (Calder, 2016: 273) but also for its unprogrammed interior public spaces construed as "minimally consumerist" (Sklair, 2017: 226). The mnemonic imagination at work here is one which moves through a specific duality: past and present are stitched together via an interplay between public and private, given that the current incarnation of the NT is significantly commodified, both 
through its construction as a brand (extended via NT Live) and through its merchandising not just of play texts, programmes, and posters etc, but also brutalism and the building itself.

Although the NT Shop caters to both theatre and architecture fandoms, it typically does so through distinct commodities, hence recognizing the sequestered expression of these focused interests, I would argue. For theatre fans, there is merchandise focused on playwrights, plays, and the experience of theatre's art world; this takes generic form via posters, prints, and badges. And for architecture fans, there are ranges of merchandise which instead very much emphasize the National's materiality and construction - its concrete design and brutalist identity. For example, a souvenir "architecture model" of the National can be purchased via its shop (National Theatre, n.d.), and as Grindrod (2018: 138-139) has observed, brutalism has been subjected to considerable merchandising, including paper cut-out models of the National and even a Brutalist London Map which "is designed to affirm the value of these buildings" (Billings, 2015: np.).

Like souvenirs of the Sydney Opera House, albeit less rampantly diversified across product types, the architectural and cut-out models of the NT "mediate experiences of the building. ... [S] ouvenirs invert the 'real' scale between the tourist and the building ... [enabling] people to experience the building as a whole" (Garduño Freeman, 2018: 136) and thereby enabling an experience of symbolic imagined ownership. The NT can sit, as a model, on my office desk or on my coffee table at home, rendered as a materialization of trails of imagination just like a theatre programme or a peaked cap. And although it may be true that "brutalism seen through a lens - be it books, photos, products or social media - is no substitute for experiencing the real thing ... [which] will live with you afterwards in indefinable ways" (Grindrod, 2018: 139), what remains significant is the different type of experience that an NT model or a Lasdun-oriented souvenir such as Patrick Dillon's (2015) book Concrete Reality: Denys Lasdun and the National Theatre can confer. By consuming architecture in this way, its fans are also performing their attachment to the NT as a building and a place, imaginatively transferring it from public space to privatized (domestic/work) domains of self-identity. The emotional home of the physical NT is, in this sense, not just revisited literally and imaginatively by its fans - it is also symbolically incorporated into people's actual homes and thus rendered meta-habitual, if you like, as a mode of "fan homecoming" which can be simultaneously ordinary, everyday, and extraordinary through the mediation of commemorative souvenirs and models (Waysdorf \& Reijnders, 2018: 3).

Fans hence enact a mnemonic imagination that bridges their first-hand and second-hand experiences of visiting the National and consuming mediated images of it, not just materializing memories of their visits but also literalizing the metaphorical Heimat of the place (Sandvoss, 2014: 134-135) by domesticating merchandized maquettes. Of course, it is in the interests of the National Theatre to facilitate this interiorization of its brand and its public building. 
Within a consumer-cultural, neoliberal context, this is one way (like the transferred cultural capital handed down from parents to socialized, theatregoing children) that the institution can seek to cement its future, hoping to be merchandized into people's self-narratives and self-identities as fans. Whereas Kershaw (1994: 174) viewed this consumerism as inimical to "authentic" theatre and performance, it might now be interpreted - within a mixed economy of public/private UK theatre funding - as one support, however problematic, to the National Theatre's centrality within the theatre world. Through the fan imagination, spectators can become symbolic "owners" of the NT, just as other parts of the institution's practice may invert this by commodifying experiences of theatrical and symbolic "ownership" (see Deeney, 2007: 341 on the NT's "Connections" programme for young people).

In this chapter, I've argued for the importance of considering an underexplored aspect of fandom - how theatrical venues/buildings such as the National Theatre on London's South Bank can act as places attracting their own modes of fandom. I've suggested that NT staff and celebrated theatre professionals become fan stand-ins in terms of legitimating the theatre's activities, ventriloquizing the attachments and engagements of "ordinary" theatre fans. And I've suggested that architecture enthusiasts tend to enact a publicizing stance on the value of Lasdun's building, positioning its weathered permanence (Klingmann, 2010: 51; Marini, 2013) as a pre-neoliberal and implicit rebuke to the increasingly commercialized, branded theatre culture of today. At the same time, both theatre fans and architecture enthusiasts work to locate imagination by consuming materializations of memory in the form of theatre programmes, architectural models, and so on. These forms of "fan homecoming" (Waysdorf \& Reijnders, 2018) therefore tend to combine repeated visits, rather than one-off pilgrimages, with symbolic incorporation into fans' actual homes. And this indicates, following Reijnders (2011), that we need a greater focus on fan memory as creatively linked to imagination via the "mnemonic imagination" (Keightley \& Pickering, 2012) - as well as recognizing that theatre and architectural fandoms can be relatively distinct interpretive communities, not always meeting up in the contemporary experience economy. The cultural and social value of the National Theatre are not just doubled or co-existent here but also over-determined. Although work on screen/media tourism has been productively in dialogue with work on media fandom for quite some time, I have argued that spatial forms of fandom which are less clearly or directly linked to mass media (Cavicchi, 2014: 53), such as theatre fandom and architectural enthusiasm, can also profitably be analysed in relation to places of the imagination.

\section{Bibliography}

Abbott, D. \& Read, C. (2017). Paradocumentation and NT live's 'CumberHamlet'. In: T. Sant (ed.), Documenting performance: The context \& processes of digital curation and archiving, pp. 165-187. London: Bloomsbury. 
Abercrombie, N. \& Longhurst, B. (1998). Audiences: A sociological theory of performance and imagination. London: Sage.

Aigner, A. (2016). Heritage-making 'from below': The politics of exhibiting architectural heritage on the Internet: A case study. International Journal of Heritage Studies 22(3): 181-199.

Atkinson, P. (2006). Everyday arias: An operatic ethnography. Lanham: AltaMira Press.

Barker, M. (2013). Live to your local cinema: The remarkable rise of livecasting. Houndmills and New York: Palgrave Macmillan.

Bennett, S. (2005). Theatre/tourism. Theatre Journal 57(3): 407-428.

Billings, H. (2015). Introduction to brutalism. In: H. Billings (ed.), Brutalist London Map. London: Blue Crow Media.

Billington, M. (2007). State of the nation: British theatre since 1945. London: Faber and Faber.

Blakemore, M. (2013). Stage blood: Five tempestuous years in the early life of the National Theatre. London: Faber and Faber.

Bucknell, J. \& Sedgman, K. (2017). Documenting audience experience: Social media as lively stratification. In: T. Sant (ed.), Documenting performance: The context \& processes of digital curation and archiving, pp. 113-130. London: Bloomsbury.

Calder, B. (2016). Raw concrete: The beauty of brutalism. London: Penguin.

Carlson, M. (1989). Places of performance: The semiotics of theatre architecture. Ithaca: Cornell University Press.

Carlson, M. (2003). The haunted stage: The theatre as memory machine. Ann Arbor: University of Michigan Press.

Cavicchi, D. (2014). Fandom before 'fan': Shaping the history of enthusiastic audiences. Reception: Texts, Readers, Audiences, History 6(1): 52-72.

Conner, L. (2013). Audience engagement and the role of arts talk in the digital era. New York: Palgrave Macmillan.

Conner, L. (2016, July 13) Taking back the arts: 21st century audiences, participatory culture and the end of passive spectatorship. L'Ordinaire des Amériques 220. Retrieved from http://orda.revues.org/2773 (20-08-2019).

Craggs, R., Geoghegan, H. \& Neate, H. (2013). Architectural enthusiasm: Visiting buildings with the twentieth century society. Environment and Planning D: Society and Space 31: 879-896.

Craggs, R., Geoghegan, H. \& Neate, H. (2016). Managing enthusiasm: Between 'extremist' volunteers and 'rational' professional practices in architectural conservation. Geoforum 74: 1-8.

Deeney, J.F. (2007). National causes/moral clauses? The National Theatre, young people and citizenship. Research in Drama Education 12(3): 331-344.

Dillon, P. (2015). Concrete reality: Denys Lasdun and the National Theatre. London: National Theatre Publishing.

Garduño Freeman, C. (2018). Participatory culture and the social value of an architectural icon: Sydney Opera House. London: Routledge.

Garner, R. (2018). Affective textualities, generalizations and focalizations: Fan reactions to Twin Peaks's 2014 paratextual return. Journal of Fandom Studies 6(1): 63-80.

Glaveanu, V.P. \& Zittoun, T. (2018). The future of imagination in sociocultural research. In: T. Zittoun \& V.P. Glaveanu (eds.), Handbook of imagination and culture, pp. 347-367. Oxford: Oxford University Press.

Goodwin, T. (1988). Britain's Royal National Theatre: The first 25 years. London: National Theatre/Nick Hern Books. 


\section{Matt Hills}

Grindrod, J. (2014). Concretopia: A journey around the rebuilding of postwar Britain. Brecon: Old Street Publishing.

Grindrod, J. (2018). How to love brutalism. London: Batsford.

Hadley, B. (2017). Theatre, social media, and meaning making. Cham: Palgrave Macmillan.

Haill, L. (ed.). (2013). National Theatre: 50 years on stage. London: National Theatre.

Hare, D. (2015). The blue touch paper: A memoir. London: Faber and Faber.

Hatherley, O. (2008). Militant modernism. Hampshire: Zero Books.

Heim, C. (2016). Audience as performer: The changing role of theatre audiences in the twenty-first century. London: Routledge.

Hills, M. (2017). Popular theatre and its 'invisible' fans: Fandom as external/internal to the theatrical field. LiLi: Zeitschrift für Literaturwissenschaft und Linguistik (online). DOI:10.1007/s41244-017-0074-2.

Hytner, N. (2017). Balancing acts: Behind the scenes at the National Theatre. London: Jonathan Cape.

Jenkins, H. (1992). Textual poachers. London: Routledge.

Jones, A. (2007). National theatres in context. Cardiff: University of Wales Press.

Keightley, E. \& Pickering, M. (2012). The mnemonic imagination: Remembering as creative practice. New York: Palgrave Macmillan.

Kershaw, B. (1994). Framing the audience for theatre. In: R. Keat, N. Whiteley \& N. Abercrombie (eds.), The authority of the consumer, pp. 166-186. London: Routledge.

Klingmann, A. (2010). Brandscapes: Architecture in the experience economy. Cambridge: MIT Press.

Linden, H. \& Linden, S. (2017). Fans and fan cultures. New York: Palgrave Macmillan.

Longhurst, B. (2007). Cultural change and ordinary life. Maidenhead: Open University Press.

Lonsway, B. (2009). Making leisure work: Architecture and the experience economy. London: Routledge.

Marini, H. (2013). A performative falling into the cityscape. Performance Research 18(4): 133-142.

Mermikides, A. (2013). Brilliant theatre-making at the national: Devising, collective creation and the director's brand. Studies in Theatre and Performance 33(2): 153-167.

MyTheaterMates.com. (2016, February 12). NEWS: Users launch independent TheatreBoard after closure of WhatsOnStage forum. Retrieved from https:// mytheatremates.com/news-users-launch-independent-theatreboard-after-closureof-whatsonstage-forum/ (20-08-2019).

National Theatre. (n.d.). Online shop. Retrieved from https://shop.nationaltheatre. org.uk (20-08-2019).

Ockman, J. \& Frausto, S. (eds.). (2005). Architourism. London: Prestel.

Open House London. (2019). National Theatre 2019 programme. Retrieved from https://openhouselondon.open-city.org.uk/listings/1172 (20-08-2019).

Reijnders, S. (2011). Places of the imagination: Media, tourism, culture. Farnham: Ashgate.

Rosenthal, D. (2013). The National Theatre story. London: Oberon Books.

Sandvoss, C. (2014). I <3 Ibiza: Music, place and belonging. In: M. Duffett (ed.), Popular music fandom, pp. 115-145. London: Routledge.

Seamon, D. (1979). A geography of the lifeworld: Movement, rest, and encounter. London: Croom Helm. 
Sklair, L. (2017). The icon project: Architecture, cities, and capitalist globalization. Oxford: Oxford University Press.

Tompkins, S. \& Todd, A. (2007). The unfinished theatre. Retrieved from www.studioandrewtodd.com/repository/publications/pdf/The-Unfinished-The-d89ae0e8.pdf (20-08-2019).

Trueman, M. (2016, July 18). Matt Trueman: Theatre rarely lets us be fans. What's On Stage. Retrieved from www.whatsonstage.com/london-theatre/news/matttrueman-theatre-latitude-festival-fans_41309.html (20-08-2019).

Tuan, Y. (1977). Space and place: The perspective of experience. Minneapolis: University of Minnesota Press.

Tulloch, J. (2018). Class 'then' and class 'now'. In: Hotel cerise. In: M.A. Click \& S. Scott (eds.), The Routledge companion to media fandom, pp. 416-427. London: Routledge.

Waysdorf, A. \& Reijnders, S. (2018). Fan homecoming: Analyzing the role of place in long-term fandom of the Prisoner. Popular Communication (online): 1-16.

Williams, R. (2018). Fan tourism and pilgrimage. In: M.A. Click \& S. Scott (eds.), The Routledge companion to media fandom, pp. 98-106. London: Routledge.

Zittoun, T. \& Rosenstein, A. (2018). Theater and imagination to (Re)discover reality. In: T. Zittoun \& V.P. Glaveanu (eds.), Handbook of imagination and culture, pp. 223-242. Oxford: Oxford University Press. 


\section{Index}

3FM Serious Request (live event) 216, 218-9, 221

\section{absent present 5}

absorption 76-77, 81

accents 51,56

active audiences 3, 136-137, 139, 146, 185, 206, 211

adaptation (in media) 22, 101, 168, 174-175, 251

affective texture(s) $68,80,175$

affectivity: in imagination 6, 12, 67-71, 74-77, 80-81, 84-85, 88-93, 249; in relation to place $205,226,297$, 302-303; see also topophilia

affiliation: with people 233,239 ; with place 205,207

agency 5, 167, 175; “imaginative" 172; in videogames 154-155; see also player agency

A la Recherche du Temps Perdu (Proust) 267, 272

"Alpine way of life" 202-203, 205-208, 212

alternative tourism $34,39,41,43,46-48$; alternative tourist $34,39,42$

Amachan 13, 134-135, 137-139, 142-146; see also asadora

ancestry $247,251-252,254$

anthropological gaze 156

Appadurai, Arjun 9, 54

appropriation 3, 12, 26; cultural 84, 202; spatial 26, 42, 48, 200, 211; commercial 216

architecture: brutalist 52, 56, 297;

landscape 115 ; in videogames 157 , 159; enthusiasm 297, 298, 304-306, 308; monumental 298, 300, 301, 305; “iconic" 304-305; fandom 298, 307 armchair travel 171, 173

artists 4, 46, 63, 166, 196, 276; digital 159; on festivals $219,230,234$, 238,240 ; in music 80,86 ; in theatre 298-300

asadora (Japanese morning drama) 13, 134-140, 142, 144-146; authenticity of filming locations 139, 142; see also Amachan; Oshin

associations 9-11, 20, 22, 25, 168, 261, 300, 305

atmosphere (of place): in everyday

life 85, 87-89, 91-92, 94; on

festivals 215 ; in music $79,80-81$; in narratives 9,278

authenticity (tourism) 3, 26, 28, 249, 283, 290; approaches to 39-42;

constructive $35,40,42$; existential $35,40,42,45,47,209$; historical 34,250 ; imaginative $12,34-35,39$, 41-42, 44-48, 174-175; objective 35, 40-42, 46; staged 39-40, 168; symbolic 249

autoethnographic play 186

"banal tourist" 37

being-in-place 220-224, 226-227

being in the world $68,79,81,171$

belonging (sense/feeling of): elective 207; geographical 1, 3-4, 6-7, 12, $14,69,93,169,172,175,200-201$, 211, 230, 300-301; social 40, 59, 70, 207, 231, 233, 239; see also place attachment; home

belongingness 231, 233, 236, 238-240

Bergdoktor (Der) 14, 200-211

Billingham, Richard 59, 63

Birmingham Film and Television Festival 59

Black History 251 
Black Sabbath 57

Blake, William 4, 166

Bourdieu, Pierre 47-48, 168

brand (place) 24, 300, 303

branding 27, 111, 113, 115, 298, 303, 305 ; nation $134,137,144,146-147$; re-branding 58, 257

Brexit 62-64

Bridge, The (Nordic Noir series) 100, 102-103, 110

Britishness 6; see also Englishness

Brutalism 297, 304-307; see also architecture

"bubbles" (tourism) 14, 34, 71, 93, 232, 253; festival 216; personal music 71,77

Burke, Vanley 61

camaraderie 230-231, 238

Carnival (Rio de Janeiro) 120, 128

Centre for Contemporary Cultural Studies 52

Citizen Kahn (TV series) 61

city (the): "ageographical” 173; "capital crime" 170, 175; colonial 122; cosmopolitan 122, 128; postcolonial 120; "traveling" 120; tropical 120; videogame $151,153,155$

cityscape $13,119,123,125,129-130$

Civil Rights Movement 251

cognition 42, 69, 71, 80-81

collaboration: cross-sectoral 24, 100-102, 110-112, 114-115; modes of 100 , 111

"collective gaze" 139,168

colonialism 120, 122, 207; semicolonialism 203, 206, 211

commemoration: in film tourism 286-287, 291; in heritage 52, 58, $60,251-252,258,301$; through souvenirs 159,307

commodification 27

communitas 40, 70, 233-234, 236-237, 240

companionship 233, 239

connectedness 233, 239

conservation 304-305

consumption: cultural 108; media 3,7 , 23, 25, 54, 158, 186, 200, 285, 305; spatial 43, 48, 302-304, 307-308

contents tourism 134

"Cool Japan" 144

"copy principle" 5

copyright 140 cosmopolitanism 119, 122-123

creativity $84-86,89,91,94,167$; in toy tourism 184-185, 188, 190-191, 196

Crime and Punishment (Dostoevsky) 268

crime series / -fiction 99-104, 109-110; crime-detective 170, 173-175;

Nordic 101-103; site-specific 100, 103, 114, 116; transmedia 103

Crossroads (soap opera) 61

cruise ship festival 14, 230-233, 235-240; authenticity of $235,239-240$

cruise tourism 231; tourists 231, 233; see also festival tourism

cultural geography $3,28,85$

cultural industry 85,119

cultural memory 68,168

cultural narratives 68,77

cultural tourism 52, 156

dark tourism 250-251, 261

decay 35-38, 41, 44, 47, 174

democratization of tourism 168

"destination image" 90

destination marketing strategy 100

diaspora 254; tourism 252

Dickens, Charles 56, 266

Dicte (Egholm) 100, 102

diegetic discrepancy 174, 176

diegetic world 6, 171, 250; in videogames 154, 158, 163; see also hyperdiegetic world

digitalization/digitization 146, 169, 173,216

digital methods 219-220

digital platform 185

discourse analysis 220

distinction (social) 34

Dostoevsky 268-269

"dreamscape" 10

embodiment 209, 285, 288-290, 291;

in music 71,76

Empire Rd (soap opera) 61

"encoding/decoding" 3

Enlightenment 4, 58

Englishness 9; see also Britishness

"environmental determinism" 9

escape 90

escapism 124

ethnography 169, 219, 234

“eventrification" 202, 232

event-space 215-216, 218, 220, 224-227 
eventsphere 216-227

everyday life: context $2-3,5-6,84$, $87,90,137-138,291$; role of imagination $12,26,84-87,90-94$ exoticism 119; see also Other experience (of place) 11,35, 163, 216-218; embodied 13, 69, 170, 220-224, 226-227, 289-290; mediatized 215-216, 219; sensory experience 2, 5-6, 11, 67-68, 73, 81, 240; see also imaginative experience

exploring 151, 153, 155, 157, 188

"faction" 247, 261

fan conventions 292-293

fandom 14, 283-294, 305; architectural 14, 307-308; asadora 143, 146; as identity 286; theatre 297-302, 304, 308 ; ventriloquized 302

fan encounters 238

"fan pilgrimage" 135, 139, 142

fan practice $25,137,284,290-291$, 294, 304

fantasy (genre) 6, 8, 25, 268, 284, 286-287, 289

"fearscape" 10, 172

festival tourism 14, 231, 234

fictional museum 270, 272-273

fictional narrative $12,20,22,174,200$, 205, 250, 286

fictional world 26, 103, 135, 249-250, 268,288

film festival 59, 112

film(-induced) tourism 14, 90, 93, 283-286, 288-290, 293-294; policy 102, 111-113

film production 111, 287; see also screen production

Fjällbacka (Läckberg) 102-103

flow: of content 20,135; during live events 218, 224, 227; in music 69, $71,77,81$; “overflow" 155 ; tourism 19, 23, 28, 79, 305

Flying down to Rio (musical) 13, 119, 121-124, 127-129

framing $38,155-158$

Game of Thrones (series) 19, 22, 25, 102, 201, 283, 287; fans 287-289, 291, 293

gamer-tourist 153-154, 163; see also videogame tourist

Gangsters (TV series) 61 geocaching 184, 186, 188-190, 193, 195-196

geography: cultural 3, 28, 85; human 85,217

genius loci 266, 278-279

gentrification 39

Gibson, Hugh 119, 124-129

Girl with the Dragon Tattoo, The

(Larsson) 100; see also Millennium

Trilogy

globalization 7, 9, 62-64, 173

Grand Theft Auto 154, 156; San

Andreas 155-158, 160, 163; V 160, 163

grounded theory 70, 170, 219, 231

habitual 86, 90, 93, 300, 307

habitus 34, 47

Hadid, Zara 58

Haley, Alex 247-248, 251-252, 255, 257-262

Harry Potter (series) 6, 24, 102, 268-269, 287; fans 288, 291-293

hashtag 185, 218, 220, 222, 226

Heimat 11, 172, 200, 203, 207, 300, 307

heritage 21-23, 28, 58, 168, 304; Gambian 247-255, 257, 259, 261; sites 2, 34, 37-41, 46; tangible \& intangible 21, 23; as urban strategy 52; see also imaginative heritage; UNESCO; World Heritage Site

heritage dissonance 250-251

heritage industry 34

heritage narratives 248, 250, 255, 257, 259, 261; see also historical narratives

heritage tourism 39, 43, 57, 168, 247

heritage tourists 14, 247

heritage-scape 248, 255, 261

"historical imaginary" 255

historical narratives 174, 261, 303; see also heritage narratives

holistic perspective $2-3,12,19,20$, 27, 29

home (sense of) 3, 7-9, 11, 12, 14, 92, 142, 207, 221, 289, 300; see also belonging

"homecoming" 293, 307-308

homo narrans 8, 167

homo sapiens 8

Hume, David 5-6

"hybrid site" 12

hyper-circulation 46 
hyper-connectivity 46

hyperdiegesis 287,288

"hyperdiegetic world" 25; see also diegetic world

hyperreality 235

identity (sense of) $10-11,68,70,74$, 77, 81; local 23, 59, 62, 120, 146; national $22-23,92,118,145-146$, 202-203; personal 75, 77-78, 205, 300, 307; transnational 23; see also Self; Other

idol (music) 138, 145, 230

imaginaries 2, 68, 87, 116, 155-157; national 118, 202, 207; "tourism" 9, 22,26

imagination (the): collective 13,118 , 249-250; in heritage 248-251;

historical 38,255 ; ironic 288 ; through literature 166-167, 170-173, 175; mnemonic 297-298, 300-303, 306-308; through mobile toy play 184-185, 196; through music 67-70, 79-81; popular (culture) 24-27, 51, 54, 58, 119; re-imagination 12,91 ; theorizing 2-11, 84-86, 88-92, 261; urban 36-38, 42-46, 155

imaginative authenticity see authenticity imaginative experience 76-77, 286, 288; modes of (in film tourism) 287 “imaginative geographies" 9, 22, 167, 268-269, 70

imaginative heritage 12, 19-23, 25-29; see also heritage

imaginative journey $7,171-172$

imagined community 302

immersion 76-77, 81, 211, 289

immigration 60,118

industrial revolution 56-57

"inherited memories" 73, 80

Innocence of Objects, The (Pamuk) 270 intervention: place 106-107, 115; sitespecific 107, 114; tourism 106 interviews (qualitative): with cruiseship festival tourists 231, 239; with literary tourists $170-171,174$; with music tourists in Europe 67, 70-81; with New Nordic Noir producers 106-107; with Oerol and 3FM Serious Request festival-goers in the Netherlands 219-221, 224, 227; with Roots-tourists 248, 254; with theatre-goers (National Theatre) in London 303; with toy tourists 184 ,
186; with urban explorer in Sweden $35,43,45,46$

island (the) 9-10; Kunta Kinteh Island 248, 250, 253, 255, 257; Terschelling Oerol festival 215-216, 218, 220, 226

"Japaneseness" 13, 146

Joyce, James 266, 268-269

Judas Priest 57

Kant, Immanuel 5-6, 79

The Killing (Nordic Noir series) 100-102

Killing Cloud (videogame) 151-152

"kitsch" 236

Kritik der Reinen Vernunft (Kant) 6

Kunta Kinteh 247-248, 252-253, 255-262

Läckberg, Camilla 102-103

landscape: coastal 108, 111, 115; cultural 22; heritage 248, 255; hybrid 100, 107; imagined 11, 116, 200, 208, 269; liminal 110; literary 251; mediated 3, 146, 248, 284; Nordic 100, 103; socio-cultural 118-119, 125 ; symbolic 25; typology of 10-11, 144, 269; urban 9, 26, 56, 125, 130

Larsson, Stieg 101-102

leisure: services 58, 63; time 40, 43; as tourism practice $129,154,158,184$, 195

lieux de mémoire 249, 262n

lieux d'imagination $249,262 \mathrm{n}$

liminality 40, 45, 107, 110, 208, 233, 237,239

literature: definition of $167,168-171$; as medium $13,21,25,69,84,88$, 134,166 ; study of $266-267$

literary narratives 14, 167-169, 173, 176

"literary pilgrimage" 19,168

literary tourism $13,21,101,166-170$, $173,175,265-269,280$; definition of 167-168; see also narrative tourism

literary tourist 14, 168-169, 174; experience 170, 267, 277, 279

liveness 14, 76, 216-218, 223, 225, 227

local communities 19-21, 23, 28, 62, 79,138

locale 217, 221-222, 224-226; see also place

local governments 13, 20-21, 23, 27-28, 55 


\section{Index}

locating 7, 86, 91; imagination 1, 85-86, 100, 107, 113, 115-116, 265

Locating Imagination (project) 70, 169, 265,283

location placement 110, 112-113, 116

Lord of the Rings (series) 6, 10, 268-269

MacCannell, Dean 39-40, 46, 283-284

Mankell, Henning 101

Marvel's Spider-Man 154, 158

mass tourism 34, 39, 115

McGoohan, Patrick 287

media: broadcast 217-219, 223-224; of communication 216-217; connective 223, 225; digital 136-137, 218, 285; mass 218, 308; popular 11, 19, 25, $135,137,185,249$

mediacentrism 3, 169; Non-mediacentric 3,67

media convergence $80,135-137,140$, 146,171

media culture $3,11,81,163$

media franchise $24,101-102,300$

media industry $23,136,288,293-294$

"media mix" 136-138

media narrative $3,7,14,79,169$

"media pilgrimage" 27

mediascape 172, 201, 249

mediated centres 218

mediation 38, 45-48, 73, 92-93, 217, 304, 307; non-mediation 38, 223; see also mediatization

mediatization 7, 27, 172-173, 212, 216; deep 216, 218, 220, 222; see also mediation

mediatized society $2,11,21$

media tourism 7, 11-12, 39, 53, 76, 79, 250, 299, 308; co-production of (model) 24; developing policies 27-29; theorizing on 20-22, 134, 169 , 249 ; "tourisification" of 23, 26-27; vicarious 143,146

media tourist 7, 14, 23, 250-251, 261, 286

media tours 22

memento 128, 273, 276

memorabilia 236, 303

"memory manager" 251

“mental image" 5, 155, 167, 175

metaphors $86,88,175,307$; in music 68,75

metropolis see city

Millenium Trilogy (Larsson) 22, 102; see also The Girl with the Dragon Tattoo "mind palace" 1

mobile geography 230-231, 236

mobilities 53-55, 62, 90, 195; corporeal 119, 129; imaginative 119, 129; immobility 51,62 ; toy $13,184-186$; see also movement modernity 52, 119-120, 128, 130, 234, 305; hyper- 51; see also postmodernity

$\operatorname{mood} 69,72,74,79-81$; boards 99 , 114

movement: of objects 195-196; of people $88,92,269,276,279,280$; see also mobilities

"multimedia afterlife" 167, 176

musée imaginaire 9

Museum of Innocence (Pamuk) 14, 265, 270-272, 274-280

Museum of the Slave Trade (Gambia) $253,255,259,260,261$

music $12,14,67,80-81,84,89,108$, 137, 290; affective 74-76; cognitive 71-74; embodied 76-79; engagement with 70-71; genres 230; as imaginative practice 68-70; see also sound

musical imagination/imaginary 70,76 , $78,80-81$

"musical mythscape" 68, 70, 74-75

music festival 73, 238; see also cruise ship festival

music tourism 12, 67, 70, 76, 90, 234

music tourist 70,75

Myers, John 59, 63

"mythophilia" 169

narrative layers 14,174

narrative space $9,25,279$

narrative tourism 175, 269-270; see also literary tourism

National Theatre (NT) 297-308

neoliberalism 206, 298, 305, 308

neo-romantic 48

"neo-tribalism" 231, 234

Nesbø, Jon 101

"nesting orientalisms" 206

Newman, Randy 51, 56, 64

nihilism 63-64

non-place 12, 51, 57-58, 175, 230, 236

Nordic Noir 13, 99-102, 109-110, 113-114; New Nordic Noir 13, 99-100, 103-104, 106-107, 110-111, 113-115; tourism 100-103

nostalgia $10,60,155,279$; reflective 74,80 
Oerol (festival) 215-227

"off-the-beaten-track" 39

"ohsindrome" 137

Oshin (morning program) 13, 134-135, 137-142, 144-147; see also asadora

Other 10-11, 120, 171-172; othering 158, 206-207, 211-212; see also Self

Pamuk, Orhan 14, 265, 270, 272-273, 276-280

parasocial relationship 138, 190, 192, 195-196, 238-239

paratexts $69,156,169,194$

participation: audience 137-138, 146, 160 ; in eventsphere 223, 225; in experience economy 235; in fandom 292, 304; tourist 170, 173, 209 participatory observation 104,107 , 186, 219, 223, 227

Peaky Blinders (TV series) 61-62

Petrach 7, 168

phantasmagoria 37, 249, 261

phenomenology $5,38,167$

photography $42,84,128,298$; in videogames $158-159$; toy 185 , 190-191

photoplay 184-186, 188-191, 195-196

picturesque $48,113,170,173$

pilgrimage 53, 136, 240; modern 78, 143, 308; religious 168; Roots 252, 255; theatre 298-299; tourism 47

place: fictional 160, 267;

geographical 106, 110, 208, 232, 236-237, 239; imagined 24-25, 72, 74, 92, 106, 266; liminal 107; mediated 106-107; theorizing 3-4, 9-11

place attachment 4, 299-300; see also belonging

place identity 4, 20-23, 29, 174

place narrative $12,14,106,174,176$

place of fandom 290-293

place(s) of (the) imagination 7, 12-14, $26,119,139,167,210,249-251$, $257,259,261$

placelessness 200, 212, 226, 232, 236-237; urban 173-174

place-making $12,23,27-28,52,64$, $212,265,297$

play: as practice $37,86,91,183$; toy play $183-188,191$; in videogames $152-155,158,163$

player agency $154-155$

playlist $71-72,75-76,78,81$ popular culture 1-2, 7-11, 14, 19-23, 25, 28-29, 84, 144, 156, 207, 249, $252,255,280,286$

porosity 36-38, 44-46; extended porosity 38,44 ; open-ended 42,44

Portmeirion 283, 287, 289, 291-293

possessive spectator $158-160,163$

possible worlds 268

postmodernity/-ism 5, 173-175, 232, 234-235

post-socialism 14, 200, 205

"poverty porn" 63

Powell, Enoch 60, 62

pre-production 100, 107, 113-114

presence: co-presence $76,89,217,222$, 285, 289; modalities of 217, 223

Prisoner, The (series) 283, 287, 289, 291-293

Proust, Marcel 266-267, 272-273

proximity $216-218,221,225$

pseudoevent 45

"pure" gaze 48

Queen Victoria 56

racism 60

Rationalism 4

realism (genre) 171

reception (audience) 3, 121, 126, 202

recreation (virtual) 151-152, 157, 159, 162

reenactment 208, 292

regeneration (urban) 37-39

representation(s) 2, 9, 13, 59-60, 63, $120,127-129$

"Rethinking Tourism in a Coastal City" 100, 104, 107, 111, 114-115

Rio (Gibson) 119, 125, 127

ritual: media 53, 70, 134, 137, 209, 286; religious $47,107,232,270$

"romantic gaze" 142, 168

Romanticism 4, 7, 166-167

"romantic poverty" 140

Roots (The Saga of an American Family) 247-248, 251-262

Roots Homecoming Festival 252-253

Roots-tourism 252-254, 258

routine see habitual

ruin(s) 34-39, 42, 46; industrial ruin

46; named ruin $37-38,46$; open-

ended ruin 34-35, 37-39, 41-42, 44, $46-47$; transitory ruin $37-38$

ruinscape 36

ruin tourism 34,43 
"schemata" 5, 8; cultural 73, 80; folk 206, 212

screen idea development 100, 106-107, 114-115

screen industry $100,106,114-115$

screen production 104, 106-107,

110-112, 115-116; see also film

production

screenshotting 152, 156-157, 159-160, 162-163

screen tourism 100-104, 110-112, 115-116

Self (the) 10-11; territories of 11,172 ; see also Other

self-identity 300,307

self-narrative 299-301, 303, 308

sense of place 3-4, 12, 63, 210-212, 249; through literature 169,174 , 176, 266, 279; through music 72 , 74,81

sensory tourism 231, 233-234

Sex and the City 102

Shaw, George 59, 63

"ship fam" 230-234, 238-240

"sight-sacralization" 46

sightseeing 41, 153, 157-158, 284-285

simulacrum 235,270

slave trade 247-248, 250-256, 259-262

social media: audience/fan interaction 138-139, 143, 146, 185, 191, 226, 238; content sharing 45-46, 146 , 160 ; representing place and locality $7,12-13,136,307$

sound $67-69,73,77-78,80-81$; see also music

Sound of Music, The (movie) 202

soundscape 76-78, 81

soundtrack 71, 75, 79

"soulscapes" 75

souvenir 40, 140, 185, 191, 236, 298 , 303-304, 307

space: hybrid 151; imagined 11, 269; liminal 237, 239, 306; lived 155, 217; mediated 153; narrative 9, 25, 279; "social" 217, 306; theorizing $86-89,94$

spacing $87-89,91$

spatiality $120,128,219$

stereotypes $6,9,22,61,113,127,129$

subconscious (the) 10

surveys 184, 186, 192, 196, 231

"symbolic environment" 10, 75 theme park $24,27,269-270,280,283$, 288

Titanic, The (ship) 57

topophilia 3-4, 10-11, 75, 118, 169, 172, 211; topophilic disposition 249; topophilic sentiments 201, 205, 211

topophobia 10-11, 118, 172

touring $88,151-154,158,163$, 208-209

tourism industry $12,22-23,25,46,79$, 90, 104, 108, 110, 119, 158, 190, $231,235,253,286$

tourism product 90,234 ; hyperreal 232, 239

tourist destination 34, 40, 45-46; Austria 206; Japan 139; Rio de Janeiro 119; Scandinavia 90, 99, 104, 106, 113, 115, 199

tourist gaze 90-91, 114, 119, 153-154, 195

touristic mindset 153-156, 158

"touristification" see media tourism

toy tourism 183-190, 192, 195-197;

typology of 197

toy tourist 13,196

tradition: festival 226, 232, 234; media \& tourism 7, 13, 67, 168-169, 200, 285, 292; socio-cultural Birmingham 58, 63; Gambia 252, 259; Rio de Janeiro 119, 123-124, 127-128, 130; Slovenia 200, 202-203, 205, 207,210

transfictional 265

transmedia: age 201-202, 211, 288, 294; franchise 24, 103, 111, 134, 211; "storytelling" 135 ; worlds 80

Trapped (Nordic Noir series) 100, 102-103, 110

Travel Bugs 183-186, 189-196

Triple disaster of 11 March 2011 135, $138,140,142,145$

Tuan, Yi-Fu 4, 67, 75, 300

Ulysses (Joyce) 268

UNESCO 247-248, 250, 253, 255, 257, 261

urban exploration 34-35, 39, 42-47; urban explorer 34-35, $41-43,45-48$

urban façade 142, 174

Urry, John 90, 119, 195, 211; with Larssen 153-154, 234, 284-285; with Sheller 120 
videogame space 153,155 ; worlds 151 , 158

videogame tourist 13,160 ; see also gamer-tourist

Virgil 168

virtual (space): worlds $151,153,159$

virtual tourism $53,153,163$

visual culture 5, 67

"visual fallacy" 67

visual presencing 224-226

visual storytelling 190
Wallander (series) 100-101, 110

wanderlust 13, 183-185, 187, 194, 196

Watch Dogs 2 151, 153, 158, 162

West Coast Universe, The 99, 103-104, 106, 111

Williams-Ellis, Clough 287

Wizarding World of Harry Potter 27, 283, 286-288, 291, 293

World Heritage Site 247-248, 250

worlding 85

Wunderkammer 275, 276 


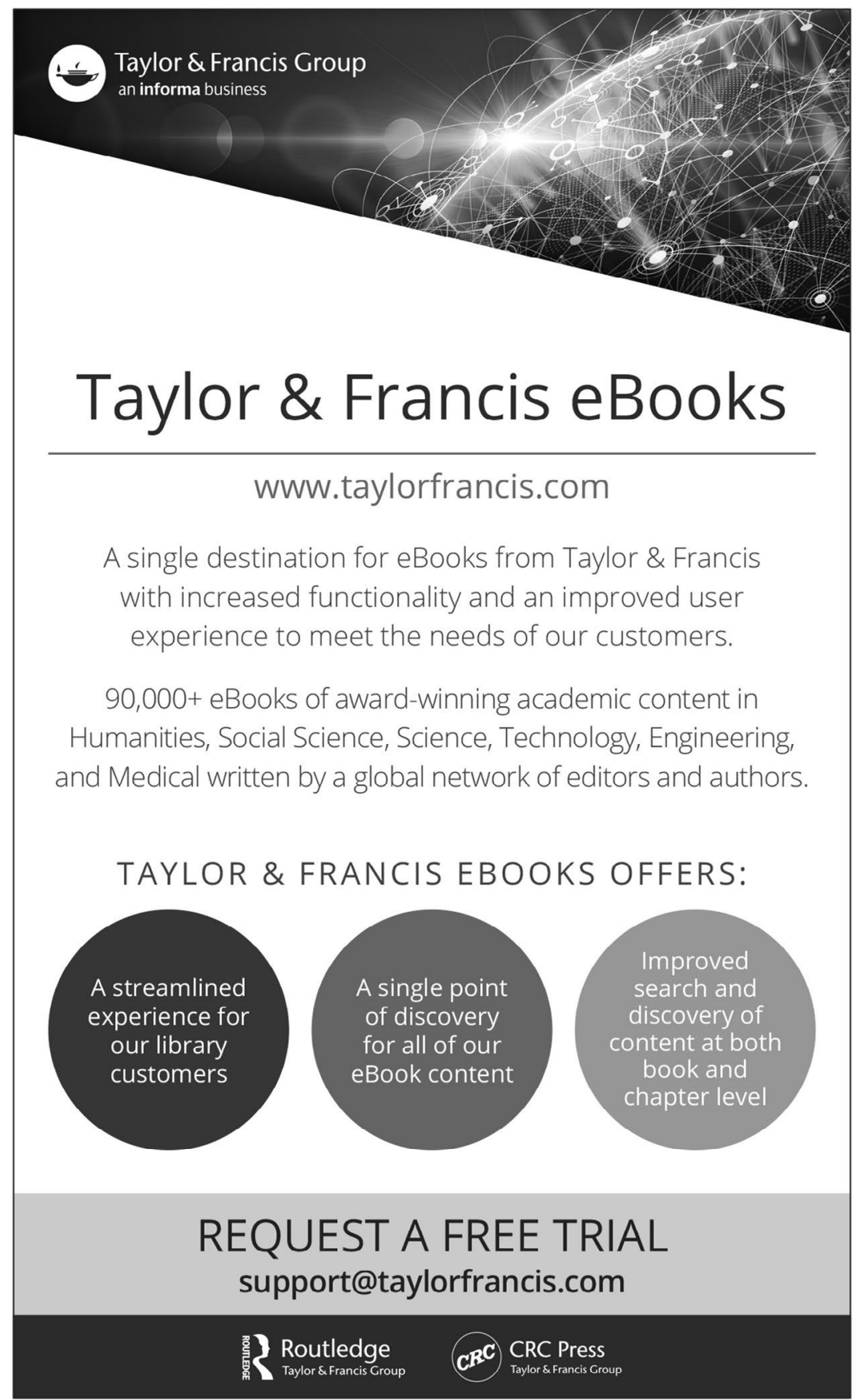

